\title{
INTRAMOLECULAR 1,3-DIPOLAR CYCLOADDITIONS OF NORBORNADIENE-TETHERED NITRILE OXIDES
}

\author{
A Thesis \\ Presented to \\ The Faculty of Graduate Studies
}

of

The University of Guelph

\author{
by \\ CAROL YMP \\ In partial fulfillment of requirements \\ for the degree of \\ Masters of Science
}

August, 2000

() Carol Yip, 2000 
National Library

of Canada

Acquisitions and

Bibliographic Services

395 Wellington Street

Ottawa ON K1A ON4

Canada
Bibliothèque nationale

du Canada

Acquisitions et

services bibliographiques

395, rue Wellington

Ottawa ON K1A ON4

Canada
Your file Votra référence

Our file Notro réfórence
The author has granted a nonexclusive licence allowing the National Library of Canada to reproduce, loan, distribute or sell copies of this thesis in microform, paper or electronic formats.

The author retains ownership of the copyright in this thesis. Neither the thesis nor substantial extracts from it may be printed or otherwise reproduced without the author's permission.
L'auteur a accordé une licence non exclusive permettant à la Bibliothèque nationale du Canada de reproduire, prêter, distribuer ou vendre des copies de cette thèse sous la forme de microfiche/film, de reproduction sur papier ou sur format électronique.

L'auteur conserve la propriété du droit d'auteur qui protège cette thèse. $\mathrm{Ni}$ la thèse ni des extraits substantiels de celle-ci ne doivent être imprimés ou autrement reproduits sans son autorisation. 


\section{ABSTRACT \\ INTRAMOLECULAR 1,3-DIPOLAR CYCLOADDITIONS OF NORBORNADIENE-TETHERED NITRILE OXIDES}

Carol Yip

University of Guelph
Advisor:

Dr. William Tam

Although the intermolecular reactions of 1,3-dipoles with norbornadiene and its derivatives have been subjected to considerable investigation, the intramolecular variants have not been studied. In this thesis, a novel strategy to a highly regio- and stereocontrolled assembly of angular fused-tricyclic frameworks via intramolecular cycloaddition reactions of norbornadiene-tethered nitrile oxides is presented. Efficient routes to the synthesis of norbornadiene-tethered ritrile oxides have been developed and their intramolecular 1,3-dipolar cycloadditions were studied. The cycloadditions occurred in good yields for a variety of substrates. In all cases, single regio- and stereoisomer of these cycloadducts were obtained.

In the course of investigating such cycloaddition reactions, a simple and convenient route to a variety of 2,3-disubstituted norbornadienes that cannot be prepared by the traditional Diels-Alder method has been developed by applying the method of double lithium halide exchange. Application of this general methodology to the synthesis of a wide variety of $\mathrm{C}-3$ substituted norbornadiene-tethered nitrile oxides is discussed. The effects of various functionalities at the C-3 position of norbornadiene upon the regioand stereoselectivity of the cycloaddition are also addressed. 
To my mom 


\section{Acknowledgements}

I wish to thank Dr. William Tam for providing me with the opportunity of this rewarding experience and for his guidance and endless patience over the past two years culminating in the completion of my M. Sc.

I also would like to thank the Tam research group for their assistance and tolerance during some of the more trying periods over the course of this work.

A special thank you goes to my parents. I am very grateful to them for their continued encouragement and unwavering support over the years.

Finally, I remain eternally indebted to Dr. Scott Browning for instilling within me an appreciation of chemistry. 


\section{Table of Contents}

Dedication i

$\begin{array}{ll}\text { Acknowledgements } & \text { ii }\end{array}$

Table of Contents

List of Tables $\quad$ xi

Glossary of Abbreviations $\quad x$

Chapter 1 Introduction 1

1.1 Cycloaddition Reactions 2

1.2 Cycloadditions with Norbornadienes 4

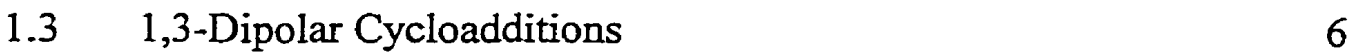

$\begin{array}{lll}\text { 1.3.1 Basic Aspects } & 6\end{array}$

1.3.2 1,3-Dipolar Cycloaddition Reactions of Nitrile $\quad 12$ Oxides

1.3.3 Synthetic Uses of Intramolecular 1,3-Dipolar $\quad 18$ Cycloadditions of Nitrile Oxides

$\begin{array}{lll}1.4 & \text { Scope of the Thesis } & 20\end{array}$

Chapter 2 Intramolecular 1,3-Dipolar Cycloadditions of NorbornadieneTethered Nitrile Oxides

$\begin{array}{lll}2.1 & \text { Introduction } & 24\end{array}$

$\begin{array}{lll}2.2 & \text { Synthesis of Cycloadducts } & 25\end{array}$

2.3 Proposed Mechanism for the Conversion of a Nitroalkane 27 to a Nitrile Oxide 
2.4 Optimization of Intramolecular 1,3-Dipolar Cycloadditions

of Norbornadiene-Tethered Nitrile Oxides

2.4.1 Conditions for the Generation of Cycloadduct

2.4.2 Effect of Solvent on Cycloaddition

2.4.3 Effect of Temperature on Cycloaddition

2.4.4 Summary

$\begin{array}{lll}2.5 & \text { Results and Discussion } & 35\end{array}$

2.5.1 Synthesis of Norbornadiene-Tethered Nitrile Oxides with Different Tether Lengths

2.5.1.1 Four-Membered Cycloadduct

2.5.1.2 Five-Membered Cycloadduct

2.5.1.3 Six-Membered Cycloadduct

2.5.1.4 Seven-Membered Cycloadduct

2.5.2 Synthesis of Norbornadiene-Tethered Nitrile Oxides Bearing Functionality within the Tether

2.5.2.1 Six-Membered Cycloadduct Bearing a $\alpha-$ Silyl Ether Substituent

2.5.2.2 Six-Membered Cycloadduct Bearing a $\alpha$-Carbonyl Substituent

2.5.2.3 Five-Membered Cycloadduct Bearing a $\gamma$-Carbonyl Substituent

2.5.3 Synthesis of Norbornadiene-Tethered Nitrile Oxides Bearing Heteroatom Within the Tether

2.5.3.1 Cycloadducts Bearing an Oxygen Within the Tether

2.5.3.2 Cycloadduct Bearing a Sulfur Within the Tether 
2.5.4 Identification of the Regio- and Stereochemistry of the Cycloadducts

2.6 Conclusions

Chapter 3 Synthesis of 2,3-Disubstituted Norbornadienes

3.1 Introduction

3.2 General Methodology for the Synthesis of 2,3-Disubstituted Norbormadienes

$\begin{array}{lll}3.3 & \text { Results and Discussion } & 69\end{array}$

3.3.1 Synthesis of 2,3-Disubstituted Norbornadienes from 2,3-Dibromonorbornadiene via Monolithium Halide Exchange

\subsubsection{Synthesis of 2,3-Disubstituted Norbornadienes} from 2,3-Dibromonorbornadiene via Double Lithium Halide Exchange

3.4 Conclusions

Chapter 4 Intramolecular 1,3-Dipolar Cycloadditions of NorbornadieneTethered Nitrile Oxides with a C-3 Substituent

4.1 Introduction

4.2 Synthesis of C-3 Substituted Cycloadducts 87

$\begin{array}{lll}4.3 & \text { Results and Discussion } & 89\end{array}$

4.3.1 Synthesis of Norbornadiene-Tethered Nitrile Oxides Bearing a Halogen at the C-3 Position

4.3.1.1 Cycloadduct Bearing a Bromo Substituent 
4.3.2 Synthesis of Norbornadiene-Tethered Nitrile Oxides Bearing an Alkyl Substituent

4.3.2.1 Cycloadduct Bearing a Methyl Substituent

4.3.2.2 Cycloadduct Bearing a Hexyl Substituent

4.3.3 Synthesis of Norbornadiene-Tethered Nitrile Oxides Bearing an Allyl Substituent

4.3.3.1 Cycloadduct Bearing an Allyl Substituent

4.3.4 Synthesis of Norbornadiene-Tethered Nitrile Oxides

Bearing an Aryl Substituent

\subsubsection{Cycloadduct Bearing a Phenyl Substituent}

98

4.3.5 Synthesis of Norbornadiene-Tethered Nitrile Oxides Bearing a Silane-Containing Substituent

4.3.5.1 Cycloadduct Bearing a Trimethylsilane Substituent

4.3.6 Synthesis of Norbornadiene-Tethered Nitrile Oxides Bearing a Carbonyl-Containing Substituent

\subsubsection{Cycloadduct Bearing a Carboxylic Acid Methyl} Ester Substituent

4.3.6.2 Cycloadduct Bearing a Carbaldehyde Substituent

4.3.7 Synthesis of Norbornadiene-Tethered Nitrile Oxides Bearing a Methoxy-Containing Substituent Substituent

4.3.8 Identification of the Regio- and Stereochemistry of the C-3 Substituent Cycloadducts 
5.1 General Procedures

5.2 Synthetic Procedures for Chapter 2: Intramolecular 1,3-Dipolar Cycloadditions of Norbornadiene-Tethered Nitrile Oxides

5.2.1 Norbornadiene-Tethered Nitrile Oxides with Different 116 Tether Lengths

5.2.1.1 Five-Membered Cycloadduct

5.2.1.2 Six-Membered Cycloadduct

120

5.2.2 Norbornadiene-Tethered Nitrile Oxides Bearing

124

Functionality Within the Tether

5.2.2.1 Six-Membered Cycloadduct Bearing a Silyl-Ether Substituent

124

5.2.3 Norbornadiene-Tethered Nitrile Oxides Bearing

129

Heteroatom Within the Tether

5.2.3.1 Five-Membered Cycloadduct Bearing an Oxygen Within the Tether

5.2.3.2 Six-Membered Cycloadduct Bearing an Oxygen Within the Tether

5.3 Synthetic Procedures for Chapter 3: 2,3-Disubstituted Norbornadienes

5.3.1 2,3-Disubtituted Norbornadienes from

2,3-Dibromonorbornadiene via Monolithium Halide Exchange

5.3.2 2,3-Disubtituted Norbornadienes from

2,3-Dibromonorbornadiene via Double Lithium Halide Exchange

5.4 Synthetic Procedures for Chapter 4: Intramolecular 1,3-Dipolar Cycloadditions of Norbornadiene-Tethered Nitrile Oxides with a C-3 Substituent

5.4.1 Norbornadiene-Tethered Nitrile Oxides Bearing a Halogen at the C-3 Position 
5.4.1.1 Cycloadduct Bearing a Bromo Substituent

5.4.1.2 Cycloadduct Bearing a Chloro Substituent

5.4.1.3 Cycloadduct Bearing an Iodo Substituent

5.4.2 Norbornadiene-Tethered Nitrile Oxides Bearing an Alkyl Substituent at the C-3 Position

5.4.2.1 Cycloadduct Bearing a Methyl Substituent

5.4.2.2 Cycloadduct Bearing a Hexyl Substituent

5.4.3 Norbornadiene-Tethered Nitrile Oxides Bearing a

Carbonyl-Containing Substituent at the C-3 Position

5.4.3.1 Cycloadduct Bearing a Carboxylic Acid Methyl $\quad 174$ Ester Substituent

5.4.3.2 Cycloadduct Precursors Bearing a Carbaldehyde Substituent

5.4.4 Norbornadiene-Tethered Nitrile Oxide Bearing a

184

Methoxy-Containing Substituent at the C-3 Position

5.4.4.1 Cycloadduct Bearing a Methoxymethyl

Substituent

Epilogue

191

References 


\section{List of Tables}

Table 1: Conditions for the Generation of Cycloadduct 30

Table 2: $\quad$ Effect of Solvent 32

Table 3: $\quad$ Effect of Temperature 33

Table 4: $\quad$ Intramolecular 1,3-Dipolar Cycloaddition of Norbornadiene- $\quad 59$ Tethered Nitrile Oxides

Table $5 \quad$ Synthesis of Monobromo-Substituted Norbornadienes $\quad 67$

Table $6 \quad$ Synthesis of Disubstituted Norbornadienes via Double 68

Table 7 Intramolecular 1,3-Dipolar Cycloadditions of C-3 Substituted 113 Norbornadiene-Tethered Nitrile Oxides 


\begin{tabular}{|c|c|}
\hline $1,3-\mathrm{DC}$ & 1,3-dipolar cycloaddition \\
\hline DIAD & diisopropyl diazodicarboxylate \\
\hline DMAP & 4-dimethylaminopyridine \\
\hline DME & 1,2-Dimethoxyethane \\
\hline DMF & dimethylformamide \\
\hline DMSO & dimethyl sulfoxide \\
\hline FMO & frontier molecular orbital \\
\hline HMPA & hexamethylphosphoramide \\
\hline HOMO & highest occupied molecular orbital \\
\hline INOC & intramolecular 1,3-dipolar cycloaddion of nitrile oxides \\
\hline IR & infrared \\
\hline LUMO & lowest unoccupied molecular orbital \\
\hline NBD & norbornadiene \\
\hline NMR & nuclear magnetic resonance \\
\hline NOESY & nuclear Overhauser and exchange spectroscopy \\
\hline PPTS & pyridinium $p$-toluenesulfonate \\
\hline $\mathrm{rt}$ & room temperature \\
\hline TBSCl & tert-butyldimethylsilyl chloride \\
\hline THF & tetrahydrofuran \\
\hline THP & tetrahydropyran \\
\hline TLC & thin layer chromatography \\
\hline
\end{tabular}




\section{Chapter 1}

\section{Introduction}




\subsection{Cycloaddition Reactions}

Classes of reactions which have found broad applicability in organic chemistry are those that address the issues of regio- and stereocontrol and are compatible with a variety of functional groups. ${ }^{\perp}$ Reactions which form multiple bonds, rings, and/or stereocenters are particularly important tools for the efficient assembly of complex molecular structures. Of the many families of reactions discovered over the past 75 years, cycloaddition reactions hold a prominent place in the arsenal of synthetic methods currently available to organic chemists and research in this field shows no signs of abatement. Growth in the use of cycloaddition reactions in heterocyclic synthesis stems from an understanding of the mechanisms. ${ }^{2}$ The Woodward-Hoffmann theories of orbital symmetry conservation have provided a basis for understanding the mechanisms of the various classes of cycloadditions. Furthermore, frontier molecular orbital theory has provided a basis for interpreting the effect of substituents on the rates and selectivities of cycloadditions.

In the formation of heterocyclic compounds from open-chain precursors, a wide range of cycloaddition processes is available. The most important types of cycloaddition processes that have been used for the synthesis of heterocycles are: 1,3-dipolar cycloadditions, hetero-Diels-Alder reactions, and $[2+2]$ cycloadditions (Scheme 1 ). ${ }^{2}$ For the construction of five-membered rings, 1.3-Dipolar cycloaddition is an efficient method 


\section{Scheme 1}

\section{Types of Cycloaddition Processes Used for Heterocyclic Synthesis}

\section{(a) 1,3-Dipolar Cycloaddition}

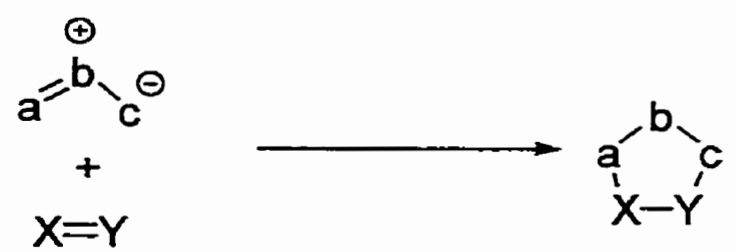

(b) Hetero-Diels-Alder Reaction

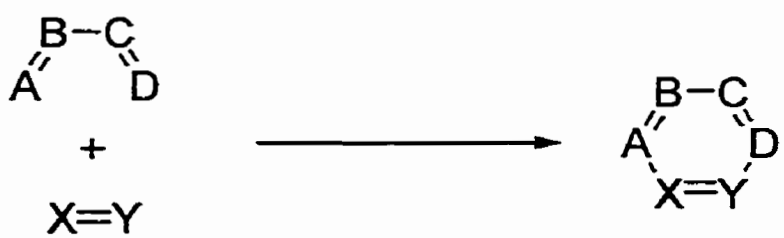

\section{(c) [2+2] Cycloaddition}

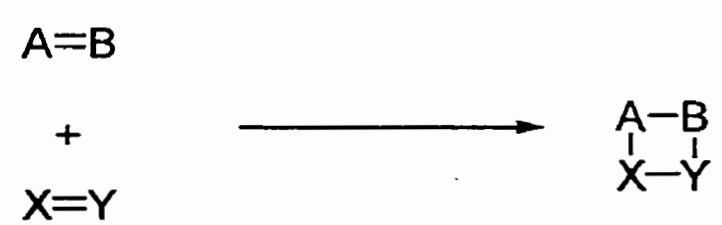

due to the availability of a wide variety of 1,3-dipoles and these undergo addition to carbon-carbon multiple bonds or to multiple bonds containing heteroatoms. While 1,3dipolar cycloaddition is considered to be the most useful method for the synthesis of fivemembered heterocyclic ring systems, the Diels-Alder reaction is best known as a method of forming cyclohexene derivatives. However, heteroatoms can be incorporated successfully into the skeleton of the diene or the dienophile, or both, to provide important routes to many six-membered heterocycles. Among the cycloaddition reactions that have been shown to have general synthetic utility are the [2+2] cycloadditions of ketenes and alkenes. $^{3}$ This latter cycloaddition process offers an efficient route to the synthesis of four-membered rings. In terms of reaction conditions, cycloadditions have been 
promoted by heat, light, Lewis acids, high pressure, sonication or metal catalysts. ${ }^{1}$ The method of choice in a particular case usually depends upon the pattern of substituents required in the product. This thesis will be concerned primarily with the former cycloaddition process-1,3-dipolar cycloaddition.

\subsection{Cycloadditions with Norbornadienes}

Bicyclo[2.2.1] hepta-2,5-diene, norbornadiene (NBD), was first reported in the patent literature in $1951 .^{4}$ Unlike other olefins containing two isolated double bonds, the two double bonds of NBD are homoconjugated. Indeed, NBD is a classic example of a molecule in which a "through-space" interaction between the two double bonds is operative (Fig. 1)..$^{5}$ Reactions of NBD follow the pattern typically observed in bridged bicyclic molecules, namely, that reactions occur preferentially on the more accessible exo face, although there are a few exceptions which yield exclusively the endo products. ${ }^{4}$

Fig. 1

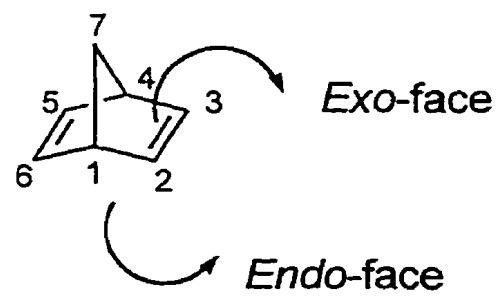


The significant strain energy $(25.6 \mathrm{kcal} / \mathrm{mol})$ of $\mathrm{NBD}$ in comparision to norbornene, which has a strain energy of $17.6 \mathrm{kcal} / \mathrm{mol}$, makes the former a suitable compound for studies of reactivity. ${ }^{4}$ The reactivity of NBD is responsible for many of the reactions it undergoes, including cycloaddition reactions under thermal, photochemical, Lewis acidic, or metal-catalyzed conditions.

Scheme 2. Various Modes of Cycloaddition of Norbornadiene

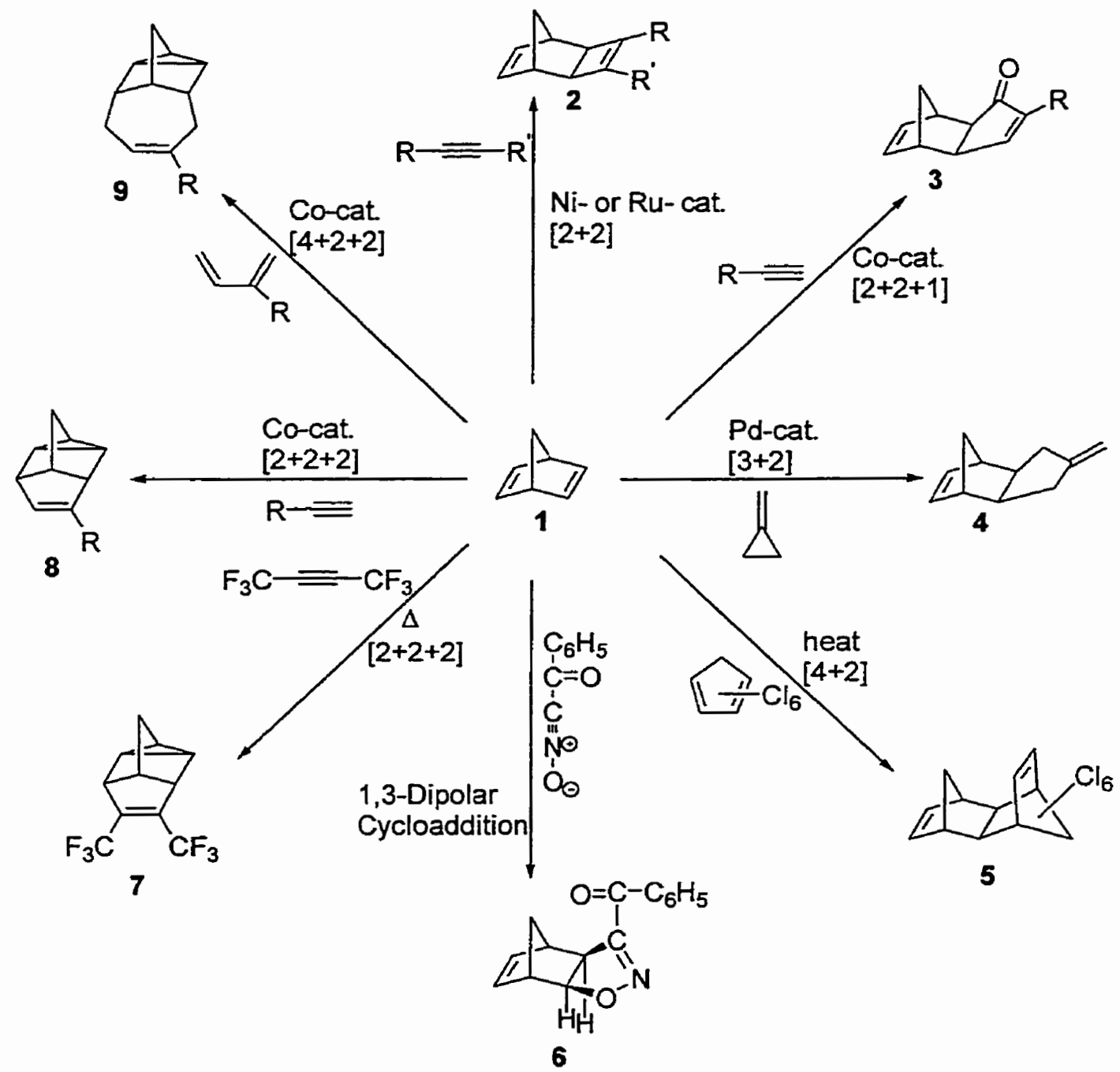


Some representative examples of thermal and metal-catalyzed cycloaddition reactions to generate novel, strained polycyclic compounds from NBD are shown (Scheme 2) ${ }^{6-8}$ There are two main types of intermolecular cycloaddition reactions with NBD. In the synthesis of cycloadducts 2 to 6 , only one of the double bonds of NBD participates in the cycloadditions to generate highly strained olefinic systems. In the formation of the cycloadducts 7 to 9 , the homoconjugated dienes of NBD are involved in the cycloaddition reactions. Noteworthy is the synthesis of 6 which belongs to a special type of cycloaddition known as the 1,3-DC reaction.

\subsection{1,3-Dipolar Cycloadditions}

\subsubsection{Basic Aspects}

Compared to the Diels-Alder reaction which was discovered in 1928 , the chemistry of the 1,3-dipolar cycloaddition (1,3-DC) reaction has evolved for more than 100 years with the discovery of diazoacetic ester by Curtius in 1883. ${ }^{9}$ Although the synthetic value of the Diels-Alder reaction soon became obvious after its discovery, the general application of 1,3-dipoles in organic chemistry was not established until the 1960s. It was the monumental work of Huisgen and co-workers which led to the general concept of 1,3-dipolar cycloaddition. ${ }^{10}$ The addition of a 1,3-dipole to an alkene for the synthesis of five-membered rings is now a classic reaction in organic chemistry. The 1,3DC reactions are used for the preparation of a vast array of molecules of fundamental 
importance for both academia and industry. ${ }^{11}$ Accessibility and low cost of reactants combined with simple reaction conditions apply in many cases to this reaction.

\section{Scheme 3}

(a) Reaction Between Dipole and Dipolarophile

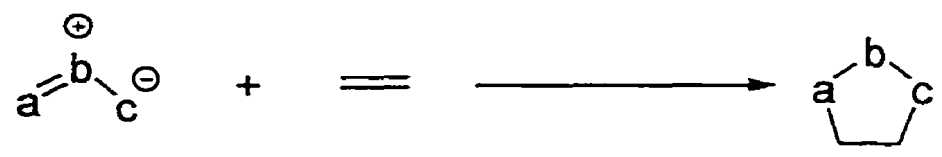

(b) Types of 1,3-Dipoles

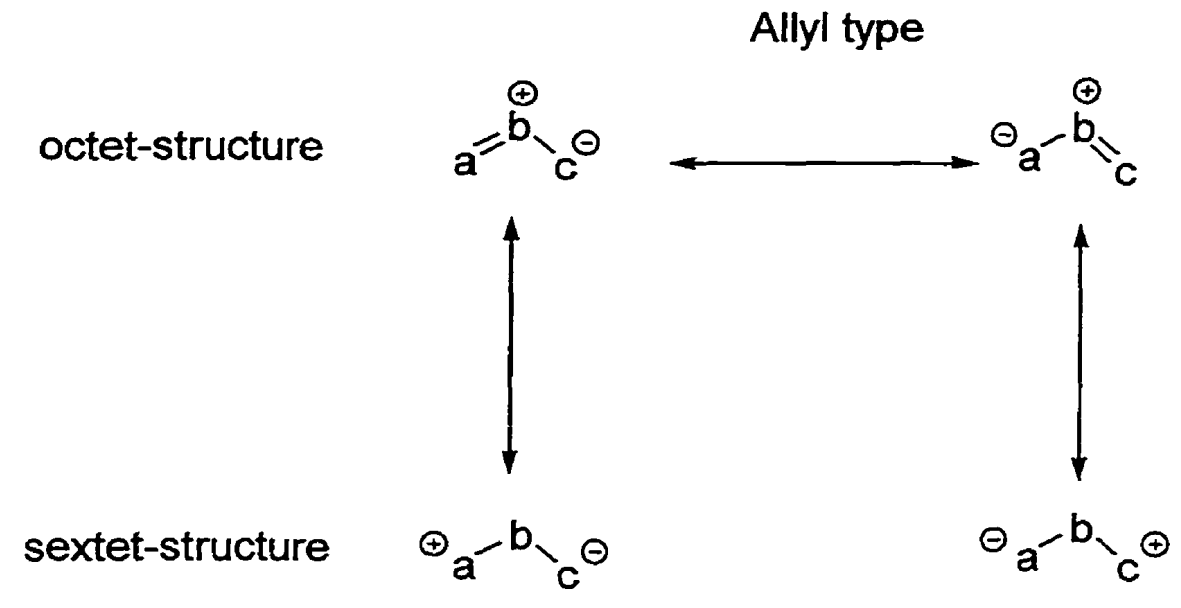

Propargyl/allenyl type

$$
\mathrm{a}=\stackrel{\oplus}{=}-\stackrel{\ominus}{\mathrm{c}} \rightleftarrows \stackrel{\ominus}{\mathrm{a}=\stackrel{\oplus}{\mathrm{b}}=\mathrm{c}}
$$

Similar to the Diels-Alder reaction, $1,3-\mathrm{DC}$ reaction is a $[\pi 4 \mathrm{~s}+\pi 2 \mathrm{~s}]$ process and it proceeds through a $6 \pi$-electron transition state. It differs from the Diels-Alder reaction in that the $4 \pi$-electron component is not a diene but a 1,3-dipole, in which the four $\pi$ electrons are distributed over only three atoms. A variety of different 1,3-dipoles have 
been discovered. $^{12}$ A 1,3-dipole undergoes 1,3-DC reactions to a multiple-bond system, the dipolarophile (Scheme 3). ${ }^{13}$ There are two types of 1,3-dipoles: the allyl type and the propargyl/allenyl type. The allyl type is characterized by four $\pi$-electrons in three parallel $\mathrm{p}_{z}$ orbitals-perpendicular to the plane of the dipole and the 1,3-dipole is bent. The two resonance structures in which the three centers have an electron octet, and the two structures in which $a$ or $c$ has an electron sextet are shown. The ambivalent character of the 1,3-dipole is illustrated by the sextet structures as the terminal centers of the $1,3-$ dipole can be both nucleophilic and electrophilic. The central atom $b$ can be a group V element (nitrogen, phosphorus, etc.) or a group VI element (oxygen, sulfur). The propargyl/allenyl type, which has a triple bond in one canonical form, contains an additional $\pi$ orbital located in the plane orthogonal to the allenyl type molecular orbital (MO), and the former orbital is therefore not directly involved in the resonance structures and reactions of the dipole. The propargyl/allenyl type is linear and the central atom $b$ is limited to nitrogen since only an atom of a group $\mathrm{V}$ element bears a positive charge in the tetravalent state. A considerable number of 1,3-dipoles containing various combinations of carbon and heteroatoms are theoretically possible and many have been made and their reactions with dipolarophiles studied. By restricting the permutations to second-row elements $(C, N, O)$, Huisgen has classified twelve dipoles of the allyl type and six dipoles of the propargyl/allenyl type. Representative examples of the two types of 1,3-dipoles are shown in Fig. 2. 
Fig. 2

Allyl type

$\stackrel{i}{\mathrm{C}}=\stackrel{\oplus}{\mathrm{I}}-\stackrel{\ominus}{\mathrm{O}}$

$\mathrm{C}=\stackrel{\oplus}{\mathrm{N}}-\stackrel{\ominus}{\mathrm{N}}$

$\mathrm{C}=\stackrel{\oplus}{\mathrm{N}}-\stackrel{\ominus}{\mathrm{C}}$

$\mathrm{O}=\stackrel{\oplus}{\mathrm{O}}-\stackrel{\ominus}{\mathrm{O}}$
Nitrones

Azomethine Imines

Azomethine Ylides
Propargyl/alleny type

$-\mathrm{C} \equiv \stackrel{\oplus}{\mathrm{N}}-\stackrel{\odot}{\odot}$

$\mathrm{N} \equiv \stackrel{\oplus}{\mathrm{N}}-\stackrel{\ominus}{\mathrm{O}}$
Nitrile Oxides

Nitrous Oxide

\section{Ozone}

The most widely accepted view of the mechanism of 1,3-DC reactions is that it is a concerted process proceeding through an unsymmetical transition state-the two new $\sigma$ bonds are both partially formed in the transition state, although not necessarily to the same extent. ${ }^{2}$ The reaction can be represented as going through a transition state in which the $4 \pi$-electron system of the dipole interacts with the $2 \pi$-electron system of the dipolarophile. This is a "thermally allowed" process on the basis of the WoodwardHoffmann rules. ${ }^{14}$ It involves the suprafacial combination of the three $\mathrm{p}_{z}$ orbitals of the 1,3-dipole and the two $\mathrm{p}_{z}$ orbitals of the dipolarophile.

The reactivity of 1,3-dipoles towards different dipolarophiles varies considerably. According to the frontier orbital treatment of $1,3-\mathrm{DC}$, the relative reactivity of a given 1,3-dipole toward a series of dipolarophiles will be determined primarily by the extent of stabilization afforded the transition state by interaction of the frontier orbitals of the two reactants. $^{2,10,12}$ Sustmann has classified the reactions into three types based on the relative frontier molecular orbital (FMO) energies between the dipole and the 
dipolarophile (Fig. 3). ${ }^{15}$ In type I 1,3-DC reactions, the dominant FMO interaction is that of the $\mathrm{HOMO}_{\text {dipole }}$ with the LUMO dipolarophile. Azomethine ylides and azomethine imines belong to this type of classification. However, most $1,3-\mathrm{DC}$ reactions fall into type II in which the similarity of the dipole and dipolarophile FMO energies implies that both the HOMO-LUMO interactions are important. Reactions of nitrones are normally classified as type II. For type III 1,3-DC reactions, the dominant FMO interaction is between the

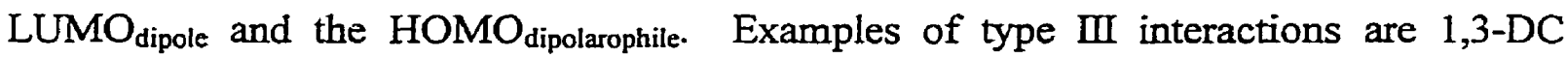
reactions of ozone and nitrous oxide. Reactions of 1,3-DC of nitrile oxides are classified as type $\Pi$, however, since nitrile oxides have relatively low lying HOMO energies, they are borderline to type III.

Fig. 3. Classification of 1,3-Dipolar Cycloaddition Reaction on the Basis of FMOs

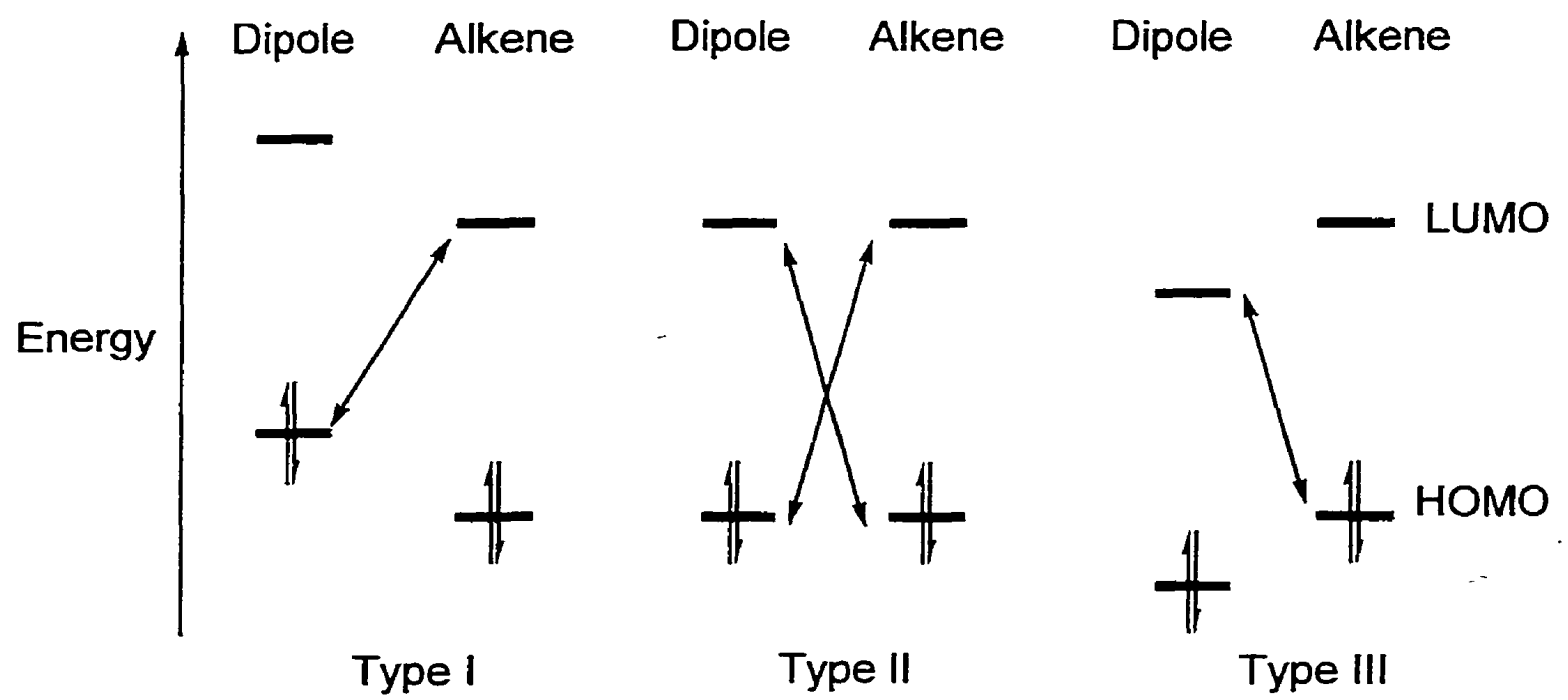

The introduction of electron-donating or electron-withdrawing substituents on the dipole or the dipolarophile can alter the relative FMO energies, and therefore the reaction type as well as the kinetics of the reaction. The smaller the energy gap between the 
controlling orbitals, the faster the reaction. Type I 1,3-DC reactions are accelerated by electron-donating substituents in the dipole and electron-withdrawing substituents in the dipolarophile, while type III 1,3-DC reactions are accelerated by electron-withdrawing substituents in the dipole and electron-donating substituents in the dipolarophile. For type III 1,3-DC reactions, the controlling interaction in these cases depends on the nature of the dipolarophile and on the electronic nature of the substituents in the dipole. These reactions can be accelerated by both electron-donating and electron-withdrawing substituents in either component. The change in orbital control from $H O M O_{\text {dipole }}$ to $\mathrm{LUMO}_{\text {dipole }}$ or vice versa from one reaction to another may have consequences on the regioselectivities of the reactions. Regioselectivity is determined by the relative magnitudes of the atomic orbital coefficients in the HOMO and LUMO of the 1,3-dipole and dipolarophile. ${ }^{11}$ The favored cycloadduct is the result of the union of the atoms having the largest coefficients in the two frontier orbitals. However, in some reactions, electronically preferred orientations may be disfavoured by steric effects.

As well as being regioselective, 1,3-DC reactions are highly stereoselective. The mechanism for cycloaddition is suprafacial and ensures the complete transfer of stereochemical information from the dipolarophile to the cycloadduct. ${ }^{16}$ Apparent exceptions have been shown to be due to isomerization either before or after the cycloaddition. Thus, $Z$-alkenes lead to cis-products while $E$-alkenes lead to transproducts (Scheme 4). This feature is common to all 1,3-DC reactions and makes these reactions particularly useful for the stereocontrolled synthesis of a variety of complex molecules. 


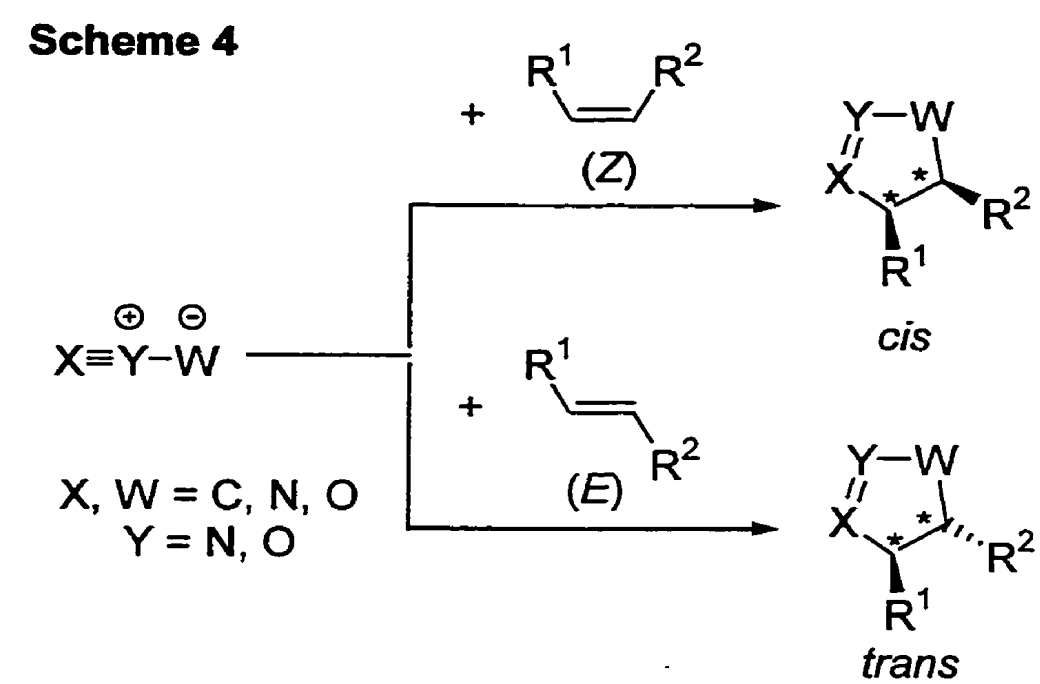

\subsubsection{1,3-Dipolar Cycloaddition Reactions of Nitrile Oxides}

Cycloadditions of 1,3-dipoles to dipolarophiles containing hetero multiple bonds, such as imines, nitriles and carbonyl components have been effected, so that a wide variety of five-membered heterocyclic compounds can be made by this general route. ${ }^{10,11}$ Nitrile oxides are among the most widely used of the 1,3-dipoles in organic synthesis, and the present chapter will focus on their roles in cycloaddition reactions. ${ }^{17,18}$

The 1,3-DC reaction of nitrile oxides with alkenes provides an efficient route to the synthesis of isoxazolines and of many five-membered heterocyclic systems. ${ }^{10,11,17,18}$ Since nitrile oxides are highly reactive 1,3-dipoles, they are almost always prepared and trapped in situ in order to avoid dimerization. Generated in the presence of a dipolarophile, they form the cycloadduct directly. The two synthetic routes to nitrile oxides most commonly employed are: (a) reaction of aldoximes with oxidizing agents or 
halogenating species or (b) reaction of primary nitroalkanes with a dehydrating agent, e.g. ethyl chloroformate in the Shimizu method or aromatic isocyanates in the Mukaiyama method (Scheme 5). ${ }^{2}$ However, both methods suffer from limitations. In the

\section{Scheme 5. Routes to Nitrile Oxides}

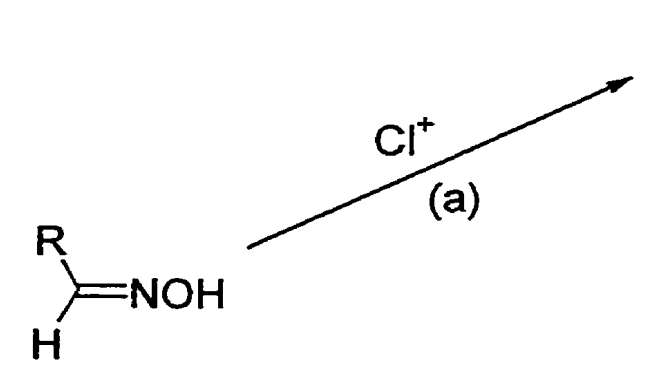<smiles>[R]C(Cl)=NO</smiles>
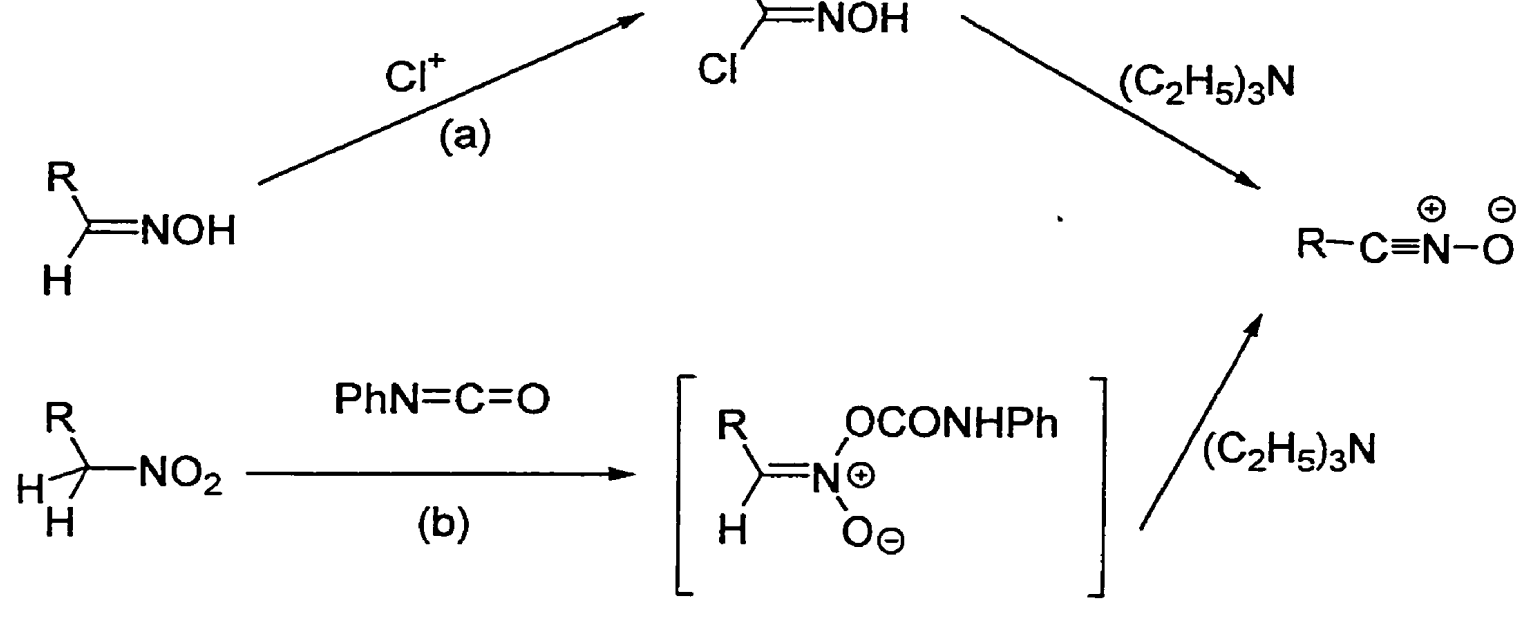

former case, the halogenating reagent may disallow the presence of some functional groups whereas in the latter, the yield of cycloaddition products often is low or side reactions predominate due to the high temperature required. Recently, a new method has been reported by Hassner and co-workers for generation of nitrile oxides in situ from nitroalkanes under milder conditions. ${ }^{13}$ The reaction of nitroalkanes with di-tert-butyl dicarbonate in the presence of 4-dimethylaminopyridine and an excess of dipolarophiles at room temperature afforded the cycloadducts in much improved yields (Scheme 6) than in the Shimizu or Mukaiyama procedure. The use of di-tert-butyl dicarbonate and DMAP was found to be superior for intramolecular cycloadditions as well. ${ }^{19}$ 
Scheme 6

$\mathrm{R}_{\mathrm{NO}_{2}}+\mathrm{EtO}_{2} \mathrm{C} \curvearrowright \frac{(\mathrm{BOC})_{2} \mathrm{O}, \mathrm{DMAP}}{20^{\circ} \mathrm{C}}$

\section{Scheme 7}<smiles>[X]C1=C2C[C+]3CC(C2)C([X])C13</smiles><smiles>[X]C1=NOC2C3CC(C([Y])C3[R])C12</smiles>

exo<smiles>[X]C1=NOC2C([R])CC1C1CC2C1[X]</smiles>

endo

$$
\begin{array}{lcc}
R=P h & X=H & 80: 20 \\
& X=C l & 82: 18 \\
R=P h C O & X=H & 81: 19 \\
& X=C N & 68: 32 \\
& X=\text { COOMe } & 75: 25
\end{array}
$$

Bimolecular 1,3-DC reactions of nitrile oxides with norbornadiene and derivatives have been documented (Scheme 7). ${ }^{7,20}$ Unfortunately, these cycloaddition reactions often yield a mixture of cycloadducts. In the 1,3-DC reactions of benzylnitrile oxide or phenylglyoxylonitrile oxide to NBD and derivatives, the exo-adducts were always the major products although the stereoselectivities were rather low.

Despite the considerable amount of literature dealing with intermolecular 1,3-DC reactions of nitrile oxides, intramolecular 1,3-DC reactions of nitrile oxides, often abbreviated INOC, have only recently started to receive synthetic and mechanistic interest by the scientific community. ${ }^{12,21,22}$ Intramolecular nitrile oxide olefin cycloaddition is an effective tool for the construction of bi- and polycyclic isoxazolines. 
Due to the rigid linear structure of the nitrile oxide, the reaction of alkenylnitrile oxides almost always proceeds to give bicyclo $[x, 3,0]$ derivatives for $x=3-5$ (eq. 1 ).
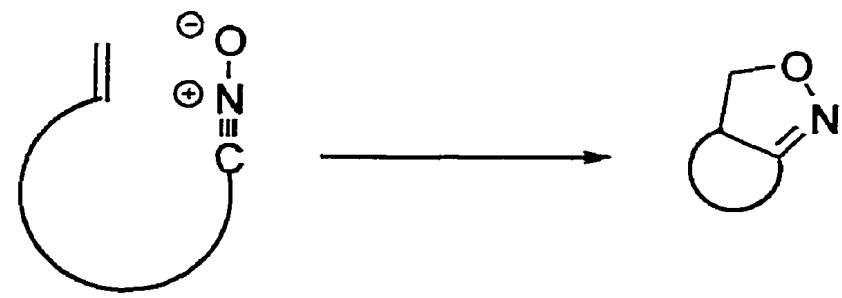

(eq. 1)

\section{Bicyclo $[x, 3,0]$}

In systems where the dipole and dipolarophile are linked by several atoms, the highly ordered transition state will induce useful regiochemical control. ${ }^{23}$ The very negative entropies of activation associated with tethering the two reactive components to form five- or six-membered heterocyclic rings suggests that the reaction is significantly more facile than the intermolecular counterpart. A favorable entropy term will help offset unfavorable electronic and steric factors. An example of the effects of chain length between dipole and dipolarophile on INOC was reported by Garanti et al. ${ }^{24}$ Treatment of the substrate $\mathbf{1 0}$ with 1-chlorooxime and triethylamine generated the nitrile oxide 11 in situ (Scheme 8). Cycloaddition gave the fused-ring isoxazoline 12. Although high yields were obtained for the reactions leading to $12 \mathbf{a}$ and $\mathbf{1 2 b}$, Garanti and co-workers found that tarry mixtures of $12 \mathrm{c}$ were obtained from which no product could be isolated and characterized. Thus, the likelihood of intramolecular cycloaddition decreases with increasing distance betweeen the reacting groups. 


\section{Scheme 8}

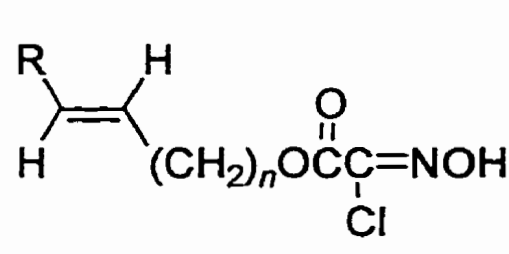

10

$$
\begin{aligned}
& \text { a } n=1, \mathrm{R}=\mathrm{H} \\
& \text { b } n=2, \mathrm{R}=\mathrm{Ph} \\
& \text { c } n=3, \mathrm{R}=\mathrm{H}
\end{aligned}
$$

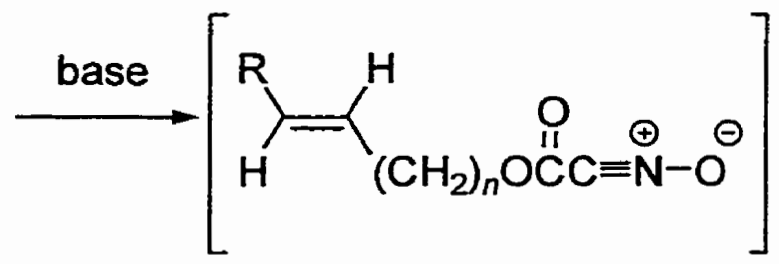

11

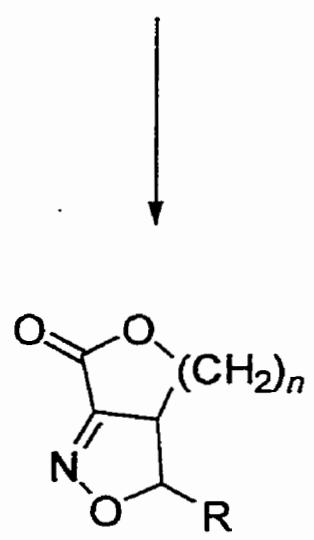

12

$$
\begin{aligned}
& \text { a } n=1, \mathrm{R}=\mathrm{H} \\
& \text { b } n=2, \mathrm{R}=\mathrm{Ph} \\
& \text { c } n=3, \mathrm{R}=\mathrm{H}
\end{aligned}
$$

Aside from the regiochemical aspects, an attractive feature of the internal cycloaddition is the opportunity to control the stereochemistry of the products at several centers. The generation of angular-fused tricyclic isoxazolines 16 via intramolecular 1,3DC of nitrile oxide precursors is an example. Nitro cycloalkenes 13 of varying ring sizes were treated with phenyl isocyanate (14) in the presence of triethylamine so as to generate the corresponding nitrile oxide 15 (Scheme 9). ${ }^{25}$ In each case, the transient nitrile oxide 15 was found to cyclize readily to the tricyclic isoxazoline 16 with yields in the range of $81-91 \%$. Three stereocenters and three rings were generated in a single reaction. 

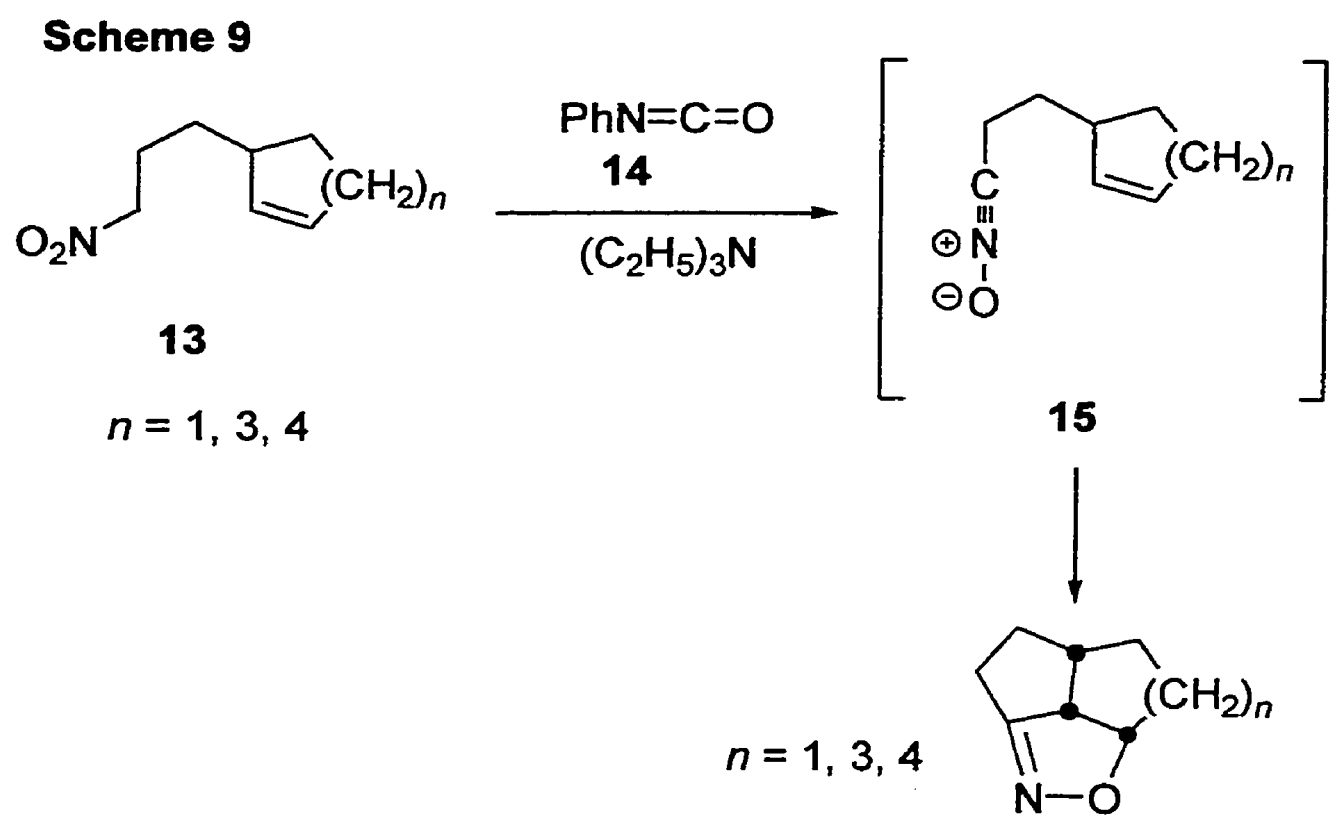

16

\section{Scheme 10}<smiles>C=CCC(C)(C)CCC[N+](=O)[O-]</smiles>

17

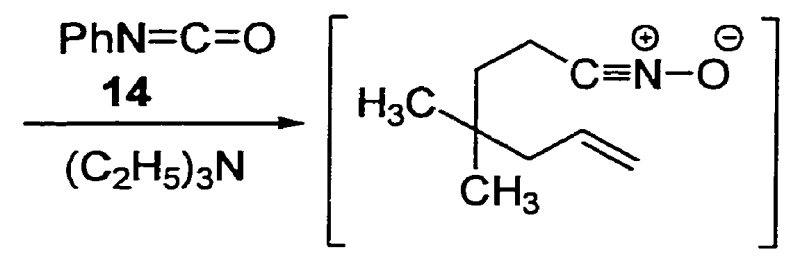

18<smiles>CC1(C)CCC2=NOCC2C1</smiles>

19

A similar cycloaddition was obtained on treatment of 4,4-dimethyl-7-nitro-1heptene (17) with phenyl isocyanate (14) in the presence of triethylamine. ${ }^{26}$ The nitrile 
oxide 18 cyclized to give the cycloadduct 19 as the exclusive product in isolated yield of $91 \%$ (Scheme 10).

\subsubsection{Synthetic Uses of Intramolecular 1,3-Dipolar Cycloadditions of Nitrile Oxides}

The application of intramolecular $1,3-\mathrm{DC}$ reactions of nitrile oxides to the synthesis of complex natural products has been recognized as a very powerful synthetic tool. The 1,3-DC reactions of nitrile oxides to olefins are especially suited for the syntheses of alkaloids because the introduction of the nitrogen atom occurs simultaneously with the assembly of the carbon skeleton. ${ }^{9}$ Kozikowski and Ishida have reported a novel strategy for the formation of tetracyclic compounds possessing suitably functionalized $C$ rings from indole-4-carboxaldehyde via an intramolecular 1,3-DC reaction of a nitrile oxide. ${ }^{27}$ In the total synthesis of the ergot alkaloid chanoclavine I (23), conversion of the nitro group of indole $\mathbf{2 0}$ into the corresponding nitrile oxide $\mathbf{2 1}$ followed the phenyl isocyanate procedure developed by Mukaiyama as described earlier (Scheme 11). The major product corresponded to isoxazoline 20a-c and no side products resulting from reaction of the dipole with the electron-rich indole nucleus were detected. The chanoclavine I (23) was formed in a subsequent series of steps from the isoxazoline nucleus.

The prowess of INOC was further demonstrated by Confalone et al. in the stereospecific preparation of the key intermediate amino alcohol 27 from cycloheptene in the synthesis of biotin (Scheme 12). ${ }^{28}$ Compound 25 underwent spontaneous cyclization 


\section{Scheme 11}<smiles>[X]C([Y])=Cc1cccc2[nH]cc(CC[N+](=O)[O-])c12</smiles>

20a $X=Y=H$

b $X=\mathrm{OCH}_{3}, Y=\mathrm{H}$

c $X=\mathrm{H}, Y=\mathrm{CH}_{2} \mathrm{OAC}$

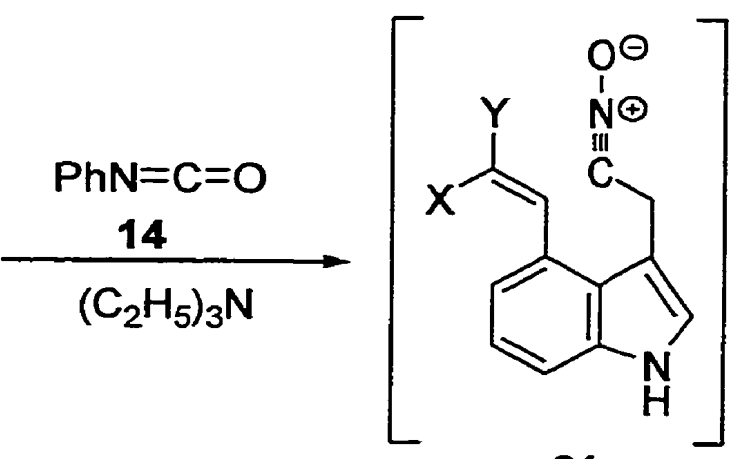

21

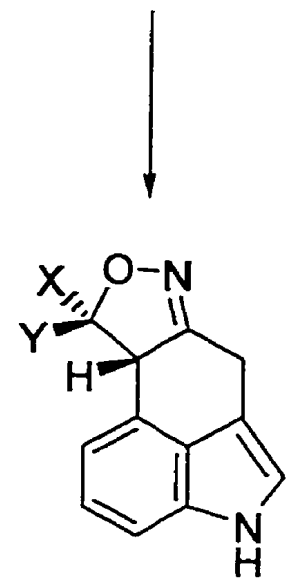

23

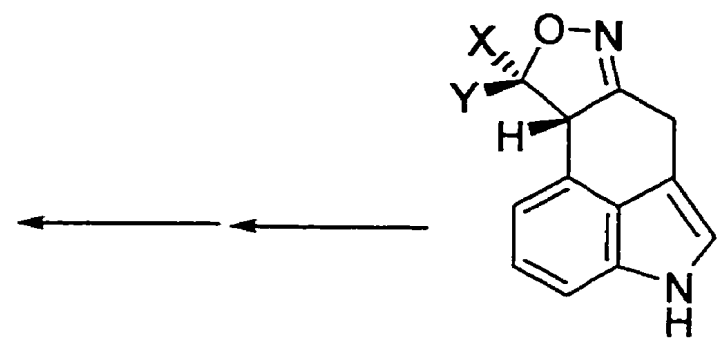

22

\section{Scheme 12}

$\mathrm{O}_{2} \mathrm{~N} \stackrel{\mathrm{PhN}=\mathrm{C}=\mathrm{O}}{14}$

24

25

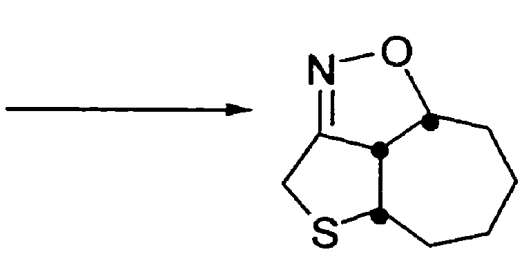

26

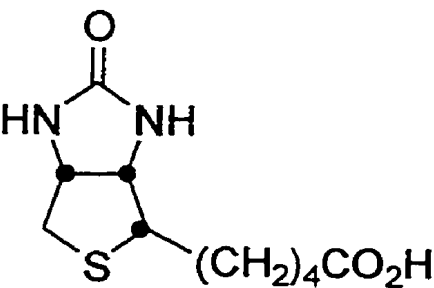

28
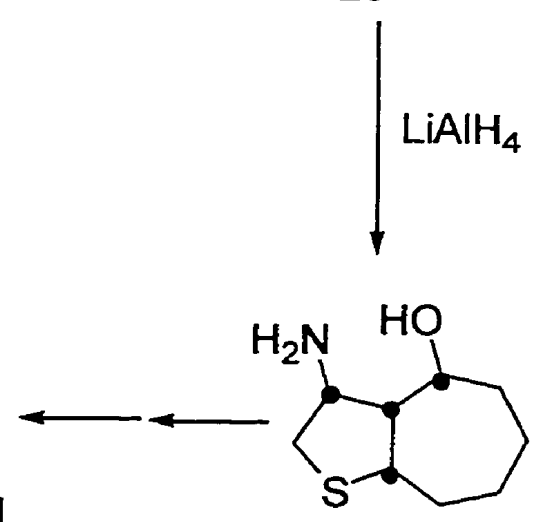

27 
to the tricyclic isoxazoline $\mathbf{2 6}$, which was then transformed into the target structure of biotin (28), taking full advantage of the stereospecificity of the key ring-forming cycloaddition.

\subsection{Scope of the Thesis}

Although the intermolecular reactions of dipoles with norbornadiene and its derivatives have been subjected to considerable investigation, the intramolecular variants have not been studied. The design and development of a novel strategy to a highly regioand stereocontrolled assembly of angular fused-tricyclic frameworks via intramolecular cycloaddition reactions of norbornadiene-tethers is the subject of the research (Scheme 13).

\section{Scheme 13}
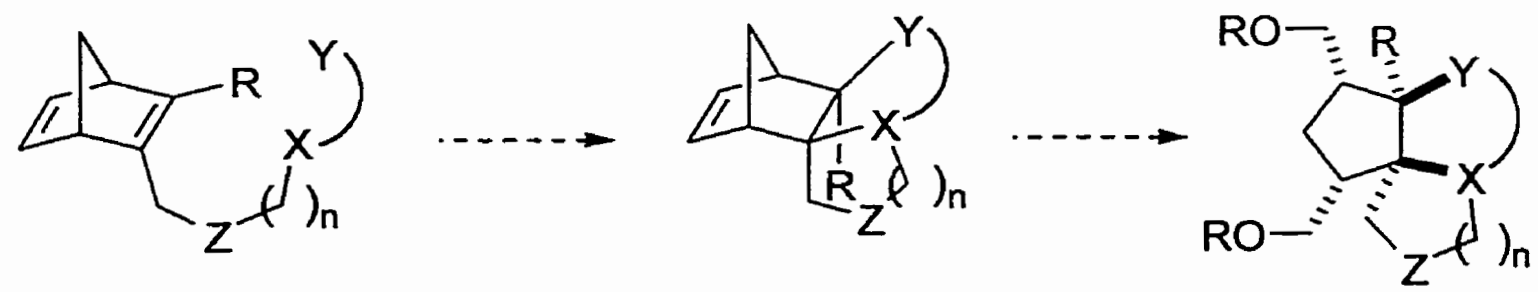

Investigation on the synthesis of norbornadiene-tethered nitrile oxides (with $\mathrm{R}=$ $\mathrm{H})$ and studies on their intramolecular 1,3-dipolar cycloaddition reactions will be the focus of Chapter 2. Subsequent selective cleavage of the N-O bond of the cycloadducts will then give $\gamma$-amino alcohols, and related compounds (Scheme 14). In the light of 
recent developments, compounds of these types have shown considerable utility in natural products synthesis. ${ }^{29-32}$

\section{Scheme 14}

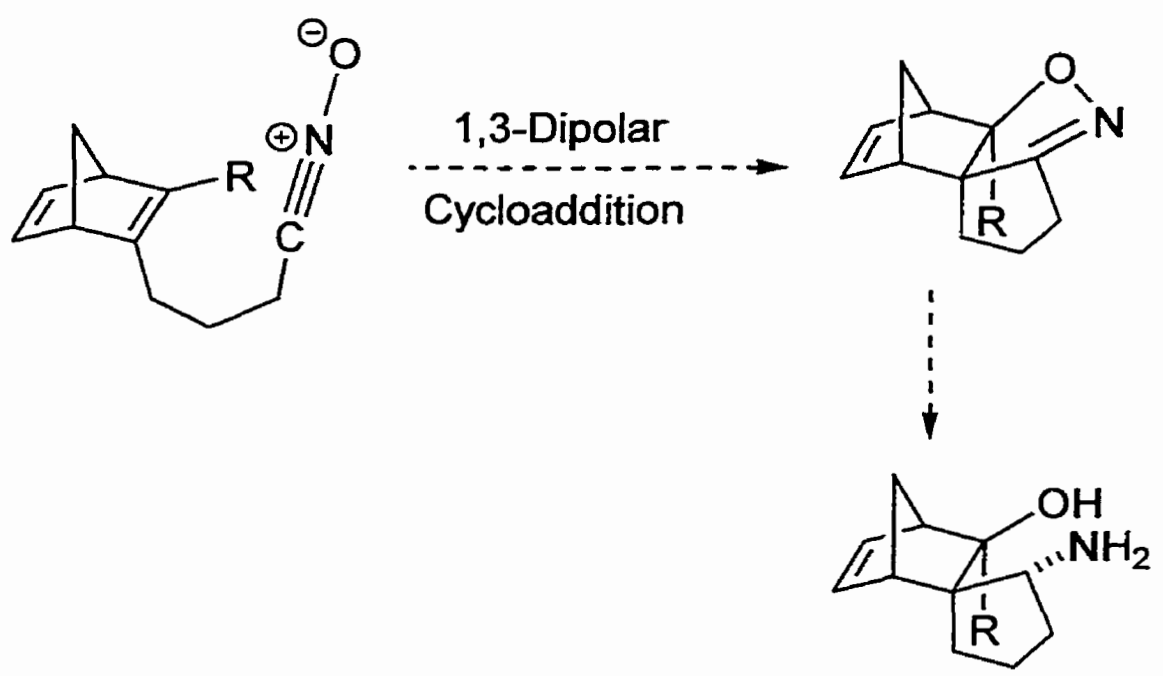

During the examination on the synthesis of such cycloadducts, a simple and convenient route to a variety of 2,3-disubstituted norbornadienes that cannot be prepared by the traditional Diels-Alder method has also been developed. ${ }^{33}$ 2,3-Disubstituted NBD are important intermediates in the synthesis of many natural products, such as prostaglandin endoperoxides $\mathrm{PGH}_{2}$ and $\mathrm{PGG}_{2}$, cis-trikentrin $\mathrm{B}$, and $\beta$-xantalol. ${ }^{34-37} \mathrm{~A}$ comprehensive account of the synthesis of a wide variety of 2,3-disubstituted NBD will be presented in Chapter 3.

Having discovered an efficient method in the generation of 2,3-disubstitued NBD, Chapter 4 continues the exploration of the intramolecular 1,3-dipolar cycloaddition reactions of norbornadiene-tethered nitriles oxides with C-3 substituents. Such a study 
opens the door to the synthesis of a vast array of functionalized cycloadducts which are of importance in natural product synthesis.

In the final chapter, the experimental procedures involved in the synthesis of all compounds will be detailed. The spectroscopic data of these compounds will also be reported.

An Epilogue discussing the significance of the research and areas requiring further study will follow. 


\section{Chapter 2}

Intramolecular 1,3-Dipolar Cycloadditions of Norbornadiene-Tethered Nitrile Oxides 


\section{$2.1 \quad$ Introduction}

Cycloaddition reactions are among the most powerful methods for the construction of rings. ${ }^{38}$ In particular, intramolecular cycloadditions with high regio- and stereocontrol are important tools for the efficient assembly of complex molecular structures. The objective of the project is to develop an efficient route for the construction of angular-fused tricyclic frameworks via intrannolecular 1,3-dipolar cycloadditions. Selective cleavage of these cycloadducts can then yield a variety of spirocyclic compounds with high regio- and stereocontrol (Scheme 5 ). In this chapter,

\section{Scheme 15. General Outline for Construction of Tricyclic \& Spirocyclic Frameworks via Intramolecular Cycloadditions of Norbornadienes and Subsequent Cleavage of the Cycloadducts}

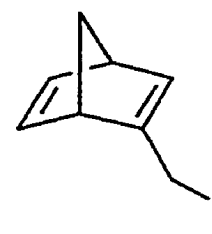<smiles>[Y]CC[X]</smiles>
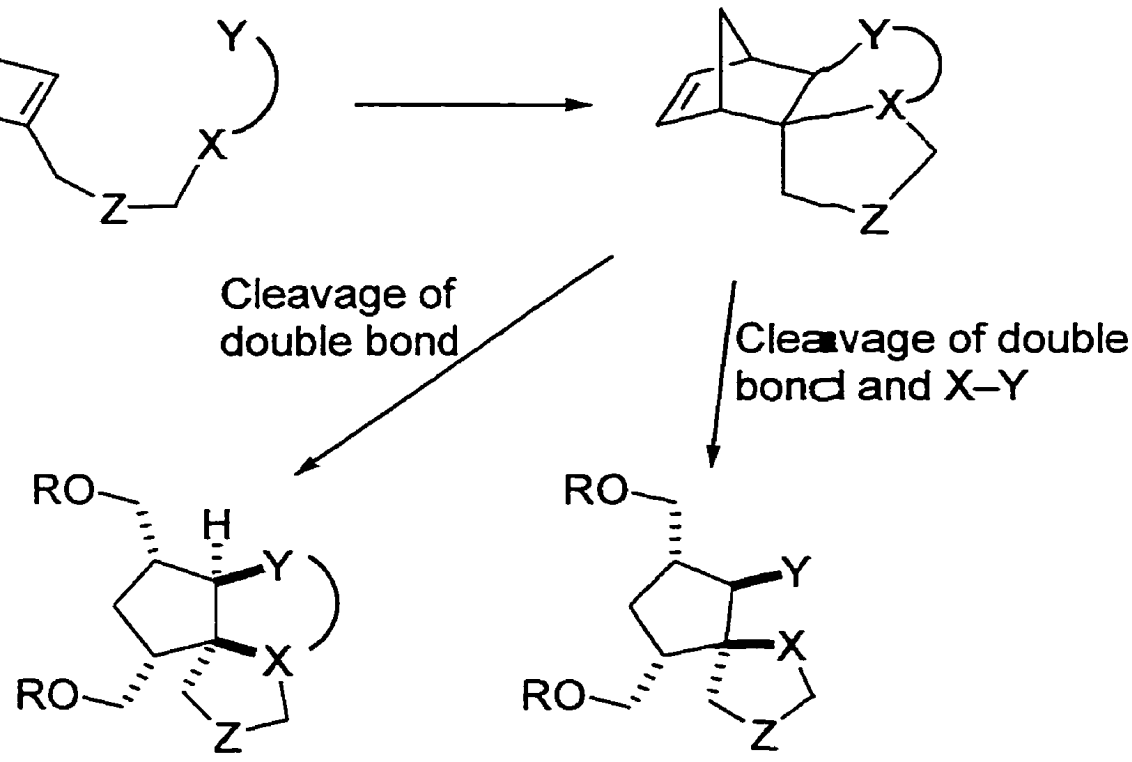
only C-2 tethered norbornadiene nitrile oxides will be focused on. The scope and limitations of the effects of tether length $(n=0,1,2,3)$ and the type of heteroatom $(Z=$ $\mathrm{O}, \mathrm{S}, \mathrm{Si}, \mathrm{N}$ ) upon the regio- and stereoselectivity of the cycloaddition will also be addressed.

1,3-Dipolar cycloadditions offer a convenient one-step route for the construction of various complex five-membered heterocycles. The 1,3-dipolar cycloadditions of nitrile oxides are well-documented in the literature. ${ }^{10,12}$ These reactions provide an efficient route to the synthesis of 2-isoxazolines which are versatile intermediates in organic synthesis. $9,11,39$ Herein, the synthesis of norbornadiene-tethered nitrile oxide and its conversion to cycloadduct will first be presented. An extensive discussion on the conditions for the generation of the cycloadduct such as solvent and temperature studies will follow. Application of the general methodology to the synthesis of various norbornadiene-tethered nitrile oxides will be reported. A comprehensive account of the identification of the cycloadducts from spectroscopic data will be detailed as well.

\subsection{Synthesis of Cycloadduct}

For the investigation on the intramolecular 1,3-DC reactions, an efficient route to the synthesis of norbornadiene-tethered nitro compound 31 was developed. This compound 31 then served as a precursor of the required nitrile oxide 32 for the cycloaddition reaction (Scheme 16). According to Schlosser and Brandsma's protocol, deprotonation of the vinylic proton of norbornadiene (1) with Schlosser's base 
${ }^{\mathrm{n}} \mathrm{BuLi} /{ }^{\mathrm{B}} \mathrm{BuOK}$ occurred smoothly at $-78^{\circ} \mathrm{C}$ in $\mathrm{THF} .{ }^{40}$ Treatment of the resulting norbornadienyl anion with an excess of 1,4-dibromobutane (29) gave the norbornadienetethered bromide 30 in good yield. ${ }^{4 I}$ Displacement of the bromide 30 with sodium nitrite in the presence of phloroglucinol in DMSO afforded the required nitro compound $31 .^{42}$ In the absence of phloroglucinol, a significant amount of the corresponding nitrite was obtained and the yield of the nitro compound 31 was very low. In the final step of the reaction pathway, 31 was converted to the intermediate nitrile oxide 32 and the

\section{Scheme 16. Proposed Route to the Synthesis of Cycloadduct}

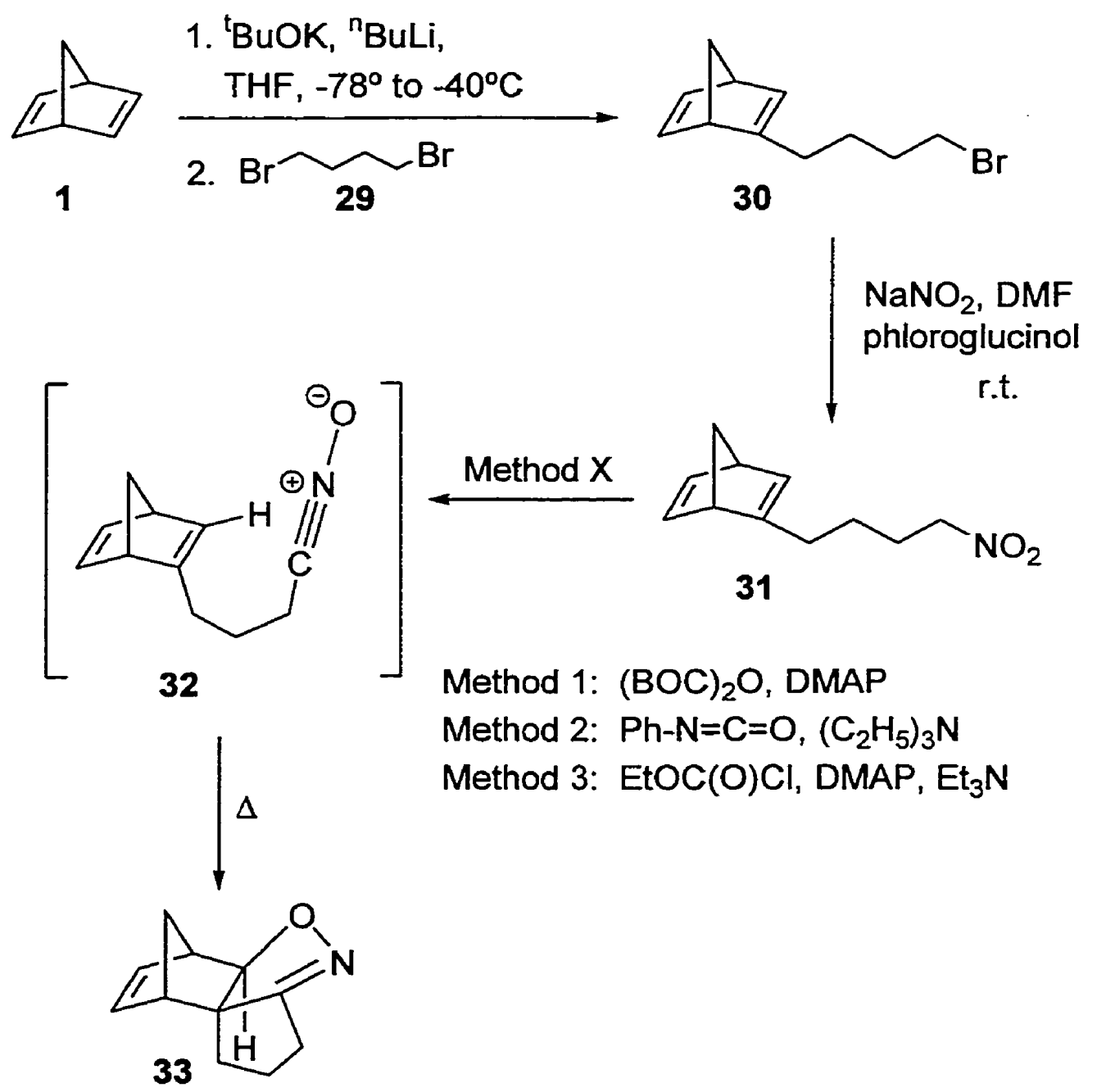


generation of the cycloadduct $\mathbf{3 3}$ was provided. The nitrile oxide intermediate $\mathbf{3 2}$ is highly reactive and must be generated and trapped in situ in order to avoid dimerization.

Although there are several methods for generation of nitrile oxide $\mathbf{3 2}$ from the nitro precursor 31, the three most widely used routes were investigated. The three methods are: (1) Hassner method ${ }^{19}$ which involves reaction of the nitro compound $\mathbf{3 1}$ with di-tert-butyl dicarbonate and 4-dimethylaminopyridine as catalyst or (2) Mukaiyama aromatic isocyanate method ${ }^{43}$ which involves reaction of $\mathbf{3 1}$ with the dehydrating agent phenyl isocyanate and the base triethylamine or (3) Shimizu ethyl chloroformate method $^{44}$ which involves reaction of $\mathbf{3 1}$ with ethyl chloroformate, 4dimethylaminopyridine and triethylamine. Reaction conditions of each cycloaddition method were investigated in the development of a general route with optimum conditions for different classes of substrates. These results will be presented in a later section.

\subsection{Proposed Mechanism for the Conversion of a Nitroalkane to a Nitrile Oxide}

Mechanisms of the three aforementioned methods for the conversion of a nitroalkane to a nitrile oxide intermediate are quite similar. Herein, only the mechanism of the Hassner method will be discussed. 


\subsubsection{Hassner $(\mathrm{BOC})_{2} \mathrm{O} / \mathrm{DMAP}$ Method}

This method is based on the rationalization that formation of nitrile oxides from nitroalkanes involves generation of a nitronate ester 35 in Scheme 17, followed by basecatalyzed elimination of a carboxylate unit. ${ }^{19}$ A detailed description of each step of the mechanistic pathway is as follows.

\section{Scheme 17. Conversion of Nitroalkane to Nitrile Oxide Intermediate}

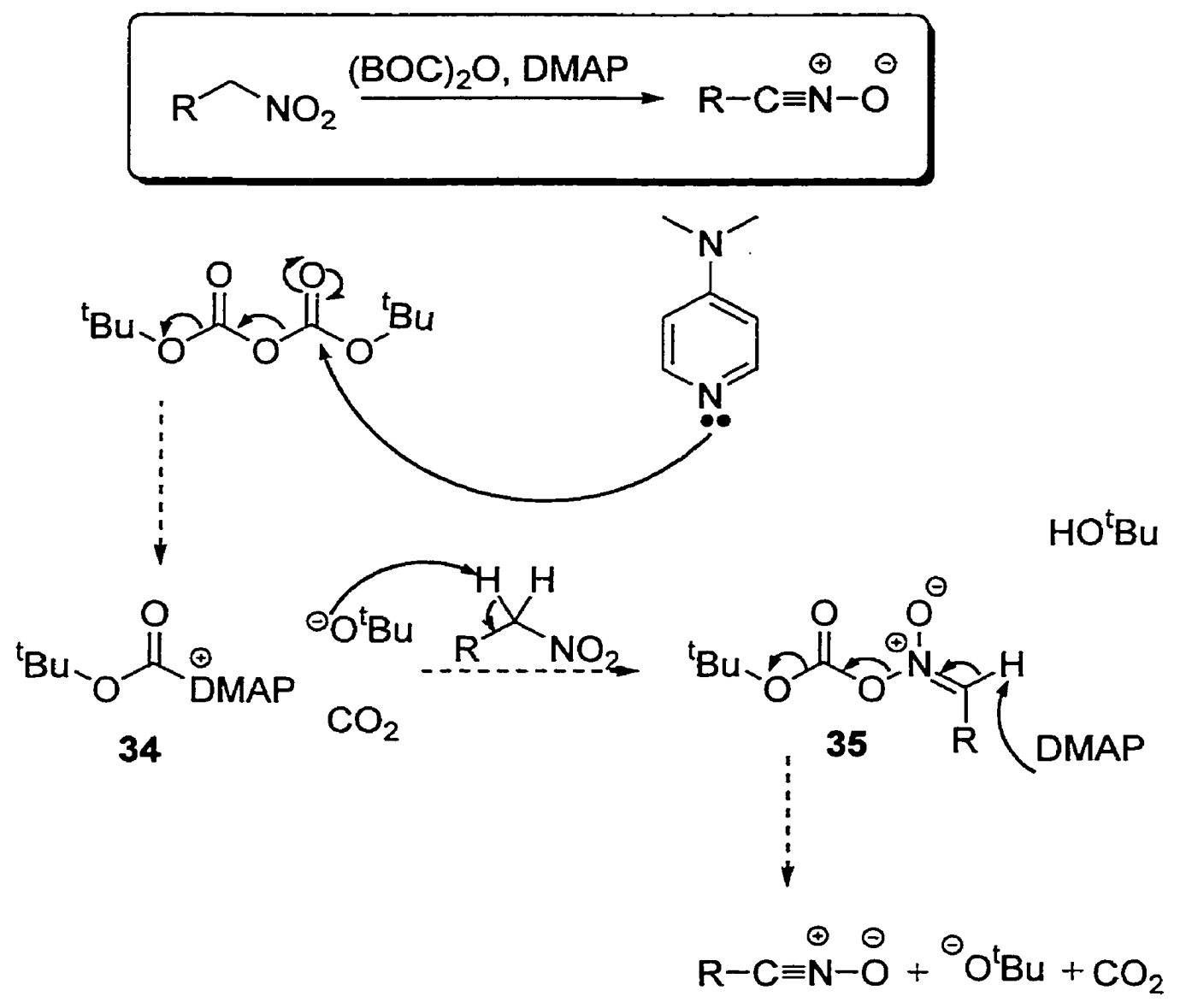

In the first step, the pyridinium nitrogen of DMAP attacks the carbonate carbon of (BOC) $)_{2} \mathrm{O}$ to generate the $N$-alkoxycarbonylpyridinium salt 34 , carbon dioxide and tert- 
butoxide. The strong base tert-butoxide then deprotonates the hydrogen at the carbon adjacent to the nitro functionality of the nitroalkane. This negatively charged nitro compound then displaces the positively charged DMAP, a good leaving group, to form the nitroate ester 35. Since DMAP is known to be an excellent catalyst for esterification of alcohols by acid anhydrides, the apparent rate determining step, namely formation of the nitronate ester 35 , is enhanced. Thus, the reaction is allowed to occur at room temperature. Furthermore, DMAP is a strong enough base to deprotonate the vinylic proton in the nitronate ester 35 to generate the corresponding nitrile oxide. The resulting tert-butoxide will then deprotonate the protonated DMAP, forming a second tert-butanol molecule. At the end of the reaction, DMAP is regenerated and hence it is a catalyst. DMAP can react with another di-tert-butyl dicarbonate molecule and the whole process is repeated again. The only side products in this reaction are $\mathrm{CO}_{2}$ and tert-butanol.

\subsection{Optimization of Intramolecular 1,3-Dipolar Cycloadditions of Norbornadiene- Tethered Nitrile Oxides}

Studies on the conversion of nitroalkane to the intermediate nitrile oxide and hence to the cycloadduct has been documented in the literature. ${ }^{12,13}$ As discussed in section 2.2, the conversion can be carried out by three different methods: the Hassner $(\mathrm{BOC})_{2} \mathrm{O} / \mathrm{DMAP}$ method, the Mukaiyama aromatic isocyanate method and the Shimizu ethyl chloroformate method. The application of these three methods to intramolecular 1,3-dipolar cycloadditions of norbornadiene-tethered nitrile oxides was undertaken. In 
order to maximize the yield of the cycloadduct obtained, solvent and temperature studies on each of these three methods were performed.

\subsubsection{Conditions for the Generation of Cycloadduct}

Table 1 displays the yields obtained from the three different cycloaddition methods. For each method, the reaction was performed either in toluene or chloroform at temperatures of $90^{\circ} \mathrm{C}$ and $60^{\circ} \mathrm{C}$ respectively. The time allowed for the

Table 1. Conditions for the Generation of Cycloadduct

\begin{tabular}{|c|c|c|c|c|}
\hline method & solvent & temperature & time & yield \\
\hline \multirow{2}{*}{$\begin{array}{l}(\mathrm{BOC})_{2} \mathrm{O} \\
\text { DMAP }\end{array}$} & toluene & $90^{\circ} \mathrm{C}$ & $96 \mathrm{~h}$ & $86 \%$ \\
\hline & $\mathrm{CHCl}_{3}$ & $60^{\circ} \mathrm{C}$ & $96 \mathrm{~h}$ & $61 \%$ \\
\hline \multirow{2}{*}{$\begin{array}{l}\mathrm{PhNCO} \\
\mathrm{Et}_{3} \mathrm{~N}\end{array}$} & toluene & $90^{\circ} \mathrm{C}$ & $96 \mathrm{~h}$ & $54 \%$ \\
\hline & $\mathrm{CHCl}_{3}$ & $60^{\circ} \mathrm{C}$ & $96 \mathrm{~h}$ & $76 \%$ \\
\hline \multirow{2}{*}{$\begin{array}{l}\mathrm{EtOCOCl} \\
\mathrm{Et}_{3} \mathrm{~N}, \mathrm{DMAP}\end{array}$} & toluene & $90^{\circ} \mathrm{C}$ & $96 \mathrm{~h}$ & $25 \%$ \\
\hline & $\mathrm{CHCl}_{3}$ & $60^{\circ} \mathrm{C}$ & $96 h$ & $72 \%$ \\
\hline
\end{tabular}


reaction was $96 \mathrm{~h}$. From Table 1 , it was observed that with the use of (BOC) $)_{2}$ O/DMAP, a higher yield of the cycloadduct was obtained for the reaction carried out in toluene at $90^{\circ} \mathrm{C}$. However, in the Mukaiyama and Shimizu methods, a different scenario was observed. For both of these methods, the use of toluene resulted in much lower yields of the cycloadducts as compared to the cases where chloroform was used. From this study, it was concluded that the Hassner (BOC) $)_{2} \mathrm{O} / \mathrm{DMAP}$ method under the reaction conditions of toluene at $90^{\circ} \mathrm{C}$ afforded the best yield of the cycloadduct.

\subsubsection{Effect of Solvent on Cycloaddition}

Having determined that the Hassner $(\mathrm{BOC})_{2} \mathrm{O} / \mathrm{DMAP}$ method was the method of choice, this method was employed for the solvent studies on the cycloaddition reactions. A wide variety of solvents were used for the investigation. As shown in Table 2, the cycloadditions were carried out at the respective temperatures of the solvent used. The period of time allowed for these reactions was more or less the same. From the results displayed, it was evident that there was no real correlation between solvent polarity and the yield of the cycloadduct obtained. Thus, independent of the solvent used, the cycloaddition reactions gave yields within the range of $60-90 \%$. Noteworthy is the reaction in toluene at $90^{\circ} \mathrm{C}$ which provided the cycloadduct with the highest yield. 
Table 2. Effect of Solvent

\begin{tabular}{lccc} 
& & \\
\hline Solvent & Temperature & Time & Yield \\
\hline Toluene & $90^{\circ} \mathrm{C}$ & $48 \mathrm{~h}$ & $86 \%$ \\
$\mathrm{THF}$ & $60^{\circ} \mathrm{C}$ & $39 \mathrm{~h}$ & $76 \%$ \\
$\mathrm{CHCl}_{3}$ & $60^{\circ} \mathrm{C}$ & $45 \mathrm{~h}$ & $61 \%$ \\
$\mathrm{ClCH}_{2} \mathrm{CH}_{2} \mathrm{Cl}$ & $80^{\circ} \mathrm{C}$ & $45 \mathrm{~h}$ & $67 \%$ \\
$\mathrm{DME}^{(\mathrm{BOC})_{2} \mathrm{O}}$ & $80^{\circ} \mathrm{C}$ & $45 \mathrm{~h}$ & $72 \%$ \\
\hline
\end{tabular}

\subsubsection{Effect of Temperature on Cycloaddition}

At this point of the study, it was established that cycloaddition was best performed in toluene. To further the investigation on the cycloaddition reactions, another reaction condition that was explored was the temperature. As illustrated in Table 3, the choice of temperature also influenced the yield, sometimes dramatically. The reactions were allowed to stir for approximately 40 to $50 \mathrm{~h}$. From Table 3, it was clear that there was an excellent correlation between the temperature and the yield of the cycloadduct obtained. As the temperature was increased, so was the yield of the cycloadduct 
achieved. Reaction temperature higher than $90^{\circ} \mathrm{C}$ was also investigated in the study by employing mesitylene as the solvent. It was found that at $150^{\circ} \mathrm{C}$, decomposition of the product was observed. Thus, it was evident that the optimum temperature at which cycloaddition could occur to provide the best yield of the cycloadduct was $90^{\circ} \mathrm{C}$.

Table 3. Effect of Temperature
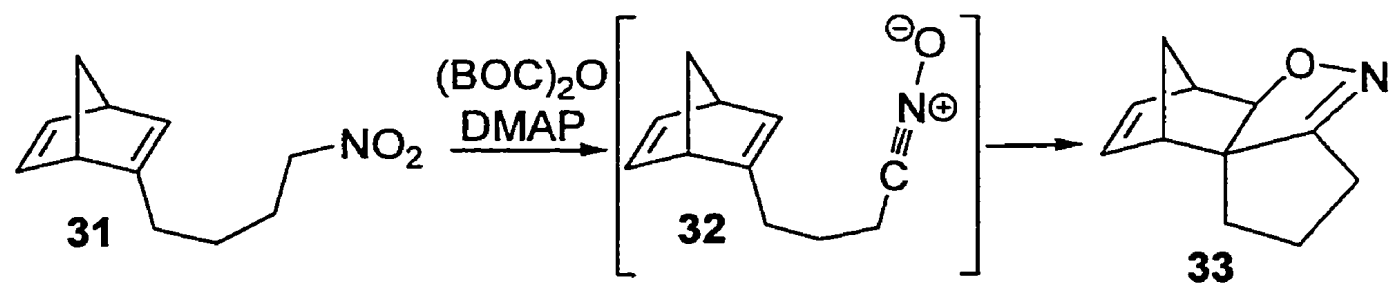

\begin{tabular}{lccc}
\hline Solvent & Temperature & Time & Yield \\
\hline Toluene & $25^{\circ} \mathrm{C}$ & $43 \mathrm{~h}$ & $46 \%$ \\
Toluene & $60^{\circ} \mathrm{C}$ & $39 \mathrm{~h}$ & $66 \%$ \\
Toluene & $90^{\circ} \mathrm{C}$ & $48 \mathrm{~h}$ & $86 \%$ \\
\hline
\end{tabular}

\subsubsection{Summary}

From the above study, it was concluded that the use of $(\mathrm{BOC})_{2} \mathrm{O}$ and DMAP in toluene at a temperature of $90^{\circ} \mathrm{C}$ were the best reaction conditions for the system investigated, providing the cycloadduct in the highest yield. As shown in Scheme 18, starting from a cheap, commercially available compound, norbornadiene (1), a complex 
angular-fused tricyclic compound $\mathbf{3 3}$ can be synthesized in just three simple steps with good yields.

Scheme 18. Optimized Conditions for Cycloaddition<smiles>C1=CC2C=CC1C2</smiles>

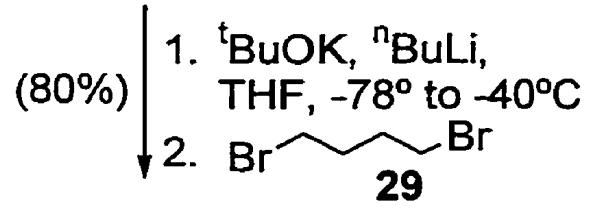

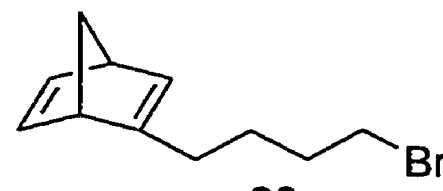

30

$\mathrm{NaNO}_{2}$, DMF phloroglucinol r.t.

$(56 \%)$
3 steps

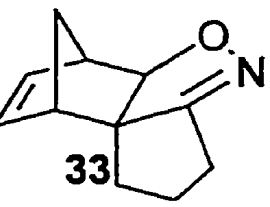

$(86 \%) \mid 90^{\circ} \mathrm{C}$
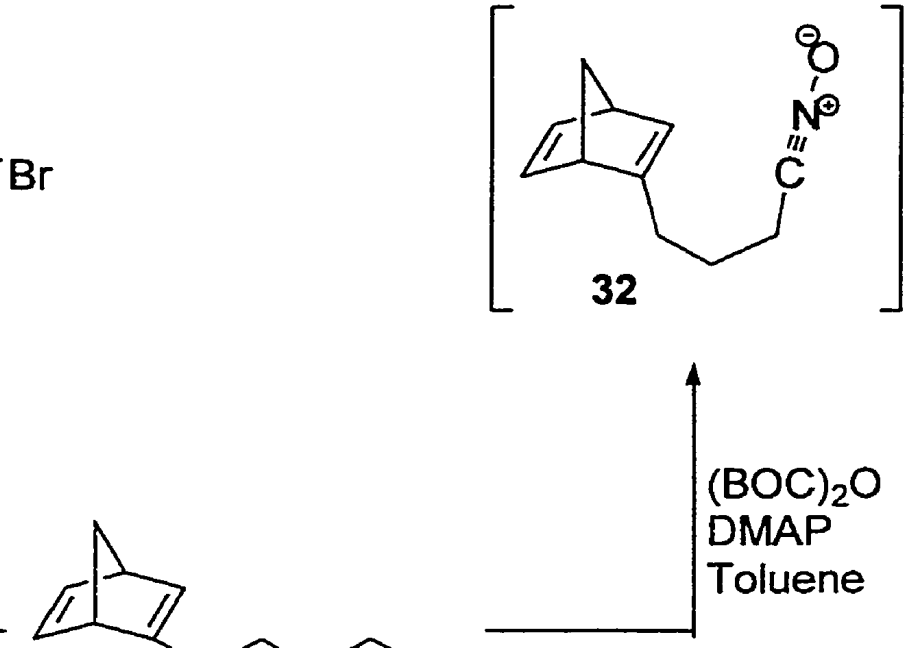

$(\mathrm{BOC})_{2} \mathrm{O}$ DMAP Toluene

31 


\subsection{Results and Discussion}

To study the generality of the intramolecular 1,3-dipolar cycloaddition of norbornadiene-tethered nitrile oxides, a variety of norbornadiene-tethered nitro compounds was synthesized and subjected to the optimized cycloaddition conditions. The synthesis of nitro compounds with different tether lengths ( $n=0,1,2,3)$ will first be presented, followed by those bearing various functionalities within the tethered norbornadiene nitrile oxides. Finally, synthesis of nitro compounds with different heteroatoms $(\mathrm{Z}=\mathrm{O}, \mathrm{S}, \mathrm{Si}, \mathrm{N})$ within the tether will be discussed.

\subsubsection{Synthesis of Norbornadiene-Tethered Nitrile Oxides with Different Tether Lengths}

\subsubsection{Four-Membered Cycloadduct}

An attempted synthesis of the four-membered cycloadduct 40 is illustrated in Scheme 19. Starting with norbornadiene (1), deprotonation of the vinylic proton was made possible by Schlosser's base in $\mathrm{THF}$ at $-78^{\circ} \mathrm{C}$. Addition of the resulting norbornadienyl anion to an excess of 3-bromo-1-propanol afforded alcohol 36 with a yield of $74 \%$. Since the hydroxyl functionality is a poor leaving group, 36 was not readily susceptible to nucleophilic substitution reaction with sodium nitrite. Thus, the hydroxyl group of 36 was first activated with tosyl chloride to generate 37 . Displacement 


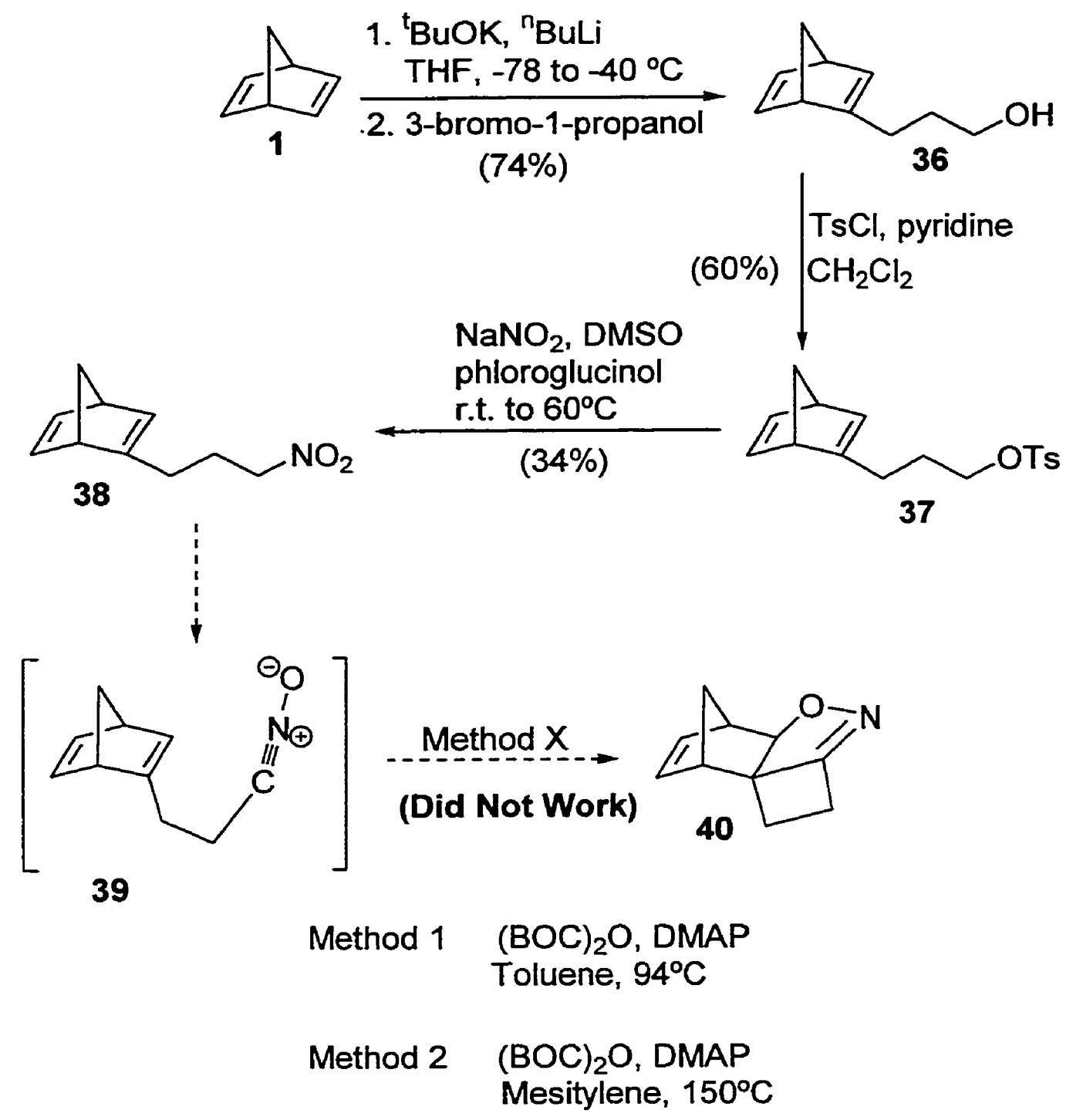

of the tosylate with sodium nitrite then afforded the required nitro compound 38 . Two attempts were then made to convert the nitro compound $\mathbf{3 8}$ to the cycloadduct $\mathbf{4 0}$. In the first case, the reaction mixture was conducted in toluene at $94^{\circ} \mathrm{C}$. After $20 \mathrm{~h}$ of reaction time, only the starting material was observed from the ${ }^{1} \mathrm{H}$ NMR $(200 \mathrm{MHz})$ spectrum. Thus, a higher boiling solvent was needed for the second attempt. Mesitylene was the solvent of choice and the reaction mixture was allowed to stir at $150^{\circ} \mathrm{C}$ for $18 \mathrm{~h}$. In this 
latter case, a mixture of unidentified materials was observed from the ${ }^{1} \mathrm{H}$ NMR (200 $\mathrm{MHz}$ ) spectrum. It was concluded that the cycloadduct $\mathbf{4 0}$ would have considerable ringstrain and cycloaddition, therefore, was not feasible.

\subsubsection{Five-Membered Cycloadduct}

Scheme 20

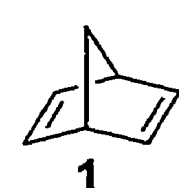

1

1. ${ }^{\mathrm{B}} \mathrm{BuOK},{ }^{\mathrm{B}} \mathrm{BuLi}$

THF, -78 to $-40^{\circ} \mathrm{C}$

2. 1,4-dibromobutane $(80 \%)$

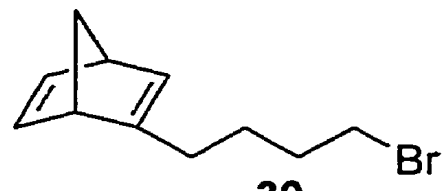

30
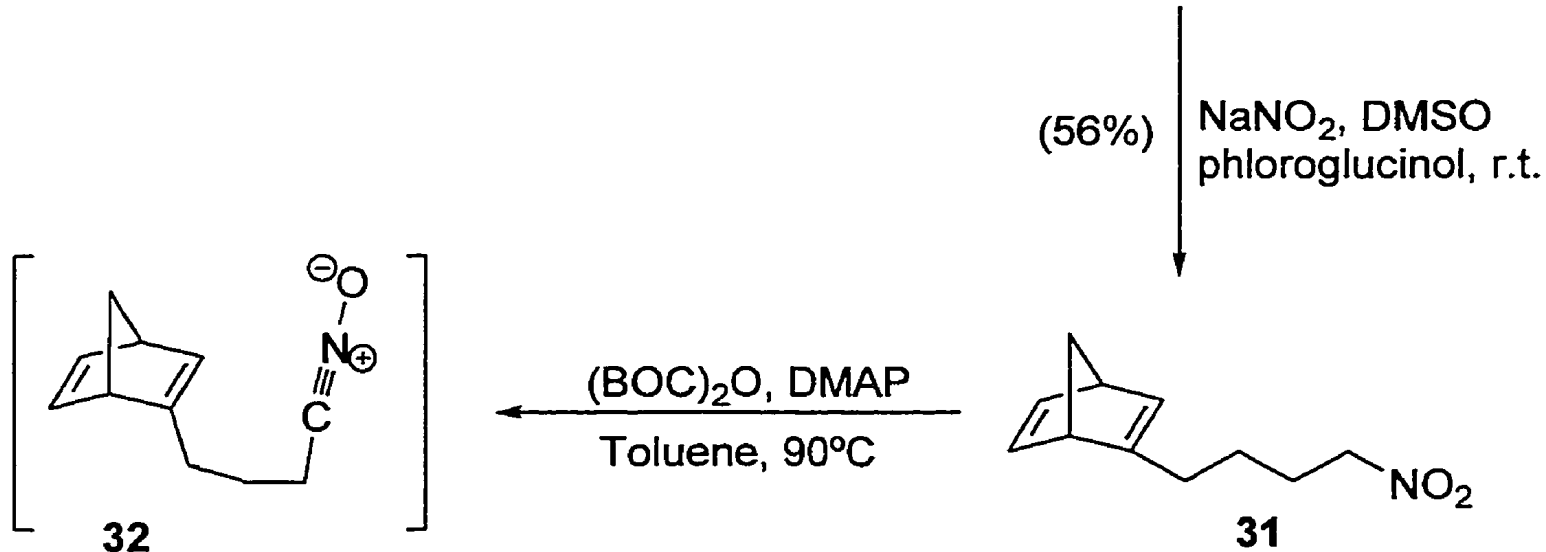

32

$\leftarrow(\mathrm{BOC})_{2} \mathrm{O}$, DMAP

Toluene, $90^{\circ} \mathrm{C}$<smiles>O=[N+]([O-])CCCCC1=CC2C=CC1C2</smiles>

31

(86\%)

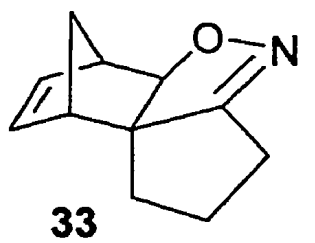


Synthesis of the five-membered cycloadduct was described earlier in section 2.2. Therefore, only a brief description will be addressed herein. As shown in Scheme 20, a relatively complex tricyclic compound $\mathbf{3 3}$ was generated from a few simple steps from norbornadiene (1). Good yield of the cycloadduct was obtained. Only a single regio- and stereoisomer of 33 was detected.

\subsubsection{Six-Membered Cycloadduct}

\section{Scheme 21}<smiles>C1=CC2C=CC1C2</smiles>

1

1. ${ }^{\mathrm{B}} \mathrm{BuOK},{ }^{\mathrm{n}} \mathrm{BuLi}$ THF, -78 to $-40^{\circ} \mathrm{C}$ 2. 1,5-dibromopentane $(81 \%)$<smiles>BrCCCCCC1=CC2C=CC1C2</smiles>

41 $(50 \%) \mid \begin{aligned} & \mathrm{NaNO}_{2}, \mathrm{DMSO} \\ & \text { phloroglucinol, r.t. }\end{aligned}$<smiles>CC1=CC2C=C(CCCCC(=O)[O-])C1C2</smiles>

43

$(75 \%)$<smiles>C1=CC2CC1C1ON=C3CCCCC321</smiles><smiles>OCOc1ccccc1</smiles>

Toluene, $90^{\circ} \mathrm{C}$<smiles>O=[N+]([O-])CCCCCC1=CC2C=CC1C2</smiles>

42 
The synthetic methodology to the six-membered cycloadduct was only a slight modification of the route to the five-membered adduct. Following Schlosser and Brandsma's protocol, the vinylic proton of norbornadiene (1) was deprotonated with ${ }^{\mathrm{n}} \mathrm{BuLi} /{ }^{\mathrm{t}} \mathrm{BuOK}$ at $-78^{\circ} \mathrm{C}$ in THF. Rather than adding the generated norbornadienyl anion to an excess of 1,4-dibromobutane as in the case of the five-membered cycloadduct, the norbornadienyl anion was added to an excess of 1,5-dibromopentane to provide 41 (Scheme 21). The resulting bromide 41 then underwent displacement reaction with sodium nitrite to give the nitro compound 42. As in the case of the five-membered cycloadduct, conversion of the bromide to the corresponding nitro compound gave poor yields. Nevertheless, the nitro compound 42 was successfully converted to the sixmembered cycloadduct 44 as the only regio- and stereoisomer with the use of the Hassner method.

\subsubsection{Seven-Membered Cycloadduct}

In order to complete a full investigation on the effect of tether length on the intramolecular 1,3-dipolar cycloaddition of tethered norbornadiene nitrile oxides, synthesis of the seven-membered cycloadduct was also attempted (Scheme 22). Noteworthy is the conversion of norbornadiene (1) to bromide 45 . In this case, the norbornadienyl anion was trapped with 1,6-dibromohexane. Although the corresponding nitro compound 46 was easily prepared, conversion of 46 to the seven-membered 
cycloadduct 48 was unsuccessful. The large spatial separation between the nitrile oxide and the double bond of norbornadiene possibly explained the difficulty in the formation of the cycloadduct.

\section{Scheme 22}

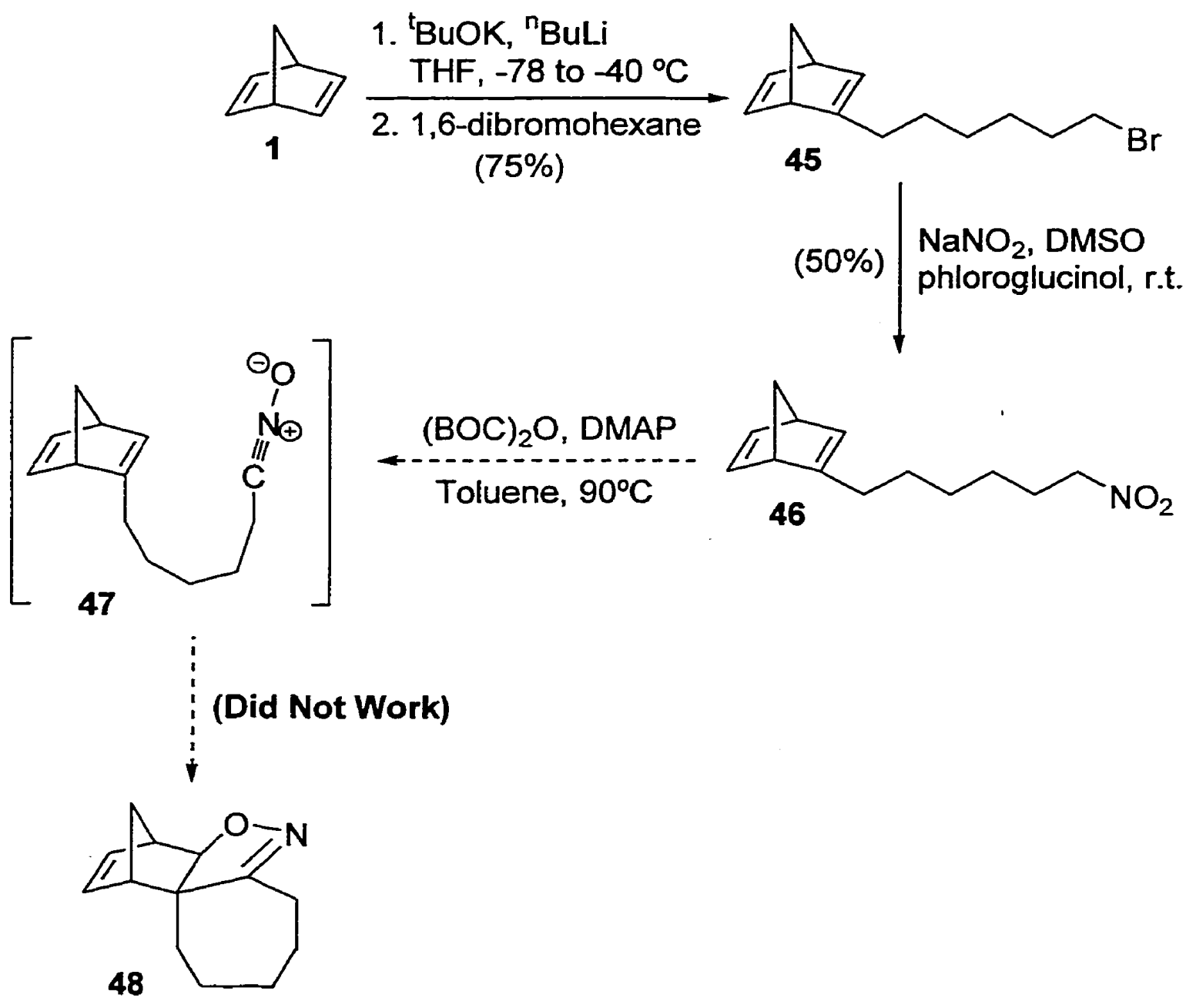




\subsubsection{Synthesis of Norbornadiene-Tethered Nitrile Oxides Bearing Functionality Within the Tether}

\subsubsection{Six-Membered Cycloadduct Bearing a $\alpha$-Silyi Ether Substituent}

In the course of studying the intramolecular 1,3-dipolar cycloadditions of norbornadiene-tethered nitrile oxides, cycloadduct precursors having functionality within the tether were also investigated. Synthesis of the nitro compound $\mathbf{5 2}$ with a silyl ether substituent is shown in Scheme 23. Hydrolysis of bromide 30 with $\mathrm{HMPA}-\mathrm{H}_{2} \mathrm{O}$ and sodium bicarbonate at $100^{\circ} \mathrm{C}$ led to the formation of the alcohol 49 in excellent yield. This latter compound was then subjected to Swern oxidation conditions to generate the corresponding aldehyde 50. Nitromethane was then added to aldehyde $\mathbf{5 0}$ in the presence of alumina to yield 51. Protection of the alcohol group with TBSCI in the presence of imidazole and DMF gave $\mathbf{5 2}$ in fair yield. Similar to previously described synthetic routes to cycloadducts, the nitro compound $\mathbf{5 2}$ was converted to the cycloadduct $\mathbf{5 4}$ with the use of the Hassner $(\mathrm{BOC})_{2} \mathrm{O} / \mathrm{DMAP}$ method in toluene at $90^{\circ} \mathrm{C}$. Although the nitro compound $\mathbf{5 2}$ bears a $\alpha$-substituent, cycloaddition occurred smoothly to afford $\mathbf{5 4}$ with a $78 \%$ yield. Only the exo cycloadduct was detected. 
Scheme 23
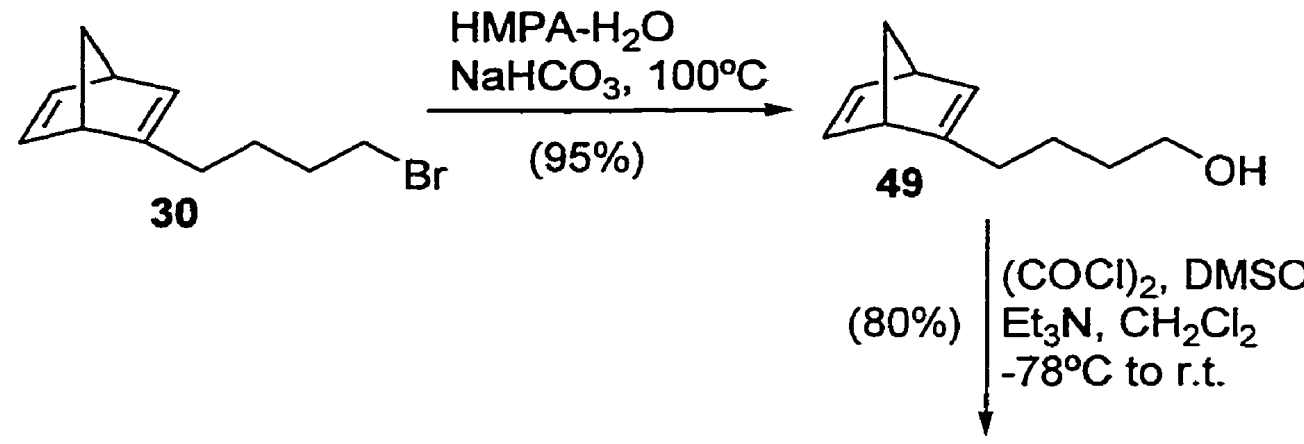<smiles>O=[N+]([O-])C[C@@H](O)CCCC1=CC2C=CC1C2</smiles>

51

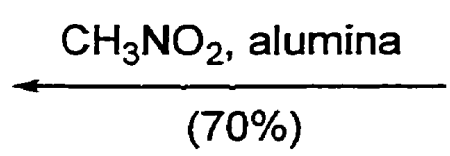
(70\%)<smiles></smiles><smiles>O=[N+]([O-])C[C@H]([OH+])CCCC1=CC2C=CC1C2</smiles>
52

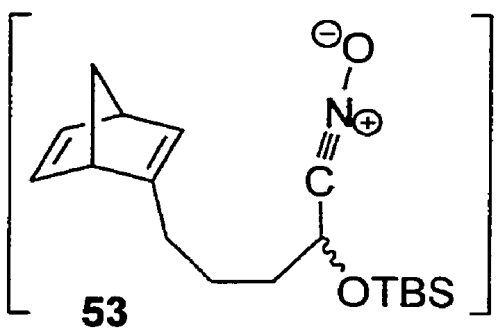

$(78 \%)$

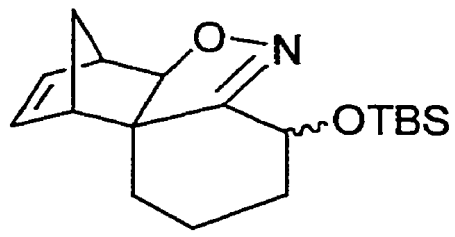

54 


\section{Scheme 24}<smiles>CC1=CC2C=CC1C2</smiles>

51
(Did Not Work)<smiles>O=C(CCCC1=CC2C=CC1C2)C[N+](=O)[O-]</smiles>

55

$\begin{array}{ll}\text { Method } 1 & \text { Dess-Martin Periodinone } \\ \mathrm{CH}_{2} \mathrm{Cl}_{2} \text {, pyridine, r.t. }\end{array}$

Method 2 oxalyl chloride, DMSO $\mathrm{Et}_{3} \mathrm{~N}, \mathrm{CH}_{2} \mathrm{Cl}_{2},-78^{\circ} \mathrm{C}$ to r.t.
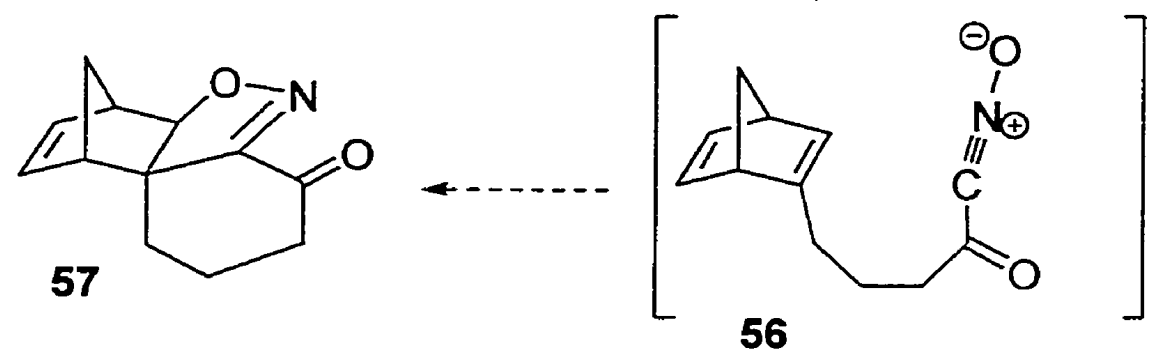

56

Since formation of the six-membered cycloadduct 54 with the $\alpha$-silyl ether functionality occurred successfully, investigation on the generation of other $\alpha$-substituted nitro precursors continued. As shown in Scheme 23, the alcohol 51 was synthesized from the bromide $\mathbf{3 0}$ in three simple steps with relatively good yields. In order to generate a six-membered cycloadduct with a $\alpha$-carbonyl substituent, $\mathbf{5 1}$ was subjected to various oxidation conditions. Two attempts were made to oxidize the secondary alcohol to the ketone functionality (Scheme 24). Unfortunately, in both cases, only a mixture of unidentified materials was detected from the ${ }^{\mathrm{I}} \mathrm{H}$ NMR (200 MHz) spectra. Thus, further investigation on the synthesis of cycloadduct $\mathbf{5 7}$ was not carried out. 


\subsubsection{Five-Membered Cycloadduct Bearing a $\gamma$-Carbonyl Substituent}

\section{Scheme 25}

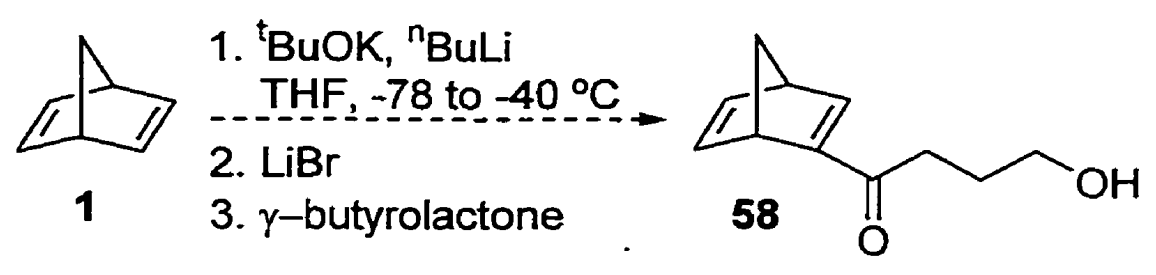

(Did Not Work)
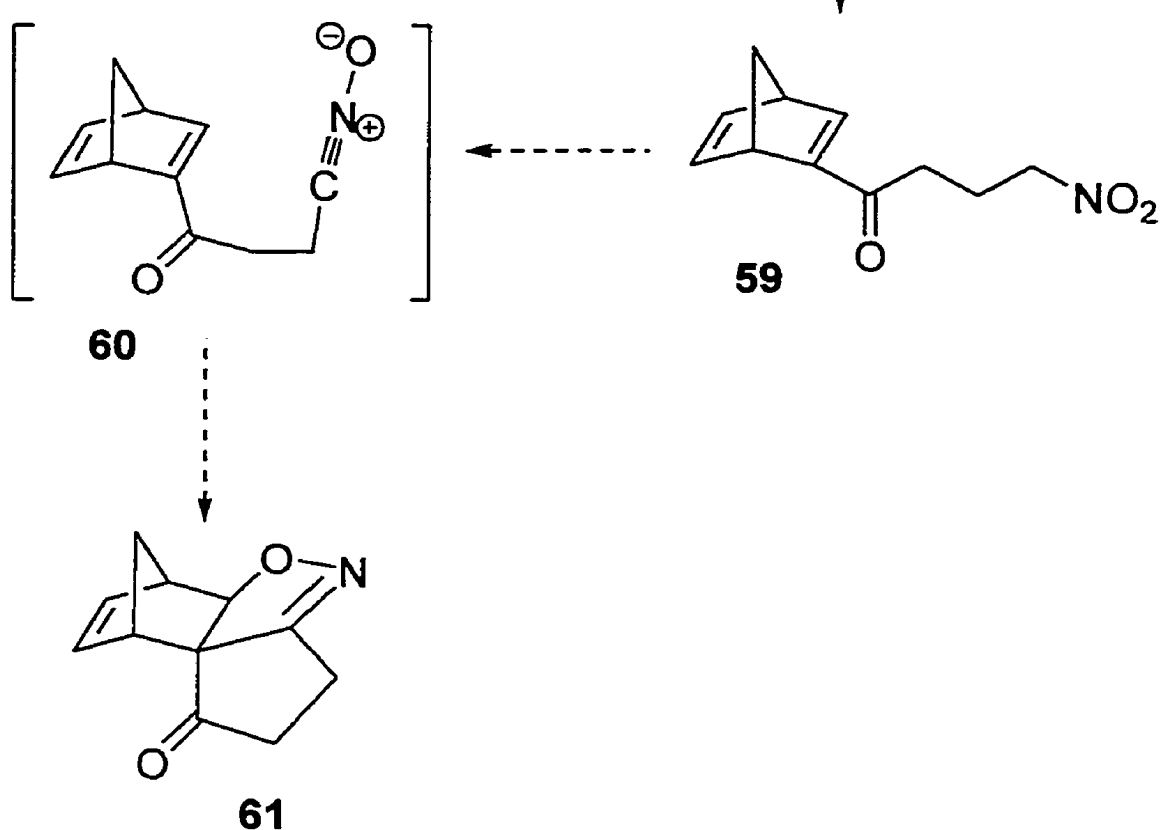

Although attempts to synthesize a cycloadduct bearing a $\alpha$-carbonyl substituent were unsuccessful, a synthetic route to the formation of cycloadduct 61 with a carbonyl functionality at the $\gamma$ position was studied. A simplified scheme for the generation of such cycloadduct is shown (Scheme 25). Synthesis of the alcohol $\mathbf{5 8}$ from norbornadiene 
(1) was attempted. Unfortunately, the crude TLC only showed a mixture of products. Further investigation on the synthesis of cycloadduct 57 was not carried out.

\subsubsection{Synthesis of Norbornadiene-Tethered Nitrile Oxides Bearing Heteroatom Within the Tether}

\subsubsection{Cycloadducts Bearing an Oxygen Within the Tether}

Synthesis of cycloadducts with an oxygen in the tether were also investigated. Methodology for the synthesis of the five-membered cycloadduct will first be presented, followed by the synthesis to the six-membered adduct.

Similar to the attempted synthesis of $\mathbf{5 8}$ from norbornadiene (1) as shown in Scheme 25, alcohol 62 was synthesized from norbornadiene (1) in the same manner (Scheme 26). The only exception to this synthesis was that rather than adding the reaction mixture to a solution of $\gamma$-butyrolactone in THF as in the case for the attempted synthesis of 58, paraformaldehyde was added to the reaction mixture to generate 62 . The norbornadiene-tethered allylic alcohol 62 was then reacted with THP-protected chloroethanol 63 in the presence of tetrabutylammonium bromide and sodium hydroxide. Compound 64 was formed in fair yield. The THP ether functionality was removed under mild acidic conditions to afford 65. Since the hydroxyl functionality is a poor leaving group, 65 was not readily susceptible to nucleophilic substitution reaction with sodium nitrite. Thus, the hydroxyl group of 65 was first converted to iodide 66 with the 
Scheme 26

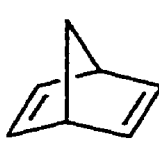

1

1. ${ }^{\mathrm{B}} \mathrm{BuOK},{ }^{\mathrm{B}} \mathrm{BuLi}$

THF, -78 to $-40^{\circ} \mathrm{C}$

2. $\mathrm{LiBr}$

3. paraformaldehyde

(57\%)

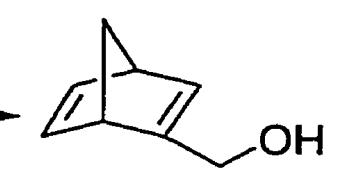

62

(66\%)<smiles></smiles>

$\mathrm{Bu}_{4} \mathrm{NBr}, \mathrm{NaOH}$

$70^{\circ} \mathrm{C}$

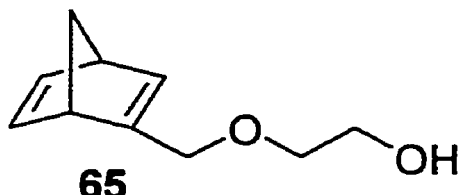

65

(98\%) $\begin{aligned} & \mathrm{I}_{2}, \mathrm{PPh}_{3} \\ & \text { Imidazole } \\ & \mathrm{THF} / \mathrm{CH}_{3} \mathrm{CN}\end{aligned}$

(98\%) $\begin{aligned} & \mathrm{I}_{2}, \mathrm{PPh}_{3} \\ & \text { Imidazole } \\ & \mathrm{THF} / \mathrm{CH}_{3} \mathrm{CN}\end{aligned}$

(98\%) $\begin{aligned} & \mathrm{I}_{2}, \mathrm{PPh}_{3} \\ & \text { Imidazole } \\ & \mathrm{THF} / \mathrm{CH}_{3} \mathrm{CN}\end{aligned}$

(98\%) $\begin{aligned} & \mathrm{I}_{2}, \mathrm{PPh}_{3} \\ & \text { Imidazole } \\ & \mathrm{THF} / \mathrm{CH}_{3} \mathrm{CN}\end{aligned}$
$\mathrm{MeOH}, \mathrm{PPTS}, 55^{\circ} \mathrm{C}$ (87\%)

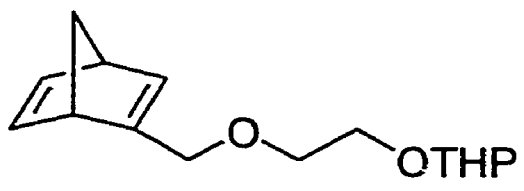

64<smiles></smiles>

66

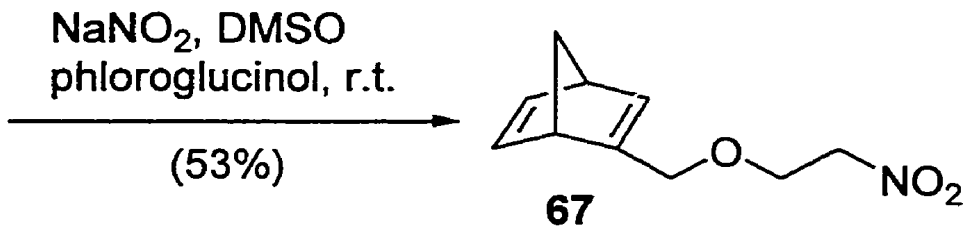

$(\mathrm{BOC})_{2} \mathrm{O}$, DMAP Toluene, $90^{\circ} \mathrm{C}$

69

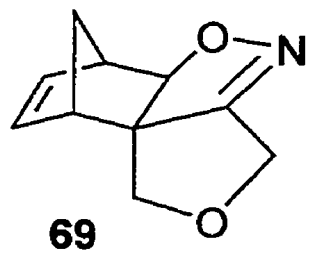<smiles>[134I]</smiles><smiles>[O+]=CCOCC1=CC2C=CC1C2</smiles>

employment of iodine, triphenylphosphine and imidazole in the presence of THF and $\mathrm{CH}_{3} \mathrm{CN}$. Displacement of the iodide with sodium nitrite then afforded the required nitro 
compound 67. Using the Hassner (BOC) $)_{2} \mathrm{O} / \mathrm{DMAP}$ method, the nitro compound 67 was converted to the required cycloadduct 69 as a single regio- and stereoisomer.

\section{Scheme 27}

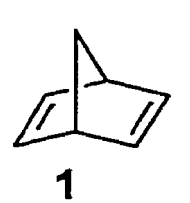

1. ${ }^{\mathrm{t} B u O K},{ }^{\mathrm{n}} \mathrm{BuLi}$

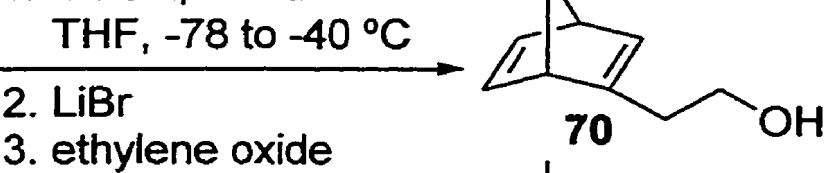

$(65 \%)$

$(88 \%)$

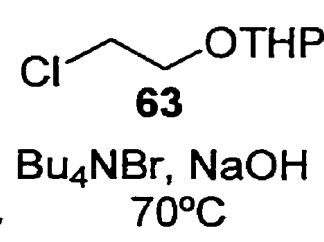<smiles>OCCOCCC1=CC2C=CC1C2</smiles>

72

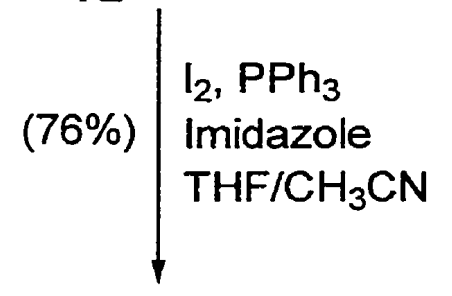

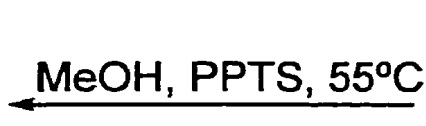

$(52 \%)$

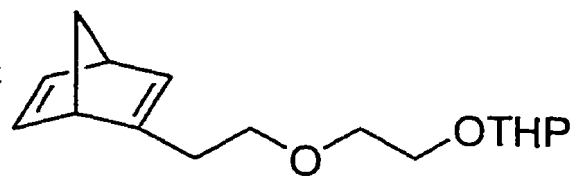

71<smiles>ICCOCCC1=CC2C=CC1C2</smiles>

$\mathrm{NaNO}_{2}, \mathrm{DMSO}$

phloroglucinol, r.t. (47\%)<smiles>[Z4]C1=CC2C=CC1C2</smiles>
$(\mathrm{BOC})_{2} \mathrm{O}, \mathrm{DMAP}$ Toluene, $90^{\circ} \mathrm{C}$<smiles>C1=CC2CC1C1CC23CCOCC3=NO1</smiles>

76
(52\%)

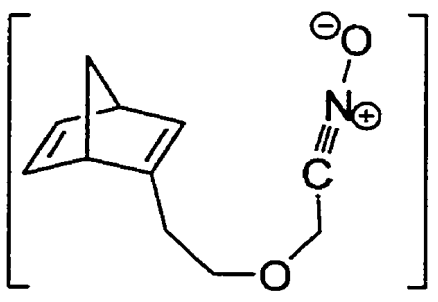

75 
The six-membered cycloadduct with an oxygen in the norbornadiene-tether was synthesized in a similar fashion (Scheme 27 ). The procedure was only slightly modified in the formation of the alcohol 70. In this case, instead of the addition of paraformaldehyde which led to the generation of the norbornadiene-tethered allylic alcohol 62 (Scheme 26), ethylene oxide was added to the reaction mixture to yield the norbornadiene-tethered homoallylic alcohol 70. Following the same reaction sequence for the five-membered cycloadduct, cycloaddition of the nitro precursor 74 occurred smoothly to provide the six-membered cycloadduct 76 bearing an oxygen in the tether with a moderate yield. The presence of an unidentified product, about $20 \%$, was also detected, however, from the ${ }^{1} \mathrm{H}$ NMR (400 MHz) spectrum.

Attempts to synthesize cycloadduct precursors with both an oxygen and a silicon functionality within the norbornadiene-tether were also undertaken (Scheme 28). Starting with the norbornadiene-tethered allylic alcohol 62, two methods were investigated to convert the alcohol 62 to 77 . In the first method, compound 77 was achieved with a yield of $29 \%$. Due to the poor yield obtained, a second attempt was needed. With the use of triethylamine and chloro(chloromethyl)dimethylsilane in THF, a much improved yield (41\%) of compound 77 was obtained. Thus, the second method was the method of choice. Since the chloro functionality is a poor leaving group, 77 was not readily susceptible to nucleophilic substitution reaction with sodium nitrite. Thus, $\mathbf{7 7}$ was first converted to iodide $\mathbf{7 8}$ by the Finkelstein method. Reaction proceeded smoothly to give 78 in good yield. Displacement of iodide with sodium nitrite, however, did not yield the required nitro compound 79. After purification of the crude reaction mixture by column chromatography, the ${ }^{\mathrm{l}} \mathrm{H}$ NMR $(200 \mathrm{MHz})$ spectrum detected the presence of 
nitro(nitromethyl)dimethylsilane and the starting material norbornadiene-tethered allylic alcohol 62. Further investigation on the synthesis of cycloadduct 81 was not attempted.

Scheme 28<smiles>CC(C)CC1=CC2C=CC1C2</smiles>

62<smiles>C[Si](C)(CCl)OCC1=CC2C=CC1C2</smiles>

$(75 \%)$
Nal, acetone $50^{\circ} \mathrm{C}$<smiles>CC1C2C=CC1C(CO[Si](C)(C)CI)=C2CO[N+](=O)[O-]</smiles>

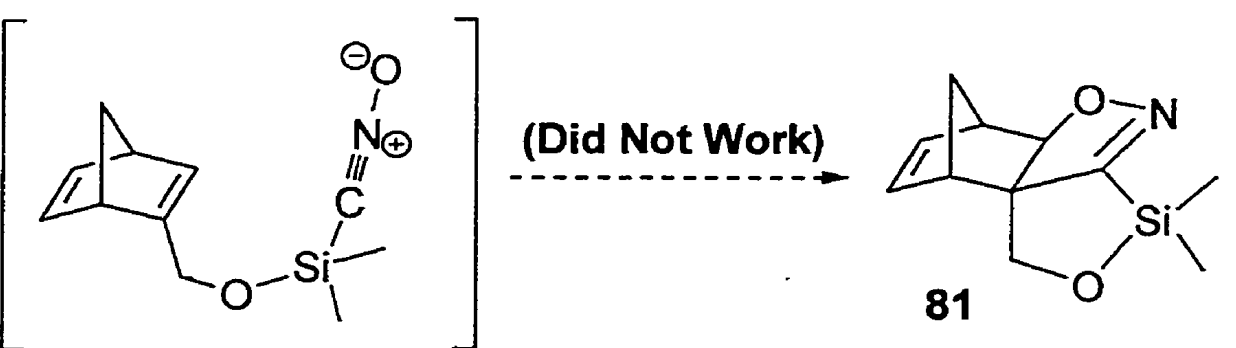

80

Method 1

1. ${ }^{\mathrm{n}} \mathrm{BuLi}, \mathrm{THF},-78^{\circ} \mathrm{C}$

2. chloro(chloromethyl)dimethylsilane (29\%)

Method 2

$\mathrm{Et}_{3} \mathrm{~N}, \mathrm{THF}$

chloro(chloromethyl)dimethylsilane

r.t.

$(41 \%)$ 
Synthetic route to cycloadduct $\mathbf{8 5}$ consisting of a lactone component was examined (Scheme 29). From the norbornadiene-tethered allylic alcohol 62, bromide 82 was formed in excellent yield. Two methods were investigated in the conversion of 82 to

\section{Scheme 29}

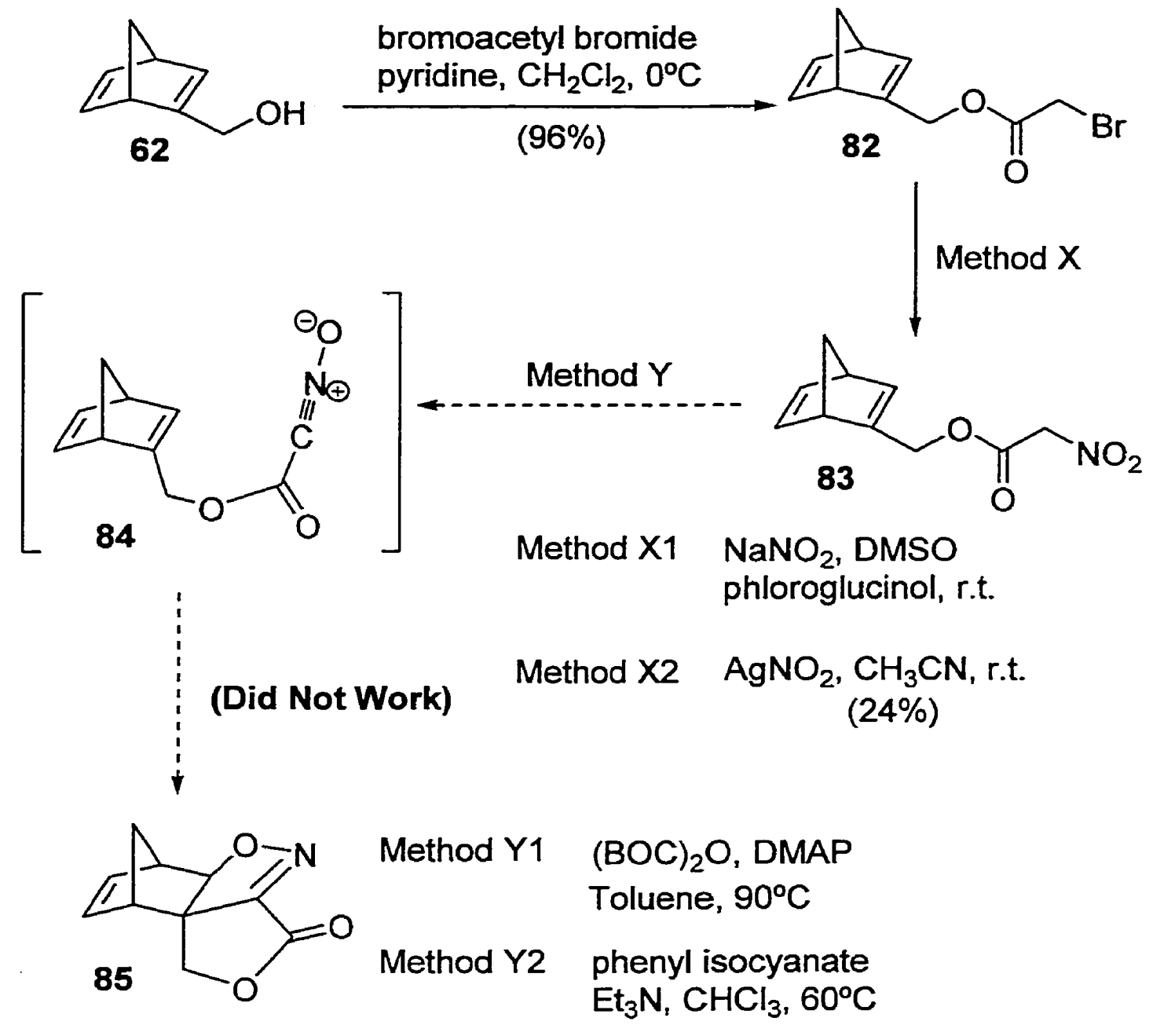

the corresponding nitro compound 83. As illustrated in Method X1, displacement of the bromide with sodium nitrite in the usual fashion did not provide the nitro compound $\mathbf{8 3}$. The presence of the nitrite compound was detected. In method X2, bromide 82 was 
converted to the nitro compound 83 with the use of $\mathrm{AgNO}_{2}$ and $\mathrm{CH}_{3} \mathrm{CN}$. Compound 83 was achieved although the yield of this reaction step was very poor (24\%). Attempts to synthesize the cycloadduct $\mathbf{8 5}$ followed. As with all the other synthetic routes to cycloadducts from the nitro precursors described to this point, the Hassner $(\mathrm{BOC})_{2} \mathrm{O} / \mathrm{DMAP}$ method was applied. The reaction was carried out in toluene at a temperature of $90^{\circ} \mathrm{C}$ (Method Y1). Unfortunately, it was found from the ${ }^{1} \mathrm{H}$ NMR (200 $\mathrm{MHz}$ ) spectrum of the crude reaction mixture that only compound 86 was present (Fig. 4). Since the Hassner method failed for this system, the Mukaiyama aromatic isocyanate method Y2, which involved reaction of the nitro compound 83 with the dehydrating agent phenyl isocyanate and the base triethylamine in chloroform, was attempted. In this case, only compound 87 was observed from the ${ }^{\mathrm{I}} \mathrm{H}$ NMR (200 MHz) spectrum of the crude reaction mixture.

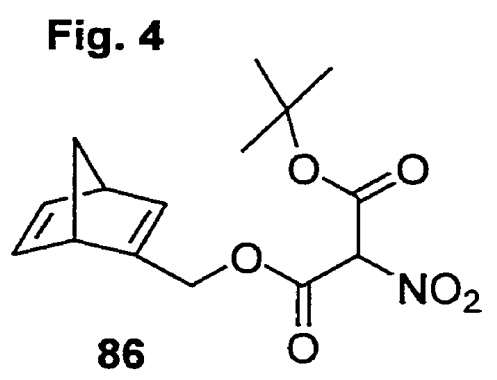<smiles>O=C(Nc1ccccc1)C(C(=O)OCC1=CC2C=CC1C2)[N+](=O)[O-]</smiles> 


\section{Scheme 30}<smiles>OCC1=CC2C=CC1C2</smiles>

62
1. $\mathrm{PPh}_{3}, \mathrm{DIAD}$

2. $\mathrm{AcSH}$

3. $\mathrm{NH}_{3}, \mathrm{MeOH}$

4. $\mathrm{ClCH}_{2} \mathrm{CH}_{2} \mathrm{OH}$

$\mathrm{NaOH}, \mathrm{H}_{2} \mathrm{O} / \mathrm{THF}$

(54\%)
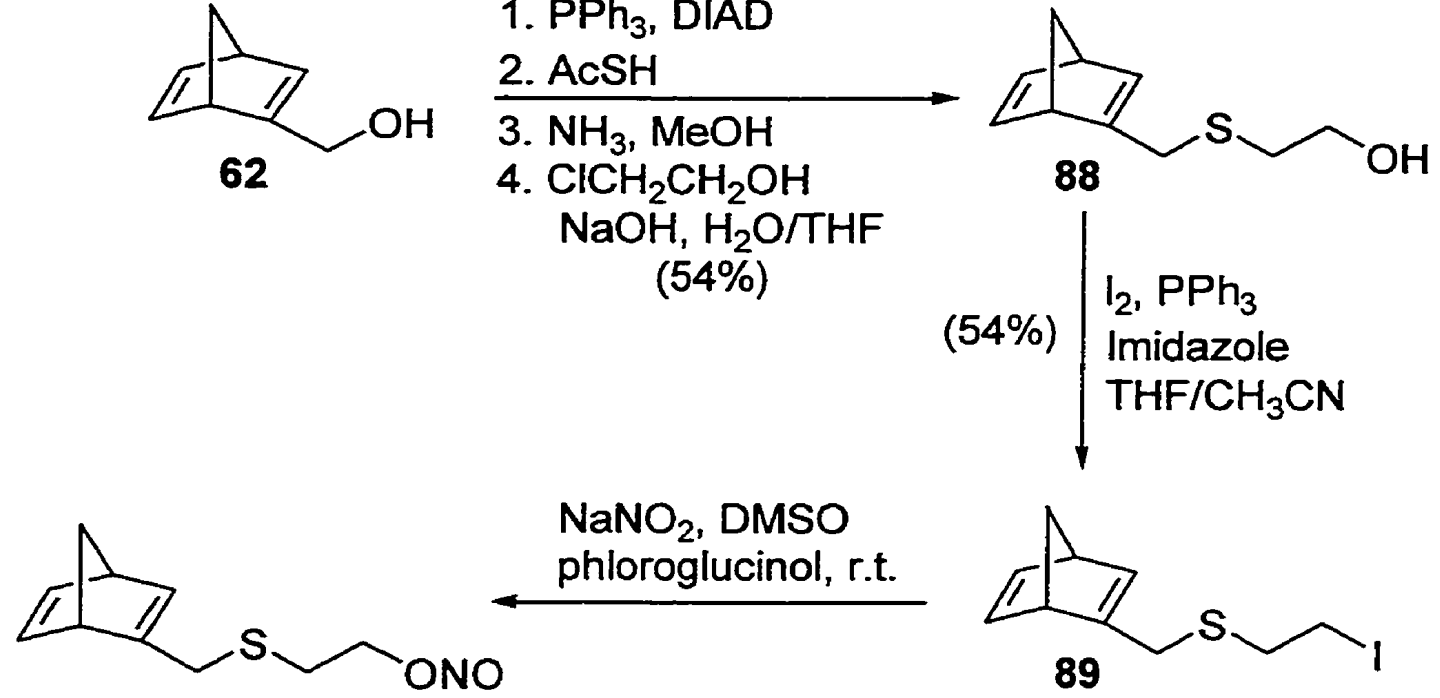

$\mathrm{NaNO}_{2}$, DMSO

phloroglucinol, r.t.

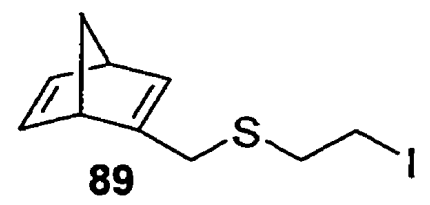

90

(57\%)
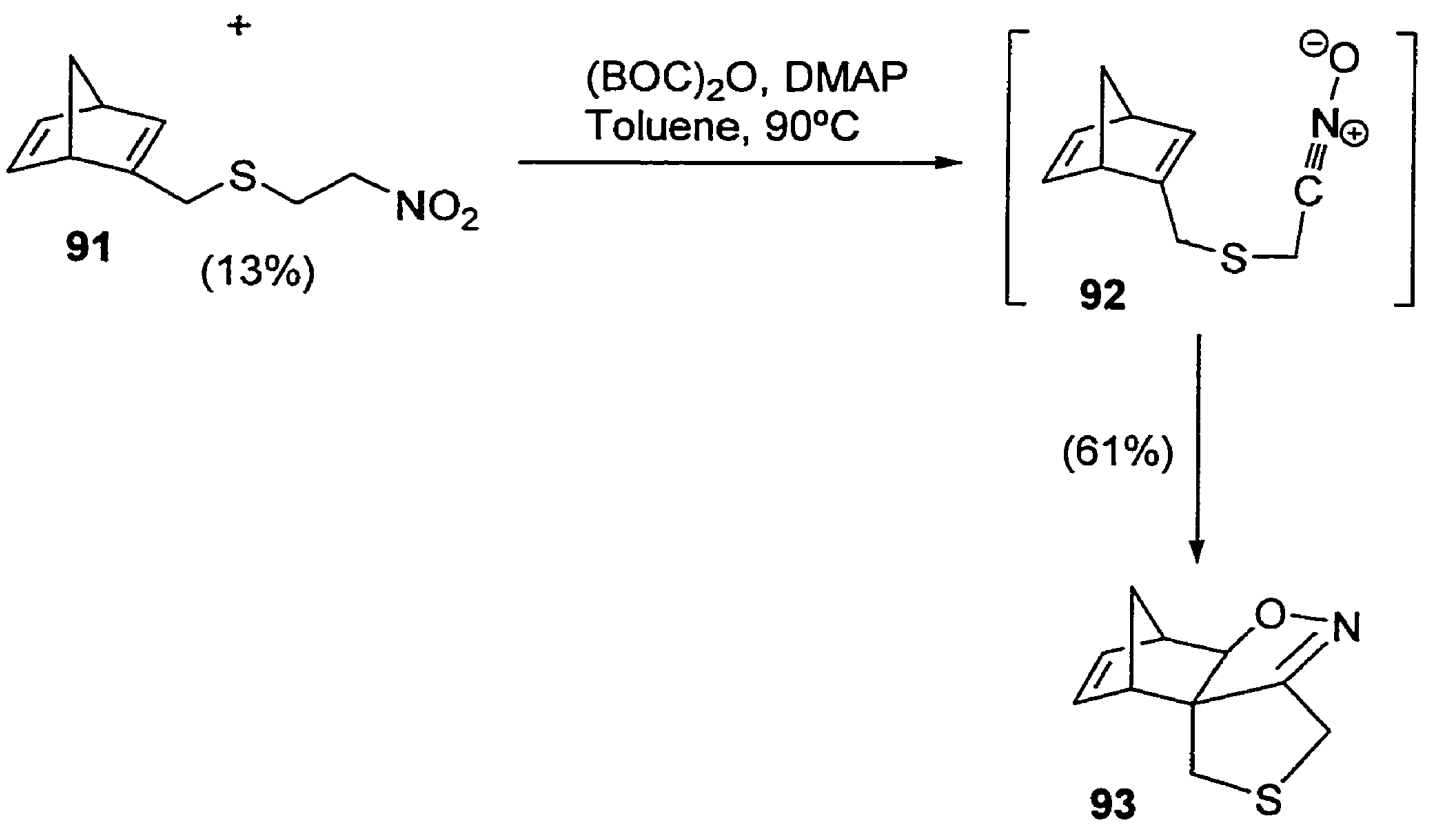

In order to broaden the studies on the effects of various heteroatoms within the norbornadiene tether on cycloaddition reactions, a synthetic route to the generation of 
cycloadduct 93 bearing a sulfur atom within the tether was investigated. As shown in Scheme 30, the norbornadiene-tethered allylic alcohol 62 was first converted to the norbornadiene-tethered allylic thiol by the Mitsunobu method. The latter compound then underwent a two-carbon homologation to yield alcohol $\mathbf{8 8}$. The hydroxyl group of $\mathbf{8 8}$ was converted to an iodide functionality with the use of iodine, triphenylphosphine and imidazole in the presence of THF and $\mathrm{CH}_{3} \mathrm{CN}$. Following the synthetic method which has been described previously for the generation of the nitro compound from the iodide compound, displacement of the iodide $\mathbf{8 9}$ with sodium nitrite would afford the required nitro compound 91. However, in this case, not only was the nitro compound 91 achieved but also the nitrite analogue 90 . In fact, the latter compound 90 was the major product of the reaction. Cycloaddition was performed. The minor product 91 was converted to the required cycloadduct 93 using the Hassner $(\mathrm{BOC})_{2} \mathrm{O} / \mathrm{DMAP}$ method in toluene at $90^{\circ} \mathrm{C}$. A moderate yield of the cycloadduct 93 was obtained.

\subsubsection{Cycloadducts Bearing a Nitrogen Within the Tether}

Thus far, cycloadducts bearing an oxygen or a sulfur atom within the norbornadiene-tether had been synthesized successfully as described in the previous sections. Herein, synthesis of cycloadduct 97 bearing a nitrogen functionality within the tether was attempted. Starting with the norbornadiene-tethered allylic alcohol 62, four attempts were made to generate 94 (Scheme 31). Since the hydroxyl functionality is a poor leaving group, 62 was not readily susceptible to nucleophilic substitution reaction 


\section{Scheme 31}

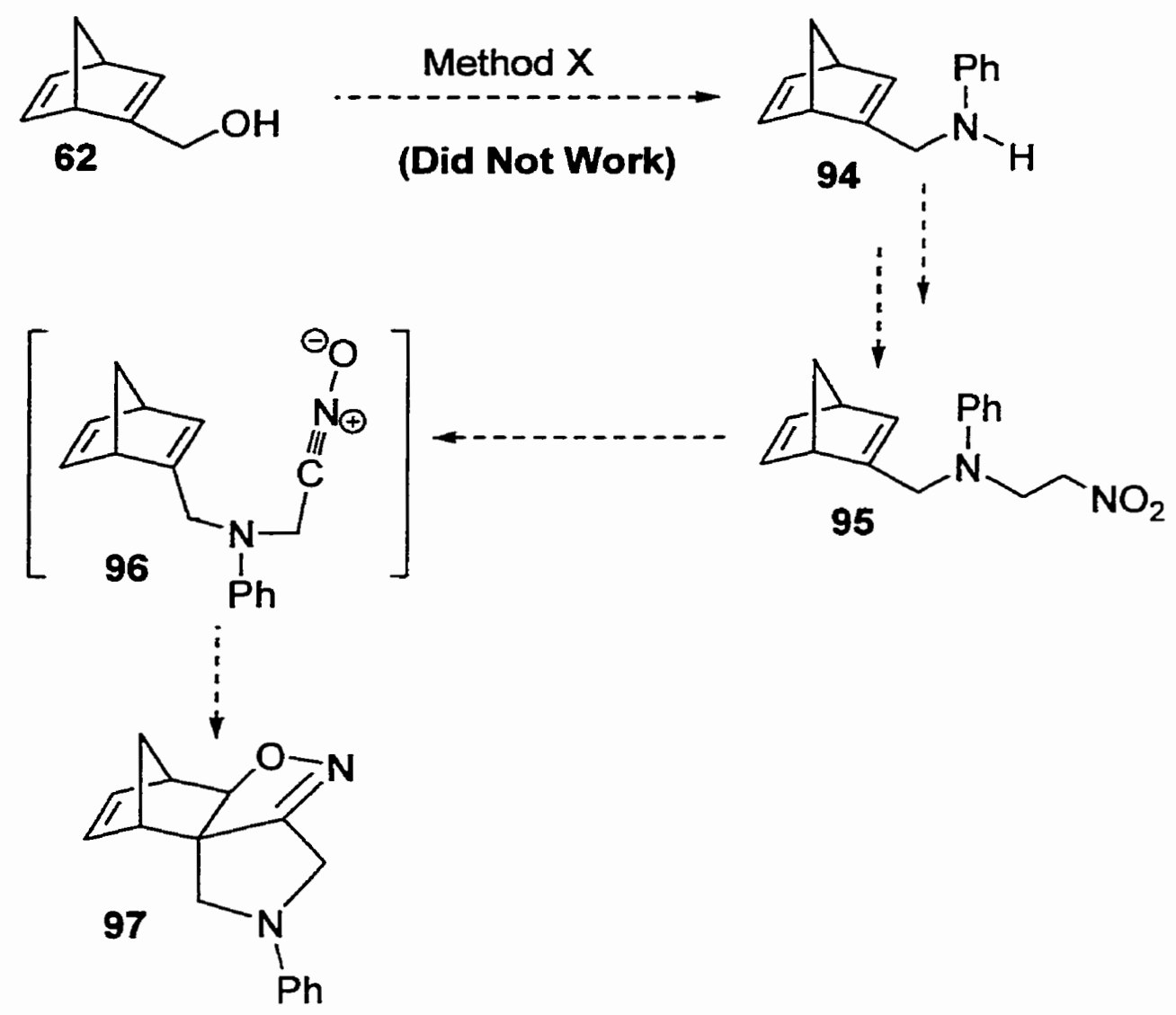

Method 1

1. ${ }^{\mathrm{n}} \mathrm{BuLi}, \mathrm{THF},-78^{\circ} \mathrm{C}$, $30 \mathrm{~min}$.

2. $\mathrm{TsCl}, \mathrm{THF},-78^{\circ} \mathrm{C}$, $10 \mathrm{~min}$.

3. $\mathrm{PhNH}_{2},-78^{\circ} \mathrm{C}, 30 \mathrm{~min}$. to r.t., $3.5 \mathrm{~h}$
Method 2 1. $\mathrm{MsCl}, \mathrm{Et}_{3} \mathrm{~N}, \mathrm{CH}_{3} \mathrm{CN}$, Method 4 $0^{\circ} \mathrm{C}, 1 \mathrm{~h}$

2. $\mathrm{PhNH}_{2}, 0^{\circ} \mathrm{C}$ to r.t., $3 \mathrm{~h}$
Method 3 1. $\mathrm{PPh}_{3}, \mathrm{DIAD}, \mathrm{THF}, 0^{\circ} \mathrm{C}$, $30 \mathrm{~min}$.

2. $\mathrm{PhNH}_{2}, \mathrm{THF}, 0^{\circ} \mathrm{C}, 1 \mathrm{~h}$ to r.t., $4.5 \mathrm{~h}$ to $60^{\circ} \mathrm{C}, 16 \mathrm{~h}$

with aniline. In the first method, the hydroxyl group of 62 was first converted to the tosylate functionality which was then later converted to the phenyl amine. However, 
after $3.5 \mathrm{~h}$ of reaction time, the ${ }^{\mathrm{l}} \mathrm{H} \mathrm{NMR}(200 \mathrm{MHz})$ spectrum of the crude only showed a mixture of aniline and the starting material 62. In the second attempt, the hydroxyl group of 62 was first converted to the mesyl functionality, which was then later converted to the phenyl amine. As with the first method, after $3 \mathrm{~h}$ of reaction time, the ${ }^{\mathrm{I}} \mathrm{H}$ NMR (200 $\mathrm{MHz}$ ) spectrum of the crude only showed a mixture of aniline and the starting material 62. The Mitsunobu method to the synthesis of 94 was then used in the last two attempts. Methods 3 and 4 were carried out under the same reaction conditions. The only difference was that in Method 4, ${ }^{\mathrm{n}} \mathrm{BuLi}$ was added. Unfortunately, in these two cases, the crude TLC showed a mixture of products. Both aniline and the starting material 62 were observed. Since conversion of 62 to 94 was unsuccessful, further investigation on the synthesis of cycloadduct 97 was not performed.

\subsubsection{Identification of the Regio- and Stereochemistry of the Cycloadducts}

Theoretically, norbornadiene-tethered nitrile oxides can undergo four possible modes of intramolecular 1,3-dipolar cycloadditions, generating a variety of cycloadducts (Scheme 32). In terms of regioselectivity, the nitrile oxide in the tether 32 can cyclize on $\mathrm{C}_{6}-\mathrm{C}_{1}-\mathrm{C}_{2}$ to give the adduct 98 or it can cyclize on $\mathrm{C}_{5}-\mathrm{C}_{6}$ to give the adduct 99 or on $\mathrm{C}_{2}$ $C_{3}$ to give 33 and $\mathbf{1 0 0}$. In terms of stereoselectivity, cycloaddition of the norbornadienetethered nitrile oxide on the $\mathrm{C}_{2}-\mathrm{C}_{3}$ double bond from the exo and endo faces can provide the exo and endo cycloadducts 33 and 100. Throughout the studies conducted, formation of adduct 99 was not detected possibly due to the large spatial separation between the 


\section{Scheme 32. Possible Cycloadducts}

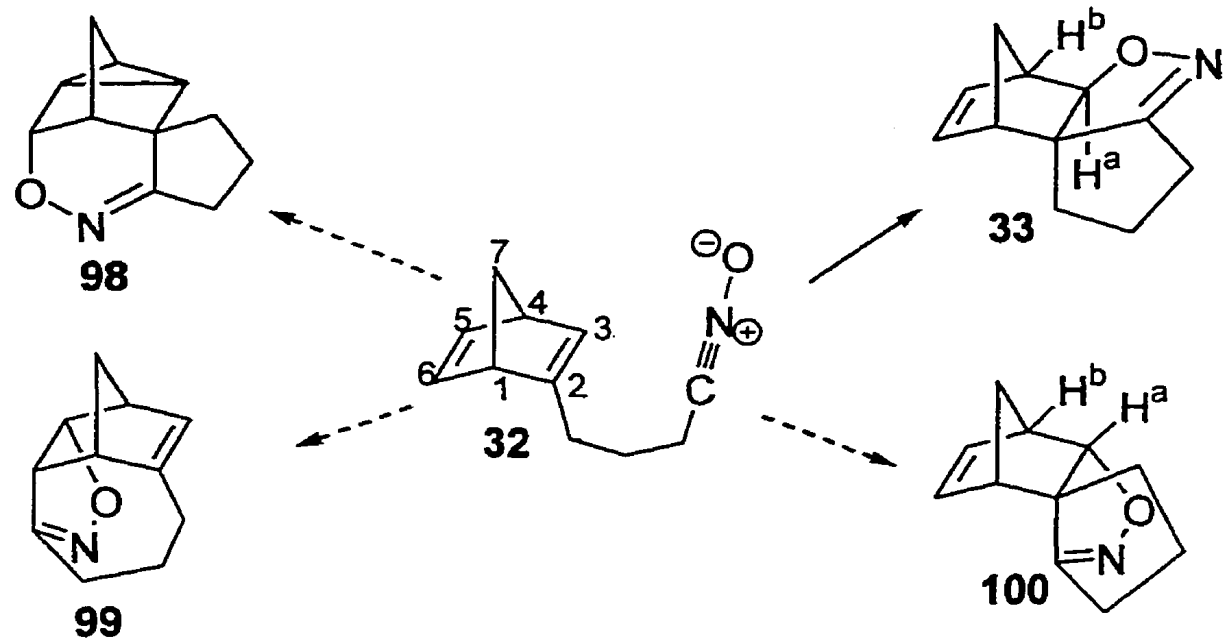

nitrile oxide and the double bond of the norbornadiene. In addition, cycloadducts 98,99 , and 100 were not observed. This could be due to the severe ring-strain found in these resulting molecules. In fact, the intramolecular cycloaddition of the norbornadienetethered nitrile oxide 32 was found to be highly regio- and stereoselective, giving the exo cycloadduct 33 as a single regio- and stereoisomer. It is noteworthy to mention here that the intermolecular 1,3-dipolar cycloaddition of norbornadiene with benzonitrile oxide produces a 4:1 exo/endo cycloadducts. ${ }^{20}$

The regio- and stereochemistry of cycloadduct 33 were confirmed by NMR techniques. The presence of the two olefinic protons in the ${ }^{1} \mathrm{H}$ NMR spectrum eliminated the possibilities of cycloadducts 98 and 99 . The exo and endo stereochemistry of the cycloadduct can easily be distinguished by the coupling constant between the proton $\mathrm{H}^{\mathrm{a}}$ adjacent to the isoxazoline oxygen and the allylic bridgehead proton $\mathrm{H}^{\mathrm{b}}$ in the ${ }^{\mathrm{l}} \mathrm{H} \mathrm{NMR}$ spectrum. ${ }^{45,46}$ Since the dihedral angle between $\mathrm{H}^{\mathrm{a}}$ and $\mathrm{H}^{\mathrm{b}}$ in the exo cycloadduct 33 is almost $90^{\circ}$, the coupling constant between these two protons is very small $(J \sim 0-2 \mathrm{~Hz})$. In the endo cycloadduct 100, the dihedral angle between $\mathrm{H}^{\mathrm{a}}$ and $\mathrm{H}^{\mathrm{b}}$ is approximately $42^{\circ}$ 
and a doublet with $J \sim 5 \mathrm{~Hz}$ would have been observed. ${ }^{47}$ NOESY experiments also provided additional confirmation of the exo stereochemistry of the cycloadduct. 


\subsection{Conclusions}

Results of the intramolecular 1,3-dipolar cycloadditions of norbornadiene-tethered nitrile oxides are illustrated in Table 4. In the course of studying the effects of tether length on the cycloaddition reactions, it was found that only cycloadducts synthesized from the nitro compounds 31 and $\mathbf{4 2}$ were obtained. In both cases, the cycloadditions were highly regio- and stereoselective, giving only the exo cycloadducts 33 and 44 . The yield of the five-membered cycloadduct 33 was slightly better than that of the sixmembered adduct 44. Unfortunately, cycloadditions to the four- and seven-membered cycloadducts (40 and $\mathbf{4 8}$ ) were not detected. Cycloaddition leading to the four-membered adduct $\mathbf{4 0}$ did not occur possibly due to the severe ring-strain found in the resulting compound. In the case of the seven-membered cycloadduct 48, the large spatial separation between the nitrile oxide and the double bond of norbornadiene possibly explained the difficulty in the formation of the cycloadduct. ${ }^{23}$ Thus, the likelihood of intramolecular cycloaddition decreases with increasing distance between the reacting groups.

To broaden the scope of the study, synthesis to cycloadduct precursor having functionality within the norbornadiene tether was also investigated. The nitrile oxide generated from the nitro compound $\mathbf{5 2}$ with a $\alpha$-silyl ether substituent provided the corresponding exo cycloadduct $\mathbf{5 4}$ in good yield.

Formation of the five- and six-membered cycloadducts (69 and 76) bearing an oxygen within the tether also proved to be successful, giving moderate yields of the cycloadducts. In the case of cycloaddition with the nitrile oxide generated from nitro 
compound 74, an unidentified product $(\sim 20 \%)$ was detected in addition to the exo cycloadduct 76. This is the only case in which a side product was observed.

Table 4. Intramolecular 1,3-Dipolar Cycloaddition of Norbornadiene-Tetherd Nitrile Oxides

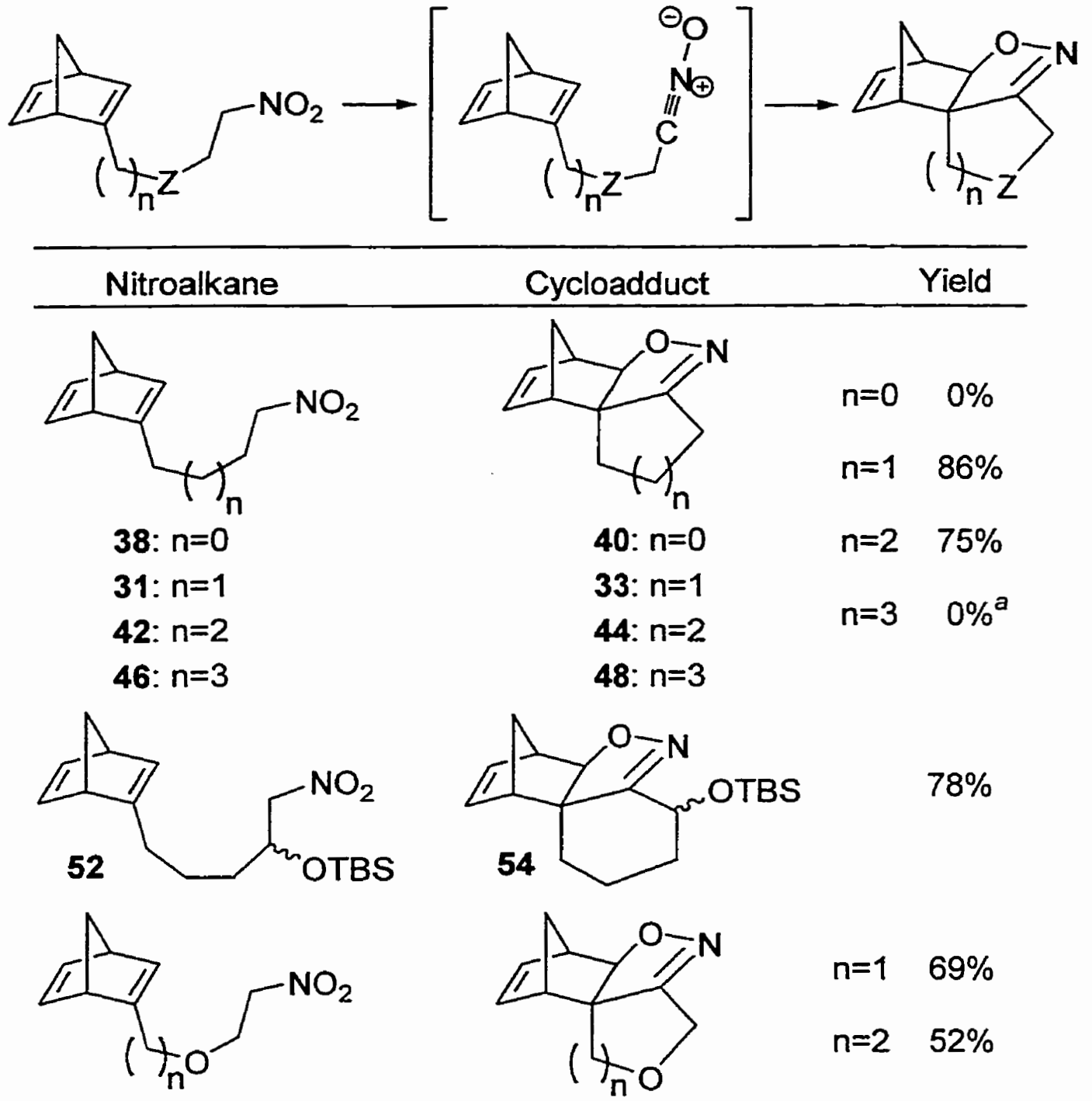

67: $n=1$

69: $n=1$

74: $n=2$

76: $n=2$
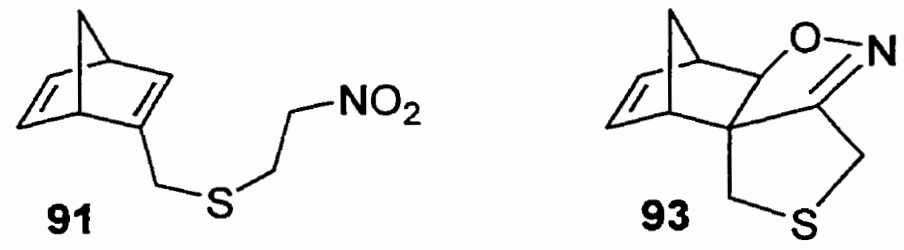

$61 \%^{a}$

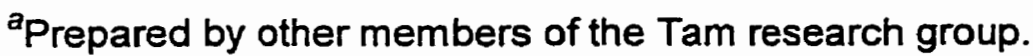


Cycloadduct precursors containing other heteroatom within the norbornadienetether were also included in the study. As shown in Table 4, cycloaddition of the nitro compound 91 bearing a sulfur within the tether occurred smoothly to generate the fivemembered cycloadduct 93 in fair yield. Similar to the other cycloadditions described above, only the exo adduct 93 was achieved. Thus, the reaction was highly regio- and stereoselective. 


\section{Chapter 3}

Synthesis of 2,3-Disubstituted Norbornadienes 


\subsection{Introduction}

In the course of studying the effects of a C-3 substituent on the regio- and stereoselectivity in the intramolecular 1,3-dipolar cycloadditions of norbornadienetethered nitrile oxides (Scheme 33$)^{48}$, a problem of synthesizing the 2,3-disubstituted norbornadienes 101 was encountered. Most of the syntheses of 2,3-disubstituted

\section{Scheme 33}

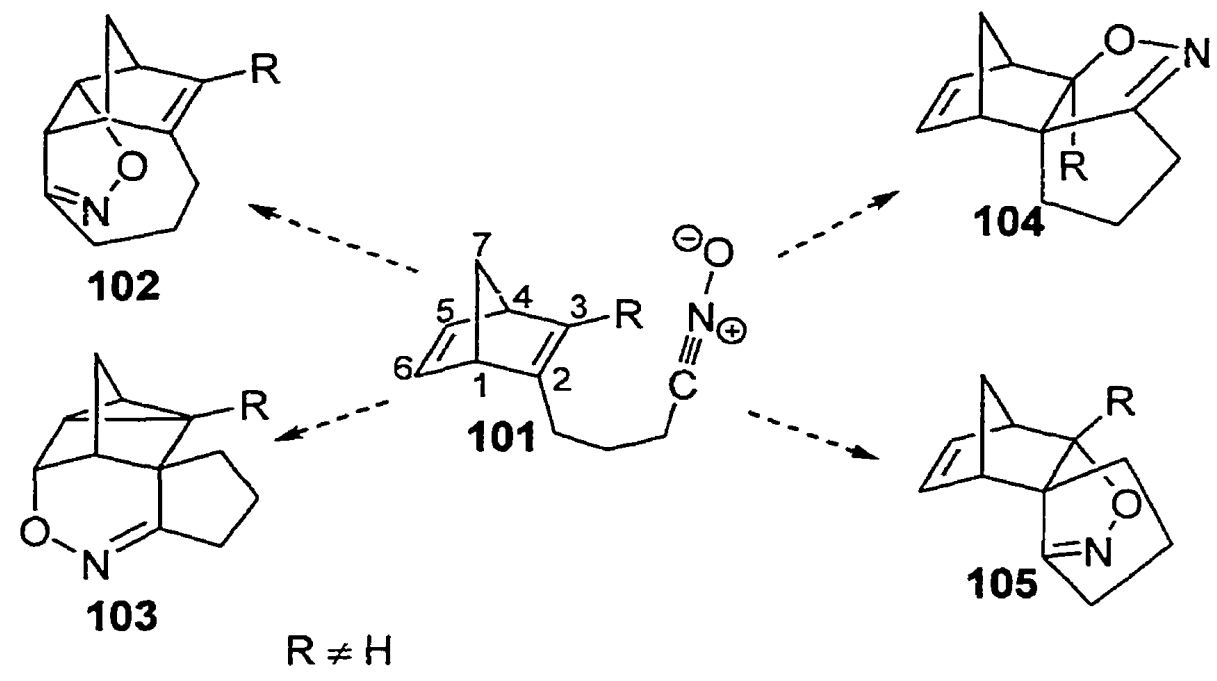

norbornadienes reported in the literature rely on Diels-Alder reactions between cyclopentadiene and highly activated acetylenes (Scheme 34). ${ }^{49-53}$ Although Diels-Alder cycloaddition reactions have drawn a great deal of synthetic attention in recent years, owing to their extensive application in the construction of ring systems which are frequently required for the synthesis of natural products, drugs and other biologically 


\section{Scheme 34}<smiles>[Tl]C1CC=CC1</smiles>

106
COOMe<smiles>CCCCCCCCC#CC(=O)OC</smiles><smiles>C[13CH3]</smiles>
$(98 \%)$

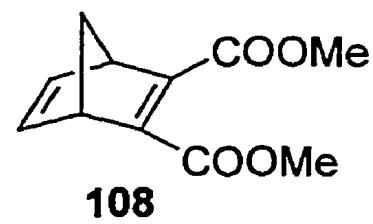

108

active compounds, there are several disadvantages in the conventional preparation of the Diels-Alder products, namely, (i) the reaction time is occasionally too long, and (ii) unsuitable in the presence of some functional groups. ${ }^{54}$ Less activated or unactivated acetylenes are notoriously poor dienophiles in Diels-Alder reactions, and are indeed resistant to [4+2] cycloaddition reactions. Thus, substituents on the norbornadiene ring system are only limited to electron-withdrawing groups. An alternative approach is required to overcome this barrier. In this chapter, a new and general procedure for the synthesis of 2,3-disubstituted norbornadienes $\mathbf{1 1 0}$ and $\mathbf{1 1 1}$ which is compatible with a wide variety of substituents $\left(E_{1}\right.$ and $\left.E_{2}\right)$ will be presented (Scheme 35$) .{ }^{33}$

\section{Scheme 35}

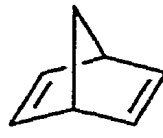

1
1. ${ }^{\mathrm{t}} \mathrm{BuOK}, \mathrm{B} \mathrm{BuLi}, \mathrm{THF},-78^{\circ}$ to $-40^{\circ} \mathrm{C}$

2. $\mathrm{BrCH}_{2} \mathrm{CH}_{2} \mathrm{Br}$<smiles>BrC1=C(Br)C2C=CC1C2Br</smiles>

$109 \mathrm{Br}$

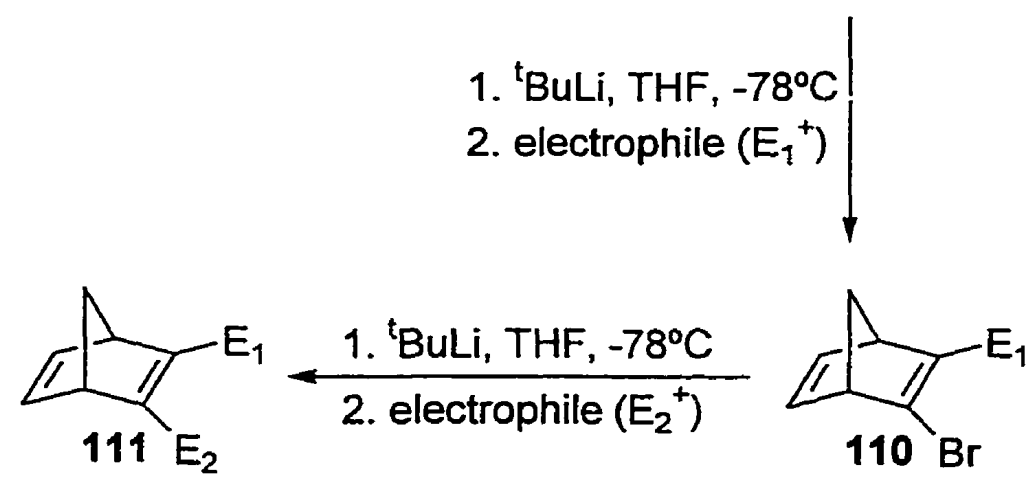


2,3-Disubstituted norbornadienes have considerable synthetic versatility in the synthesis of many natural products. Some of these compounds are key intermediates for the synthesis of biologically active analogues of the prostaglandin endoperoxides $\mathrm{PGH}_{2}$ and $\mathrm{PGG}_{2}$, cis-trikentrin $\mathrm{B}$, and $\beta$-santalol. ${ }^{34-37}$ Another interesting aspect of the chemistry of 2,3-disubstituted norbornadienes involves the photochemical isomerization of norbornadiene derivatives to the corresponding quadricyclanes and its catalytic reversal. $^{55-59}$ Extensive investigation of 2,3-disubstituted norbornadienes-quadricyclanes interconversion for solar energy storage has demonstrated the efficiency and switching potential of these reversible systems. ${ }^{60-62}$

\subsection{General Methodology for the Synthesis of 2,3-Disubstituted Norbornadienes}

Schlosser and Brandsma showed independently that deprotonation of the vinylic hydrogen of norbornadiene (1) could be achieved by the use of Schlosser's base, a mixture of $n$-butyllithium ( ${ }^{\mathrm{n}} \mathrm{BuLi}$ ) and potassium or sodium tert-butoxide ( ${ }^{\mathrm{B}} \mathrm{BuOK}$ or ${ }^{\mathrm{t}} \mathrm{BuONa}$ ) in tetrahydrofuran at $-78^{\circ} \mathrm{C} .{ }^{40,63}$ Trapping of the metalated norbornadiene with electrophiles led to the formation of various 2-substituted norbornadienes (Scheme 36).

\section{Scheme 36}

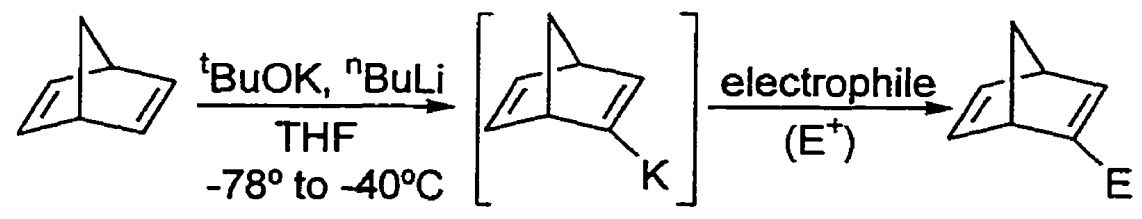


The application of fast lithium-bromine exchange for the synthesis of 2,3-dibromobicyclo[2.2.1]hepta-2,5-diene was reported by Szeimies and co-workers during their studies on the isomerization of quadricyclanes to the corresponding oxasesquinorbornatrienes. ${ }^{64}$ In an attempt to improve the yield of dibromide 109 obtained by Szeimies, the reaction procedure was modified in order to achieve a more reliable large-scale $(10-20 \mathrm{~g}$ scale) synthesis of the compound (Scheme 37$)$.

\section{Scheme 37}

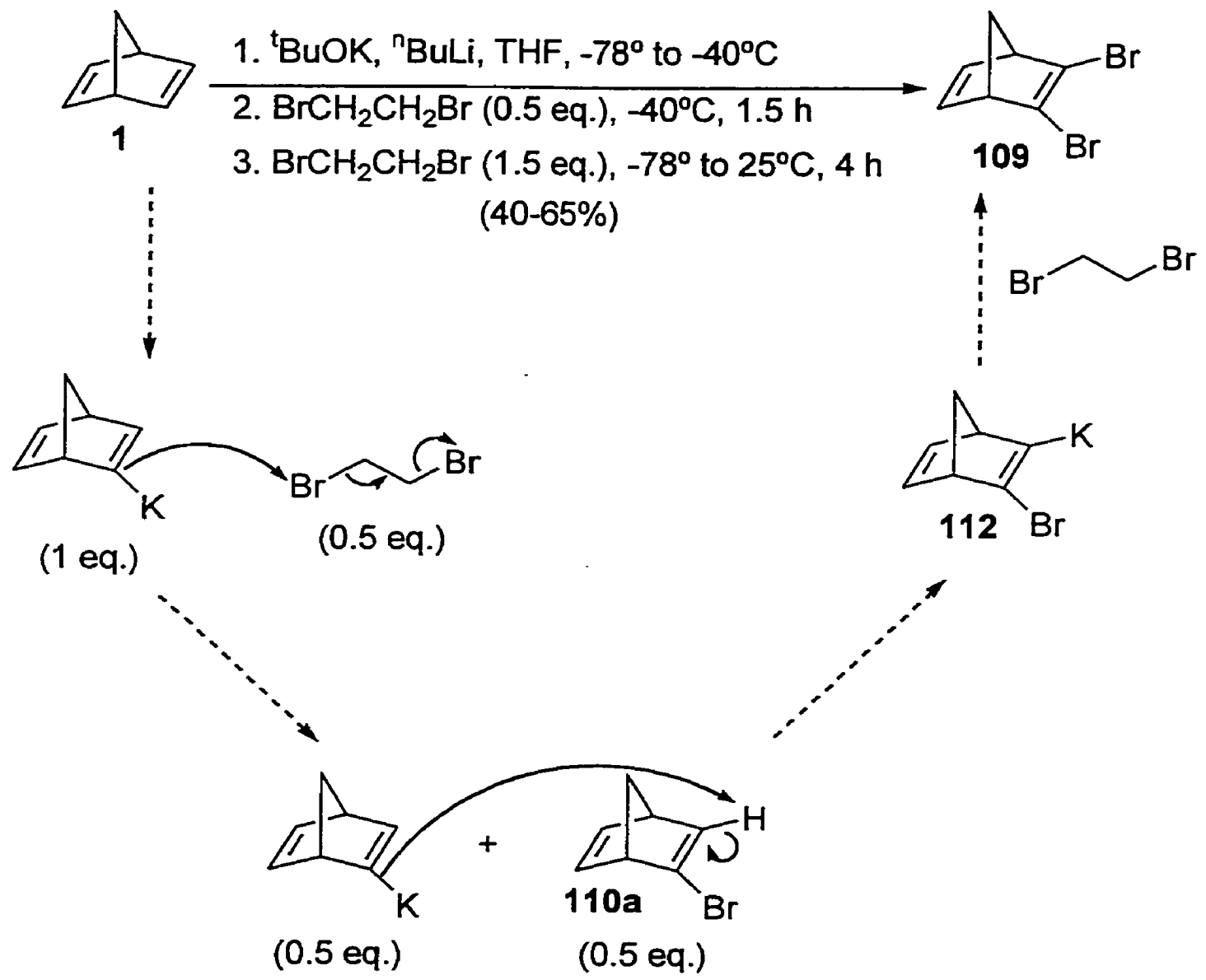

After deprotonation of the vinylic hydrogen of norbornadiene (1) with Schlosser's base in THF at $-78^{\circ} \mathrm{C}, 0.5$ equivalent of 1,2 -dibromoethane was added to the norbornadienyl 
potassium. The reaction mixture was kept at $-40^{\circ} \mathrm{C}$ for $1.5 \mathrm{~h}$. Another 1.5 equivalent of 1,2-dibromoethane was added which would then react with the remaining 0.5 equivalent of norbornadienyl potassium. It was found that maintaining the reaction mixture at the correct temperature was extremely important at this stage. If the temperature was either too high or too low, serious side reactions could occur, thus lowering the yield of dibromide 109. Since the acidity of the vinylic hydrogen was enhanced by the vicinal bromide in $110 \mathrm{a}$, the norbornadienyl potassium was basic enough to remove the proton to afford 112. Addition of an excess of 1,2-dibromoethane then led to the formation 109.

Monolithium halide exchange of 109 with ${ }^{\text {B }} \mathrm{BuLi}$ (2 equivalents) produced 2bromo-3-lithionorbornadiene (113). Trapping of this organolithium with electrophiles (Table 5) generated a variety of 2,3-disubstituted norbornadienes bearing a bromine functionality in moderate to good yields. Formation of the intermediate, norbornenyne (114), was not detected in any case (eq. 2). ${ }^{65}$

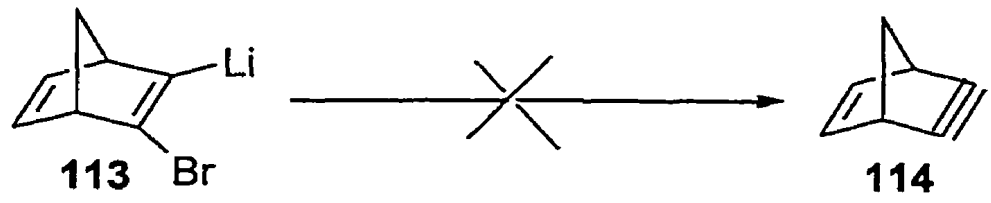

\section{(eq. 2)}

$113 \mathrm{Br}$

\section{4}

A second lithium halide exchange in $\mathbf{1 1 0 b}$ was carried out, followed by trapping of the generated organolithium with various electrophiles (Table 6). A broad range of 2,3-disubstituted norbornadienes (111a - 111g) having different functionalities was obtained in fair yields. From the above examples, the application of double lithium halide exchange proved to be a versatile methodology for the preparation of 2,3disubstituted norbornadienes containing a methyl group. Nonetheless, particular 
Table 5. Synthesis of Monobromo-Substituted Norbornadienes

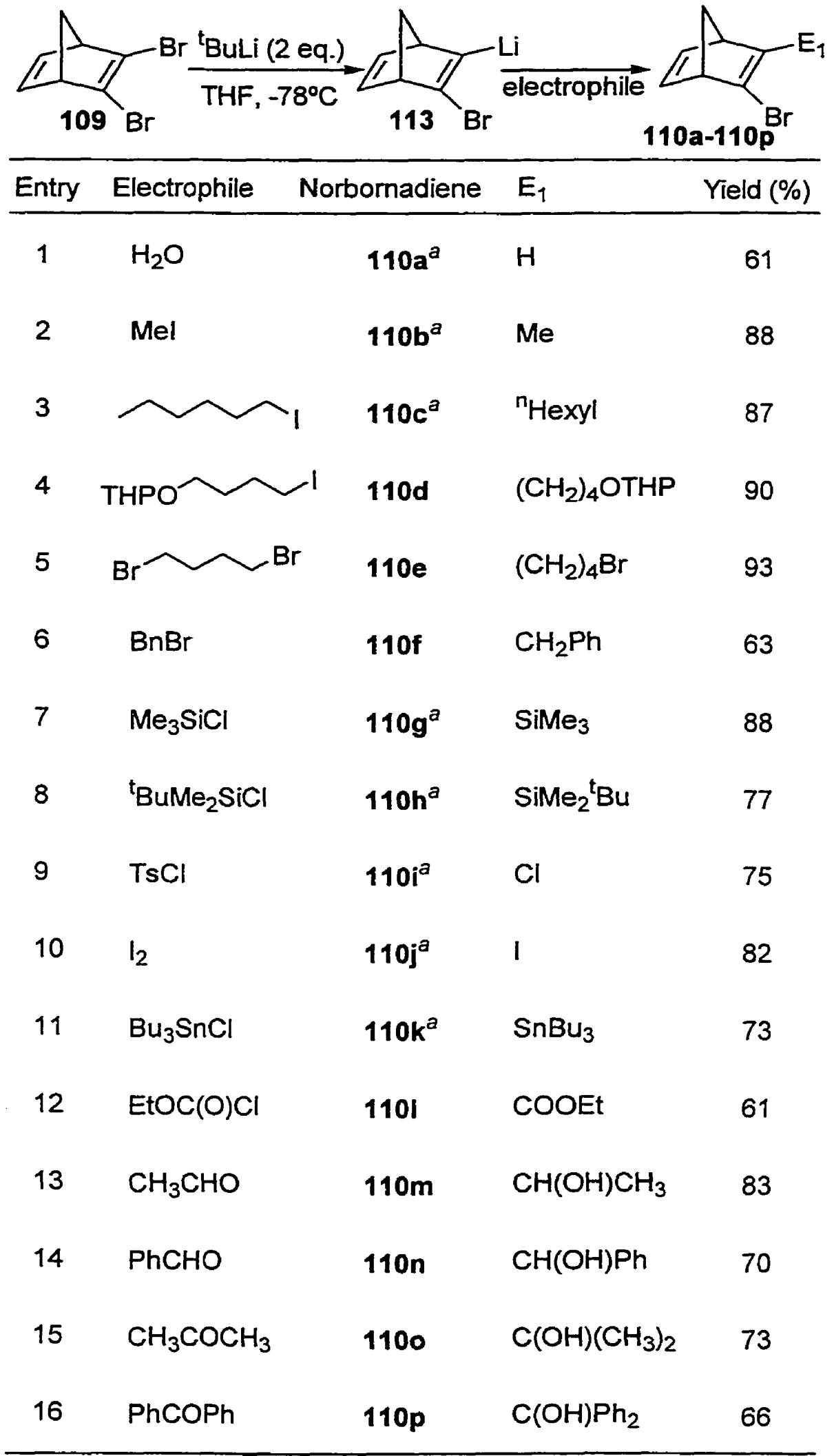

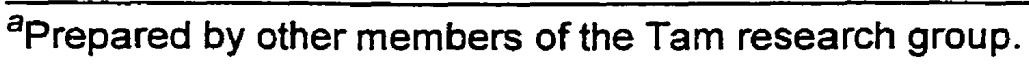


attention should be paid to the reactions of $110 \mathrm{c}$ and $110 \mathrm{~d}$ with 1,4 -dibromobutane (entry 8) and methyl chloroformate (entry 9) respectively which led to the formation of the $2,3-$ disubstituted norbornadienes 111h and 111i. These disubstituted adducts served as important precursors for the synthesis of norbornadiene-tethered nitrile oxides in the studies of intramolecular 1,3-dipolar cycloaddition reactions.

Table 6. Synthesis of Disubstituted Norbornadienes via Double Lithium-Halide Exchange

\begin{tabular}{|c|c|c|c|c|c|}
\hline \multicolumn{2}{|c|}{ Entry $E_{1}$} & \multirow[t]{2}{*}{ Electrophile } & \multicolumn{2}{|c|}{ Norbornadiene $E_{2}$} & Yield (\%) \\
\hline 1 & $\mathrm{Me}$ & & $111 a^{a}$ & ${ }^{n}$ Hexyl & 80 \\
\hline 2 & Me & & $111 b^{a}$ & $\left(\mathrm{CH}_{2}\right)_{4} \mathrm{Br}$ & 41 \\
\hline 3 & Me & $\mathrm{Me}_{3} \mathrm{SiCl}$ & $111 c^{a}$ & $\mathrm{SiMe}_{3}$ & 71 \\
\hline 4 & Me & $\mathrm{TsCl}$ & $111 d^{a}$ & $\mathrm{Cl}$ & 73 \\
\hline 5 & $\mathrm{Me}$ & $l_{2}$ & $111 \mathrm{e}^{a}$ & 1 & 60 \\
\hline 6 & $\mathrm{Me}$ & $\mathrm{EtOC}(\mathrm{O}) \mathrm{Cl}$ & $111 f$ & COOEt & 77 \\
\hline 7 & Me & MeCOMe & $111 \mathrm{~g}$ & $\mathrm{C}(\mathrm{OH}) \mathrm{Me}_{2}$ & 80 \\
\hline 8 & ${ }^{n}$ Hexyl & & $111 \mathrm{~h}$ & $\left(\mathrm{CH}_{2}\right)_{4} \mathrm{Br}$ & 54 \\
\hline 9 & $\left(\mathrm{CH}_{2}\right)_{4} \mathrm{O}$ & IP $\mathrm{MeOC}(\mathrm{O}) \mathrm{Cl}$ & $111 i$ & COOMe & 74 \\
\hline
\end{tabular}

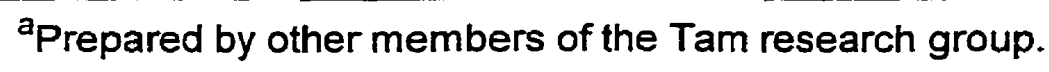




\subsection{Results and Discussion}

\subsubsection{Synthesis of 2,3-Disubstituted Norbornadienes from 2,3- Dibromonorbornadiene via Monolithium-Halide Exchange}

As illustrated in Table 5 of section 3.2, a diversified array of 2,3-disubstituted norbornadienes having a bromine functionality as one of the substitutents was generated from monolithium-halide exchange of 2,3-dibromonorbornadiene (109) with 2 equivalents of ${ }^{t} \mathrm{BuLi}$. A wide variety of electrophiles was used in the synthesis, including water, alkyl halides, various heteroatoms, acyl chlorides, aldehydes, and ketones. A detailed discussion of the synthesis involving the aforementioned electrophiles as well as some of the attempted synthesis using less reactive electrophiles will be presented.

Since the first three entries of Table 5 were performed by other members of the Tam research group, only a brief overview of the reactions will be given. It is important to note that only with the exception of the first entry of Table 5, the monolithium-halide exchange in 2-bromo-3-lithionorbornadiene (113) led to the formation of 2,3disubstituted norbornadienes. In the first entry, a monosubstituted product was generated from the reaction of $\mathbf{1 1 3}$ with water as the electrophile. In the second and third entries, the intermediate 113 was trapped with alkyl halides. Reactions of 113 with iodomethane and iodohexane led to the formation of $110 \mathrm{~b}$ and $110 \mathrm{c}$ respectively in good yields.

The two most important disubstituted analogues generated are $110 \mathrm{~d}$ and $110 \mathrm{e}$. These were used in the synthesis of C-2, C-3-disubstituted norbornadiene-tethered nitrile oxides 101 (Scheme 33) in the studies of intramolecular 1,3-dipolar cycloaddition 
reactions. Trapping of 2-bromo-3-lithionorbornadiene (113) with THP-protected iodopentanol and 1,4-dibromonorbornadiene (29) provided 110d (Scheme 38) and 110e (Scheme 39) respectively. Noteworthy is the former reaction which gave the highest yield among all of the 2,3-disubstituted norbornadienes generated by monolithiumbromide exchange.

As shown in Scheme 40, 2-bromo-3-lithionorbornadiene (113) could also be trapped with benzyl bromide. The reaction occurred smoothly to yield the disubstituted adduct $\mathbf{1 1 0 f}$ in moderate yield.

\section{Scheme 38}

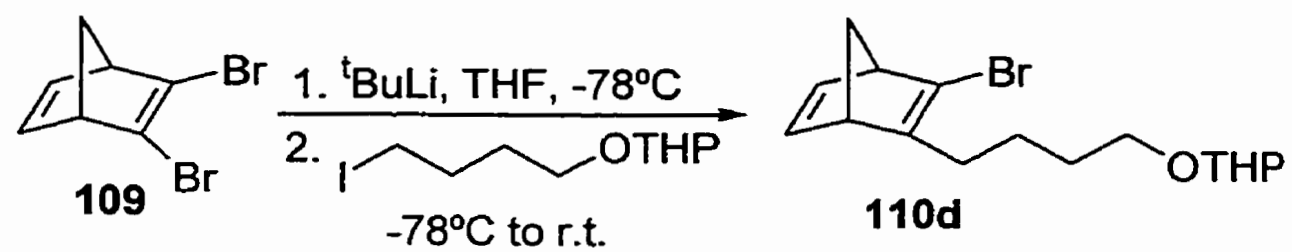

$(90 \%)$

Scheme 39

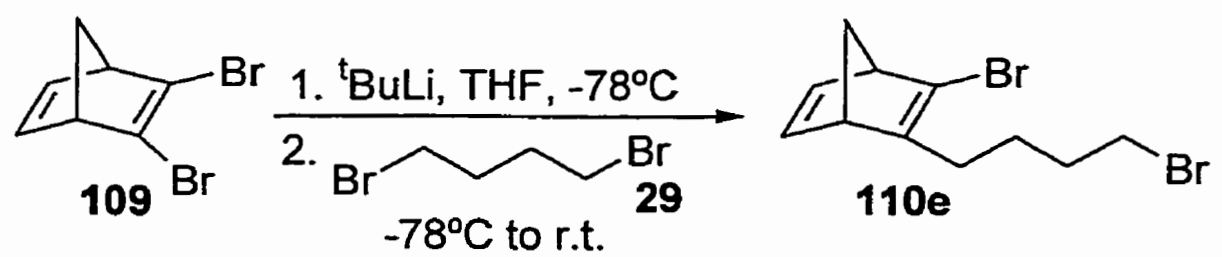

(93\%)

\section{Scheme 40}

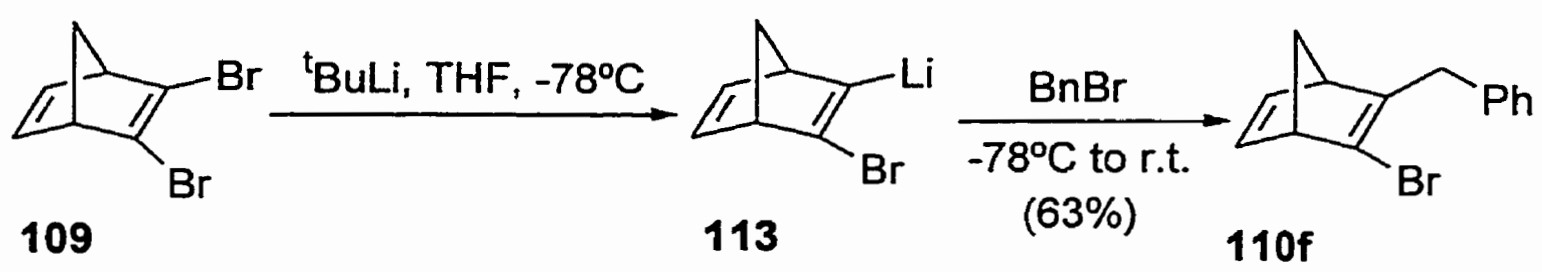


In an attempt to synthesize 2,3-disubstituted norbornadienes with heteroatoms ( $\mathrm{Si}$, $\mathrm{Cl}, \mathrm{I}$ and Sn), a wide variety of electrophiles were used. Trapping of the intermediate 2bromo-3-lithionorbornadiene (113) with silyl chlorides (entries $\mathcal{Z}$ and 8), tosyl chloride (entry 9), iodine (entry 10), and tributyltin chloride (entry 11) afforded the corresponding products in fair yields. The following two syntheses also fall into this category of 2,3disubstituted norbornadienes bearing heteroatoms. As shown in Scheme 41, reaction of 109 with dimethyl disulfide was carried out. Unfortunately, a mixture of products was observed from the crude TLC.

\section{Scheme 41}

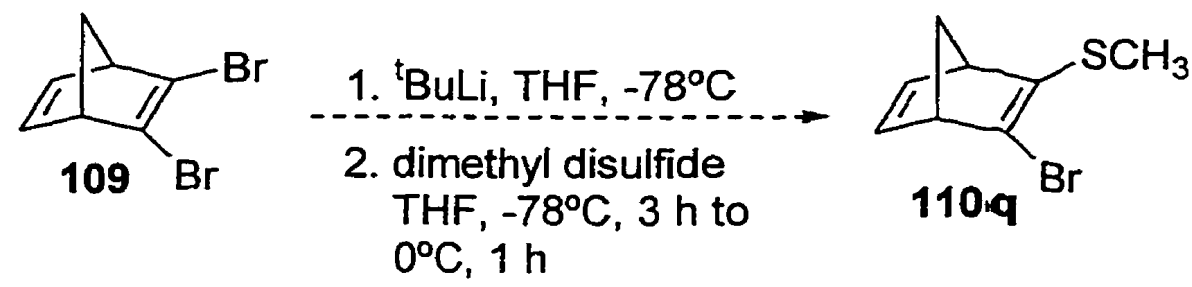

(Did Not Work)

Since good yields of the 2,3-disubstituted norbornadienes $110 \mathrm{i}$ and $110 \mathrm{j}$ were obtained from the reactions of $\mathbf{1 1 3}$ with tosyl choride and iodine respectively, synthesis of 110r was attempted (Scheme 42). In the first method, the intermediate 113 was added to a mixture of "Selectfluor" and THF. A solubility problem was encountered as the "Selectfluor" did not dissolve in THF. The reaction mixture was allowed to stir at $-78^{\circ} \mathrm{C}$ for $1 \mathrm{~h}$. At this point, the crude TLC showed no indication of the formation of product. The undissolved "Selectfluor" in the synthesis could possibly account for the disappointing result. A slightly modified method was then applied. In this case, the 
order of addition was reversed. Rather than adding 113 to "Selectfluor", the electrophile was added to the intermediate 113 . The reaction was also carried out for a significantly longer period of time. Unfortunately, the ${ }^{1} \mathrm{H}$ NMR spectrum only showed a mixture of unidentified materials.

\section{Scheme 42}<smiles>O=[Se]C1C(Br)=C(Br)C2C=CC1C2</smiles>

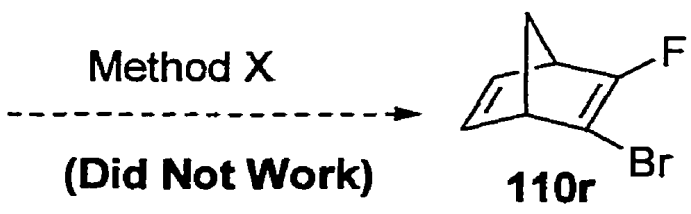

Method 1

1. ${ }^{\mathrm{B}}$ BuLi, THF, $-78^{\circ} \mathrm{C}, 30 \mathrm{~min}$.

2. Selectfluor, $-78^{\circ} \mathrm{C}, 15 \mathrm{~min}$. to r.t., $1 \mathrm{~h}$

Method 2

1. 'BuLi, THF, $-78^{\circ} \mathrm{C}, 30 \mathrm{~min}$.

2. Selectfluor, $-78^{\circ} \mathrm{C}, 5 \mathrm{~h}$

Having investigated the reactions of various heteroatom-containing electrophiles with 2-bromo-3-lithionorbornadiene (113) to provide 2,3-disubstituted norbornadienes bearing the heteroatom and bromine substituents, the challenge to make other functionalized 2,3-disubstituted norbornadienes, which could lead to further studies on the intramolecular cycloadditions of C-2, C-3-disubstituted norbornadiene-tethered nitrile oxides, was undertaken. Reactions involving the trapping of the intermediate 113 with carbonyl-containing electrophiles were investigated.

In the reaction of 2-bromo-3-lithionorbornadiene (113) with ethyl chloroformate, the corresponding ester 1101, was generated (Scheme 43). Particular attention should be paid to the experimental procedure of this reaction. In most reactions involving 
electrophiles, the product was synthesized by the addition of the electrophile to the intermediate. However, if this order of addition was followed with the use of ethyl chloroformate, double addition of the nucleophile could occur, leading to the formation of side products. Thus, in order to maximize the yield of the reaction, the intermediate 113 was added to ethyl chloroformate. As shown in Table 5, the yield of the reaction was comparable to those obtained from synthesis involving heteroatom-containing electrophiles.

\section{Scheme 43}

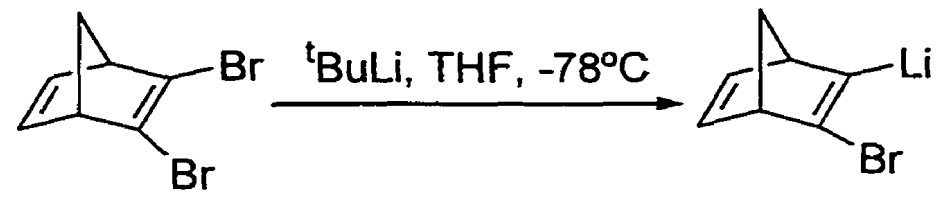<smiles>CCOC(=O)C1=C(Br)C2C=CC1C2</smiles>

Attempts to synthesize 2,3-disubstituted norbornadienes bearing an aldehyde functionality were carried out as well. Similar to the experimental procedure for the generation of 1101 , the synthesis of 110 s (Scheme 44) also involved the addition of the intermediate 2-bromo-3-lithionorbornadiene (113) to the electrophile. In this case, DMF was used. Unfortunately, the yield of the reaction was only $18 \%$. Another route to the 
synthesis of 110 s was needed. As demonstrated earlier, 1101 was obtained in good yield via monolithium-halide exchange (Scheme 43). An attempt to reduce the carboxylic acid ethyl ester functionality to an aldehyde using only $\mathrm{I}$ equivalent of DIBAL in $\mathrm{CH}_{2} \mathrm{Cl}_{2}$ at $-78^{\circ} \mathrm{C}$ was performed (Scheme 45 ). In this case, only starting material was detected from

${ }^{\mathrm{I}} \mathrm{H}$ NMR (200 MHz) spectroscopy. Although the direct approach, by way of monolithium-bromide exchange, gave a low yield of the product $110 \mathrm{~s}$, it was nonetheless the better route.

\section{Scheme 44}

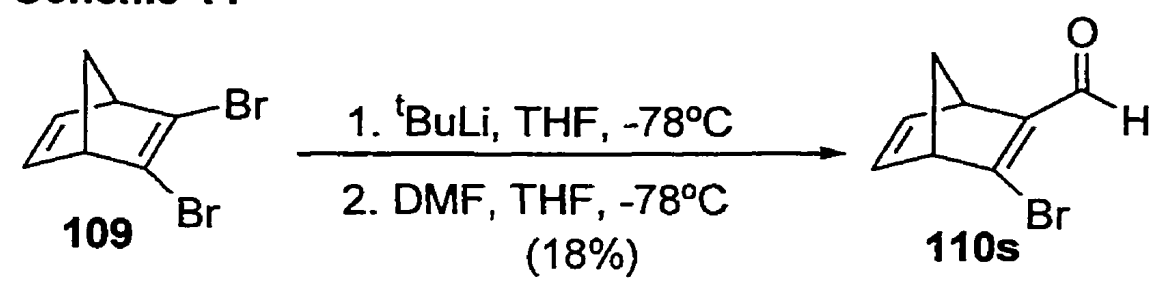

\section{Scheme 45}<smiles>CCOC(=O)C1=C(Br)[C@H]2C=C[C@@H]1C2</smiles>

Thus far, only 2,3-disubstituted norbornadienes bearing carbonyl functionalities such as ethyl ester 1101 and aldehyde 110 s have been discussed. The synthesis of 2,3disubstituted norbornadiene with a ketone group as one of the substituents was explored. As shown in Scheme 46, an attempt to generate $110 t$ from the reaction of the intermediate 113 with acetyl chloride was made. Similar to reactions involving electrophiles bearing carbonyl groups, the intermediate 113 was added to the electrophile 
in order to suppress the formation of possible side products. However, the attempt to generate 110t was unsuccessful. The crude TLC showed a mixture of products.

\section{Scheme 46}<smiles>[B]C1=C(Br)C2C=CC1C2</smiles>

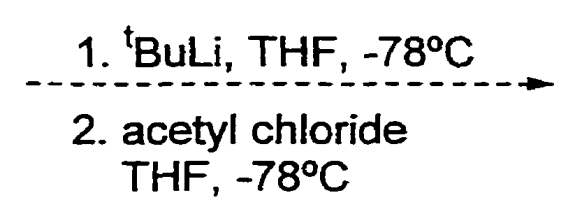<smiles>CC(=O)C1=C(Br)C2C=CC1C2</smiles>
(Did Not Work)

In addition to the investigations on 2,3-disubstituted norbornadienes having a carbonyl group as one of the substituents, synthesis of 2,3-disubstitued norbornadienes having an alcohol functionality was also performed. The synthesis of adducts having a primary alcohol functionality will first be presented, followed by those with secondary alcohols and last but not least, the ones with tertiary alcohols. Various aldehydes were used as the electrophiles in the synthesis of adducts bearing primary and secondary alcohols. In the case of the formation of adducts with tertiary alcohols, ketones were used.

Four different methods were attempted to generate the disubstituted adduct bearing a primary alcohol functionality 110u (Scheme 47) using the electrophile paraformaldehyde. In the first method, the generated intermediate 113 was added to a stirred solution of paraformaldehyde in THF whereas in the second method, the order of 


\title{
Scheme 47
}

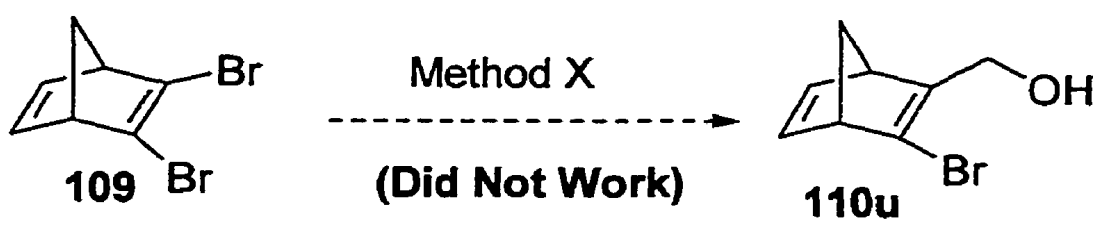

\author{
Method 1 1. ${ }^{\mathrm{t} B u L i}, \mathrm{THF},-78^{\circ} \mathrm{C}, 1 \mathrm{~h}$ \\ 2. paraformaldehyde, THF \\ r.t., $4 \mathrm{~h}$
}
Method 2 1. ${ }^{\mathrm{t} B u L i}, \mathrm{THF},-78^{\circ} \mathrm{C}, 1.2 \mathrm{~h}$
2. paraformaldehyde, THF r.t., $15 \mathrm{~h}$
Method $3 \quad$ 1. ${ }^{\mathrm{t}} \mathrm{BuLi}, \mathrm{THF},-78^{\circ} \mathrm{C}, 1 \mathrm{~h}$
2. paraformaldehyde, THF $-78^{\circ} \mathrm{C}, 55 \mathrm{~min}$.
Method 4 1. ${ }^{\mathrm{t}} \mathrm{BuLi}$, THF, $-78^{\circ} \mathrm{C}, 1 \mathrm{~h}$
2. paraformaldehyde, THF $-100^{\circ} \mathrm{C}, 30 \mathrm{~min}$.

addition was reversed with the addition of paraformaldehyde to the intermediate $\mathbf{1 1 3}$. Although the reaction of method 2 was carried out for a significantly longer period of time than that of method 1 , both ${ }^{\mathrm{l}} \mathrm{H}$ NMR $(200 \mathrm{MHz})$ spectra showed a mixture of unidentified materials. With the conclusion that the reactions were too vigorous at room temperature, the following two attempts were carried out at much lower temperatures, at $-78^{\circ} \mathrm{C}$ and $-100^{\circ} \mathrm{C}$ in methods 3 and 4 respectively. The time allowed for the reactions was also much shorter. Unfortunately, in these latter two methods, the crude TLCs of the reaction mixtures only showed a mixture of products. 
Although the direct synthesis of 2,3-disubstituted norbomadiene bearing a primary alcohol substituent failed via monolithium-bromide exchange, an alternative approach to the synthesis of $110 u$ was investigated. Similar to the reaction of 113 with ethyl chloroformate to generate $110 \mathrm{l}$ (Scheme 42), 110v was synthesized using the same experimental procedure with the exception that methyl chloroformate was used as the electrophile (Scheme 48). A slightly better yield of the 2,3-disubstituted norbornadiene was obtained with methyl chloroformate than with ethyl chloroformate. The ester 110v then underwent reduction with DIBAL in $\mathrm{CH}_{2} \mathrm{Cl}_{2}$ at $-78^{\circ} \mathrm{C}$ to provide $110 \mathrm{u}$ in fair yield.

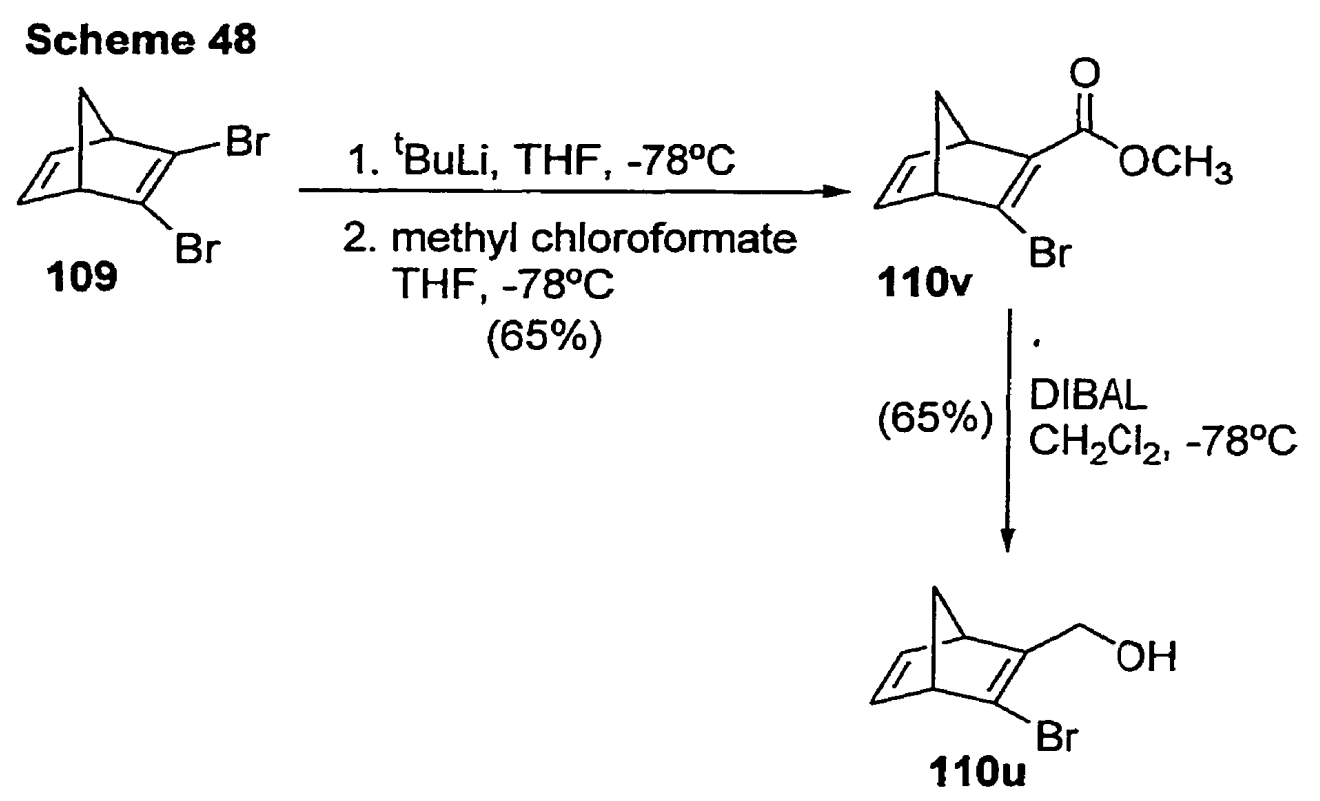

Synthesis of 2,3-disubstituted norbornadienes with a secondary alcohol functionality could be performed with the monolithium-halide exchange procedure. Good yields were obtained for these adducts. As illustrated in Scheme 49, reaction of 2bromo-3-lithionorbornadiene (113) with acetaldehyde provided $110 \mathrm{~m}$ with a yield of 
$83 \%$. Reaction of the intermediate 113 with benzaldehyde was also investigated (Scheme 50). In this case, a slightly lower yield of the adduct $110 \mathrm{n}$ was obtained.

\section{Scheme 49}

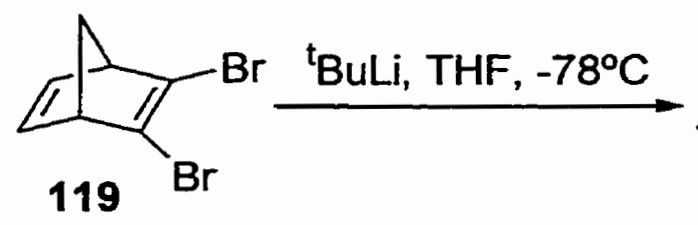<smiles>ClC1=C(Br)C2C=CC1C2</smiles>

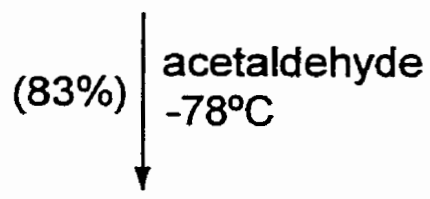<smiles>CC(O)C1=C(Br)C2C=CC1C2</smiles>

\section{Scheme 50}

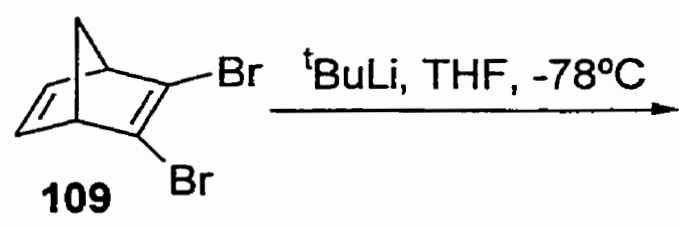<smiles>ClC1=C(Br)C2C=CC1C2</smiles>

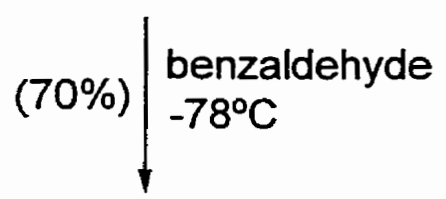<smiles>O=C(O)C1=C(Br)C2C=CC1C2</smiles>

To further the studies on the construction of 2,3-disubstituted norbornadienes, investigations on the synthesis of adducts bearing a tertiary alcohol substituent was 
carried out. Various ketones served as the electrophiles in these reactions. In Scheme 51, the reaction of 2-bromo-3-lithionorbornadiene (113) with acetone occurred smoothly to afford 1100 in fair yield. Another example on the synthesis of adduct with a tertiary alcohol group as one of the substituents is shown in Scheme 52. The slightly lower yield obtained for product 110 p could possibly be accounted by its considerable steric bulkiness.

\section{Scheme 51}

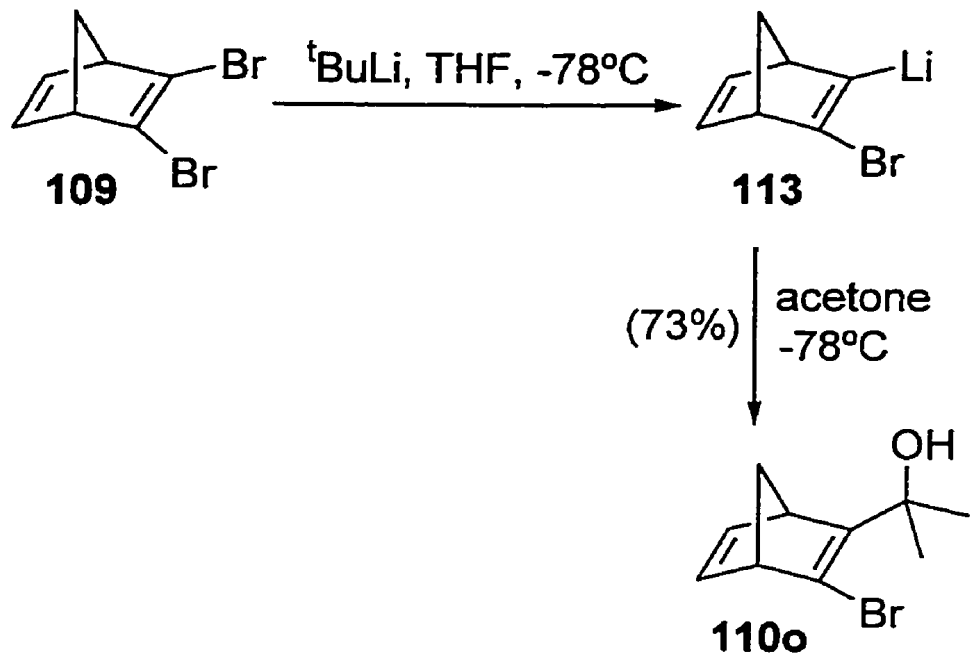

Scheme 52
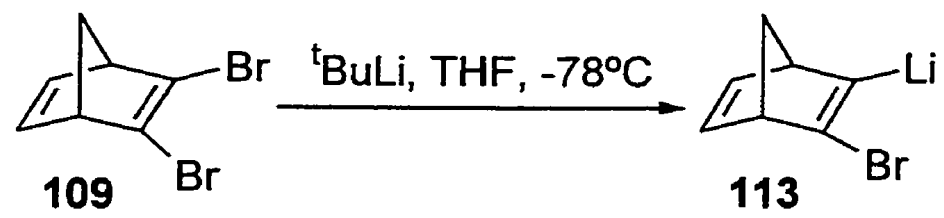

$(66 \%)$ benzophenone $-78^{\circ} \mathrm{C}$<smiles>O=C1C(Br)=C(C(O)(c2ccccc2)c2ccccc2)C2C=CC1C2</smiles> 


\subsubsection{Synthesis of 2,3-Disubstituted Norbornadienes from 2,3- Dibromonorbornadiene via Double Lithium Halide Exchange}

At this point, only synthesis of 2,3-disubstituted norbornadienes bearing a bromine group as one of the substituents have been demonstrated. However, in order to broaden our studies on the intramolecular 1,3-dipolar cycloadditions of C-2, C-3disubstituted norbornadiene-tethered nitrile oxides, a versatile methodology to the synthesis of 2,3-disubstituted norbornadienes with various functionalities other than bromine was needed.

As shown in Table 6 in section 3.2, a variety of 2,3-disubstituted norbornadienes was generated by double lithium-halide exchange. A second lithium halide exchange of 110b followed by trapping of the generated intermediate with 1-bromohexane (Table 6, entry 1), 1,4-dibromobutane (entry 2), trimethylsilyl chloride (entry 3), tosyl chloride (entry 4), iodine (entry 5) provided a broad range of 2,3-disubstituted norbornadienes $(111 \mathrm{a}-111 \mathrm{e})$ with various functional groups in moderate to good yields.

Similar to the previous studies on the synthesis of 1101 from 2,3dibromonorbornadiene (109), the investigation to functionalize the bromide $110 \mathrm{~b}$ with a carbonyl group by carrying out a second lithium-halide exchange continued. Result on the synthesis of the adduct bearing a carboxylic acid ethyl ester group will first be presented, followed by a brief examination on the synthesis of the adduct bearing an aldehyde group.

As shown in Scheme 53, monolithium-bromide exchange of $110 \mathrm{~b}$ with 2 . equivalents of ${ }^{t} \mathrm{BuLi}$ generated the intermediate 2-methyl-3-lithionorbornadiene. As with 
the synthesis of 1101, particular attention should be paid to the experimental procedure of this reaction. In order to suppress the formation of side products, the generated organolithium was added to a solution of ethyl chloroformate in THF. The reaction occurred smoothly to provide $111 \mathrm{f}$ with a yield of $77 \%$.

\section{Scheme 53}

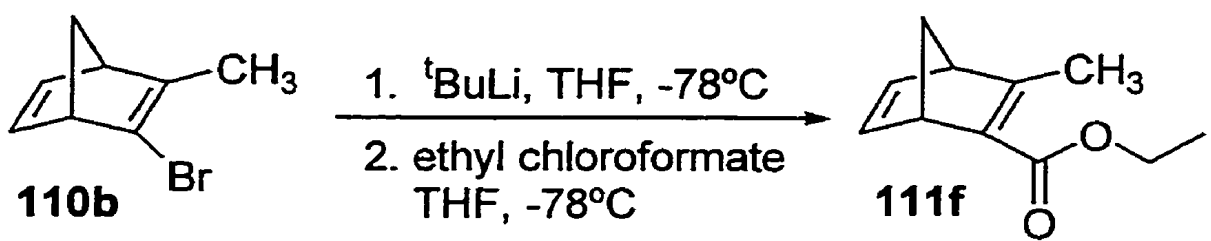

$(77 \%)$

Although unsuccessful attempts were made to synthesize 2,3-disubstituted norbornadienes with aldehyde and bromine functionalities via monolithium-bromide exchange of 109 (Scheme 44) or the indirect approach of reducing 1101 with DIBAL (Scheme 45), the challenge to generate 111j was undertaken. As shown in Scheme 54, $111 f$ was reduced with 1.0 equivalent of DIBAL in $\mathrm{CH}_{2} \mathrm{Cl}_{2}$ at $-78^{\circ} \mathrm{C}$. Unfortunately, the ${ }^{1} \mathrm{H}$ NMR (200 MHz) spectrum of the crude reaction mixture gave no evidence of the formation of the product. The signal corresponding to an aldehyde group was not detected.

\section{Scheme 54}

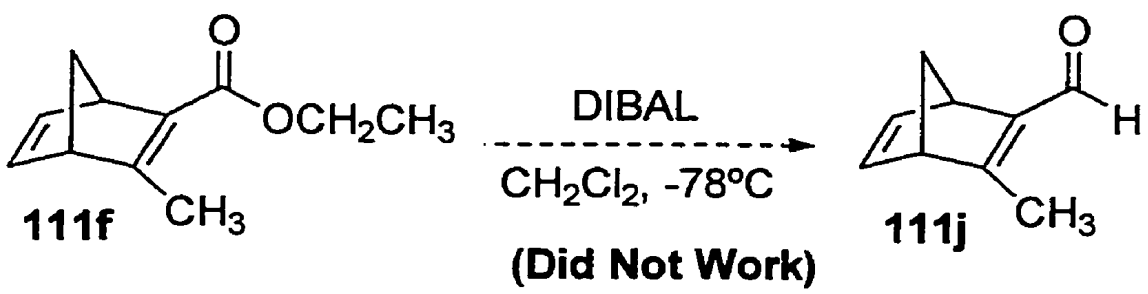


Synthesis of 2,3-disubstituted norbornadienes with tertiary alcohol functionality from $110 \mathrm{~b}$ was also examined. As illustrated in Scheme 55, reaction of $110 \mathrm{~b}$ with acetone generated 111g. This reaction gave the highest yield among all of the 2,3disubstituted norbornadienes synthesized from $110 \mathrm{~b}$.

\section{Scheme 55}<smiles>CC1=C(Br)C2C=CC1C2</smiles>

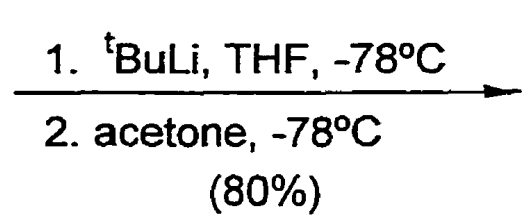<smiles>CC1=C(C(C)(C)O)C2C=CC1C2</smiles>

Particular attention should be drawn to the synthesis of the 2,3-disubstituted norbornadienes $111 \mathrm{~h}$ and 111i. These compounds served! as important precursors of the norbornadiene-tethered nitrile oxides for the studies of intramolecular 1,3-dipolar cycloaddition reactions. Trapping of bromide $110 \mathrm{c}$ with 1 , 4-dibromobutane (Scheme 56) led to the formation of $111 \mathrm{~h}$.

\section{Scheme 56}
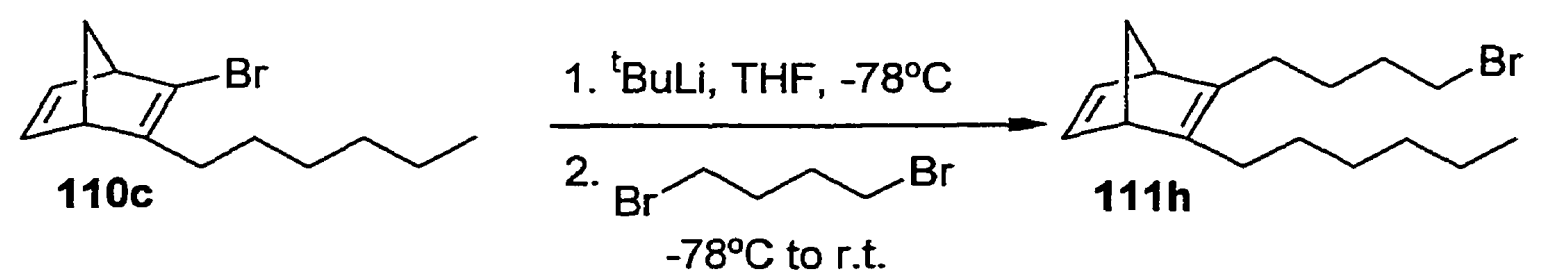

$(54 \%)$

As demonstrated earlier, reactions which involved. ethyl chloroformate often led to 2,3-disubstituted norbornadienes in moderate yields. Herein, the synthesis of $111 i$ 
from 110d which involved the electrophile methyl chloroformate is reported (Scheme 57). Similar to other reaction involving carbonyl-containing electrophiles mentioned to date, the same experimental procedure applied. The reaction proceeded by the addition of the intermediate organolithium to methyl chloroformate. Good yield of the 2,3disubstituted norbornadiene 111i was obtained.

\section{Scheme 57}

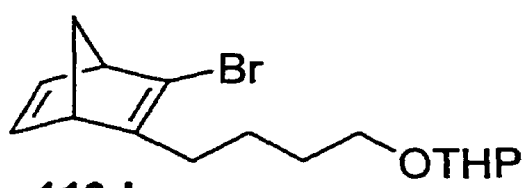

110d
1. ${ }^{\mathrm{B}} \mathrm{BuLi}, \mathrm{THF},-78^{\circ} \mathrm{C}$

2. methyl chloroformate THF,$-78^{\circ} \mathrm{C}$ $(74 \%)$<smiles>COC(=O)C1=C(CCCC[OH+])C2C=CC1C2</smiles>

$111 \mathrm{i}$

Investigation on the synthesis of 2,3-disubstituted norbornadiene bearing a phenyl functionality was also carried out. The attempt to convert compound $110 \mathrm{~g}$ to $111 \mathrm{k}$ with the use of tetrakis(triphenylphosphine)palladium(0) and tributylphenyltin was made. Unfortunately, a mixture of products was observed from the crude TLC.

\section{Scheme 58}<smiles></smiles>

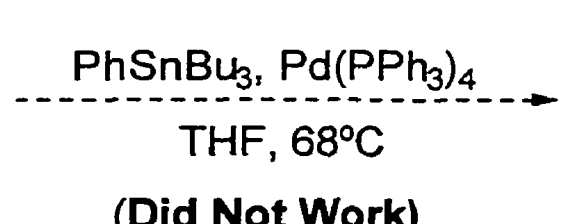<smiles>C[SiH](C)C1=C(c2ccccc2)C2C=CC1C2</smiles>

(Did Not Work) 


\subsection{Conclusions}

Various 2,3-disubstituted norbornadienes that are impossible to prepare by the traditional Diels-Alder method were synthesized in moderate to good yields by double lithium-halide exchange of 2,3-dibromonorbornadiene. Analogues $110 \mathbf{a}-110 \mathrm{p}$ are very useful precursors for the synthesis of many other 2,3-disubstituted norbornadienes. Some of these compounds are used in the studies of intramolecular 1,3-dipolar cycloaddition reactions of norbornadiene-tethered nitrile oxides.

Although the 2,3-disubstituted norbornadienes $111 \mathrm{a}-111 \mathrm{i}$ are synthesized via a second lithium-halide exchange as discussed earlier, alternative methodologies to these compounds are possible. For instance, coupling of the bromides 110 with organotin compounds (for the Stille coupling ${ }^{66-67}$ ), with organoboron compounds (for the Suzuki coupling ${ }^{68}$ ), with alkenes (for the Heck reaction ${ }^{69}$ ), and with 1-alkynyl (for the CastroStephens-Sonogashira coupling ${ }^{70}$ ) to generate broad classes of vinyl, aryl, and alkynyl norbornadienes. These coupling reactions in the synthesis of novel conjugated norbornadiene-based polymers are currently under investigation in the Tam group. Studies on the asymmetric lithium-halide exchange of 2,3-dibromonorbornadiene (109) by precomplexation of ${ }^{t} \mathrm{BuLi}$ with a chiral base $\mathrm{b}^{34}$ are also underway. 


\section{Chapter 4}

Intramolecular 1,3-Dipolar Cycloadditions of Norbornadiene-Tethered Nitrile Oxides with a C-3 Substituent 


\subsection{Introduction}

Having discovered a simple and convenient method to synthesize various 2,3disubstituted norbornadiene via double lithium halide exchange (Chapter 3 ), investigation of the intramolecular 1,3-dipolar cycloadditions of norbornadiene-tethered nitrile oxides bearing a C-3 substituent was pursued (Scheme 59). In this chapter, a novel strategy to cycloadduct precursors with a C-3 substituent will first be presented. Application of this general methodology for the synthesis of a wide variety of C-3 substituted norbornadiene-tethered nitrile oxides will follow. The effects of various functionalitieselectron donating or electron withdrawing - at the C-3 position of norbornadiene and the size of these functionalities upon the regio- and stereoselectivity of the cycloaddition will also be addressed. Identification of the cycloadducts from spectroscopic data will then be discussed. In the final section, a brief summary detailing the intramolecular 1,3-dipolar cycloaddition of C-3 substituted norbornadiene-tethered nitrile oxides will be presented.

\section{Scheme 59}

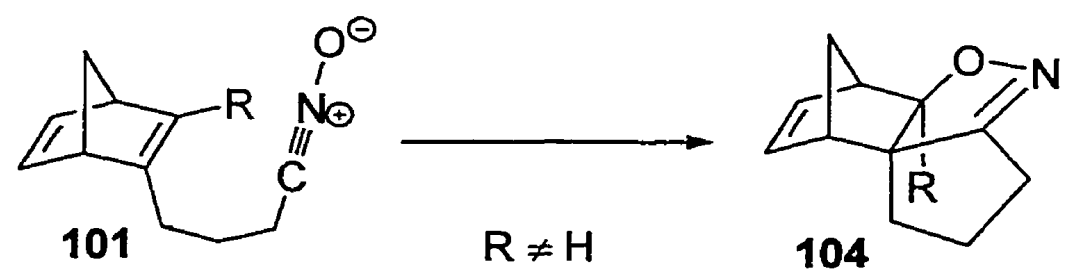




\subsection{Synthesis of C-3 Substituted Cycloadducts}

The methodology for the synthesis of C-3 substituted cycloadducts is very similar to the one described for the unsubstituted adducts in section 2.2. A general route for the synthesis of C-3 substituted cycloadducts from norbornadiene (1) is shown in Scheme 60. This method was applied to the synthesis of cycloadducts bearing a methyl, hexyl, bromo, chloro, or TMS group at the C-3 position. Following Schlosser and Brandsma's protocol, deprotonation of the vinylic proton of norbornadiene (1) with Schlosser's base ${ }^{\mathrm{n}} \mathrm{BuLi} /{ }^{\mathrm{t}} \mathrm{BuOK}$ occurred smoothly at $-78^{\circ} \mathrm{C}$ in $\mathrm{THF}{ }^{40,63}$ The generated norbornadienyl anion was then trapped with 0.5 equivalent of 1,2 -dibromoethane. The remaining 0.5 equivalent of norbornadienyl potassium then acted as a base, deprotonating the vinylic proton from 2-bromonorbornadiene. Addition of an excess of 1,2-dibromoethane then led to the formation of 2,3-dibromonorbornadiene (109). Monolithium halide exchange of 109 with 'BuLi produced 2-bromo-3-lithionorbornadiene. Trapping of this organolithium with electrophiles generated a variety of 2,3-disubstituted norbornadienes bearing a bromine functionality $\mathbf{1 1 0}$ in good yields. A second lithium halide exchange was then performed under the same reaction conditions as described. The generated organolithium was then trapped with 1,4-dibromobutane (29) to give the norbornadienetethered bromide 111. Displacement of the bromide with sodium nitrite in the presence of phloroglucinol in DMSO afforded the corresponding nitro compound 115 . In the final step of the reaction pathway, 115 was converted to the cycloadduct 104 with the use of the Hassner $(\mathrm{BOC})_{2} \mathrm{O} / \mathrm{DMAP}$ method in toluene at $90^{\circ} \mathrm{C}$. Generally, good yields of the cycloadducts were obtained. 
Scheme 60. Proposed Route to the Synthesis of C-3 Substituted Cycloadduct<smiles>C1=CC2C=CC1C2</smiles>

1

1. 'BuOK, "BuLi,

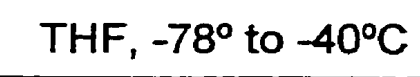

2. $\mathrm{Br} \sim \mathrm{Br}$

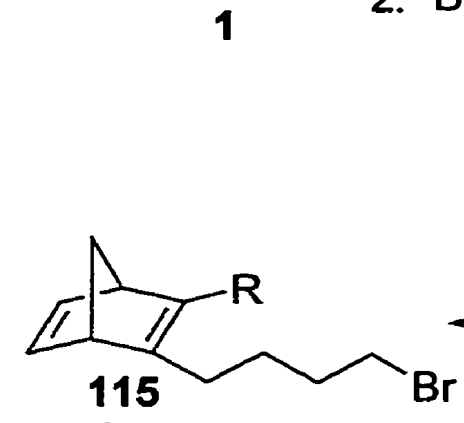

1. ${ }^{\mathrm{t}} \mathrm{BuLi}, \mathrm{THF},-78^{\circ} \mathrm{C}$

2. $\mathrm{Br} \sim \mathrm{Br}$<smiles>[18OH]C1C2C=CC1C=C2</smiles>

$\mathrm{NaNO}_{2}, \mathrm{DMF}$

phloroglucinol

r.t.

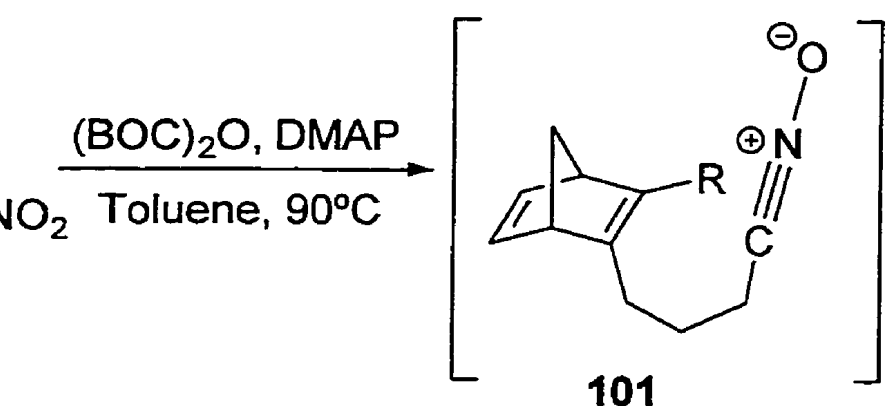

101

$\mathrm{R} \neq \mathrm{H}$
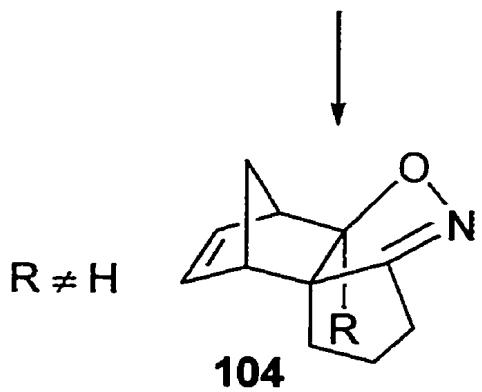


\subsection{Results and Discussion}

\subsubsection{Synthesis of Norbornadiene-Tethered Nitrile Oxides Bearing a Halogen at the C-3 Position}

\subsubsection{Cycloadduct Bearing a Bromo Substituent}

\section{Scheme 61}
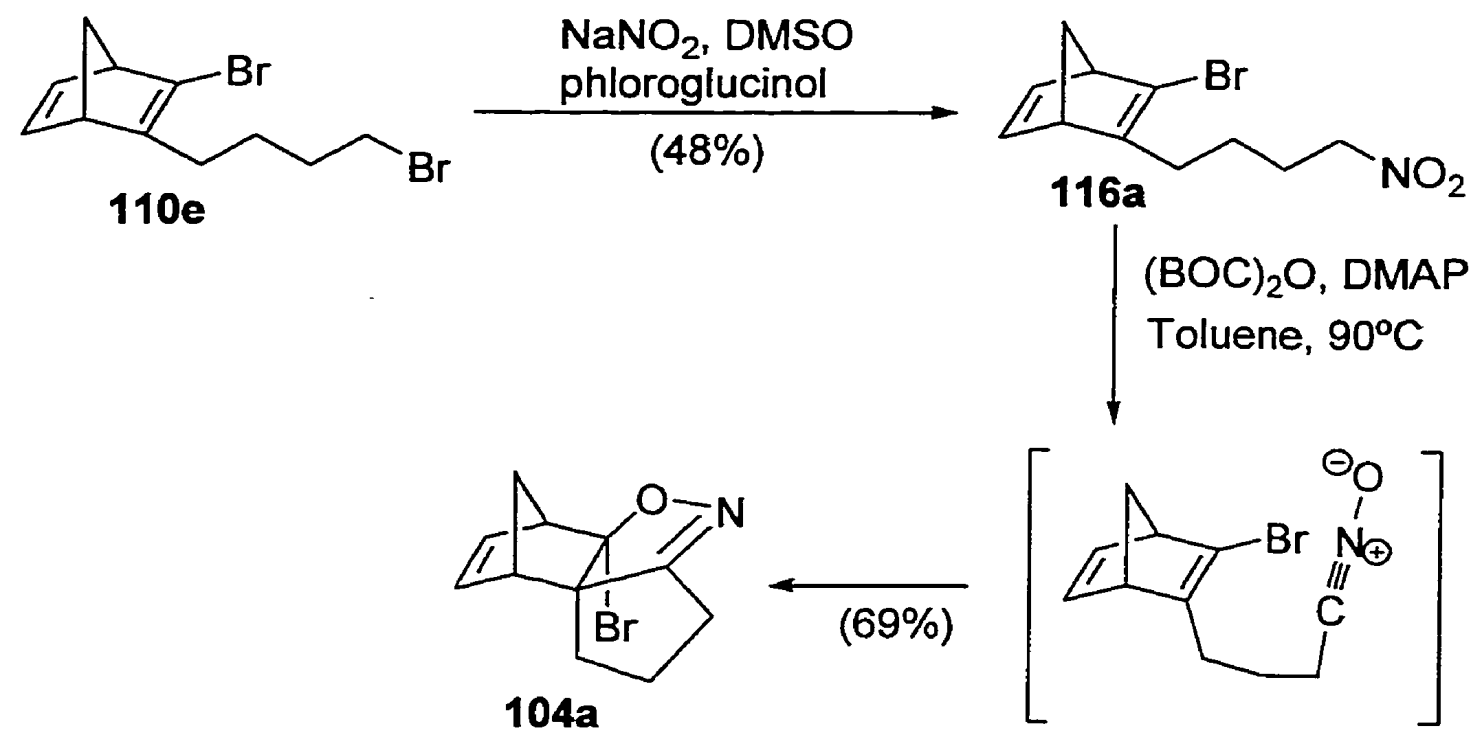

$101 a$

Synthesis to the bromo-substituted cycloadduct 104a was among the shortest in comparision to routes leading to other substituted cycloadducts. In this case, only one lithium halide exchange was required in the synthetic route. Following the general synthetic methodology described in section 4.2 , monolithium-halide exchange with ${ }^{\mathrm{t}} \mathrm{BuLi}$ produced 2-bromo-3-lithionorbornadiene, which was then trapped with 1,4dibromobutane (29) to afford the norbornadiene-tethered bromide 110e. Displacement of 
the bromide with sodium nitrite gave 116a (Scheme 61). In the usual fashion, by the employment of the Hassner $(\mathrm{BOC})_{2} \mathrm{O} / \mathrm{DMAP}$ method, 116a was converted to the required bromo-substituted cycloadduct $\mathbf{1 0 4 a}$ with a yield of $69 \%$. Only a single regioand stereoisomer of $104 a$ was obtained.

\subsubsection{Cycloadduct Bearing a Chloro Substituent}

Since cycloaddition of bromo-substituted norbornadiene-tethered nitrile oxides was possible leading to cycloadduct $\mathbf{1 0 4 a}$, investigation on the effects of other halogen substituent at the C-3 position was carried out. It was thought that the size of the substituent might affect the yield of the cycloadduct obtained. Thus, synthesis of chlorosubstituted cycloadduct precursors was performed (Scheme 62). Starting with 2,3dibromonorbornadiene (109), monolithium halide exchange of 109 produced 2-bromo-3lithionorbornadiene. Trapping of this organolithium with tosyl chloride gave $110 \mathrm{i}$ in moderate yield. A second lithium halide exchange was then carried out, followed by trapping of the generated organolithium with 1,4-dibromobutane. The norbornadienetethered bromide 115a was obtained in good yield. In the usual manner, conversion of $115 \mathrm{a}$ to the corresponding nitro compound $116 \mathrm{~b}$ took place. Compound $116 \mathrm{~b}$ then cyclized under the conditions of the Hassner (BOC) $)_{2} \mathrm{O} / \mathrm{DMAP}$ method. The chlorosubstituted cycloadduct $104 \mathrm{~b}$ was obtained with a yield of $89 \%$ which was significantly higher than that of the bromo-substituted cycloadduct 104a. Indeed, a sterically smaller 
substituent did improve the yield of the cycloaddition reaction. The reaction was highly regio- and stereoselective, giving only the exo cycloadduct.

\section{Scheme 62}

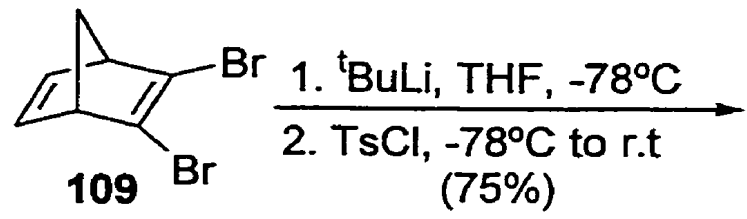<smiles>ClC1=C(Br)C2C=CC1C2</smiles>

1. 'tBuLi, THF, $-78^{\circ} \mathrm{C}$

2. 1,4-dibromobutane $-78^{\circ} \mathrm{C}$ to r.t.

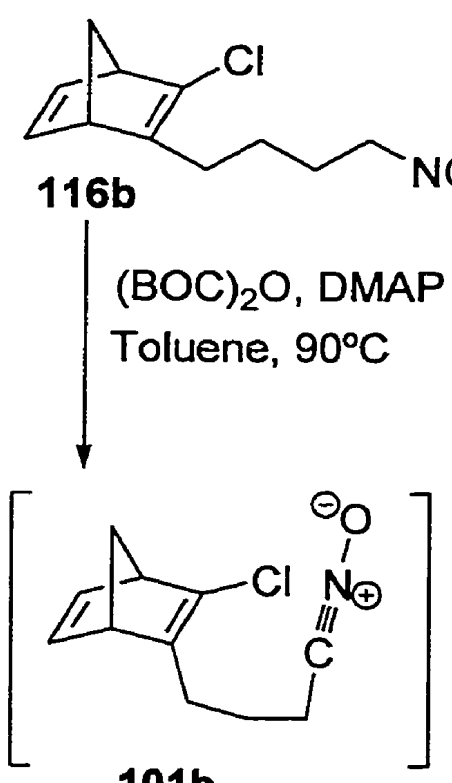

101b

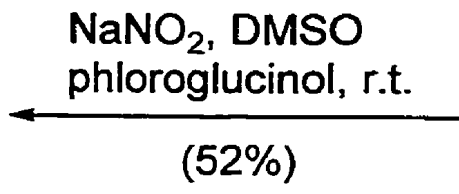

$(89 \%)$<smiles>ClC1=C(CCCCBr)C2C=CC1C2</smiles>

$115 a$

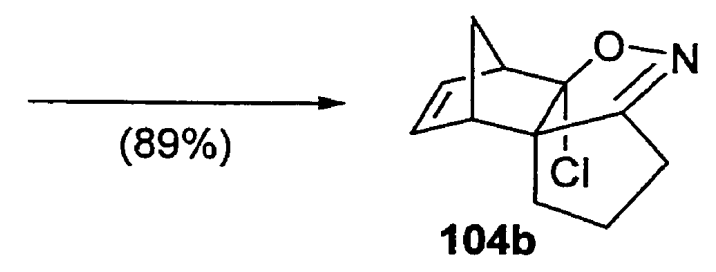




\subsubsection{Cycloadduct Bearing an Iodo Substituent}

In order to have a full understanding on the effects of the size of the halogen atom on cycloaddition reactions, investigation on the cycloaddition of iodo-substituted norbornadiene-tethered nitrile oxide was needed. The synthetic route is shown in Scheme 63. Starting with 110d (see section 3.3.I for the synthesis), lithium halide exchange of $110 \mathrm{~d}$ generated the required organolithium. Trapping of the generated organolithium with iodine afforded the iodo-substituted compound $\mathbf{1 1 7}$ in good yield. The THP ether functionality was then removed under mild acidic conditions to provide 118. Since the hydroxyl functionality is a poor leaving group, $\mathbf{1 1 8}$ was not readily susceptible to nucleophilic substitution reaction with sodium nitrite. Thus the hydroxyl group of 118 was first converted to 119 with the employment of iodine, triphenylphosphine and imidazole in the presence of THF and $\mathrm{CH}_{3} \mathrm{CN}$. Displacement of the iodide with sodium nitrite then gave the required nitro compound 116c. Using the Hassner $(\mathrm{BOC})_{2} \mathrm{O} / \mathrm{DMAP}$ method in toluene at $90^{\circ} \mathrm{C}, 116 \mathrm{c}$ was converted to the iodosubstituted cycloadduct 104c. In this case, only a $5 \%$ yield of the adduct was achieved. Thus, the size of the halogen is an important factor in cycloaddition reaction. The larger the halogen atom at the C-3 position of the norbornadiene-tethered nitrile oxide, the lower the yield of the cycloadduct obtained. The cycloaddition remained highly regioand stereoselective since only the exo cycloadduct was obtained. 


\section{Scheme 63}

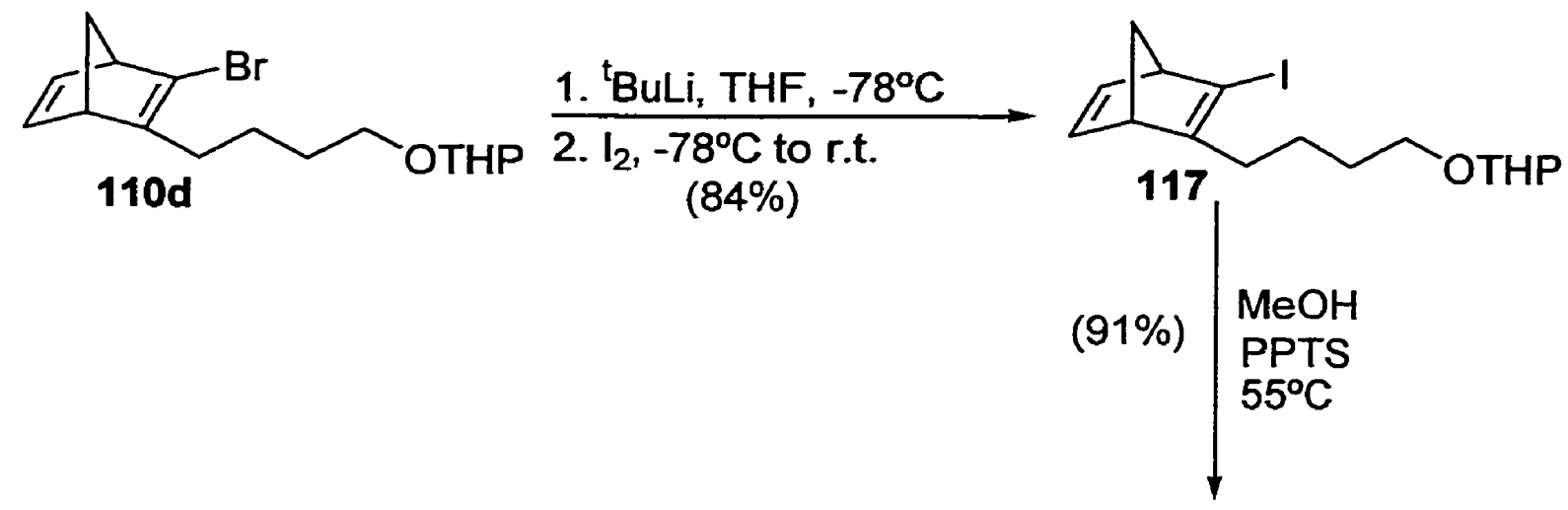<smiles>ICCCCC1=C(I)C2C=CC1C2</smiles>

119

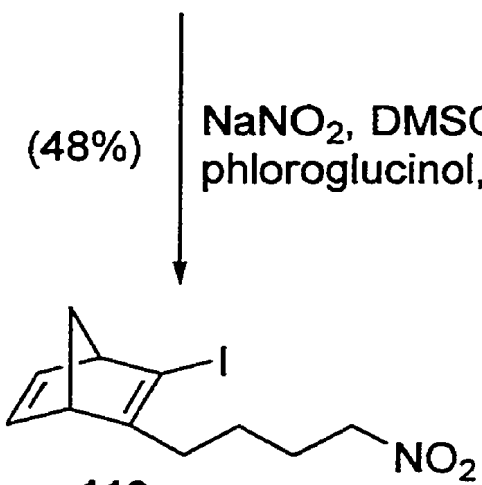
$116 \mathrm{c}$

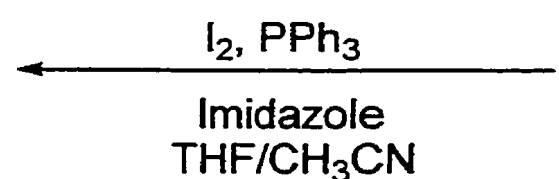

(77\%)

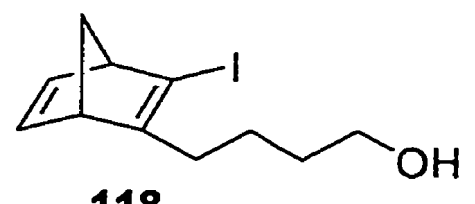

118
$\frac{(\mathrm{BOC})_{2} \mathrm{O}, \mathrm{DMAP}}{\text { Toluene, } 90^{\circ} \mathrm{C}}\left[\begin{array}{cc}\Theta_{\mathrm{O}} \\ \frac{1}{\mathrm{~N}}\end{array}\right]$

$(5 \%)$

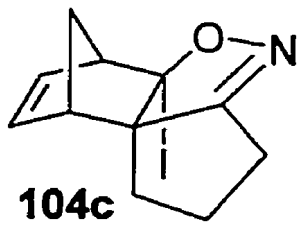




\subsubsection{Synthesis of Norbornadiene-Tethered Nitrile Oxides Bearing an Alkyl}

Substituent at the C-3 Position

\subsubsection{Cycloadduct Bearing a Methyl Substituent}

\section{Scheme 64}<smiles>CC1C2C=CC(C2)C1CCCCBr</smiles>

$111 b$

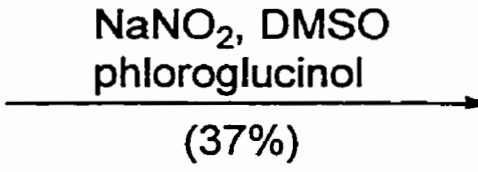

$(37 \%)$<smiles>CC1=C2C3C=CC(C3=C1CCCCN=O)C2C</smiles>

116d
$(\mathrm{BOC})_{2} \mathrm{O}, \mathrm{DMAP}$

Toluene, $90^{\circ} \mathrm{C}$

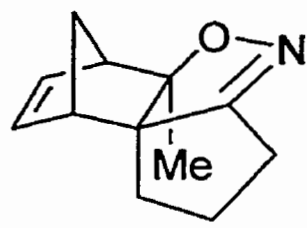

104d
$(82 \%)$

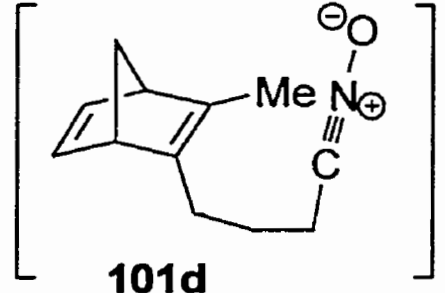

101d

Following the general methodology for the synthesis of $\mathrm{C}-3$ substituted cycloadducts, the methyl substituted adduct 101d was obtained. To synthesize cycloadduct precursors bearing a methyl substituent, the organolithium generated from the monolithium halide exchange was first trapped with iodomethane. A brief outline of the synthetic route is shown in Scheme 64. In the usual fashion, the norbornadienetethered bromide $115 \mathrm{c}$ was converted to the nitro compound $116 \mathrm{~d}$ with sodium nitrite and DMSO in the presence of phloroglucinol. Using the Hassner (BOC) 2 O/DMAP method in toluene at $90^{\circ} \mathrm{C}, 116 \mathrm{~d}$ was then converted to the required cycloadduct $104 \mathrm{~d}$ with a yield 
of $82 \%$. As was reported in Chapter 2, the yield of the five-membered cycloadduct without a C-3 substituent was $86 \%$. Surprisingly, the presence of a methyl functionality at the C-3 position had little effect on the cycloaddition reaction. Similarly, only a single regio- and stereoisomer of $\mathbf{1 0 4 d}$ was obtained.

\subsubsection{Cycloadduct Bearing a Hexyl Substituent}

Having successfully synthesized the methyl substituted cycloadduct 104d, study on the synthesis of norbornadiene-tethered nitrile oxide precursors bearing alkyl substituent with considerable more steric bulk at the C-3 position was undertaken. In this case, synthesis of cycloadduct bearing a hexyl substituent at the C-3 position was investigated. Following the general methodology described in section 4.2, the organolithium generated from the monolithium halide exchange was first trapped with iodohexane. Scheme 65 showed a brief reaction sequence. Displacement of the norbornadiene-tethered bromide $111 \mathrm{~h}$ with sodium nitrite afforded 116e with a yield of $40 \%$. In the usual fashion, the nitro compound $116 \mathrm{e}$ was converted to the cycloadduct 104e. The cycloaddition occurred smoothly to give the hexyl substituted cycloadduct 104e with a yield of $83 \%$ which was marginally better than that achieved for the methyl substituted adduct 104d. In fact, the long alkyl chain at the C-3 position had no effect on the cycloaddition reaction. The cycloaddition provided a single regio- and stereoisomer of cycloadduct $104 \mathrm{e}$. 


\section{Scheme 65}

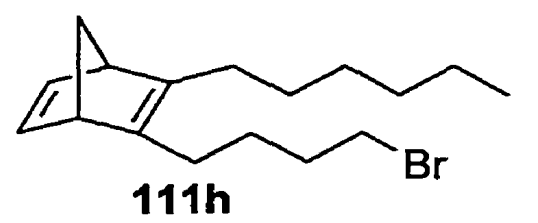

$111 \mathrm{~h}$

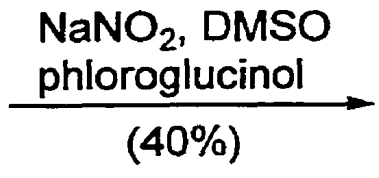

$(40 \%)$

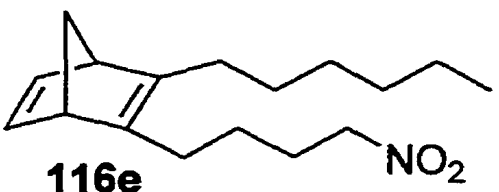

$(\mathrm{BOC})_{2} \mathrm{O}, \mathrm{DMAP}$ Toluene, $90^{\circ} \mathrm{C}$

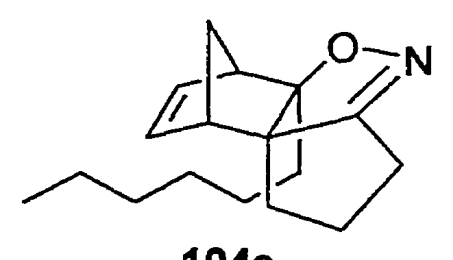

$104 e$

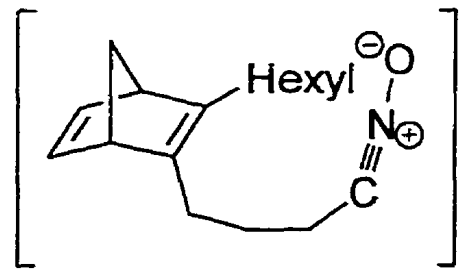

$101 e$

\subsubsection{Synthesis of Norbornadiene-Tethered Nitrile Oxide Bearing an Allyl Substituent at the C-3 Position}

\subsubsection{Cycloadduct Bearing an Allyl Substituent}

Synthesis of allyl-substituted norbornadiene-tethered nitrile oxide precursors was also included in the study. As shown in Scheme 66, lithium halide exchange with compound 110d led to the formation of the organolithium. Trapping of the organolithium with allyl bromide gave $\mathbf{1 2 0}$ with a $64 \%$ yield. In the usual fashion, removal of the THP ether functionality was carried out under mild acidic conditions with the use of methanol and PPTS at a temperature of $55^{\circ} \mathrm{C}$. Surprisingly, the alcohol 121 was not obtained. The ${ }^{1} \mathrm{H}$ NMR $(200 \mathrm{MHz})$ spectrum only showed a mixture of 
unidentified materials. Further investigation on the synthesis of cycloadduct $104 f$ was not carried out.

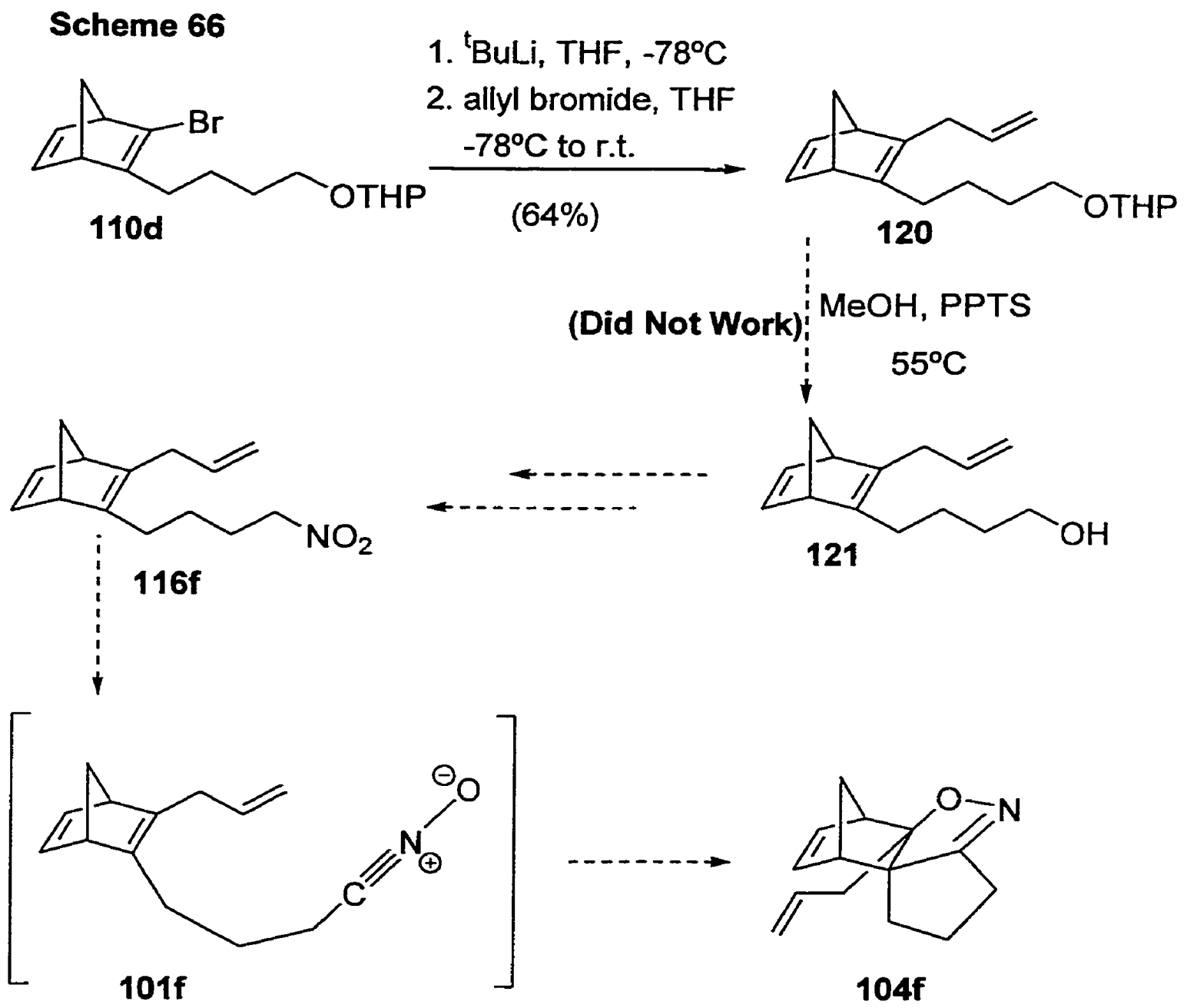


4.3.4 Synthesis of Norbornadiene-Tethered Nitrile Oxide Bearing an Aryl Substituent at the C-3 Position

\subsubsection{Cycloadduct Bearing a Phenyl Substituent}

\section{Scheme 67}<smiles></smiles>
Method X (Did Not Work)<smiles></smiles>
122

Method $1 \mathrm{PhSnBu}_{3}, \mathrm{Pd}\left(\mathrm{PPh}_{3}\right)_{4}, \mathrm{LiBr}$ THF, $65^{\circ} \mathrm{C}, 16 \mathrm{~h}$ Method $2 \mathrm{PhSnBu}_{3}, \mathrm{Pd}\left(\mathrm{PPh}_{3}\right)_{4}, \mathrm{LiBr}$ Toluene, $110^{\circ} \mathrm{C}, 16 \mathrm{~h}$<smiles>CCC1=C(CCCC[N+](=O)[O-])C2C=CC1C2</smiles><smiles>[13CH2][13CH3]</smiles>

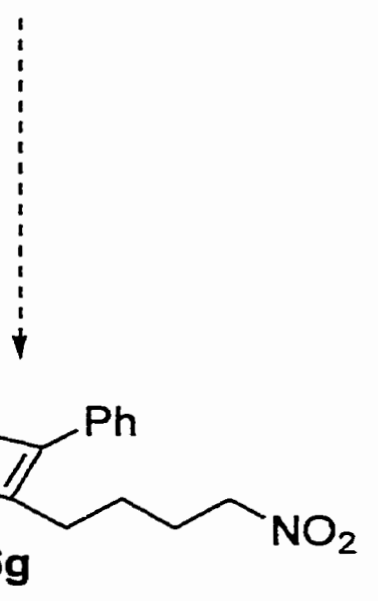

1019

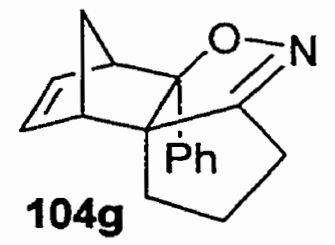

Thus far, only cycloadducts bearing straight chain alkyl groups at the C-3 position were investigated. To broaden the scope of the study, synthesis to the phenyl-substituted 
cycloadduct $104 \mathrm{~g}$ was also addressed. Two different synthetic routes were attempted to generate phenyl-substituted norbornadiene-tethered nitrile oxide precursors (Scheme 67). For both methods 1 and 2, only a mixture of products was observed from the TLC of the crude reaction mixture. Another route to the synthesis of phenyl-substituted norbornadiene-tethered nitrile oxide was required. As shown in Scheme 68, an attempt was made to convert $116 \mathrm{a}$ to compound $116 \mathrm{~g}$. In this method, phenyitrichlorosilane, $\mathrm{KOH} / \mathrm{H}_{2} \mathrm{O}$ and palladium (II) chloride were employed. Unfortunately, the ${ }^{\prime} \mathrm{H}$ NMR (200 $\mathrm{MHz}$ ) spectrum only showed a mixture of unidentified materials. Synthesis of cycloadduct $104 \mathrm{~g}$ was not investigated further.

\section{Scheme 68}<smiles>O=[N+]([O-])CCCCC1=C(Br)C2C=CC1C2</smiles>

$116 a$
$\mathrm{PhSnCl}, \mathrm{KOH} / \mathrm{H}_{2} \mathrm{O}, \mathrm{PdCl}_{2}$ $90^{\circ} \mathrm{C}$ (Did Not Work)<smiles>CC(C)(C)C1=C(c2ccccc2)C2C=CC1C2</smiles>

$116 \mathrm{~g}$

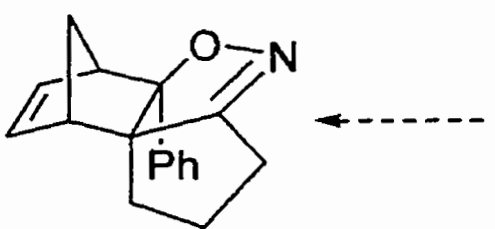

$104 \mathrm{~g}$

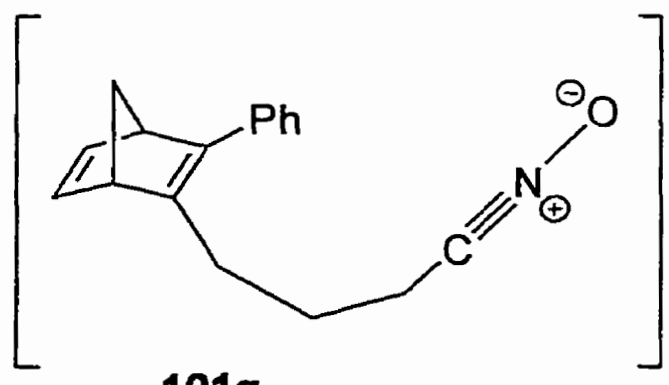

$101 \mathrm{~g}$ 


\subsubsection{Synthesis of Norbornadiene-Tethered Nitrile Oxide Bearing a Silane-}

Containing Substituent at the C-3 Position

\subsubsection{Cycloadduct Bearing a Trimethylsilane Substituent}

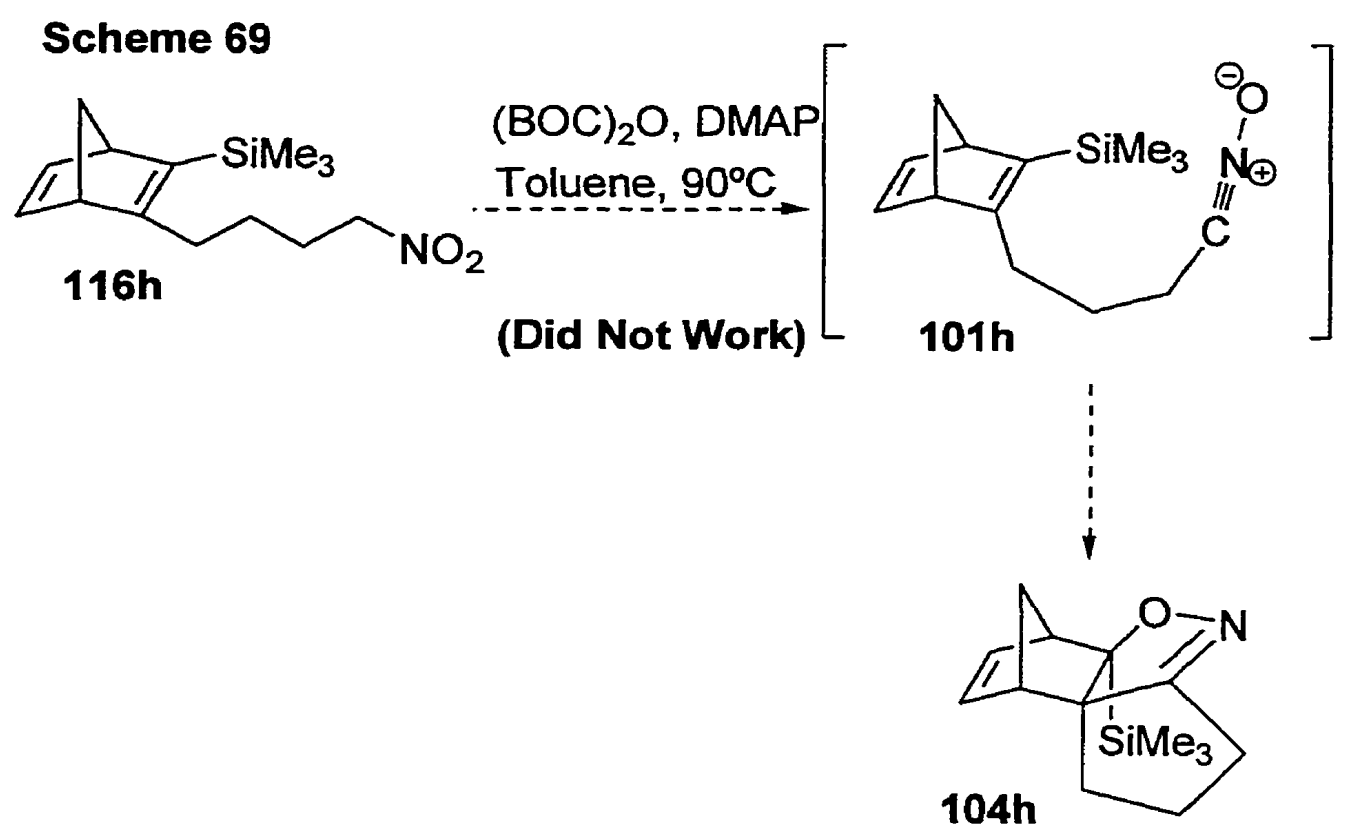

Following the general methodology described in section 4.2 , synthesis of the trimethylsilane-substituted norbornadiene-tethered nitro compound 116h was attempted by other members of the Tam research group. In this reaction sequence, the organolithium generated from the monolithium halide exchange was first trapped with trimethylsilyl chloride. A brief outline of the synthetic route is shown in Scheme 69. In the usual fashion, the norbornadiene-tethered bromide was converted to the nitro compound $116 \mathrm{~h}$ with sodium nitrite and DMSO in the presence of phloroglucinol. Intramolecular 1,3-dipolar cycloaddition of $116 \mathrm{~h}$ was attempted using the Hassner 
$(\mathrm{BOC})_{2} \mathrm{O} / \mathrm{DM}$ MP method in toluene at $90^{\circ} \mathrm{C}$. However, no cycloadduct was detected from the ${ }^{\mathrm{l}} \mathrm{H}$ NMR spectrum. Due to the large steric bulk of this $\mathrm{C}-3$ substitutent, intramolecular cycloaddition between the nitrile oxide and the double bond of norbornadiene was not possible.

\subsubsection{Synthesis of Norbornadiene-Tethered Nitrile Oxides Bearing a Carbonyl- Containing Substituent at the C-3 Position}

\subsubsection{Cycloadduct Bearing a Carboxylic Acid Methyl Ester Substituent}

In the course of studying the intramolecular 1,3-dipolar cycloaddition of C-3 substituted norbornadiene-tethered nitrile oxides, cycloadduct precursors having a carboxylic acid methyl ester functionality at the C-3 position were also investigated. Synthesis of the nitro compound $\mathbf{1 1 6} \mathbf{i}$ with the carboxylic acid methyl ester substituent is shown in Scheme 70. Lithium halide exchange of 110d followed by trapping of the organolithium with methyl chloroformate provided compound $\mathbf{1 1 1 i}$ in moderate yield. Deprotection of the THP ether functionality under mild acidic conditions then gave the alcohol 123. The hydroxyl group of 123 was then converted to 124 with the use of iodine, triphenylphosphine and imidazole in the presence of THF and $\mathrm{CH}_{3} \mathrm{CN}$. Displacement of the iodide with sodium nitrite then afforded the required nitro compound 116i. In the usual fashion, the nitro compound $116 \mathrm{i}$ was converted to the carboxylic acid methyl ester-substituted cycloadduct 104i. A moderate yield of the adduct 104i was 
obtained. The reaction was highly regio- and stereoselective, providing only the exo adduct of 104i.

Scheme 70

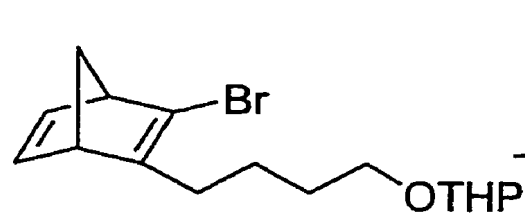

110d
1. ${ }^{\mathrm{t}} \mathrm{BuLi}, \mathrm{THF},-78^{\circ} \mathrm{C}$

2. methyl chloroformate

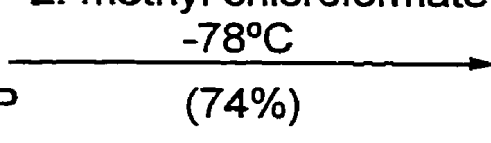

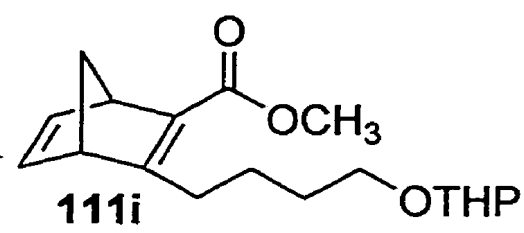

1111

(89\%) $\mid \mathrm{MeOH}, \mathrm{PPTS}$ $55^{\circ} \mathrm{C}$<smiles>COC(=O)C1=C(CCCCI)C2C=CC1C2</smiles>

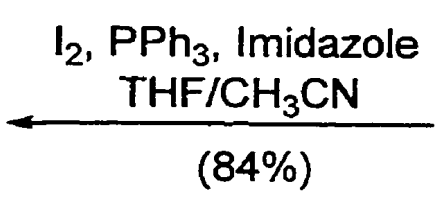
(84\%)<smiles>COC(=O)C1=C(CCCCO)C2C=CC1C2</smiles>

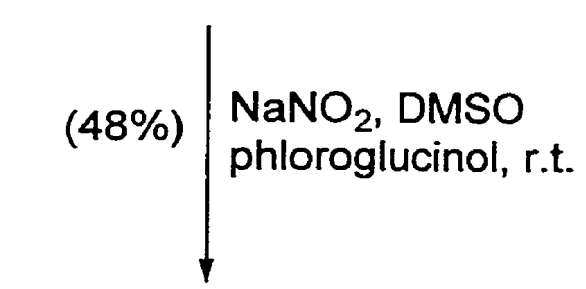<smiles>COC(=O)C1=C(CCCC[N+](=O)[O-])C2C=CC1C2</smiles>

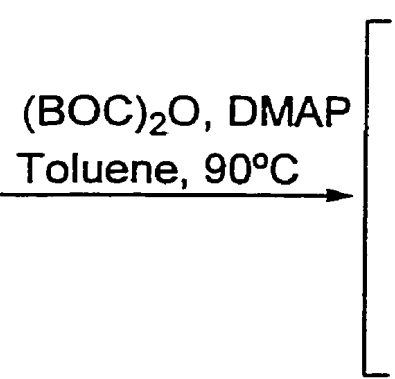<smiles></smiles>
(71\%)

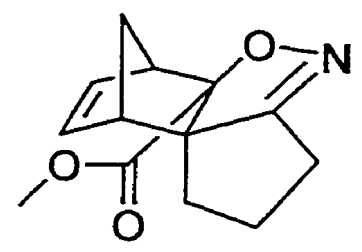




\subsubsection{Cycloadduct Bearing a Carbaldehyde Substituent}

Since carboxylic acid methyl ester-substituted norbornadiene-tethered nitrile oxide precursors could be easily prepared as shown above (Scheme 70), numerous attempts to synthesize the carbaldehyde-substituted norbornadiene-tethered nitrile oxide analogues were undertaken. The objective was to study whether the carbonyl-containing substitutents affect the intramoleular 1,3-dipolar cycloaddition reactions.

Starting with 116i, reduction of the ester functionality to the carbaldehyde 116j with the use of only 1 equivalent of DIBAL in $\mathrm{CH}_{2} \mathrm{Cl}_{2}$ at $-78^{\circ} \mathrm{C}$ was performed (Scheme 71). Both ${ }^{1} \mathrm{H}$ NMR (200 MHz) and IR spectroscopies on the crude reaction mixture did not detect the formation of $\mathbf{1 1 6 j}$.

\section{Scheme 71}<smiles>COC(=O)C1=C(CCCC[N+](=O)[O-])C2C=CC1C2</smiles>

$116 i$

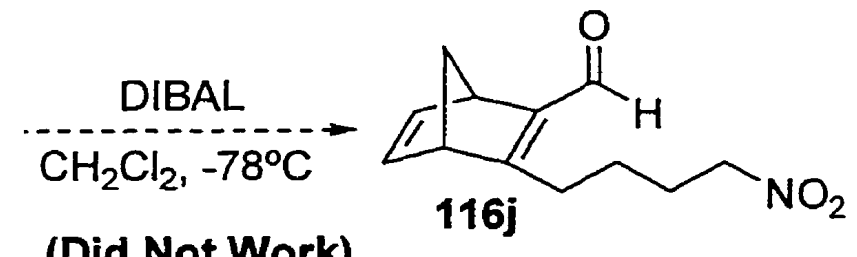

(Did Not Work)

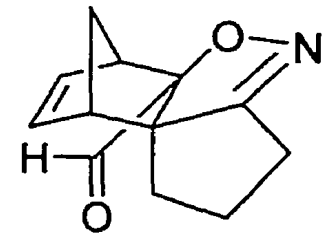

104j

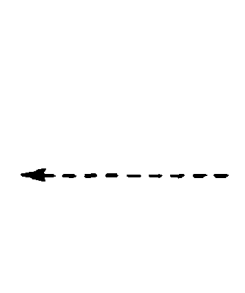

L

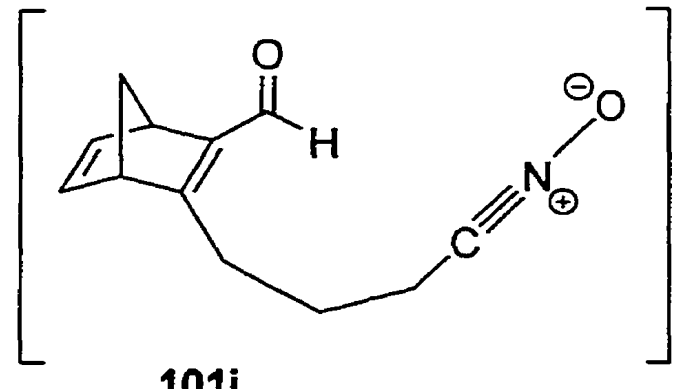

101j 
Rather than synthesizing the carbaldehyde from reduction of the carboxylic acid methyl ester functionality, an attempt to synthesize the carbaldehyde from lithium halide exchange of 110e was carried out. Two methods were shown for the conversion of 110e to $\mathbf{1 1 5 b}$ (Scheme 72). Unfortunately, from the TLCs of the crude reaction mixture of both methods, only a mixture of products was observed.

\section{Scheme 72}

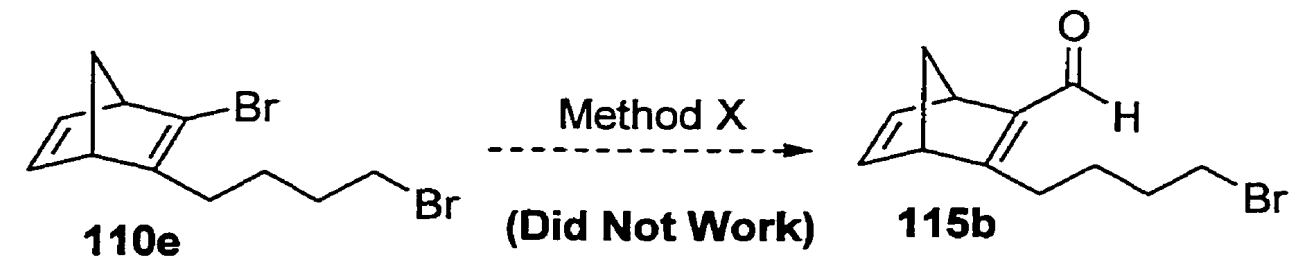

$$
\begin{array}{ll}
\text { Method } 1 & \text { 1. }{ }^{\mathrm{t} B u L i}(1.0 \mathrm{eq}), \mathrm{THF},-78^{\circ} \mathrm{C} \\
& \text { 2. DMF, THF, }-78^{\circ} \mathrm{C} \\
\text { Method 2 } & \begin{array}{l}
\text { 1. }{ }^{\mathrm{t}} \mathrm{BuLi}(2.0 \mathrm{eq}), \mathrm{THF},-78^{\circ} \mathrm{C} \\
\text { 2. DMF, THF, }-78^{\circ} \mathrm{C}
\end{array}
\end{array}
$$
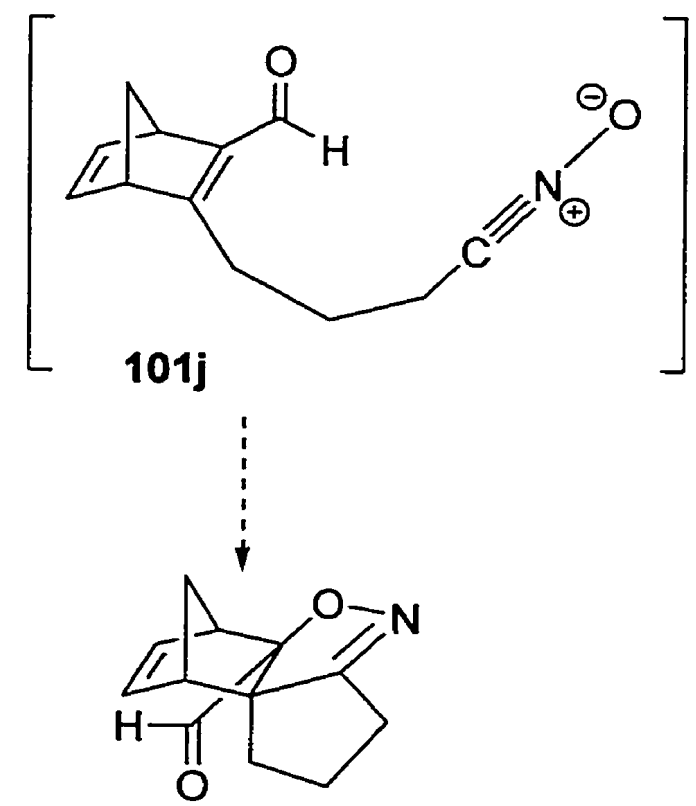

104j

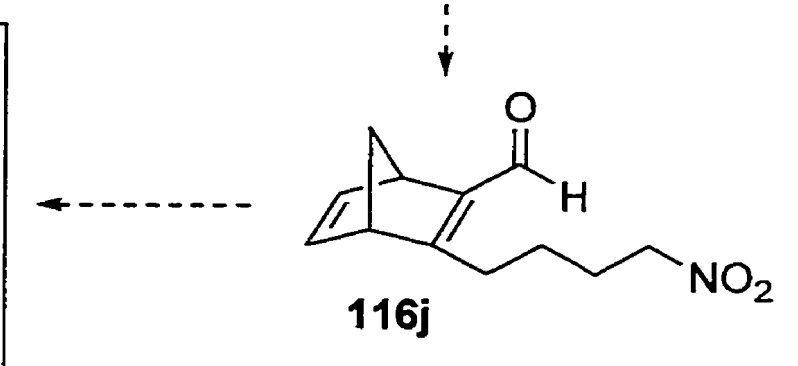


Since compound 110e contained two bromides, selective lithium halide exchange would be required to generate the carbaldehyde functionality at the C-3 position. In the following synthesis, hydration of $110 \mathrm{e}$ to 125 with $\mathrm{DMSO} / \mathrm{H}_{2} \mathrm{O}$ and sodium bicarbonate at $85^{\circ} \mathrm{C}$ was first performed (Scheme 73 ). Attempts were then made to convert 125 to 126. Conditions for the lithium halide exchange and the trapping of the generated organolithium with DMF are shown. Both methods had failed. The ${ }^{1} \mathrm{H} N M R(200 \mathrm{MHz})$ spectra only detected the presence of the norbornadiene-tethered alcohol and DMF.

\section{Scheme 73}

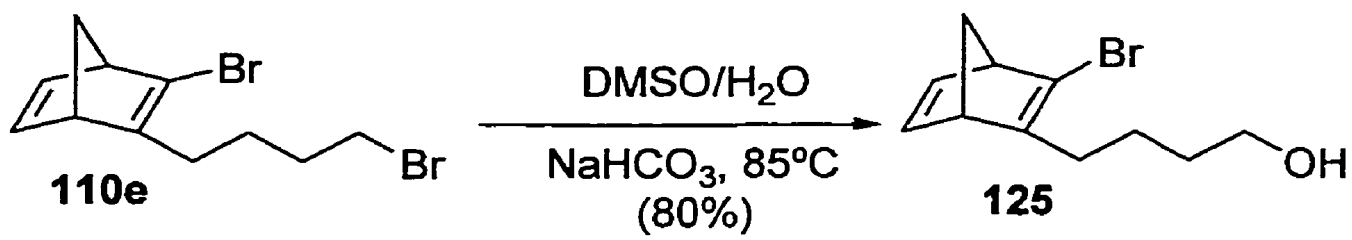

Method 1 1. 'BuLi (3.0eq), THF, $-78^{\circ} \mathrm{C}, 30 \mathrm{~min}$.

2. $\operatorname{DMF}(3.4 \mathrm{eq}), \mathrm{THF},-78^{\circ} \mathrm{C}, 1.5 \mathrm{~h}$ to r.t., $2 \mathrm{~h}$

Method 2 1. ${ }^{\mathrm{t}} \mathrm{BuLi}(4.8 \mathrm{eq}), \mathrm{THF},-78^{\circ} \mathrm{C}, 30 \mathrm{~min}$.

2. DMF (7.9eq), THF, $-78^{\circ} \mathrm{C}, 5 \mathrm{~h}$<smiles>O=CC1=CC2C=CC(C2)[C@H]1CCCC[N+](=O)[O-]</smiles>

116j

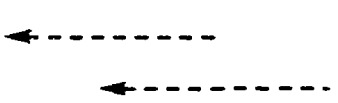

!

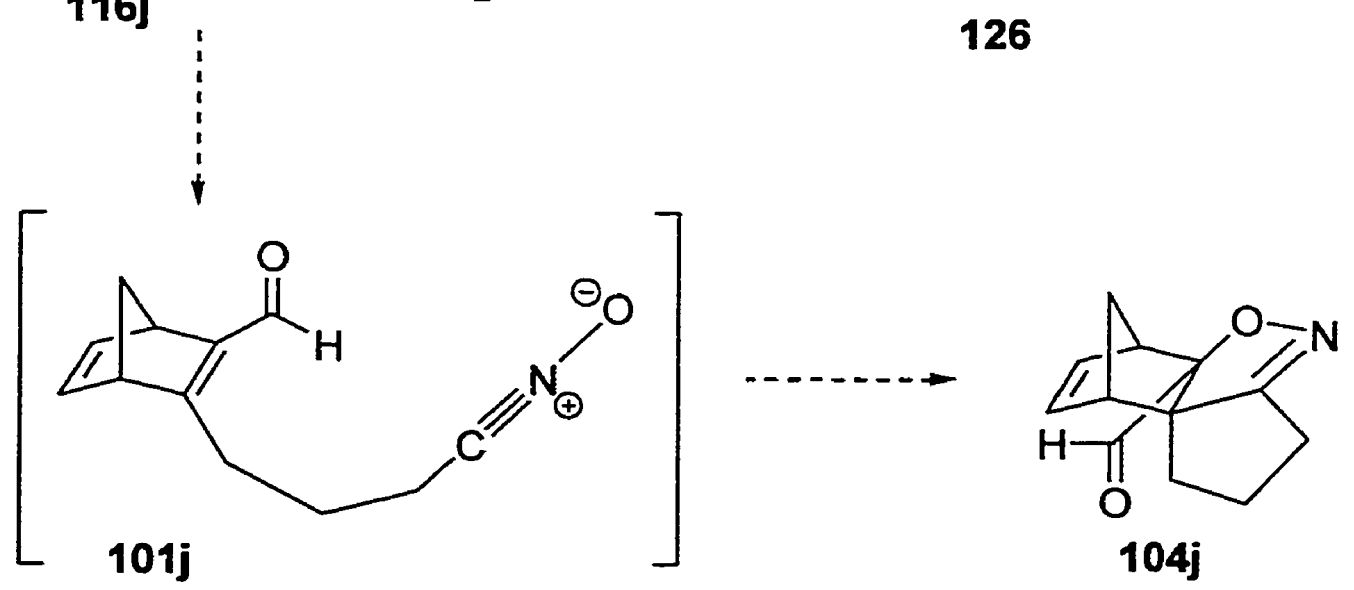

Method X

(Did Not Work) 
The two attempts to the synthesis of $\mathbf{1 1 6 j}$ which will be discussed both involve activation of the hydroxyl functionality of $\mathbf{1 2 5}$. In Scheme 74 , the norbornadienetethered alcohol $\mathbf{1 2 5}$ was activated with tosyl chloride in the presence of pyridine and $\mathrm{CH}_{2} \mathrm{Cl}_{2}$ at room temperature. The reaction occurred smoothly to give compound $\mathbf{1 2 7}$ in good yield. Lithium halide exchange of 127 was carried out, followed by trapping of the organolithium with DMF. Conditions for the reaction are shown. Unfortunately, the ${ }^{\mathrm{t}} \mathrm{H}$ NMR (200 MHz) spectrum of the crude reaction mixture only showed a mixture of the starting materials 127 and DMF.

\section{Scheme 74}<smiles>OCCCCC1=C(Br)C2C=CC1C2</smiles>

125

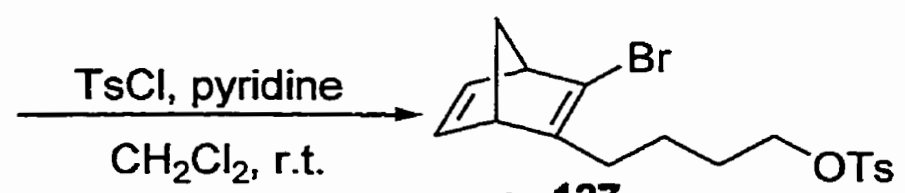

(81\%)

\section{7}

1. ${ }^{\mathrm{t}} \mathrm{BuLi}, \mathrm{THF},-78^{\circ} \mathrm{C}, 15 \mathrm{~min}$.

(Did Not Work) 2. DMF, THF, $-78^{\circ} \mathrm{C}, 4.5 \mathrm{~h}$ to r.t., $45 \mathrm{~min}$.

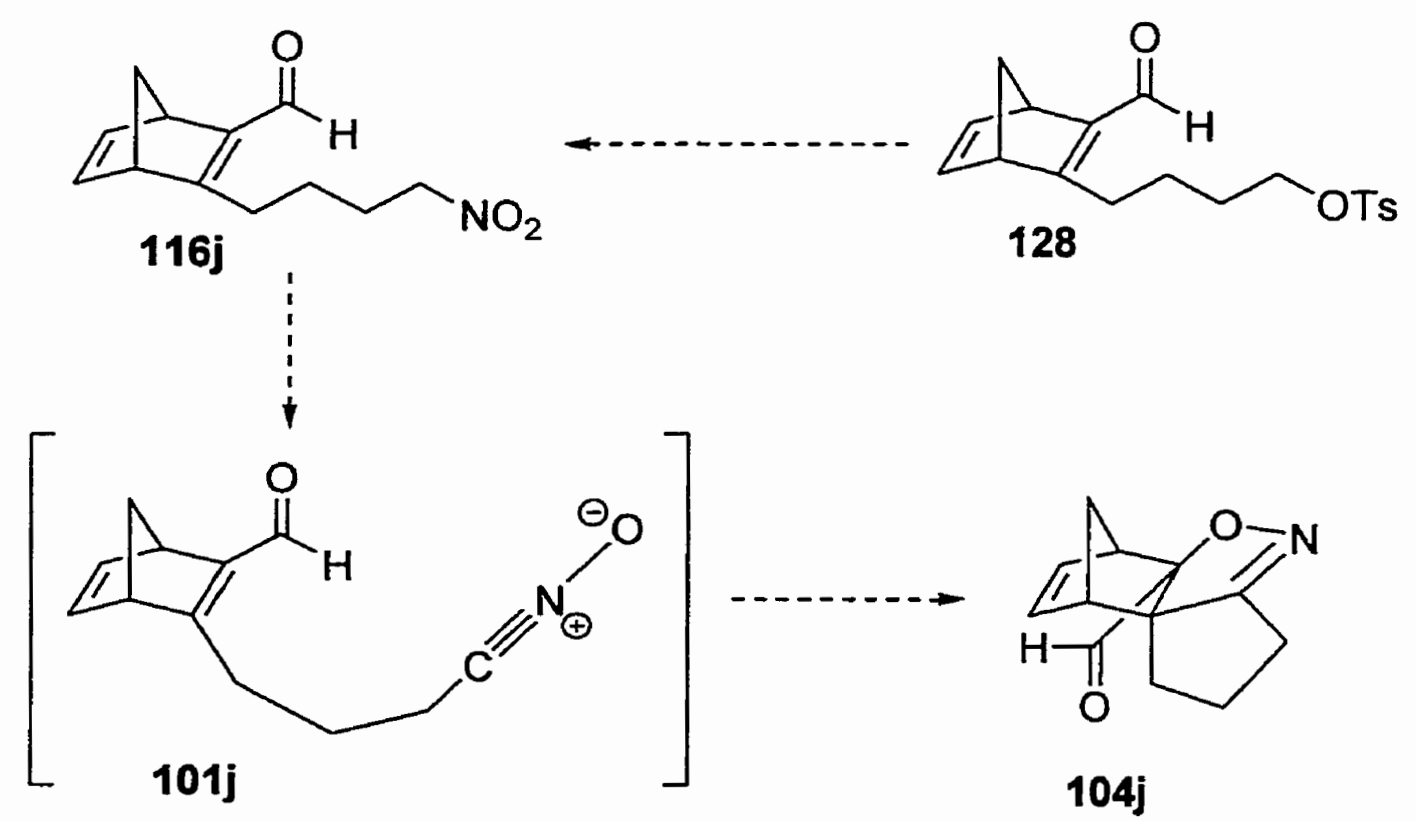


Since generation of the carbaldehyde functionality at the C-3 position of the tosylprotected compound 128 failed, another synthesis to activate the alcohol group of $\mathbf{1 2 5}$ was studied. In this route, the hydroxyl group of 125 was activated with $\mathrm{TBSCl}$ in the presence of imidazole and DMF (Scheme 75).

\section{Scheme 75}

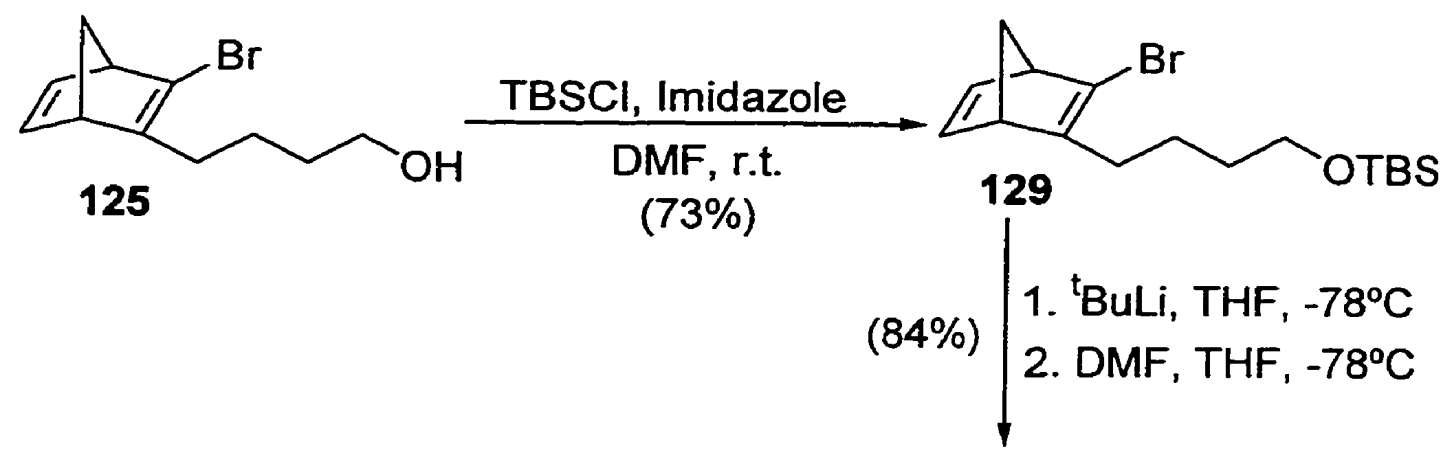<smiles>O=CC1=CCC2C=CC1C2</smiles>
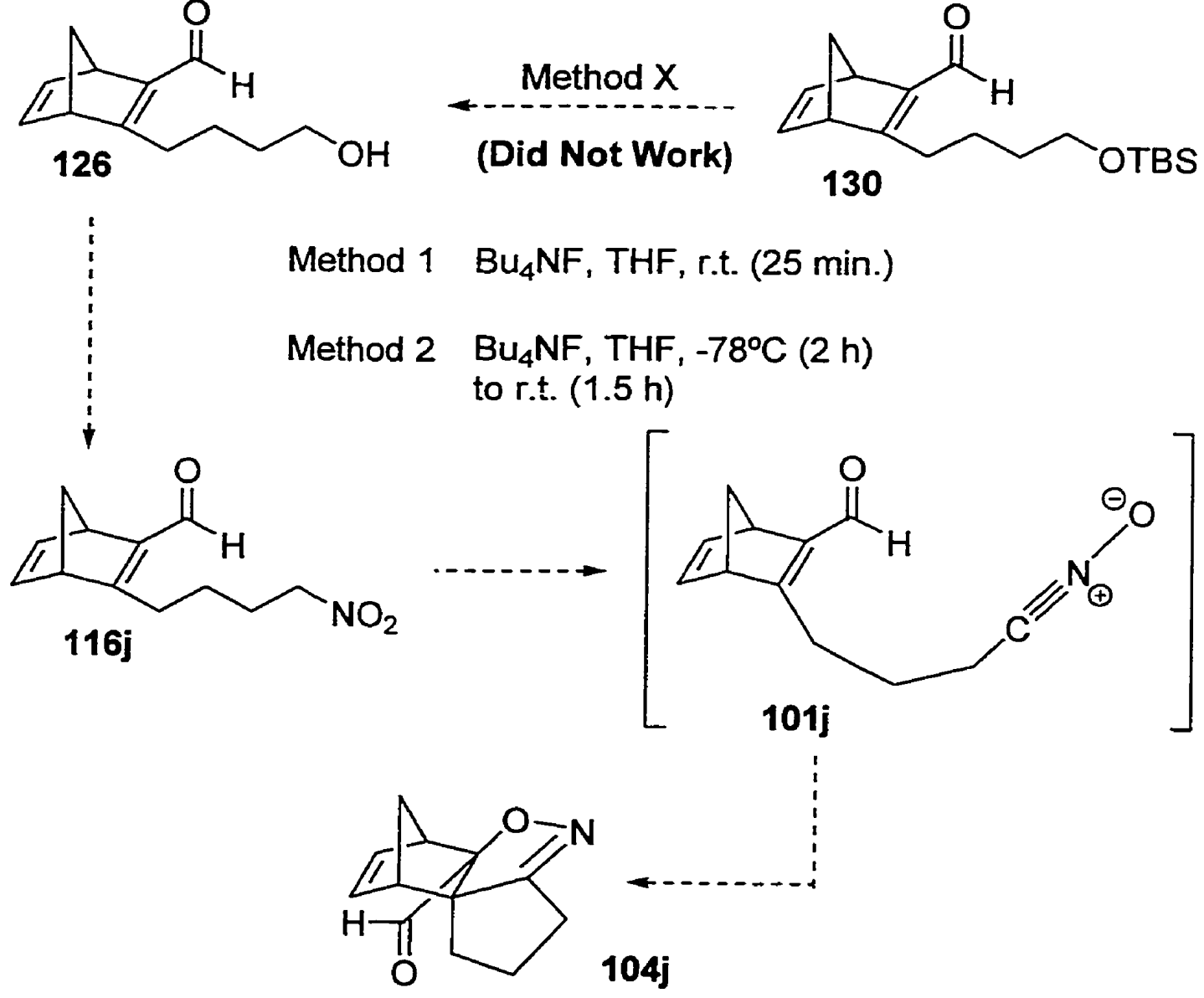
Although the reaction occurred smoothly to afford 129, the yield of the TBS-protected compound 129 was slightly lower than that achieved for the tosyl-protected analogue 127. Nevertheless, the investigation on the generation of a carbaldehyde-substituted precursor continued. Similar to the synthesis described for the tosyl-protected compound 127, lithium halide exchange of 129 was performed, followed by trapping of the organolithium with DMF. Successfully, the carbaldehyde-substituted compound 130 was obtained with a yield of $84 \%$. The TBS group was then removed to afford compound 131. Two methods were attempted. Both involved the use of tetrabutylammonium fluoride. In both cases, no product was observed from the ${ }^{1} \mathrm{H}$ NMR (200 MHz) spectrum. At this point, it was established that synthesis to tethered-norbornadiene precursors bearing a carbaldehyde functionality at the C-3 position was possible. Investigation of the conversion of $110 d$ to 131 was performed (Scheme 76). In the usual fashion, lithium halide exchange of $\mathbf{1 1 0 d}$ generated the required organolithium which was then trapped with DMF. The reaction occurred smoothly, although the yield of the reaction was low. Following the same reaction procedure which was applied to precursors with THP ether functionality, removal of the THP ether was attempted under mild acidic conditions. Unfortunately, only a mixture of products was observed from the TLC of the crude reaction mixture. 


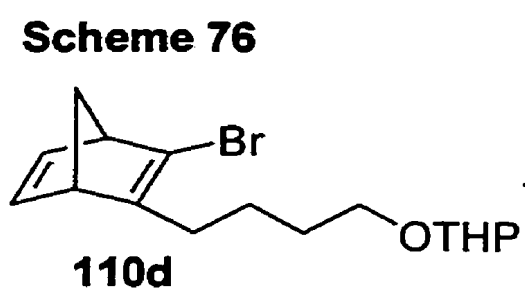

110d

$\frac{\text { 1. }{ }^{\mathrm{t}} \mathrm{BuLi}, \mathrm{THF},-78^{\circ} \mathrm{C}}{\text { 2. DMF, THF, }-78^{\circ} \mathrm{C}}$ to r.t.

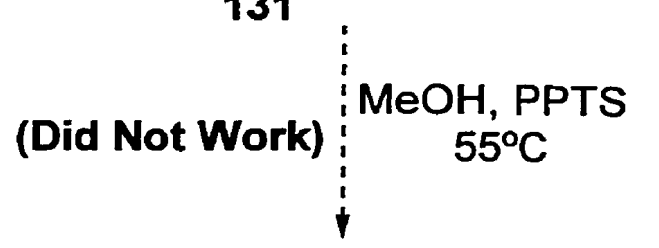<smiles>O=CC1=C(CCCC[N+](=O)[O-])C2C=CC1C2</smiles>

116j

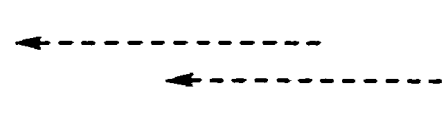




\section{Scheme 77}<smiles>COC(=O)C1=C(CCCC[OH+])C2C=CC1C2</smiles>

111i

$$
\frac{\text { DIBAL }}{\mathrm{CH}_{2} \mathrm{Cl}_{2},-78^{\circ} \mathrm{C}}
$$

(70\%)

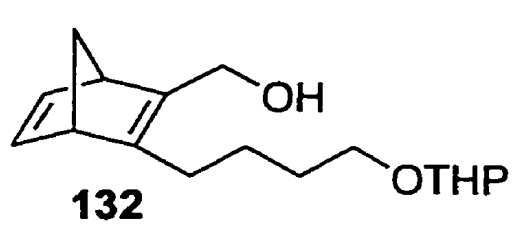

132

(78\%)
1. $\mathrm{NaH}, \mathrm{THF}$ r.t. to $30^{\circ} \mathrm{C}$

2. $\mathrm{CH}_{3}$ l, r.t.<smiles>COCC1=C(CCCCO)C2C=CC1C2</smiles>

134 (82\%) $\begin{aligned} & \mathrm{I}_{2}, \mathrm{PPh}_{3} \\ & \text { Imidazole } \\ & \mathrm{THF} / \mathrm{CH}_{3} \mathrm{CN}\end{aligned}$
MeOH, PPTS, $55^{\circ} \mathrm{C}$ $(95 \%)$

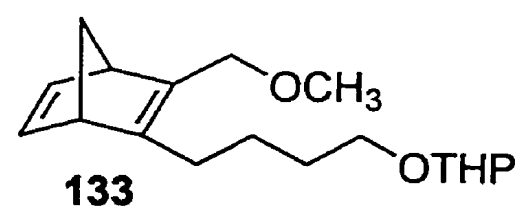<smiles>COCC1=C(CCCCI)C2C=CC1C2</smiles>

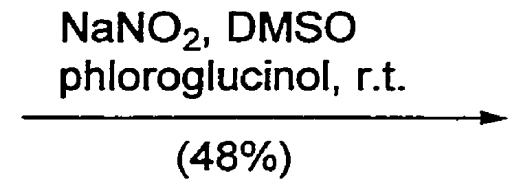

$\mathrm{NaNO}_{2}$, DMSO

phloroglucinol, r.t.

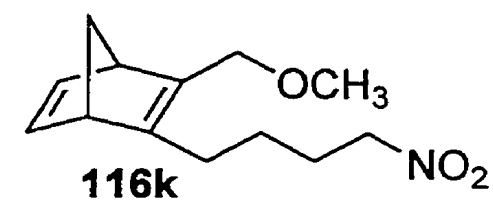

$(\mathrm{BOC})_{2} \mathrm{O}, \mathrm{DMAP}$

Toluene, $90^{\circ} \mathrm{C}$

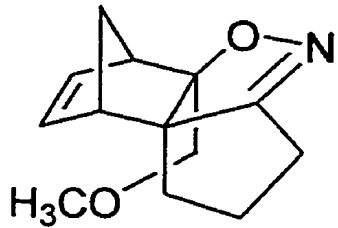

$104 k$
$(66 \%)$

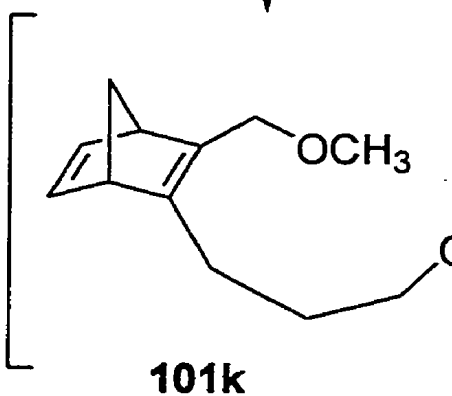

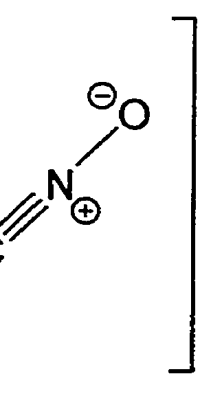


investigation on the synthesis of methoxymethyl-substituted norbornadiene-tethered nitrile oxide precursors is reported. Starting with compound 111i, reduction of the carboxylic acid methyl ester occurred smoothly to give compound 132 bearing the hydroxymethyl functionality (Scheme 77). Protection of the alcohol functionality with iodomethane generated $\mathbf{1 3 3}$ in good yield. Following the same reaction sequence shown in the synthesis of the carboxylic acid methyl ester-substituted norbornadiene-tethered nitro compound 116i, deprotection of 133 was carried out under mild acidic conditions. Since the hydroxyl functionality is a poor leaving group, 134 was not susceptible to nucleophilic substitution reaction with sodium nitrite. Thus, the hydroxyl group of 134 was first converted to 135 . Displacement of the iodide with sodium nitrite then afforded the required nitro compound 116k. Using the Hassner method, 116k was converted to the corresponding cycloadduct $104 \mathbf{k}$ with a yield of $66 \%$. Only a single regio- and stereoisomer of the cycloadduct was obtained.

\subsubsection{Identification of the Regio- and Stereochemistry of the C-3 Substituted Cycloadducts}

For cycloadducts without a C-3 substituent, the regio and stereochemistry of these adducts were confirmed by using NMR techniques. As discussed in section 2.5 .4 , the small coupling constant between $\mathrm{H}^{\mathrm{a}}$ and $\mathrm{H}^{\mathrm{b}}$ (Scheme 32 ) of cycloadducts 33 (normally $J$ $<1.5 \mathrm{~Hz}$ ) in the ${ }^{\mathrm{I}} \mathrm{H} \mathrm{NMR}$ indicated the exo stereochemistry of the cycloadducts. With a substituent at $\mathrm{C}-3(\mathrm{R} \neq \mathrm{H})$, this method of identification is no longer useful. In these 
cases, NOESY experiments were used to confirm the exo stereochemistry of the cycloadducts. Furthermore, these assignments were also supported by X-ray crystallography. An X-ray crystal structure of the cycloadduct bearing a methyl substituent at the $\mathrm{C}-3$ position was obtained. ${ }^{71}$

\subsection{Conclusions}

Results of the intramolecular 1,3-dipolar cycloadditions of C-3 substituted norbornadiene-tethered nitrile oxides are illustrated in Table 7 . In the course of studying the effects of the size of the halogen atom on cycloaddition reactions, it was found that the smaller the halogen atom used as the C-3 substituent, the higher the yield of the cycloadduct obtained. Cycloadducts bearing a bromo 104a, chloro 104b or iodo 104c substituent at the C-3 position were investigated. The highest yield was obtained for the chloro-substituted adduct $\mathbf{1 0 4 b}$ while the lowest yield was obtained for the iodo adduct 104c.

To broaden the scope of the studies, synthesis of cycloadduct precursors bearing a methyl or hexyl substituent was also investigated. The yields achieved for these two cycloadducts $104 d$ and $104 e$ were more or less the same. Since the hexyl chain is free rotating, its long chain had no effect on the cycloaddition reaction.

Cycloadduct bearing a trimethylsilane substituent $104 \mathrm{~h}$ at the $\mathrm{C}-3$ position was included in the study. Unfortunately, no cycloadduct was detected from the ${ }^{1} \mathrm{H}$ NMR spectrum. Due to the large steric bulk of this C-3 substitutent, intramolecular 
cycloaddition between the nitrile oxide and the double bond of norbornadiene was not possible.

Formation of cycloadducts bearing a carboxylic acid methyl ester functionality $104 i$ or a methoxymethyl substituent $104 k$ at the $C-3$ position also proved to be successful, giving moderate yields of the cycloadducts.

Table 7. Intramolecular 1,3-Dipolar Cycloaddition of C-3 Substituted Norbornadiene-Tethered Nitrile Oxides

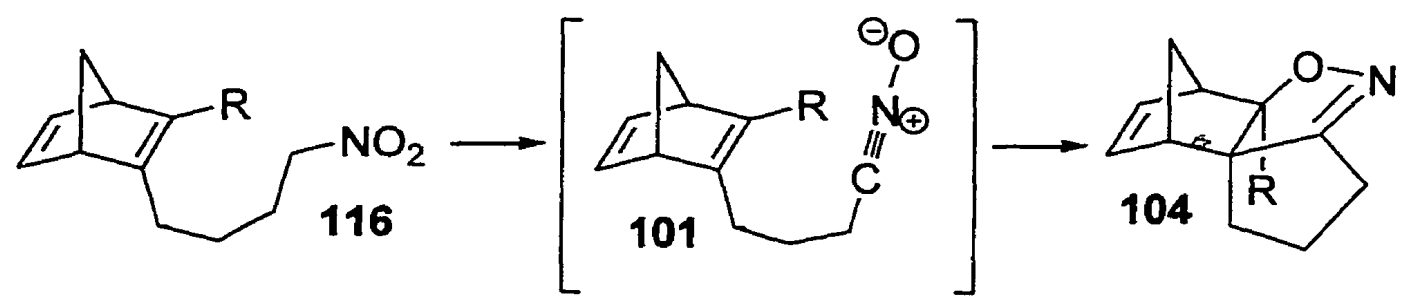

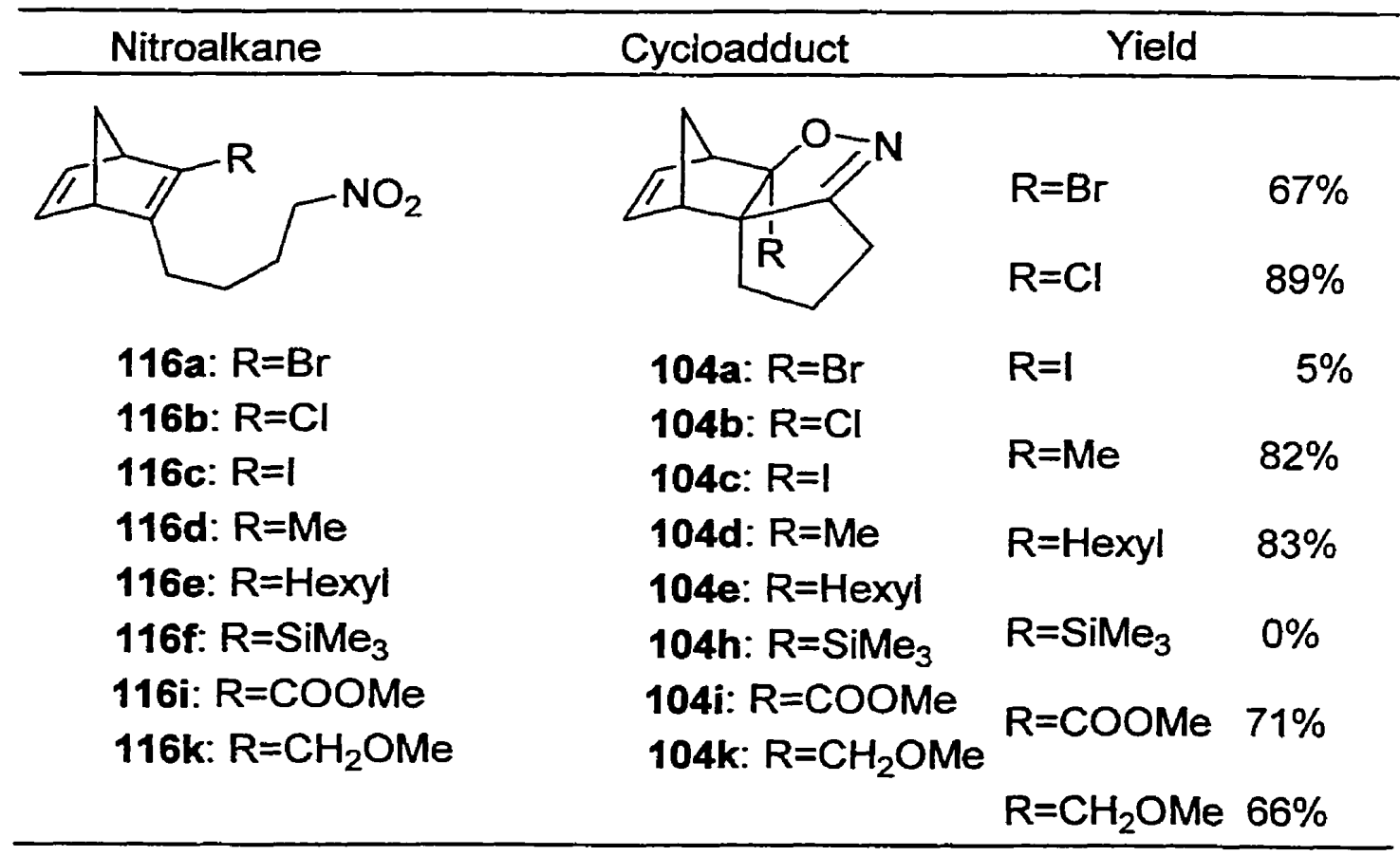




\section{Chapter 5}

\section{Experimental Procedures}




\subsection{General Procedures}

All reactions were carried out under an inert atmosphere of dry nitrogen using flame-dried glassware. Chromatographic purification refers to flash chromatograhy ${ }^{72}$ using the indicated solvent (mixture) and Silicycle silica gel ( $230-400$ mesh). $R_{f}$ values reported as $\mathrm{v} / \mathrm{v}$ with the indicated solvent (mixture) were obtained by using thin-layer chromatography (TLC) on Merck precoated silica gel $60 \mathrm{~F}_{254}$ plates. Visualization of spots on TLC plates was accomplished by the use of UV light $(250 \mathrm{~nm})$ and the plates were stained in anisaldehyde with heating. Infrared spectra were recorded on a Bomem MB-100 FTIR spectrophotometer. All NMR spectra were recorded on a Bruker-400 spectrometer. Chemical shifts were reported in parts per million (ppm) from tetramethylsilane with the solvent resonance as the internal standard. In the measurement of ${ }^{1} \mathrm{H}$ NMR chemical shifts, internal chloroform ( $\delta 7.26 \mathrm{ppm}$ ) was used as reference whereas internal deuterochloroform $(\delta 77.0 \mathrm{ppm})$ was used for ${ }^{13} \mathrm{C}$ NMR chemical shifts. High resolution mass spectra were obtained from Mass Spectrometry Laboratory Services Division at the University of Guelph. Elemental analyses were performed by Canadian Microanalytical Service Ltd., British Columbia or by Quantitative Technologies Inc., New Jersey.

Commercial reagents were used without purification unless otherwise stated. Solvents were purified by distillation under dry nitrogen prior to use: from $\mathrm{CaH}_{2}$ $\left(\mathrm{CH}_{2} \mathrm{Cl}_{2}\right.$, 1,2-dichloroethane, chloroform, DMF, Et ${ }_{3} \mathrm{~N}$, pyridine); from $4 \AA$ molecular 
sieves (DMSO); from sodium (toluene); from potassium/benzophenone (THF); and from sodium/benzophenone $\left(\mathrm{Et}_{2} \mathrm{O}\right)$.

5.2 Synthetic Procedures for Chapter 2: Intramolecular 1,3-Dipolar Cycloadditions of Norbornadiene-Tethered Nitrile Oxides

\subsubsection{Norbornadiene-Tethered Nitrile Oxides with Different Tether Lengths}

\subsubsection{Five-Membered Cycloadduct}<smiles>C1=CC2C=CC1C2</smiles>

1

$$
7
$$

32

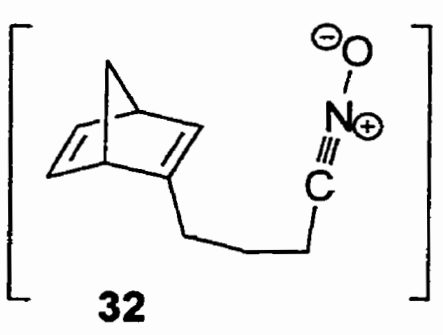

$(86 \%)$

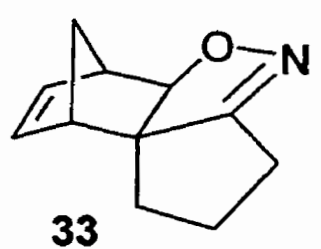

1. 'BuOK, ${ }^{\mathrm{n}} \mathrm{BuLi}$

$\frac{\mathrm{THF},-78 \text { to }-40^{\circ} \mathrm{C}}{\text { 2. 1,4-dibromobutane }}$

(80\%)<smiles>BrCCCCC1=CC2C=CC1C2</smiles>

30

$(56 \%)$

$\mathrm{NaNO}_{2}, \mathrm{DMSO}$

phloroglucinol, r.t.

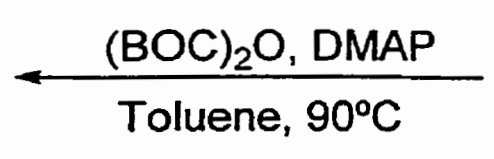

Toluene, $90^{\circ} \mathrm{C}$

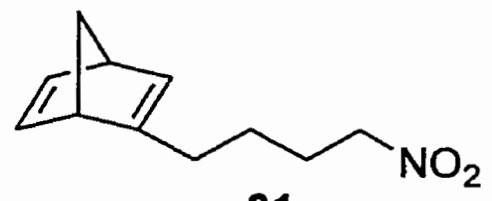

31 
Preparation of Bromide 30. Norbornadiene (1) (3.50 mL, $32.5 \mathrm{mmol}$ ) was added to a flame-dried three-necked flask containing potassium $t$-butoxide $(2.70 \mathrm{~g}, 24.0 \mathrm{mmol})$ and THF (30 mL) which was cooled at $-78^{\circ} \mathrm{C}$ (cryobath). $n$-Butyllithium $(9.60 \mathrm{~mL}, 2.5 \mathrm{M}$, $24.0 \mathrm{mmol}$ ) was added dropwise through a dropping funnel to the solution over $1 \mathrm{~h}$, maintaining the temperature below $-65^{\circ} \mathrm{C}$. The reaction mixture was stirred at $-65^{\circ} \mathrm{C}$ for $30 \mathrm{~min}$. and at $-40^{\circ} \mathrm{C}$ for $30 \mathrm{~min}$. After cooling the mixture to $-78^{\circ} \mathrm{C}$, this light brown solution was added via a cannula over $30 \mathrm{~min}$. to a cooled flask containing 1,4dibromobutane $(29)(7.64 \mathrm{~mL}, 64.0 \mathrm{mmol})$ in THF $(15 \mathrm{~mL})$ at $-65^{\circ} \mathrm{C}$. The reaction mixture was stirred at $-40^{\circ} \mathrm{C}$ for $2 \mathrm{~h}$ and at $0^{\circ} \mathrm{C}$ for $2 \mathrm{~h}$. After the reaction was quenched with saturated ammonium chloride $(50 \mathrm{~mL})$ and water $(50 \mathrm{~mL})$, the aqueous layer was extracted with diethyl ether $(3 \times 100 \mathrm{~mL})$, and the combined organic layers were washed sequentially with water $(100 \mathrm{~mL})$ and brine $(100 \mathrm{~mL})$ and dried over magnesium sulfate. The solvent was removed by rotary evaporation and the crude product was purified by vacuum distillation to give three fractions. The first fraction $\left(5-6\right.$ torr at $\left.65^{\circ} \mathrm{C}-80^{\circ} \mathrm{C}\right)$ contained mainly the excess 1,4 -dibromobutane (29). The second fraction $(1-3$ torr at $50^{\circ} \mathrm{C}-60^{\circ} \mathrm{C}$ ) contained 1,4-dibromobutane (29) and product in a ratio of $4: 1$ as determined by ${ }^{1} \mathrm{H}$ NMR. The third fraction $\left(0.8-1.0\right.$ torr at $\left.65^{\circ} \mathrm{C}-88^{\circ} \mathrm{C}\right)$ contained pure bromide 30 ( $4.37 \mathrm{~g}, 19.2 \mathrm{mmol}, 80 \%)$ as a colorless oil.

2-(4-Bromobutyl)bicyclo[2.2.1]hepta-2,5-diene (30). $R_{f} 0.83$ (EtOAc:hexanes = 1:9); IR (neat, $\mathrm{NaCl}) 3064$ (m), 2966 (s), 2934 (s), 2865 (m), 1555 (w), 1437 (m), 1306 (m), $1261(\mathrm{~m}) \mathrm{cm}^{-1} ;{ }^{1} \mathrm{H}$ NMR $\left(\mathrm{CDCl}_{3}, 400 \mathrm{MHz}\right) \delta 6.75(\mathrm{~m}, 2 \mathrm{H}), 6.15(\mathrm{~m}, 1 \mathrm{H}), 3.49$ (br. s, $1 \mathrm{H}), 3.39(\mathrm{t}, 2 \mathrm{H}, J=6.6 \mathrm{~Hz}), 3.28(\mathrm{~m}, 1 \mathrm{H}), 2.26-2.18(\mathrm{~m}, 2 \mathrm{H}), 2.07-1.92(\mathrm{~m}, 2 \mathrm{H})$, 
$1.88-1.74(\mathrm{~m}, 2 \mathrm{H}), 1.65-1.48(\mathrm{~m}, 2 \mathrm{H}) ;{ }^{13} \mathrm{C} \mathrm{NMR}\left(\mathrm{CDCl}_{3}, 100 \mathrm{MHz}\right) \delta 157.9,143.8$, $142.2,134.0,73.4,53.3,50.0,33.6,32.2,30.4,25.6$.

Conversion of Bromide 30 to Nitro Compound 31. Bromide 30 ( $4.00 \mathrm{~g}, 17.6 \mathrm{mmol})$ in DMSO $(10 \mathrm{~mL})$ was added via a cannula to a flask containing $\mathrm{NaNO}_{2}(3.01 \mathrm{~g}, 43.6$ mmol) and phloroglucinol $(3.55 \mathrm{~g}, 21.9 \mathrm{mmol})$ in DMSO $(8 \mathrm{~mL})$. The light brown reaction mixture was stirred at room temperature for $48 \mathrm{~h}$. After quenching the reaction with water $(100 \mathrm{~mL})$, the aqueous layer was extracted with diethyl ether $(4 \times 40 \mathrm{~mL})$ and the combined organic layers were washed sequentially with water $(100 \mathrm{~mL})$ and brine $(100 \mathrm{~mL})$ and dried over magnesium sulfate. The solvent was removed by rotary evaporation and the crude product was purified by column chromatography (EtOAc:hexanes $=1: 9)$ to give $31(1.91 \mathrm{~g}, 9.88 \mathrm{mmol}, 56 \%)$ as a colorless viscous oil.

2-(4-Nitrobutyl)bicyclo[2.2.1] hepta-2,5-diene (31). $R_{f} 0.40$ (EtOAc:hexanes = 1:9); IR (neat, $\mathrm{NaCl}) 3065$ (w), 2969 (s), 2933 (s), 2866 (m), 1553 (s), 1434 (m), 1382 (m), 1301 (m) $\mathrm{cm}^{-1} ;{ }^{1} \mathrm{H} \mathrm{NMR}\left(\mathrm{CDCl}_{3}, 400 \mathrm{MHz}\right) \delta 6.73(\mathrm{~m}, 2 \mathrm{H}), 6.15(\mathrm{~m}, 1 \mathrm{H}), 4.35(\mathrm{t}, 2 \mathrm{H}, J=7.0$ $\mathrm{Hz}), 3.49(\mathrm{~m}, 1 \mathrm{H}), 3.25(\mathrm{~m}, 1 \mathrm{H}), 2.24(\mathrm{~m}, 2 \mathrm{H}), 1.97-1.90(\mathrm{~m}, 4 \mathrm{H}), 1.51(\mathrm{~m}, 2 \mathrm{H}) ;{ }^{13} \mathrm{C}$ $\operatorname{NMR}\left(\mathrm{CDCl}_{3}, 100 \mathrm{MHz}\right) \delta 157.2,143.7,142.1,134.4,75.4,73.4,53.2,50.0,30.4,26.7$, 23.6. HRMS calcd. for $\mathrm{C}_{11} \mathrm{H}_{15} \mathrm{NO}_{2}: \mathrm{m} / \mathrm{z}$ 193.1103, found $\mathrm{m} / \mathrm{z}$ 193.1105. Anal. Calcd. for $\mathrm{C}_{11} \mathrm{H}_{15} \mathrm{NO}_{2}$ : C, 68.37; $\mathrm{H}, 7.82 ; \mathrm{N}, 7.25$. Found $\mathrm{C}, 68.59 ; \mathrm{H}, 7.79 ; \mathrm{N}, 7.20$. 
In situ Generation of Nitrile Oxide from Nitro Compound 31 and Subsequent Cycloaddition.

Di-tert-butyl dicarbonate, $(\mathrm{BOC})_{2} \mathrm{O}(274 \mathrm{mg}, 1.25 \mathrm{mmol})$, in toluene $(2.5 \mathrm{~mL})$ was added via a cannula to a flame-dried flask containing the nitro compound 31 (100 mg, 0.518 mmol), 4-dimethylaminopyridine, DMAP (12.4 mg, $0.101 \mathrm{mmol})$, in toluene (2.5 mL). The reaction mixture was stirred at $90^{\circ} \mathrm{C}$ for $96 \mathrm{~h}$. The solvent was removed by rotary evaporation and the crude product was purified by column chromatography (EtOAc:hexanes $=1: 9)$ to give cycloadduct $33(77.6 \mathrm{mg}, 0.443 \mathrm{mmol}, 86 \%)$ as white crystals. Recrystallization with 10\% EtOAc/hexanes provided colorless needle-like crystals.

Cycloadduct 33. $R_{f} 0.25$ (EtOAc:hexanes $\left.=1: 9\right) ; \mathrm{mp} 67.5^{\circ} \mathrm{C} ; \mathrm{IR}\left(\mathrm{CH}_{2} \mathrm{Cl}_{2}\right) 3073(\mathrm{w})$, $2979(\mathrm{~s}), 2949$ (s), 1647 (w), 1446 (w), 1430 (w), $1320(\mathrm{~m}), 1256(\mathrm{~m}), 1246(\mathrm{~m}) \mathrm{cm}^{-1} ;{ }^{1} \mathrm{H}$ $\operatorname{NMR}\left(\mathrm{CDCl}_{3}, 400 \mathrm{MHz}\right) \delta 6.27(\mathrm{dd}, 1 \mathrm{H}, J=5.7,3.0 \mathrm{~Hz}), 6.00(\mathrm{dd}, 1 \mathrm{H}, J=5.7,3.2 \mathrm{~Hz})$, $4.33(\mathrm{~s}, 1 \mathrm{H}), 3.18(\mathrm{~m}, \mathrm{IH}), 2.75$ (br. s, $1 \mathrm{H}), 2.34(\mathrm{t}, 2 \mathrm{H}, J=7.8 \mathrm{~Hz}), 2.16-1.96(\mathrm{~m}, 2 \mathrm{H})$, $1.77(\mathrm{~m}, 1 \mathrm{H}), 1.72(\mathrm{~d}, 1 \mathrm{H}, J=9.3 \mathrm{~Hz}), 1.57(\mathrm{dd}, 1 \mathrm{H}, J=9.1,1.1 \mathrm{~Hz}), 1.31$ (ddd, $1 \mathrm{H}, J=$ $12.8,7.9,2.3 \mathrm{~Hz}) ;{ }^{13} \mathrm{C} \mathrm{NMR}\left(\mathrm{CDCl}_{3}, 100 \mathrm{MHz}\right) \delta 167.5,138.0,135.3,92.6,76.2,50.5$, 46.7, 44.4, 32.0, 24.0, 20.2. HRMS calcd. for $\mathrm{C}_{\mathrm{I} 1} \mathrm{H}_{13} \mathrm{NO}$ : $\mathrm{m} / \mathrm{z} 175.0997$, found $\mathrm{m} / \mathrm{z}$ 175.0999. Anal. Calcd. for $\mathrm{C}_{11} \mathrm{H}_{13} \mathrm{NO}: \mathrm{C}, 75.40 ; \mathrm{H}, 7.48 ; \mathrm{N}, 7.99$. Found $\mathrm{C}, 75.60 ; \mathrm{H}$, $7.55 ; \mathrm{N}, 7.88$. 


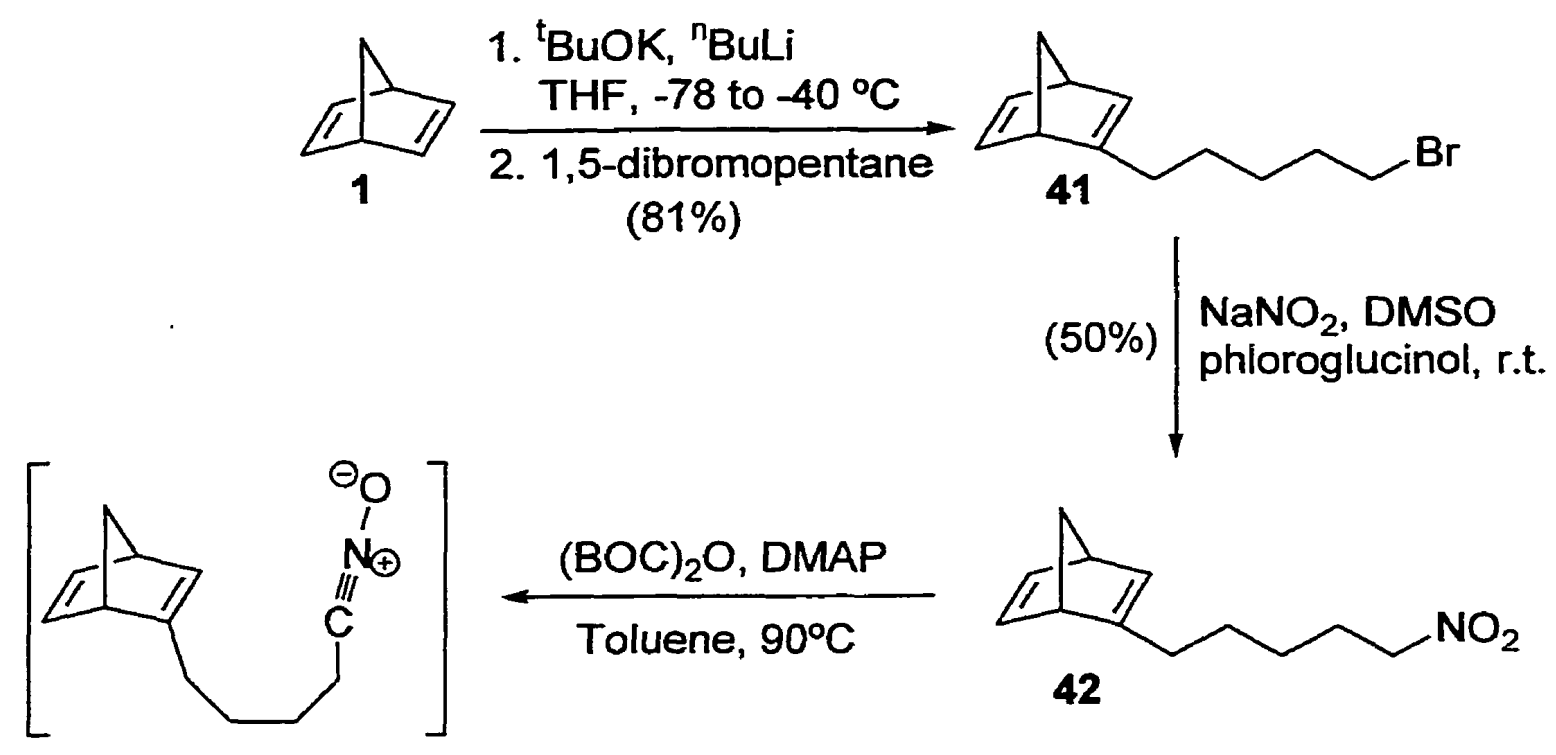

43

$(75 \%)$

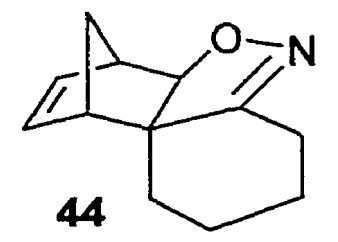

Preparation of Bromide 41. Norbornadiene (1) $(24.0 \mathrm{~mL}, 222 \mathrm{mmol})$ was added to a flame-dried three-necked flask containing potassium $t$-butoxide $(18.7 \mathrm{~g}, 167 \mathrm{mmol})$ and THF (220 mL) which was cooled at $-78^{\circ} \mathrm{C}$ (cryobath). $n$-Butyllithium $(66.8 \mathrm{~mL}, 2.5 \mathrm{M}$, $167 \mathrm{mmol}$ ) was added dropwise through a dropping funnel to the solution over $1 \mathrm{~h}$, maintaining the temperature below $-65^{\circ} \mathrm{C}$. The reaction mixture was stirred at $-65^{\circ} \mathrm{C}$ for $30 \mathrm{~min}$. and at $-40^{\circ} \mathrm{C}$ for $30 \mathrm{~min}$. After cooling the mixture to $-78^{\circ} \mathrm{C}$, this light brown solution was added via a cannula over $30 \mathrm{~min}$. to a cooled flask containing 1,5- 
dibromopentane $(100 \mathrm{~mL}, 734 \mathrm{mmol})$ in THF $(80 \mathrm{~mL})$ at $-65^{\circ} \mathrm{C}$. The reaction mixture was stirred at $-40^{\circ} \mathrm{C}$ for $2 \mathrm{~h}$ and at $0^{\circ} \mathrm{C}$ for $2 \mathrm{~h}$. After the reaction was quenched with saturated ammonium chloride $(200 \mathrm{~mL})$ and water $(200 \mathrm{~mL})$, the aqueous layer was extracted with diethyl ether $(3 \times 300 \mathrm{~mL})$, and the combined organic layers were washed sequentially with water $(400 \mathrm{~mL})$ and brine $(400 \mathrm{~mL})$ and dried over magnesium sulfate. The solvent was removed by rotary evaporation and the crude product was purified by vacuum distillation to give three fractions. The first fraction $\left(3-5\right.$ torr at $\left.65^{\circ} \mathrm{C}-80^{\circ} \mathrm{C}\right)$ contained mainly the excess 1,5 -dibromopentane. The second fraction $\left(1-3\right.$ torr at $60^{\circ} \mathrm{C}$ $-70^{\circ} \mathrm{C}$ ) contained 1,5 -dibromopentane and product in a ratio of $3: 1$ as determined by ${ }^{1} \mathrm{H}$ NMR. The third fraction $\left(0.2-0.8\right.$ torr at $\left.70^{\circ} \mathrm{C}-85^{\circ} \mathrm{C}\right)$ contained pure bromide $41(32.5$ $\mathrm{g}, 135 \mathrm{mmol}, 81 \%)$ as a colorless oil.

2-(5-Bromopentyl)bicyclo[2.2.1]hepta-2,5-diene (41). $R_{f} 0.65$ (hexanes); IR (neat, $\mathrm{NaCl}) 3117$ (w), 3064 (w), 2966 (s), 2933 (s), 2863 (m), 1622 (w), 1555 (w), $1460(w)$, $1430(w), 1301$ (m), 1262 (w), 1246 (w), $1184(w) \mathrm{cm}^{-1} ;{ }^{\mathrm{l}} \mathrm{H} \mathrm{NMR}\left(\mathrm{CDCl}_{3}, 400 \mathrm{MHz}\right) \delta$ $6.75(\mathrm{~m}, 2 \mathrm{H}), 6.13(\mathrm{~m}, 1 \mathrm{H}), 3.49(\mathrm{~m}, 1 \mathrm{H}), 3.40(\mathrm{t}, 2 \mathrm{H}, J=6.8 \mathrm{~Hz}), 3.27(\mathrm{~m}, 1 \mathrm{H}), 2.20(\mathrm{~m}$, $2 \mathrm{H}), 1.98(\mathrm{dt}, 1 \mathrm{H}, J=5.7,1.5 \mathrm{~Hz})=1.94(\mathrm{dm}, 1 \mathrm{H}, J=5.7 \mathrm{~Hz}), 1.85(\mathrm{~m}, 2 \mathrm{H}), 1.48-1.36$ $(\mathrm{m}, 4 \mathrm{H}) ;{ }^{13} \mathrm{C} \mathrm{NMR}\left(\mathrm{CDCl}_{3}, 100 \mathrm{MHz}\right) \delta 158.5,143.8,142.3,133.6,73.5,53.4,50.0$, 33.9, 32.7, 31.2, 27.8, 26.3. HRMS calcd. for $\mathrm{C}_{12} \mathrm{H}_{17} \mathrm{Br}$ : $\mathrm{m} / \mathrm{z} 240.0514$, found $\mathrm{m} / \mathrm{z}$ 240.0516 .

Conversion of Bromide 41 to Nitro Compound 42. Bromide 41 (2.03 g, $8.42 \mathrm{mmol}$ ) in DMSO $(2.5 \mathrm{~mL})$ was added via a cannula to a flask containing $\mathrm{NaNO}_{2}(2.06 \mathrm{~g}, 29.9$ mmol) and phloroglucinol $(1.81 \mathrm{~g}, 11.2 \mathrm{mmol})$ in DMSO $(3.5 \mathrm{~mL})$. The light brown 
reaction mixture was stirred at room temperature for $48 \mathrm{~h}$. After quenching the reaction with water $(40 \mathrm{~mL})$, the aqueous layer was extracted with diethyl ether $(4 \times 40 \mathrm{~mL})$ and the combined organic layers were washed sequentially with water $(80 \mathrm{~mL})$ and brine (80 $\mathrm{mL}$ ) and dried over magnesium sulfate. The solvent was removed by rotary evaporation and the crude product was purified by column chromatography (EtOAc:hexanes = 1:19) to give 42 (866 mg, $4.18 \mathrm{mmol}, 50 \%$ ) as a colorless viscous oil.

2-(5-Nitropentyl)bicyclo[2.2.1] hepta-2,5-diene (42). $R_{f} 0.43$ (EtOAc:hexanes = 1:19); IR (neat, $\mathrm{NaCl}) 3065$ (w), $2969(\mathrm{~m}), 2932(\mathrm{~m}), 2864(\mathrm{~m}), 1553(\mathrm{~s}), 1461(\mathrm{w}), 1435(\mathrm{~m})$, $1383(\mathrm{~m}), 1301(\mathrm{~m}), 1185(\mathrm{w}) \mathrm{cm}^{-1} ;{ }^{1} \mathrm{H} \mathrm{NMR}\left(\mathrm{CDCl}_{3}, 400 \mathrm{MHz}\right) \delta 6.73(\mathrm{~m}, 2 \mathrm{H}), 6.12$ $(\mathrm{m}, 1 \mathrm{H}), 4.35(\mathrm{t}, 2 \mathrm{H}, J=7.0 \mathrm{~Hz}), 3.48(\mathrm{~m}, 1 \mathrm{H}), 3.25(\mathrm{~m}, 1 \mathrm{H}), 2.20(\mathrm{~m}, 2 \mathrm{H}), 2.02-1.92$ $(\mathrm{m}, 4 \mathrm{H}), 1.46(\mathrm{~m}, 2 \mathrm{H}), 1.33(\mathrm{~m}, 2 \mathrm{H}) ;{ }^{13} \mathrm{C} \mathrm{NMR}\left(\mathrm{CDCl}_{3}, 100 \mathrm{MHz}\right) \delta 157.9,143.7,142.1$, $133.8,75.5,73.4,53.3,49.9,30.9,27.1,26.2,25.7$. HRMS calcd. for $\mathrm{C}_{12} \mathrm{H}_{17} \mathrm{NO}_{2}: \mathrm{m} / \mathrm{z}$ 207.1259, found $\mathrm{m} / \mathrm{z}$ 207.1258. Anal. Calcd. for $\mathrm{C}_{\mathrm{l} 2} \mathrm{H}_{17} \mathrm{NO}_{2}: \mathrm{C}, 69.54 ; \mathrm{H}, 8.27 ; \mathrm{N}, 6.76$. Found C, 69.39; H, 8.29; N, 6.79.

In situ Generation of Nitrile Oxide from Nitro Compound 42 and Subsequent Cycloaddition.

Di-tert-butyl dicarbonate, $(\mathrm{BOC})_{2} \mathrm{O}(333 \mathrm{mg}, 1.53 \mathrm{mmol})$, in toluene $(2.5 \mathrm{~mL})$ was added via a cannula to a flame-dried flask containing the nitro compound 42 (129 mg, 0.621 mmol), 4-dimethylaminopyridine, DMAP (12.3 $\mathrm{mg}, 0.101 \mathrm{mmol})$, in toluene $(2.5 \mathrm{~mL})$. The reaction mixture was stirred at $90^{\circ} \mathrm{C}$ for $65 \mathrm{~h}$. The solvent was removed by rotary evaporation and the crude product was purified by column chromatography 
(EtOAc:hexanes $=1: 9)$ to give cycloadduct $44(88.5 \mathrm{mg}, 0.468 \mathrm{mmol}, 75 \%$ ) as a colorless viscous oil.

Cycloadduct 44. $R_{f} 0.23$ (EtOAc:hexanes = 1:9); IR (neat, $\mathrm{NaCl}$ ) $3062(\mathrm{w}), 2975(\mathrm{~s})$, $2936(\mathrm{~s}), 2859(\mathrm{~m}), 1626(\mathrm{w}), 1448(\mathrm{~m}), 1354(\mathrm{w}), 1326(\mathrm{~m}), 1255(\mathrm{w}), 1232(\mathrm{w}), 1148$ (w), 1049 (w) $\mathrm{cm}^{-1} ;{ }^{1} \mathrm{H} \mathrm{NMR}\left(\mathrm{CDCl}_{3}, 400 \mathrm{MHz}\right) \delta 6.29(\mathrm{dd}, 1 \mathrm{H}, J=5.8,3.0 \mathrm{~Hz}), 5.97$ (dd, $1 \mathrm{H}, J=5.7,3.2 \mathrm{~Hz}), 4.02(\mathrm{t}, 1 \mathrm{H}, J=1.3 \mathrm{~Hz}), 3.16(\mathrm{~m}, 1 \mathrm{H}), 2.90(\mathrm{~m}, 1 \mathrm{H}), 2.59(\mathrm{dm}$, $1 \mathrm{H}, J=13.6 \mathrm{~Hz}), 2.08(\mathrm{td}, 1 \mathrm{H}, J=13.3,5.3 \mathrm{~Hz}), 1.98(\mathrm{~m}, 1 \mathrm{H}), 1.72-1.65(\mathrm{~m}, 2 \mathrm{H}), 1.61$ $-1.52(\mathrm{~m}, 3 \mathrm{H}), 1.49-1.40(\mathrm{~m}, 2 \mathrm{H}) ;{ }^{13} \mathrm{C} \mathrm{NMR}\left(\mathrm{CDCl}_{3}, 100 \mathrm{MHz}\right) \delta 160.8,137.9,133.9$, $90.9,67.8,50.7,44.7,44.3,36.7,27.4,23.8,22.6$. HRMS calcd. for $\mathrm{C}_{12} \mathrm{H}_{15} \mathrm{NO}: \mathrm{m} / \mathrm{z}$ 189.1154, found $\mathrm{m} / \mathrm{z} 189.1159$ 
5.2.2.1 Six-Membered Cycloadduct Bearing a $\alpha$-Silyl Ether Substituent

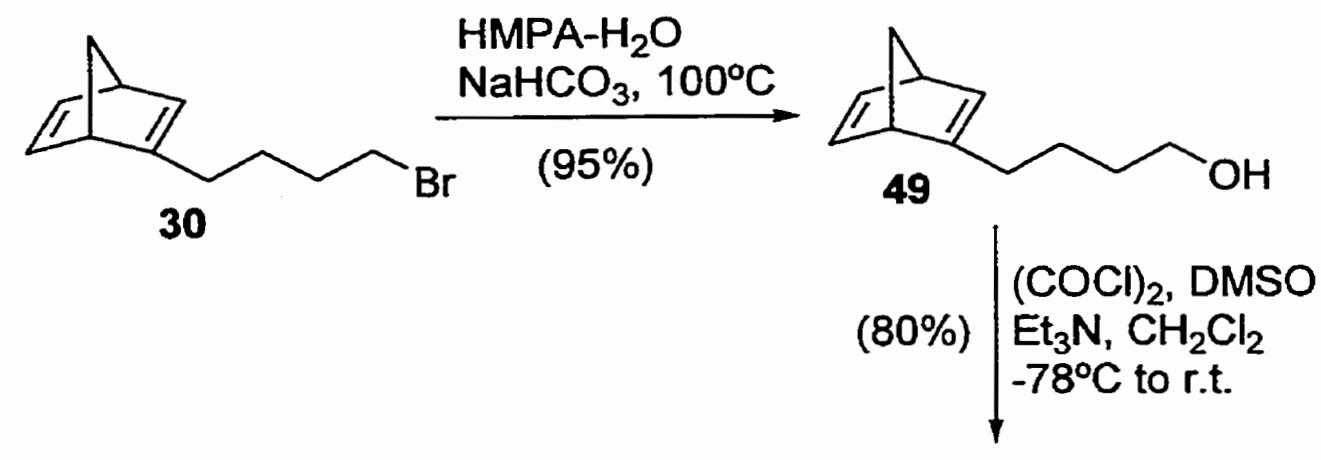<smiles>O=[N+]([O-])C[C@@H](O)CCCC1=CC2C=CC1C2</smiles>

51

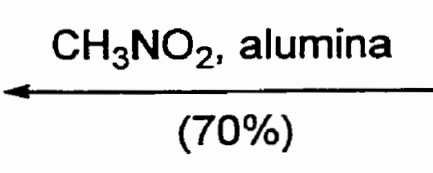

$(70 \%)$<smiles>O=CCCCC1=CC2C=CC1C2[Sb](=O)(=O)[O-]</smiles>

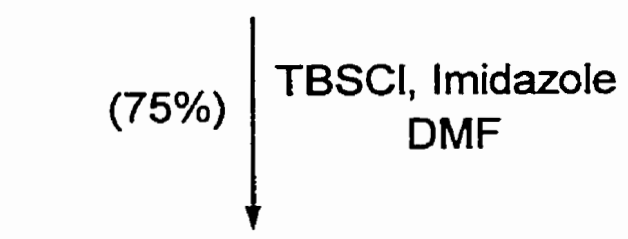<smiles>[R5][OH+]C(CCCC1=CC2C=CC1C2)C[N+](=O)[O-]</smiles>

52

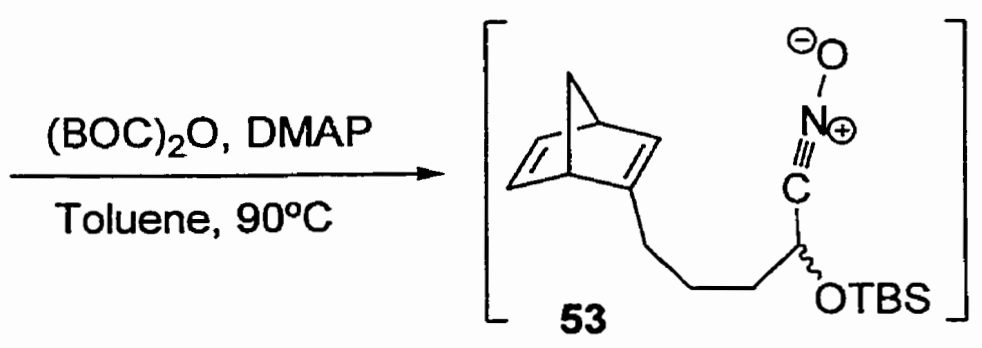

$(78 \%)$

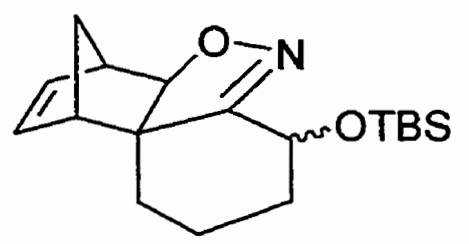

54 
Preparation of Alcohol 49. HMPA (187 mL), water $(33 \mathrm{~mL})$ and sodium bicarbonate ( $7.50 \mathrm{~g}, 89.3 \mathrm{mmol})$ were added to a flask containing bromide 30 (10.1 g, $44.4 \mathrm{mmol})$. The reaction mixture was stirred at $100^{\circ} \mathrm{C}$ for $36 \mathrm{~h}$. After quenching the reaction with water $(500 \mathrm{~mL})$, the aqueous layer was extracted with diethyl ether $(4 \times 400 \mathrm{~mL})$, and the combined organic layers were washed sequentially with water $(500 \mathrm{~mL})$ and brine $(500$ $\mathrm{mL}$ ) and dried over magnesium sulfate. The solvent was removed by rotary evaporation and the crude product was purified by vacuum distillation $\left(0.2\right.$ torr at $\left.90^{\circ} \mathrm{C}\right)$ to give alcohol $49(6.93 \mathrm{~g}, 42.2 \mathrm{mmol}, 95 \%)$ as a colorless oil.

4-(Bicyclo[2.2.1]hepta-2,5-dien-2-yl)butan-1-ol (49). ${ }^{1} \mathrm{H}$ and ${ }^{13} \mathrm{C}$ NMR spectral data were identical to those reported in the literature. ${ }^{73}$

Oxidation of Alcohol 49 to Aldehyde 50. DMSO (5.00 mL, $70.5 \mathrm{mmol}$ ) was added dropwise to a flame-dried flask containing oxalyl chloride $(3.30 \mathrm{~mL}, 37.8 \mathrm{mmol})$ and $\mathrm{CH}_{2} \mathrm{Cl}_{2}(60 \mathrm{~mL})$ at $-78^{\circ} \mathrm{C}$. Five minutes after the addition, alcohol $49(5.13 \mathrm{~g}, 31.2$ $\mathrm{mmol})$ in $\mathrm{CH}_{2} \mathrm{Cl}_{2}(30 \mathrm{~mL})$ was added via a cannula at $-78^{\circ} \mathrm{C}$. The reaction mixture was stirred for $30 \mathrm{~min}$. at $-78^{\circ} \mathrm{C}$. Triethylamine $(21.0 \mathrm{~mL}, 150.7 \mathrm{mmol})$ was then added and the reaction mixture was stirred at room temperature for $2 \mathrm{~h}$. After quenching the reaction with water $(80 \mathrm{~mL})$, the aqueous layer was extracted with diethyl ether $(3 \times 100$ $\mathrm{mL})$, and the combined organic layers were washed sequentially with water $(100 \mathrm{~mL})$ and brine $(100 \mathrm{~mL})$ and dried over magnesium sulfate. The solvent was removed by rotary evaporation and the crude product was purified by vacuum distillation $\left(1-2\right.$ torr at $75^{\circ} \mathrm{C}$ $\left.-85^{\circ} \mathrm{C}\right)$ to give aldehyde $50(4.05 \mathrm{~g}, 25.0 \mathrm{mmol}, 80 \%)$ as a colorless oil. 
4-(Bicyclo[2.2.1]hepta-2,5-dien-2-yl)butanal (50). ${ }^{\mathrm{L}} \mathrm{H}$ and ${ }^{13} \mathrm{C}$ NMR spectral data were identical to those reported in the literature. ${ }^{73}$

Conversion of Aldehyde 50 to Nitroalcohol 51. Nitromethane (0.05 mL, $0.923 \mathrm{mmol})$ was added to a flask containing aldehyde $50(120 \mathrm{mg}, 0.738 \mathrm{mmol})$ at $0^{\circ} \mathrm{C} .^{74}$ Dry alumina was added at $0^{\circ} \mathrm{C}$ and the reaction mixture was stirred for $3 \mathrm{~h}$ and allowed to stand at room temperature for $24 \mathrm{~h}$. Column chromatography (EtOAc:hexanes $=1: 4$ ) provided 51 (115 mg, $0.520 \mathrm{mmol}, 70 \%)$ as a colorless viscous oil.

5-(Bicyclo[2.2.1]hepta-2,5-dien-2-yl)-1-nitropentan-2-ol (51). $R_{f} 0.50$ (EtOAc:hexanes = 1:4); IR (neat, $\mathrm{NaCl}) 3536(\mathrm{~m}), 3437$ (m), 3064 (w), 2971 (s), 2934 (s), 2865 (m), 1621 (w), 1555 (s), 1457 (w), $1422(\mathrm{~m}), 1384(\mathrm{~m}), 1301(\mathrm{~m}), 1097(\mathrm{~m}) \mathrm{cm}^{-1} ;{ }^{\mathrm{l}} \mathrm{H} \mathrm{NMR}\left(\mathrm{CDCl}_{3}\right.$, $400 \mathrm{MHz}) \delta 6.74(\mathrm{~m}, 2 \mathrm{H}), 6.15(\mathrm{~m}, 1 \mathrm{H}), 4.42-4.29(\mathrm{~m}, 3 \mathrm{H}), 3.50(\mathrm{~m}, 1 \mathrm{H}), 3.27(\mathrm{~m}, 1 \mathrm{H})$ $2.63(\mathrm{~m}, 1 \mathrm{H}), 2.22(\mathrm{~m}, 2 \mathrm{H}), 1.95(\mathrm{~m}, 2 \mathrm{H}), 1.55-1.39(\mathrm{~m}, 4 \mathrm{H}) ;{ }^{13} \mathrm{C} \mathrm{NMR}\left(\mathrm{CDCl}_{3}, 100\right.$ $\mathrm{MHz}) \delta 157.8,143.9,143.8,142.22,142.18,134.18,134.16,80.57,80.56,73.5,68.45$, $68.41,53.34,53.33,50.0,33.2,33.1,30.93,30.88,22.62,22.59$. HRMS calcd. for $\mathrm{C}_{12} \mathrm{H}_{17} \mathrm{NO}_{3}: \mathrm{m} / \mathrm{z} 223.1208$, found $\mathrm{m} / \mathrm{z} 223.1204$.

Conversion of Nitroalcohol 51 to Nitro Compound 52. To a flame-dried flask containing nitroalcohol 51 (103 $\mathrm{mg}, 0.460 \mathrm{mmol})$ in DMF (1 mL), imidazole $(56.0 \mathrm{mg}$, $0.823 \mathrm{mmol}$ ) and tert-butyldimethylsilyl chloride (104 $\mathrm{mg}, 0.690 \mathrm{mmol}$ ) were added at room temperature. The reaction mixture was stirred at room temperature for $18 \mathrm{~h}$. After quenching the reaction with water $(10 \mathrm{~mL})$, the aqueous layer was extracted with $1: 9$ $\mathrm{CH}_{2} \mathrm{Cl}_{2} /$ hexanes $(3 \times 20 \mathrm{~mL})$, and the combined organic layers were washed sequentially 
with water $(20 \mathrm{~mL})$ and brine $(20 \mathrm{~mL})$ and dried over magnesium sulfate. The solvent was removed by rotary evaporation and the crude product was purified by column chromatography (EtOAc:hexanes $=1: 19)$ to give $52(116 \mathrm{mg}, 0.344 \mathrm{mmol}, 75 \%)$ as a colorless oil.

TBS-Protected Alcohol-containing Nitro Compound (52). $R_{f} 0.43$ (EtOAc:hexanes $=$ 1:19); IR (neat, $\mathrm{NaCl}) 3066$ (w), 2958 (s), 2932 (s), 2859 (m), 1557 (s), 1472 (w), 1463 (w), $1386(w), 1362(w), 1301(w), 1258(\mathrm{~m}), 1112(\mathrm{~m}), 1021(\mathrm{w}) \mathrm{cm}^{-1} ;{ }^{1} \mathrm{H} \mathrm{NMR}\left(\mathrm{CDCl}_{3}\right.$; $400 \mathrm{MHz}) \delta 6.74(\mathrm{~m}, 2 \mathrm{H}), 6.14(\mathrm{~m}, 1 \mathrm{H}), 4.39-4.30(\mathrm{~m}, 3 \mathrm{H}), 3.50(\mathrm{~m}, 1 \mathrm{H}), 3.26(\mathrm{~m}, 1 \mathrm{H})$, $2.20(\mathrm{~m}, 2 \mathrm{H}), 1.96(\mathrm{~m}, 2 \mathrm{H}), 1.55-1.41(\mathrm{~m}, 4 \mathrm{H}), 0.85(\mathrm{~s}, 9 \mathrm{H}), 0.06(\mathrm{~s}, 3 \mathrm{H}), 0.01(\mathrm{~s}, 3 \mathrm{H})$ ${ }^{13} \mathrm{C} \mathrm{NMR}\left(\mathrm{CDCl}_{3}, 100 \mathrm{MHz}\right) \delta 157.7,153.6,143.84,143.80,142.15,142.09,134.2$, $134.1,81.01,80.99,73.5,70.0,69.9,53.3,50.0,34.7,34.6,31.2,31.1,25.6,22.4,22.1$, 17.8, -4.7, -5.2, -5.3. HRMS calcd. for $\mathrm{C}_{18} \mathrm{H}_{31} \mathrm{SiNO}_{3}: \mathrm{m} / \mathrm{z} 337.2073$, found $\mathrm{m} / \mathrm{z}$ 337.2078 .

In situ Generation of Nitrile Oxide from Nitro Compound 52 and Subsequent Cycloaddition.

Di-tert-butyl dicarbonate, $(\mathrm{BOC})_{2} \mathrm{O}(55.0 \mathrm{mg}, 0.252 \mathrm{mmol})$, in toluene $(0.5 \mathrm{~mL})$ was added via a cannula to a flame-dried flask containing the nitro compound $52(35.0 \mathrm{mg}$, $0.104 \mathrm{mmol})$, 4-dimethylaminopyridine, DMAP (2.5 $\mathrm{mg}, 0.020 \mathrm{mmol})$, in toluene $(0.5$ $\mathrm{mL}$ ). The reaction mixture was stirred at $90^{\circ} \mathrm{C}$ for $18 \mathrm{~h}$. The solvent was removed by rotary evaporation and the crude product was purified by column chromatography (EtOAc:hexanes $=1: 19$ ) to give two separable diastereomers of exo cycloadducts 54a 
(14.8 $\mathrm{mg}, 0.0463 \mathrm{mmol})$ and $54 \mathrm{~b}(11.0 \mathrm{mg}, 0.0344 \mathrm{mmol})$ with a combined yield of $78 \%$ (25.8 $\mathrm{mg}, 0.0807 \mathrm{mmol}$ ) as colorless viscous oils.

Cycloadduct 54a. $R_{f} 0.31$ (EtOAc:hexanes =1:19); IR (neat, NaCl) 3064 (w), 2934 (s), 2857 (m), 1555 (w), 1361 (w), 1257 (m), 1115 (m), 1063 (m), 1027 (m) $\mathrm{cm}^{-1}$; 'H NMR $\left(\mathrm{CDCl}_{3}, 400 \mathrm{MHz}\right) \delta 6.34(\mathrm{dd}, 1 \mathrm{H}, J=5.7,3.0 \mathrm{~Hz}), 6.00(\mathrm{dd}, 1 \mathrm{H}, J=5.7,3.2 \mathrm{~Hz}), 4.68$ (t, $1 \mathrm{H}, J=2.4 \mathrm{~Hz}), 4.07$ (s, 1H), 3.36 (br. s, $1 \mathrm{H}), 3.20$ (t, $1 \mathrm{H}, J=1.4 \mathrm{~Hz}), 2.07-1.94$ (m, 2H), $1.73-1.46$ (m, 4H), 0.89 (br. s, 9H), 0.10 (br. s, 3H), 0.06 (br. s, 3H); ${ }^{13} \mathrm{CNMR}$ $\left(\mathrm{CDCl}_{3}, 100 \mathrm{MHz}\right) \delta 160.4,138.8,134.0,92.2,67.1,64.7,50.7,46.6,44.6,37.1,36.2$, $25.7,17.7,-5.0,-5.2$.

Cycloadduct 54b. $R_{f} 0.23$ (EtOAc:hexanes = 1:19); $\mathbb{R}$ (neat, $\mathrm{NaCl}$ ) $3064(\mathrm{w}), 2934$ (s), 2857 (m), 1555 (w), 1361 (w), 1257 (m), 1115 (m), 1063 (m), 1027 (m) cm ; ${ }^{-1}{ }^{1}$ NMR $\left(\mathrm{CDCl}_{3}, 400 \mathrm{MHz}\right) \delta 6.29(\mathrm{dd}, 1 \mathrm{H}, J=5.7,3.0 \mathrm{~Hz}), 6.01(\mathrm{dd}, 1 \mathrm{H}, J=5.7,3.2 \mathrm{~Hz}), 4.43-$ 4.39 (m, 1H), $4.14-4.13(\mathrm{~m}, 1 \mathrm{H}), 3.22$ (t, $1 \mathrm{H}, J=1.4 \mathrm{~Hz}), 2.85(\mathrm{~m}, 1 \mathrm{H}), 2.17(\mathrm{~m}, 1 \mathrm{H})$, $1.80-1.59(\mathrm{~m}, 4 \mathrm{H}), 1.42(\mathrm{~m}, 1 \mathrm{H}), 0.94$ (br. s, 1H), 0.91 (m, 8H), 0.14 (br. s, 3H), 0.09 (m, 3H); ${ }^{13} \mathrm{C} \mathrm{NMR}\left(\mathrm{CDCl}_{3}, 100 \mathrm{MHz}\right) \delta 162.1,137.8,134.2,91.8,69.4,68.4,50.9,45.3$, $44.4,38.1,36.2,25.8,22.1,-4.9,-5.4$. 


\subsubsection{Five-Membered Cycloadduct Bearing an Oxygen Within the Tether}

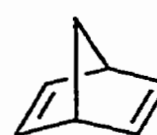

1

1. ${ }^{\mathrm{B}} \mathrm{BuOK},{ }^{\mathrm{n}} \mathrm{BuLi}$

THF, -78 to $-40^{\circ} \mathrm{C}$

2. $\mathrm{LiBr}$

3. paraformaldehyde

$(57 \%)$

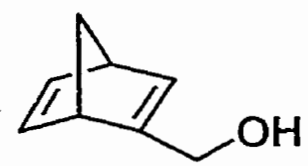

62

$(66 \%) \mid \begin{gathered}\mathrm{Cl}_{6 \mathbf{6 3}} \\ \mathrm{Bu}_{4} \mathrm{NBr}, \mathrm{NaOH} \\ 70^{\circ} \mathrm{C}\end{gathered}$<smiles>OCCOCC1=CC2C=CC1C2</smiles>

$\mathrm{MeOH}, \mathrm{PPTS}, 55^{\circ} \mathrm{C}$

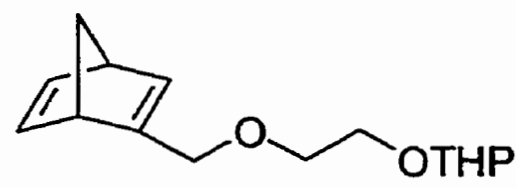

64

$$
\text { (98\%) } \mid \begin{aligned}
& \mathrm{I}_{2}, \mathrm{PPh}_{3} \\
& \text { Imidazole } \\
& \mathrm{THF}_{\mathrm{CH}} \mathrm{CH}_{3} \mathrm{CN}
\end{aligned}
$$<smiles></smiles>

66
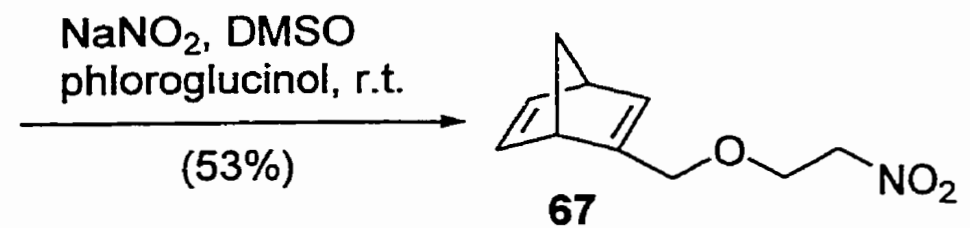

$(\mathrm{BOC})_{2} \mathrm{O}$, DMAP

Toluene, $90^{\circ} \mathrm{C}$

(69\%)

68 
Preparation of Alcohol 62. Norbornadiene (1) $(14.0 \mathrm{~mL}, 130 \mathrm{mmol})$ was added to a flame-dried three-necked flask containing potassium $t$-butoxide $(10.6 \mathrm{~g}, 94.5 \mathrm{mmol})$ and THF (200 mL) which was cooled at $-78^{\circ} \mathrm{C}$ (cryobath). $n$-Butyllithium $(50.0 \mathrm{~mL}, 1.6 \mathrm{M}$, $80.0 \mathrm{mmol}$ ) was added dropwise through a dropping funnel to the solution over $1 \mathrm{~h}$, maintaining the temperature below $-65^{\circ} \mathrm{C}$. The reaction mixture was stirred at $-65^{\circ} \mathrm{C}$ for $30 \mathrm{~min}$. and at $-40^{\circ} \mathrm{C}$ for $30 \mathrm{~min}$. After cooling the mixture to $-78^{\circ} \mathrm{C}$, a solution of lithium bromide $\left(9.00 \mathrm{~g}, 104 \mathrm{mmol}\right.$, dried at $150^{\circ} \mathrm{C}$ under vacuum-pump for $\left.1 \mathrm{~h}\right)$ in THF $(50 \mathrm{~mL})$ was added via a cannula at $-65^{\circ} \mathrm{C}$. The reaction mixture was stirred vigorously at $-50^{\circ} \mathrm{C}$ for $15 \mathrm{~min}$. and dry paraformaldehyde powder $(33.1 \mathrm{~g}, 367 \mathrm{mmol}$, dried under vacuum overnight) was added. The reaction mixture was stirred at $-50^{\circ} \mathrm{C}$ for $10 \mathrm{~min}$. and at room temperature for $2 \mathrm{~h}$. After the reaction was quenched with saturated ammonium chloride $(50 \mathrm{~mL})$, the excess paraformaldehyde was filtered by suction filtration and the solid was washed thoroughly with diethyl ether. The aqueous layer was extracted with diethyl ether $(3 \times 100 \mathrm{~mL})$, and the combined organic layers were washed sequentially with water $(100 \mathrm{~mL})$ and brine $(100 \mathrm{~mL})$ and dried over magnesium sulfate. The solvent was removed by rotary evaporation and the crude product was purified by vacuum distillation $\left(12\right.$ torr at $\left.90^{\circ} \mathrm{C}-95^{\circ} \mathrm{C}\right)$ to give pure alcohol $62(5.58 \mathrm{~g}, 45.7 \mathrm{mmol}, 57 \%)$ as a colorless oil.

(Bicyclo[2.2.1]hepta-2,5-dien-2-yl)methanol (62). ${ }^{1} \mathrm{H}$ and ${ }^{13} \mathrm{C}$ NMR spectral data were identical to those reported in the literature. ${ }^{40}$

Conversion of 62 to 64 . To a flame-dried flask containing alcohol 62 (1.03 g, 8.46 mmol), THP-protected chloroethanol $63(2.79 \mathrm{~g}, 17.0 \mathrm{mmol})$ and tetrabutylammonium bromide (565 mg, $1.70 \mathrm{mmol}), 50 \% \mathrm{NaOH}(2.6 \mathrm{~g}$ in $2.6 \mathrm{~mL}$ water, $65.0 \mathrm{mmol}$ ) was 
added at $0^{\circ} \mathrm{C} .^{75}$ The reaction mixture was stirred at $70^{\circ} \mathrm{C}$ for $42 \mathrm{~h}$. After quenching the reaction with saturated sodium chloride $(25 \mathrm{~mL})$ and water $(50 \mathrm{~mL})$, the aqueous layer was extracted with diethyl ether $(3 \times 100 \mathrm{~mL})$, and the combined organic layers were washed sequentially with water $(100 \mathrm{~mL})$ and brine $(100 \mathrm{~mL})$ and dried over magnesium sulfate. The solvent was removed by rotary evaporation and the crude product was purified by column chromatography (EtOAc:hexanes $=1: 4)$ to give $64(1.41 \mathrm{~g}, 5.63$ mmol, 66\%) as a colorless oil.

THP-protected Alcohol 64. A mixture of two diastereomers. $R_{f} 0.47$ (EtOAc:hexanes $=$ 1:4); IR (neat, $\mathrm{NaCl}) 3065$ (w), 2939 (s), 2868 (s), 1556 (w), 1352 (m), 1260 (w), 1202 (m), 1185 (m), 1127 (s), 1077 (s), 1036 (s), 1021 (s) $\mathrm{cm}^{-1} ;{ }^{1} \mathrm{H}$ NMR (CDCl, $\left.400 \mathrm{MHz}\right) \delta$ $6.76(\mathrm{~m}, 1 \mathrm{H}), 6.69(\mathrm{dd}, 1 \mathrm{H}, J=5.0,3.0 \mathrm{~Hz}), 6.43(\mathrm{~m}, 1 \mathrm{H}), 4.61(\mathrm{t}, 1 \mathrm{H}, J=3.6 \mathrm{~Hz}), 4.16$ (ddd, $1 \mathrm{H}, J=13.1,3.0,1.4 \mathrm{~Hz}), 4.10(\mathrm{dt}, 1 \mathrm{H}, J=13.4,1.7 \mathrm{~Hz}), 3.86-3.78(\mathrm{~m}, 2 \mathrm{H}), 3.58$ $-3.43(\mathrm{~m}, 6 \mathrm{H}), 2.00(\mathrm{~m}, 1 \mathrm{H}), 1.95(\mathrm{dt}, 1 \mathrm{H}, J=5.9,1.4 \mathrm{~Hz}), 1.80(\mathrm{~m}, 1 \mathrm{H}), 1.69(\mathrm{~m}, 1 \mathrm{H})$, $1.62-1.46(\mathrm{~m}, 4 \mathrm{H}) ;{ }^{13} \mathrm{C} \mathrm{NMR}\left(\mathrm{CDCl}_{3}, 100 \mathrm{MHz}\right) \delta 154.91,154.87,143.2,142.50$, $142.46,138.43,138.39,98.71,98.66,73.54,73.50,69.44,69.43,68.7,66.48,66.46,62.0$, 51.2, 51.1, 50.1, 30.4, 25.3, 19.3. Anal. Calcd. for $\mathrm{C}_{15} \mathrm{H}_{22} \mathrm{O}_{3}: \mathrm{C}, 71.97 ; \mathrm{H}, 8.86$. Found $\mathrm{C}, 71.92 ; \mathrm{H}, 8.89$.

Conversion of 64 to 65 . To a flame-dried flask containing $64(1.31 \mathrm{~g}, 5.22 \mathrm{mmol})$ in $\mathrm{MeOH}$ (43 mL), pyridium p-toluenesulfonate, PPTS (143 mg, $0.569 \mathrm{mmol}$ ), was added at room temperature. The reaction mixture was stirred at $55^{\circ} \mathrm{C}$ for $45 \mathrm{~min}$. After quenching the reaction with water $(30 \mathrm{~mL})$, the aqueous layer was extracted with diethyl ether $(3 \times 50$ $\mathrm{mL}$ ), and the combined organic layers were washed sequentially with water $(50 \mathrm{~mL})$ and 
brine $(50 \mathrm{~mL})$ and dried over magnesium sulfate. The solvent was removed by rotary evaporation and the crude product was purified by column chromatography (EtOAc:hexanes $=1: 4)$ to give $65(754 \mathrm{mg}, 4.54 \mathrm{mmol}, 87 \%)$ as a colorless oil.

2-(Bicyclo[2.2.1] hepta-2,5-dien-2-yl-methoxy)ethanol (65). $R_{f} 0.10$ (EtOAc:hexanes $=$ 1:4); IR (neat, $\mathrm{NaCl}) 3412$ (s), 3065 (w), 2968 (s), 2934 (s), 2866 (s), 1556 (w), 1449 (w), 1351 (m), 1187 (w), 1129 (s), 1110 (s), 1064 (s) cm ${ }^{-1}{ }^{1} \mathrm{H}$ NMR (CDCl $\left.3,400 \mathrm{MHz}\right) \delta$ $6.77(\mathrm{dd}, 1 \mathrm{H}, J=5.2,3.1 \mathrm{~Hz}), 6.71(\mathrm{dd}, 1 \mathrm{H}, J=5.1,3.0 \mathrm{~Hz}), 6.44(\mathrm{~m}, 1 \mathrm{H}), 4.15(\mathrm{dd}, 1 \mathrm{H}$, $J=13.0,1.3 \mathrm{~Hz}), 4.09$ (dd, 1H, $J=13.0,1.5 \mathrm{~Hz}), 3.67(\mathrm{t}, 2 \mathrm{H}, J=4.5 \mathrm{~Hz}), 3.53(\mathrm{~m}, 1 \mathrm{H})$, $3.47-3.37$ (m, 3H), 2.63 (br. s, $1 \mathrm{H}), 2.00$ (dt, $1 \mathrm{H}, J=5.9,1.6 \mathrm{~Hz}), 1.96$ (dm, $1 \mathrm{H}, J=5.9$ $\mathrm{Hz}) ;{ }^{13} \mathrm{C} \mathrm{NMR}\left(\mathrm{CDCl}_{3}, 100 \mathrm{MHz}\right) \delta 154.6,143.2,142.4,138.7,73.6,70.9,69.5,61.6$, 51.2, 50.1. Anal. Calcd. for $\mathrm{C}_{10} \mathrm{H}_{14} \mathrm{O}_{2}: \mathrm{C}, 72.26 ; \mathrm{H}, 8.49$. Found $\mathrm{C}, 72.46 ; \mathrm{H}, 8.43$.

Conversion of Alcohol 65 to Iodide 66. To a flame-dried flask containing $\mathrm{PPh}_{3}$ (296 $\mathrm{mg}, 1.13 \mathrm{mmol})$, imidazole $(170 \mathrm{mg}, 2.49 \mathrm{mmol})$, acetonitrile $(1.5 \mathrm{~mL})$ and THF $(0.5$ $\mathrm{mL}), \mathrm{I}_{2}(318 \mathrm{mg}, 2.51 \mathrm{mmol})$ was added at $0^{\circ} \mathrm{C}$. The reddish-brown reaction mixture was stirred for $15 \mathrm{~min}$. at $0^{\circ} \mathrm{C}$. Alcohol $65(93.1 \mathrm{mg}, 0.560 \mathrm{mmol})$ in acetonitrile $(1 \mathrm{~mL})$ was added via a cannula at $0^{\circ} \mathrm{C}$. The reaction mixture was stirred at room temperature for 5.5 h. The reaction mixture was diluted with $\mathrm{CH}_{2} \mathrm{Cl}_{2}(15 \mathrm{~mL})$ and quenched with water (15 $\mathrm{mL})$. The aqueous layer was extracted with diethyl ether $(3 \times 20 \mathrm{~mL})$, and the combined organic layers were washed sequentially with water $(20 \mathrm{~mL})$ and brine $(20 \mathrm{~mL})$ and dried over magnesium sulfate. The solvent was removed by rotary evaporation and the crude product was purified by column chromatography (EtOAc:hexanes $=1: 19$ ) to give iodide 66 (151 mg, $0.55 \mathrm{mmol}, 98 \%)$ as a colorless oil. 
2-(2-Iodoethoxymethyl)bicyclo[2.2.1]hepta-2,5-diene (60). $R_{f} 0.40$ (EtOAc:hexanes $=$ 1:19); IR (neat, $\mathrm{NaCl}$ ) 3064 (w), 2934 (m), 2866 (m), 1556 (w), 1350 (w), 1261 (w), 1187 (m), 1126 (m), 1085 (s), 10059 (m), 1019 (w) $\mathrm{cm}^{-1} ;{ }^{\mathrm{I}} \mathrm{H}$ NMR (CDCl $\left.3,400 \mathrm{MHz}\right) \delta$ $6.78(\mathrm{dd}, 1 \mathrm{H}, J=5.1,3.2 \mathrm{~Hz}), 6.71(\mathrm{dd}, 1 \mathrm{H}, J=5.0,3.0 \mathrm{~Hz}), 6.46(\mathrm{~m}, 1 \mathrm{H}), 4.16(\mathrm{dd}, 1 \mathrm{H}$, $J=12.9,1.2 \mathrm{~Hz}), 4.10(\mathrm{dd}, 1 \mathrm{H}, J=12.9,1.5 \mathrm{~Hz}), 3.59-3.53(\mathrm{~m}, 3 \mathrm{H}), 3.46(\mathrm{~m}, 1 \mathrm{H}), 3.20$ $(\mathrm{t}, 2 \mathrm{H}, J=6.8 \mathrm{~Hz}), 2.01(\mathrm{dt}, 1 \mathrm{H}, J=5.9,1.5 \mathrm{~Hz}), 1.97(\mathrm{dm}, 1 \mathrm{H}, J=5.9 \mathrm{~Hz}) ;{ }^{13} \mathrm{C} \mathrm{NMR}$ $\left(\mathrm{CDCl}_{3}, 100 \mathrm{MHz}\right) \delta 154.3,14: 3.1,142.3,138.9,73.5,70.0,69.0,51.1,50.0,3.17$ HRMS calcd. for $\mathrm{C}_{10} \mathrm{H}_{13} \mathrm{IO}: \mathrm{m} / \mathrm{z} 276.0013$, found $\mathrm{m} / \mathrm{z} 276.0009$.

Conversion of Iodide 66 to Nitro Compound 67 . Iodide 66 (344 mg, $1.24 \mathrm{mmol}$ ) in DMSO (1.2 mL) was added via a cannula to a flask containing $\mathrm{NaNO}_{2}(321 \mathrm{mg}, 4.65$ $\mathrm{mmol}$ ) and phloroglucinol (263 mg, $1.63 \mathrm{mmol}$ ) in DMSO (1.2 mL). The light brown reaction mixture was stirred at room temperature for $36 \mathrm{~h}$. After quenching the reaction with water $(10 \mathrm{~mL})$, the aqueous layer was extracted with diethyl ether $(4 \times 20 \mathrm{~mL})$ and the combined organic layers were washed sequentially with water (50 mL) and brine (50 $\mathrm{mL}$ ) and dried over magnesium sulfate. The solvent was removed by rotary evaporation and the crude product was purified by column chromatography (EtOAc:hexanes $=1: 4$ ) to give 67 (128 mg, $0.656 \mathrm{mmol}, 53 \%)$ as a colorless viscous oil.

2-(2-Nitroethoxymethyl)bicyclo [2.2.1]hepta-2,5-diene (67). $R_{f} 0.44$ (EtOAc:hexanes $=$ 1:4); IR (neat, $\mathrm{NaCl}) 3066(\mathrm{w}), 2980(\mathrm{~m}), 2936$ (m), $2868(\mathrm{~m}), 1557(\mathrm{~s}), 1466(\mathrm{w}), 1421$ (m), $1372(\mathrm{~m}), 1309$ (w), 1300 (w), $1283(\mathrm{w}), 1218(\mathrm{~m}), 1187(\mathrm{w}), 1129(\mathrm{~m}), 1091(\mathrm{~m})$, $1032(\mathrm{w}) \mathrm{cm}^{-1} ;{ }^{1} \mathrm{H} \mathrm{NMR}\left(\mathrm{CDCl}_{3,}, 400 \mathrm{MHz}\right) \delta 6.77$ (dd, $1 \mathrm{H}, J=5.2,3.1 \mathrm{~Hz}$ ), $6.72(\mathrm{dd}$, $1 \mathrm{H}, J=5.1,3.0 \mathrm{~Hz}), 6.49(\mathrm{~m}, 1 \mathrm{H}), 4.49(\mathrm{t}, 2 \mathrm{H}, J=4.9 \mathrm{~Hz}), 4.17$ (dd, $1 \mathrm{H}, J=12.9,1.3$ 
$\mathrm{Hz}), 4.10(\mathrm{dd}, 1 \mathrm{H}, J=12.9,1.5 \mathrm{~Hz}), 3.82(\mathrm{~m}, 2 \mathrm{H}), 3.55(\mathrm{~m}, 1 \mathrm{H}), 3.40(\mathrm{~m}, 1 \mathrm{H}), 2.01(\mathrm{~m}$, $1 \mathrm{H}), 1.97(\mathrm{~m}, 1 \mathrm{H}) ;{ }^{13} \mathrm{C} \mathrm{NMR}\left(\mathrm{CDCl}_{3}, 100 \mathrm{MHz}\right) \delta 153.8,143.2,142.4,139.7,75.1,73.7$, 69.5, 64.8, 51.1, 50.1. Anal. Calcd. for $\mathrm{C}_{10} \mathrm{H}_{13} \mathrm{NO}_{3}$ : $\mathrm{C}, 61.53 ; \mathrm{H}, 6.71 ; \mathrm{N}, 7.17$. Found C, 61.44; H, 6.70; N, 7.31.

\section{In situ Generation of Nitrile Oxide from Nitro Compound 67 and Subsequent Cycloaddition.}

Di-tert-butyl dicarbonate, $(\mathrm{BOC})_{2} \mathrm{O}(206 \mathrm{mg}, 0.944 \mathrm{mmol})$, in toluene $(2 \mathrm{~mL})$ was added via a cannula to a flame-dried flask containing the nitro compound $67(68.9 \mathrm{mg}, 0.353$ mmol), 4-dimethylaminopyridine, DMAP (15.4 mg, $0.126 \mathrm{mmol})$, in toluene $(1 \mathrm{~mL})$. The reaction mixture was stirred at $90^{\circ} \mathrm{C}$ for $64 \mathrm{~h}$. The solvent was removed by rotary evaporation and the crude product was purified by column chromatography (EtOAc:hexanes $=1: 9)$ to give cycloadduct $69(43.0 \mathrm{mg}, 0.243 \mathrm{mmol}, 69 \%)$ as a colorless viscous oil.

Cycloadduct 69. $R_{f} 0.28$ (EtOAc:hexanes = 1:4); $\mathrm{IR}$ (neat, $\mathrm{NaCl}$ ) 3055 (m), $2986(\mathrm{~m}$ ),

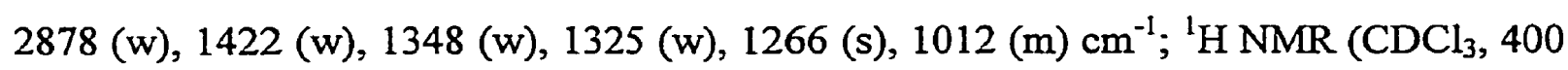
MHz) $\delta 6.39(\mathrm{dd}, 1 \mathrm{H}, J=5.8,3.0 \mathrm{~Hz}), 6.15(\mathrm{dd}, 1 \mathrm{H}, J=5.7,3.3 \mathrm{~Hz}), 4.68(\mathrm{t}, 1 \mathrm{H}, J=1.5$ $\mathrm{Hz}), 4.40(\mathrm{~m}, 2 \mathrm{H}), 3.88(\mathrm{~d}, 1 \mathrm{H}, J=8.6 \mathrm{~Hz}), 3.51(\mathrm{~d}, 1 \mathrm{H}, J=8.5 \mathrm{~Hz}), 3.36(\mathrm{~m}, 1 \mathrm{H}), 3.08$ $(\mathrm{m}, 1 \mathrm{H}), 1.91(\mathrm{dm}, 1 \mathrm{H}, J=9.4 \mathrm{~Hz}), 1.77(\mathrm{dm}, 1 \mathrm{H}, J=9.4 \mathrm{~Hz}) ;{ }^{13} \mathrm{C} \mathrm{NMR}\left(\mathrm{CDCl}_{3}, 100\right.$ $\mathrm{MHz}) \delta 164.6,138.2,136.7,92.9,76.7,73.2,61.0,50.6,47.1,44.7$. Anal. Calcd. for $\mathrm{C}_{10} \mathrm{H}_{1 \mathrm{II}} \mathrm{NO}_{2}: \mathrm{C}, 67.78 ; \mathrm{H}, 6.26 ; \mathrm{N}, 7.90$. Found $\mathrm{C}, 68.02 ; \mathrm{H}, 6.23 ; \mathrm{N}, 7.86$. 


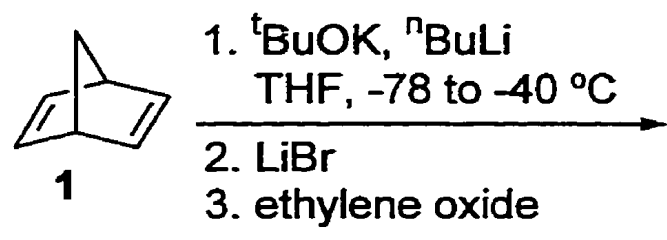

(65\%)<smiles>O=C1C=C2C=CC1C2</smiles>

70

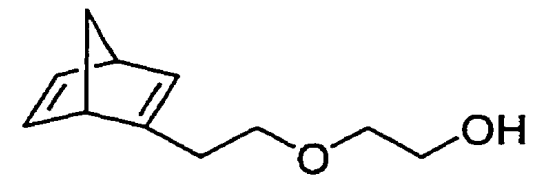

72

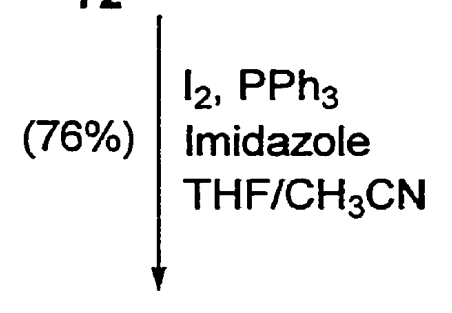<smiles>[Y]C1=CC2C=CC1C2</smiles>

$(\mathrm{BOC})_{2} \mathrm{O}, \mathrm{DMAP}$

Toluene, $90^{\circ} \mathrm{C}$

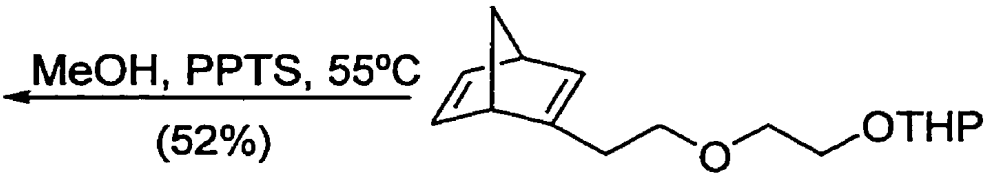

71
74

63

$70^{\circ} \mathrm{C}$
76
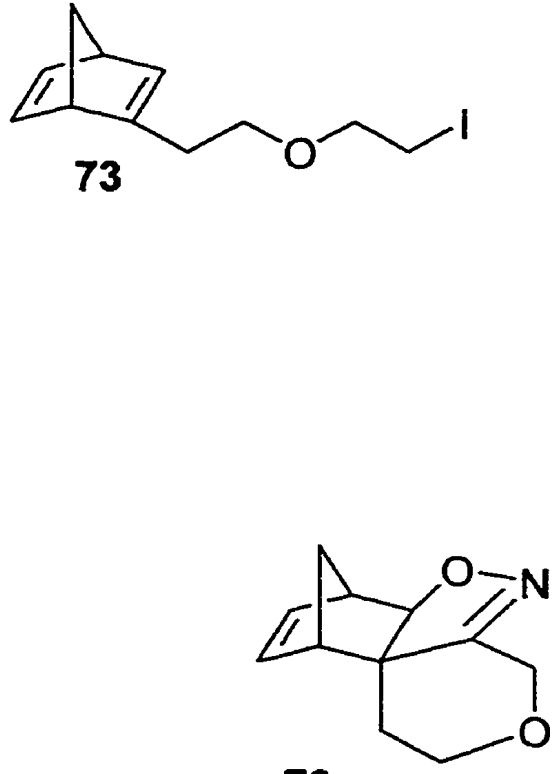

(47\%)

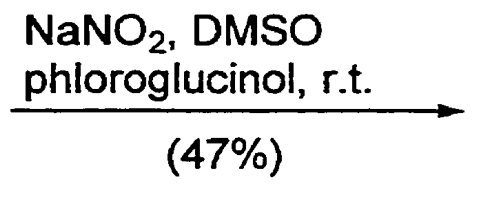

(52\%)

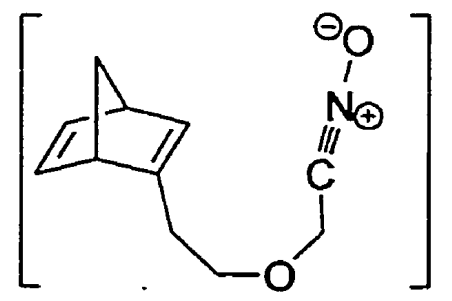

75 
Preparation of Alcohol 70. Norbornadiene (1) $(5.60 \mathrm{~mL}, 51.9 \mathrm{mmol})$ was added to a flame-dried three-necked flask containing potassium $t$-butoxide $(4.18 \mathrm{~g}, 37.2 \mathrm{mmol})$ and THF $(60 \mathrm{~mL})$ which was cooled at $-78^{\circ} \mathrm{C}$ (cryobath). $n$-Butyllithium $(14.0 \mathrm{~mL}, 2.5 \mathrm{M}$, $35.0 \mathrm{mmol}$ ) was added dropwise through a dropping funnel to the solution over $1 \mathrm{~h}$, maintaining the temperature below $-65^{\circ} \mathrm{C}$. The reaction mixture was stirred at $-65^{\circ} \mathrm{C}$ for $30 \mathrm{~min}$. and at $-40^{\circ} \mathrm{C}$ for $30 \mathrm{~min}$. After cooling the mixture to $-78^{\circ} \mathrm{C}$, ethylene oxide ( $3.93 \mathrm{~g}, 89.2 \mathrm{mmol}$ ) was added. The reaction mixture was stirred at $-40^{\circ} \mathrm{C}$ for $30 \mathrm{~min}$., at $0^{\circ} \mathrm{C}$ for $30 \mathrm{~min}$. and at room temperature for $20 \mathrm{~min}$. After the reaction was quenched with water $(80 \mathrm{~mL})$, the aqueous layer was extracted with diethyl ether $(4 \times 80 \mathrm{~mL})$, and the combined organic layers were washed sequentially with water $(100 \mathrm{~mL})$ and brine $(100 \mathrm{~mL})$ and dried over magnesium sulfate. The solvent was removed by rotary evaporation and the crude product was purified by bulb-to-bulb distillation $(6-8$ torr at $\left.85^{\circ} \mathrm{C}-95^{\circ} \mathrm{C}\right)$ to give pure alcohol $70(3.03 \mathrm{~g}, 22.2 \mathrm{mmol}, 65 \%)$ as a colorless oil.

2-(Bicyclo[2.2.1]hepta-2,5-dien-2-yl)ethanol (70). ${ }^{1} \mathrm{H}$ and ${ }^{13} \mathrm{C}$ NMR spectral data were identical to those reported in the literature. ${ }^{40}$

Conversion of 70 to 71 . To a flame-dried flask containing alcohol $70(2.87 \mathrm{~g}, 21.0$ mmol), THP-protected chloroethanol $63(6.97 \mathrm{~g}, 42.3 \mathrm{mmol})$ and tetrabutylammonium bromide ( $1.42 \mathrm{~g}, 4.28 \mathrm{mmol}), 50 \% \mathrm{NaOH}(6.50 \mathrm{~g}$ in $6.5 \mathrm{~mL}$ water, $163 \mathrm{mmol}$ ) was added at $0^{\circ} \mathrm{C}^{75}$ The reddish-brown reaction mixture was stirred at $70^{\circ} \mathrm{C}$ for $48 \mathrm{~h}$. After quenching the reaction with saturated sodium chloride $(20 \mathrm{~mL})$ and water $(30 \mathrm{~mL})$, the aqueous layer was extracted with diethyl ether $(3 \times 50 \mathrm{~mL})$, and the combined organic layers were washed sequentially with water $(50 \mathrm{~mL})$ and brine $(50 \mathrm{~mL})$ and dried over 
magnesium sulfate. The solvent was removed by rotary evaporation and the crude product was purified by column chromatography (EtOAc:hexanes $=1: 4)$ to give 71 (4.88 $\mathrm{g}, 18.5 \mathrm{mmol}, 88 \%)$ as a colorless oil.

THP-protected Alcohol 71. $R_{f} 0.54$ (EtOAc:hexanes = 1:4); IR (neat, NaCl) 3065 (w), 2938(s), $2867(\mathrm{~s}), 1556(\mathrm{w}), 1352(\mathrm{w}), 1307(\mathrm{~m}), 1202(\mathrm{~m}), 1184(\mathrm{~m}), 1126(\mathrm{~s}), 1077(\mathrm{~s})$, $1037(\mathrm{~s}), 1021(\mathrm{~s}) \mathrm{cm}^{-1} ;{ }^{1} \mathrm{H} \mathrm{NMR}\left(\mathrm{CDCl}_{3}, 400 \mathrm{MHz}\right) \delta 6.69(\mathrm{~m}, 2 \mathrm{H}), 6.17(\mathrm{~m}, 1 \mathrm{H}), 4.60$ $(\mathrm{m}, 1 \mathrm{H}), 3.82(\mathrm{~m}, 2 \mathrm{H}), 3.58-3.47(\mathrm{~m}, 6 \mathrm{H}), 3.44(\mathrm{~m}, 1 \mathrm{H}), 3.30(\mathrm{~m}, 1 \mathrm{H}), 2.46(\mathrm{~m}, 2 \mathrm{H})$, $1.94(\mathrm{dm}, 1 \mathrm{H}, J=5.6 \mathrm{~Hz}), 1.89(\mathrm{dm}, 1 \mathrm{H}, J=5.6 \mathrm{~Hz}), 1.80(\mathrm{~m}, 1 \mathrm{H}), 1.68(\mathrm{~m}, 1 \mathrm{H}), 1.58-$ $1.46(\mathrm{~m}, 4 \mathrm{H}) ;{ }^{13} \mathrm{C} \mathrm{NMR}\left(\mathrm{CDCl}_{3}, 100 \mathrm{MHz}\right) \delta 155.2,143.6,142.3,134.9,98.7,73.5,69.9$, 69.5, 66.4, 61.9, 53.5, 50.0, 31.6, 30.4, 25.3, 19.3. Anal. Calcd. for $\mathrm{C}_{16} \mathrm{H}_{24} \mathrm{O}_{3}$ : C, 72.69; H, 9.15. Found C, 72.78; H, 9.11.

Conversion of 71 to 72 . To a flame-dried flask containing $71(4.58 \mathrm{~g}, 17.3 \mathrm{mmol})$ in $\mathrm{MeOH}$ (140 mL), pyridium p-toluenesulfonate, PPTS (529 mg, $2.11 \mathrm{mmol}$ ), was added at room temperature. The reaction mixture was stirred at $55^{\circ} \mathrm{C}$ for $45 \mathrm{~min}$. Approximately $100 \mathrm{~mL}$ of $\mathrm{MeOH}$ was then removed by rotary evaporation. After quenching the reaction with water $(100 \mathrm{~mL})$, the aqueous layer was extracted with diethyl ether $(4 \times 100 \mathrm{~mL})$, and the combined organic layers were washed sequentially with water $(100 \mathrm{~mL})$ and brine $(100 \mathrm{~mL})$ and dried over magnesium sulfate. The solvent was removed by rotary evaporation and the crude product was purified by column chromatography (EtOAc:hexanes = 1:4) to give $72(1.61 \mathrm{~g}, 8.93 \mathrm{mmol}, 52 \%)$ as a colorless oil.

2-(2-Bicyclo[2.2.1]hepta-2,5-dien-2-yl-ethoxy)ethanoI (72). $R_{f} 0.16$ (EtOAc:hexanes $=$ 1:4); IR (neat, $\mathrm{NaCl}) 3421$ (s), 3064 (w), 2964 (s), 2933 (s), 2866 (s), 1686 (w), 1556 (w), 
$1457(w), 1357$ (w), 1306 (m), $1226(w), 1122(s), 1057(s) \mathrm{cm}^{-1} ;{ }^{1} \mathrm{H}$ NMR $\left(\mathrm{CDCl}_{3}, 400\right.$ $\mathrm{MHz}) \delta 6.73(\mathrm{~m}, 2 \mathrm{H}), 6.20(\mathrm{~m}, 1 \mathrm{H}), 3.67(\mathrm{~m}, 2 \mathrm{H}), 3.53(\mathrm{t}, 2 \mathrm{H}, J=6.9 \mathrm{~Hz}), 3.50(\mathrm{~m}, 2 \mathrm{H})$, $3.48(\mathrm{~m}, 1 \mathrm{H}), 3.30(\mathrm{~m}, 1 \mathrm{H}), 2.53-2.41(\mathrm{~m}, 3 \mathrm{H}), 1.96(\mathrm{dm}, 1 \mathrm{H}, J=5.8 \mathrm{~Hz}), 1.92(\mathrm{dm}$, $1 \mathrm{H}, J=5.7 \mathrm{~Hz}) ;{ }^{13} \mathrm{C} \mathrm{NMR}\left(\mathrm{CDCl}_{3}, 100 \mathrm{MHz}\right) \delta 155.1,143.7,142.3,135.2,73.6,71.6$, 69.2, 61.6, 53.5, 50.0, 31.6. Anal. Calcd. for $\mathrm{C}_{11} \mathrm{H}_{16} \mathrm{O}_{2}:$ C, 73.30; H, 8.95. Found $\mathrm{C}$, 73.12; H, 8.99.

Conversion of Alcohol 72 to Iodide 73. To a flame-diried flask containing $\mathrm{PPh}_{3}$ (4.38 g, $16.7 \mathrm{mmol})$, imidazole $(2.51 \mathrm{~g}, 36.9 \mathrm{mmol})$, acetonitrile $(15 \mathrm{~mL})$ and THF $(7.5 \mathrm{~mL}), \mathrm{I}_{2}$ $(4.76 \mathrm{~g}, 37.5 \mathrm{mmol})$ was added at $0^{\circ} \mathrm{C}$. The reddish-brown reaction mixture was stirred for $15 \mathrm{~min}$. at $0^{\circ} \mathrm{C}$. Alcohol $72(1.50 \mathrm{~g}, 8.33 \mathrm{mmol})$ in acetonitrile $(23 \mathrm{~mL})$ was added via a cannula at $0^{\circ} \mathrm{C}$. The reaction mixture was stirred at room temperature for $4 \mathrm{~h}$. The reaction mixture was diluted with $\mathrm{CH}_{2} \mathrm{Cl}_{2}(25 \mathrm{~mL})$ and quenched with water $(25 \mathrm{~mL})$. The aqueous layer was extracted with diethyl ether $(3 \times 50 \mathrm{~mL})$, and the combined organic layers were washed sequentially with water $(50 \mathrm{~mL})$ and brine $(50 \mathrm{~mL})$ and dried over magnesium sulfate. The solvent was removed by rotary evaporation and the crude product was purified by column chromatography (EtOAc:hexanes $=1: 19)$ to give iodide $73(1.85 \mathrm{~g}, 6.38 \mathrm{mmol}, 76 \%)$ as a colorless oil.

2-[2-(2-Iodoethoxy)-ethyl]bicyclo[2.2.1] hepta-2,5-diene (73). $R_{f} 0.39$ (EtOAc:hexanes = 1:19); IR (neat, $\mathrm{NaCl}) 3064$ (w), 2968 (m), 2932 (m), 2865 (m), 1555 (w), 1357 (w),

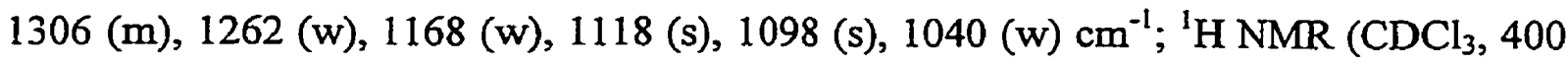
MHz) $\delta 6.74(\mathrm{~m}, 2 \mathrm{H}), 6.22(\mathrm{~m}, 1 \mathrm{H}), 3.68(\mathrm{t}, 2 \mathrm{H}, J=7.0 \mathrm{~Hz}), 3.55(\mathrm{t}, 2 \mathrm{H}, J=7.0 \mathrm{~Hz})$, $3.49(\mathrm{~m}, 1 \mathrm{H}), 3.33(\mathrm{~m}, 1 \mathrm{H}), 3.22$ (t, $2 \mathrm{H}, J=7.0 \mathrm{~Hz}), 2.48(\mathrm{~m}, 2 \mathrm{H}), 1.99$ (dt, $1 \mathrm{H}, J=5.7$, 
$1.6 \mathrm{~Hz}), 1.93(\mathrm{dt}, 1 \mathrm{H}, J=5.7,1.6 \mathrm{~Hz}) ;{ }^{13} \mathrm{C} \mathrm{NMR}\left(\mathrm{CDCl}_{3}, 100 \mathrm{MHz}\right) \delta 154.9,143.7$, $142.2,135.3,73.6,71.3,69.1,53.5,50.0,31.6,3.0$. HRMS calcd. for $\mathrm{C}_{11} \mathrm{H}_{15} \mathrm{IO}: \mathrm{m} / \mathrm{z}$ 290.0169, found $\mathrm{m} / \mathrm{z} 290.0164$.

Conversion of Iodide 73 to Nitro Compound 74. Iodide $73(1.60 \mathrm{~g}, 5.53 \mathrm{mmol})$ in DMSO (5 mL) was added via a cannula to a flask containing $\mathrm{NaNO}_{2}(1.43 \mathrm{~g}, 20.7 \mathrm{mmol})$ and phloroglucinol $(1.17 \mathrm{~g}, 7.21 \mathrm{mmol})$ in DMSO $(5 \mathrm{~mL})$. The light brown reaction mixture was stirred at room temperature for $69 \mathrm{~h}$. After quenching the reaction with water $(30 \mathrm{~mL})$, the aqueous layer was extracted with diethyl ether $(4 \times 40 \mathrm{~mL})$ and the combined organic layers were washed sequentially with water $(50 \mathrm{~mL})$ and brine $(50 \mathrm{~mL})$ and dried over magnesium sulfate. The solvent was removed by rotary evaporation and the crude product was purified by column chromatography (EtOAc:hexanes $=1: 4)$ to give 74 (539 $\mathrm{mg}, 2.58 \mathrm{mmol}, 47 \%$ ) as a colorless oil.

2-[2-(2-Nitroethoxy)ethyl]bicyclo[2.2.1]hepta-2,5-diene (74). $R_{f} 0.45$ (EtOAc:hexanes = 1:4); IR (neat, $\mathrm{NaCl}) 3065$ (w), 2969 (m), 2933 (m), 2867 (m), 1559 (s), $1421(\mathrm{w})$, 1380 (m), 1364 (m), 1307 (w), 1219 (w), 1125 (m), 1042 (w) cm ${ }^{-1} ;{ }^{1} \mathrm{H} \mathrm{NMR}\left(\mathrm{CDCl}_{3}, 400\right.$ MHz) $\delta 6.70(\mathrm{~m}, 2 \mathrm{H}), 6.17(\mathrm{~m}, 1 \mathrm{H}), 4.48(\mathrm{t}, 2 \mathrm{H}, J=5.0 \mathrm{~Hz}), 3.91(\mathrm{t}, 2 \mathrm{H}, J=5.1 \mathrm{~Hz})$, 3.52 (t, 2H, $J=6.9 \mathrm{~Hz}$ ), 3.45 (m, 1H), 3.27 (m, 1H), 2.44 (m, 2H), 1.94 (dt, $1 \mathrm{H}, J=5.7$, $1.6 \mathrm{~Hz}), 1.90(\mathrm{dm}, 1 \mathrm{H}, J=5.7 \mathrm{~Hz}) ;{ }^{13} \mathrm{C} \mathrm{NMR}\left(\mathrm{CDCl}_{3}, 100 \mathrm{MHz}\right) \delta 154.7,143.6,142.1$, $135.3,75.0,73.5,69.5,65.9,53.4,50.0,31.3$. HRMS calcd. for $\mathrm{C}_{11} \mathrm{H}_{15} \mathrm{NO}_{3}: \mathrm{m} / \mathrm{z}$ 209.1052, found $\mathrm{m} / \mathrm{z} 209.1051$. 


\section{In situ Generation of Nitrile Oxide from Nitro Compound 74 and Subsequent}

\section{Cycloaddition.}

Di-tert-butyl dicarbonate, $(\mathrm{BOC})_{2} \mathrm{O}(310 \mathrm{mg}, 1.42 \mathrm{mmol})$, in toluene $(3 \mathrm{~mL})$ was added via a cannula to a flame-dried flask containing the nitro compound 74 (109 $\mathrm{mg}, 0.521$ mmol), 4-dimethylaminopyridine, DMAP $(22.4 \mathrm{mg}, 0.183 \mathrm{mmol})$, in toluene (1 mL). The reaction mixture was stirred at $90^{\circ} \mathrm{C}$ for $64 \mathrm{~h}$. The solvent was removed by rotary evaporation and the crude product was purified by column chromatography (EtOAc:hexanes = 1:9) to give cycloadduct $76(51.5 \mathrm{mg}, 0.269 \mathrm{mmol}, 52 \%$; contaminated with a minor cycloadduct $\sim 20 \%$ ) as a colorless viscous oil.

Cycloadduct 76. $R_{f} 0.23$ (EtOAc:hexanes = 1:4); IR (neat, $\left.\mathrm{NaCl}\right) 2976(\mathrm{~m}), 2853$ (w), 1460 (w), 1326 (w), 1094 (s), $1081^{-}$(s), 1054 (m) cm ${ }^{-1}$ ' ${ }^{\mathrm{H}} \mathrm{NMR}\left(\mathrm{CDCl}_{3}, 400 \mathrm{MHz}\right) \delta$ $6.34(\mathrm{dd}, 1 \mathrm{H}, J=5.8,3.0 \mathrm{~Hz}), 6.06(\mathrm{dd}, 1 \mathrm{H}, J=5.7,3.3 \mathrm{~Hz}), 4.50(\mathrm{~d}, 1 \mathrm{H}, J=12.6 \mathrm{~Hz})$, $4.19(\mathrm{~s}, 1 \mathrm{H}), 4.10(\mathrm{~d}, 1 \mathrm{H}, J=12.6 \mathrm{~Hz}), 3.92(\mathrm{ddd}, 1 \mathrm{H}, J=12.0,4.6,1.5 \mathrm{~Hz}), 3.70(\mathrm{td}, 1 \mathrm{H}$, $J=12.3,2.0 \mathrm{~Hz}), 3.26(\mathrm{~m}, 1 \mathrm{H}), 3.09(\mathrm{~m}, 1 \mathrm{H}), 2.18(\mathrm{td}, 1 \mathrm{H}, J=13.3,4.6 \mathrm{~Hz}), 1.64-1.63$ $(\mathrm{m}, 2 \mathrm{H}), 1.45(\mathrm{dm}, 1 \mathrm{H}, J=13.6 \mathrm{~Hz}) ;{ }^{13} \mathrm{C} \mathrm{NMR}\left(\mathrm{CDCl}_{3}, 100 \mathrm{MHz}\right) \delta 156.2,137.8,134.5$, $91.4,69.7,64.8,62.3,50.1,44.7,44.4,38.3$. HRMS calcd. for $\mathrm{C}_{11} \mathrm{H}_{13} \mathrm{NO}_{2}$ : (CI, $\left.[\mathrm{M}+\mathrm{H}]^{+}\right) \mathrm{m} / \mathrm{z}$ 192.1025, found $\mathrm{m} / \mathrm{z} 192.1032$. 


\subsection{Synthetic Procedures for Chapter 3: 2,3-Disubstituted Norbornadienes}

\subsubsection{2,3-Disubstituted Norbornadienes from 2,3-Dibromonorbornadiene via Monolithium-halide Exchange}

Synthesis of Compound 110d.

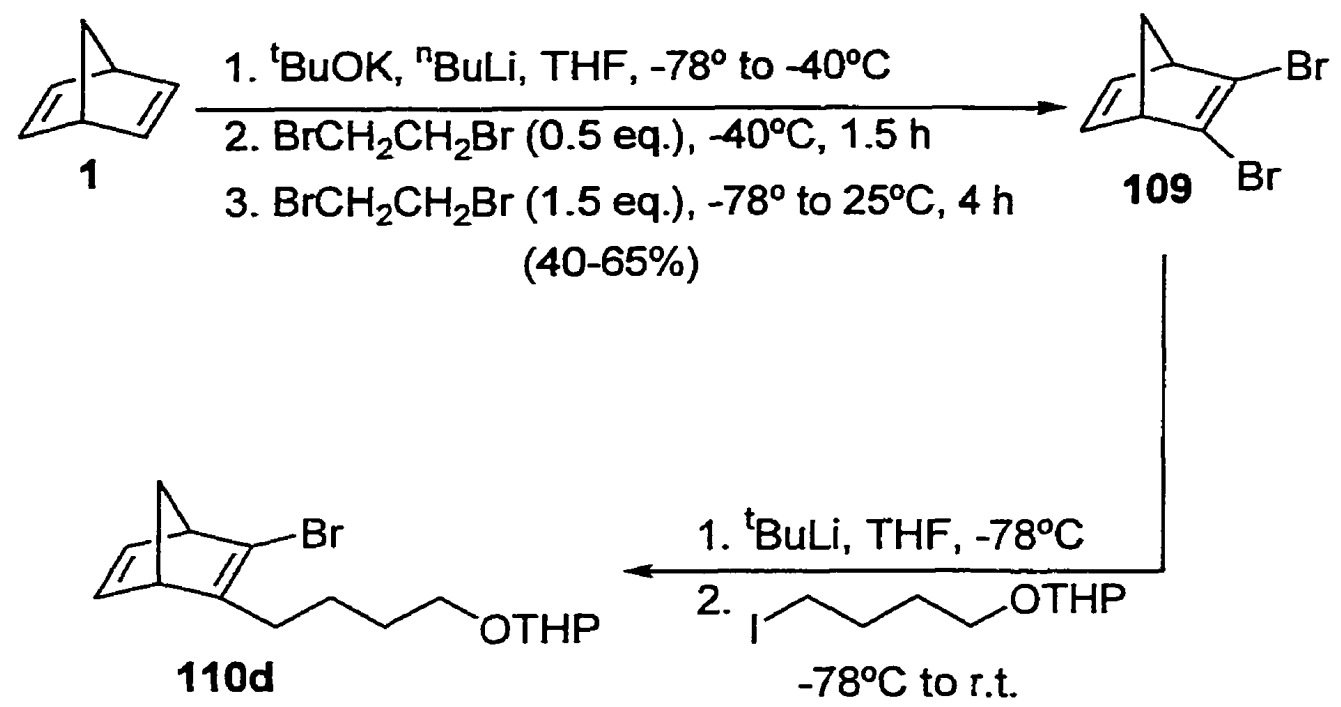

(90\%)

Preparation of Dibromide 109. Norbornadiene (1) $(35.0 \mathrm{~mL}, 324 \mathrm{mmol})$ was added to a flame-dried three-necked flask containing potassium $t$-butoxide $(18.7 \mathrm{~g}, 167 \mathrm{mmol})$ and THF (240 mL), which was cooled at $-78^{\circ} \mathrm{C}$ (cryobath). $n$-Butyllithium $(66.0 \mathrm{~mL}, 2.5 \mathrm{M}$, $165 \mathrm{mmol}$ ) was added dropwise through a dropping funnel over $2 \mathrm{~h}$, maintaining the temperature below $-70^{\circ} \mathrm{C}$. The reaction mixture was stirred at $-65^{\circ} \mathrm{C}$ for $30 \mathrm{~min}$. and at $-40^{\circ} \mathrm{C}$ for $30 \mathrm{~min}$. After cooling the mixture to $-78^{\circ} \mathrm{C}, 1,2$-dibromoethane $(7.20 \mathrm{~mL}, 83.5$ mmol) was added, and the mixture was stirred at $-40^{\circ} \mathrm{C}$ for $1.5 \mathrm{~h}$. Excess $1,2-$ 
dibromoethane $(21.6 \mathrm{~mL}, 250 \mathrm{mmol})$ was then added at $-70^{\circ} \mathrm{C}$. The brown mixture was stirred at $-40^{\circ} \mathrm{C}$ for $2 \mathrm{~h}$ and at room temperature for $4 \mathrm{~h}$. After quenching the reaction with saturated ammonium chloride $(150 \mathrm{~mL})$ and water $(300 \mathrm{~mL})$, the aqueous layer was extracted with diethyl ether $(4 \times 300 \mathrm{~mL})$, and the combined organic layers were washed sequentially with water $(500 \mathrm{~mL})$ and brine $(500 \mathrm{~mL})$ and dried over magnesium sulfate. The solvent was removed by rotary evaporation, and the crude product was purified by vacuum distillation to give three fractions. The first fraction $\left(20-30\right.$ torr at $40^{\circ} \mathrm{C}-$ $60^{\circ} \mathrm{C}$ ) contained mainly the excess 1,2 -dibromoethane and norbornadiene. The second fraction $\left(10-15\right.$ torr at $\left.50^{\circ} \mathrm{C}-60^{\circ} \mathrm{C}\right)$ contained 2-bromonorbornadiene and 2,3dibromonorbornadiene in a ratio of $2: 1$ as determined by ${ }^{1} \mathrm{H}$ NMR. The third fraction (6 -9 torr at $\left.80^{\circ} \mathrm{C}-100^{\circ} \mathrm{C}\right)$ contained pure $109(13.6 \mathrm{~g}, 54.4 \mathrm{mmol}, 65 \%)$ as a colorless oil. 2,3-Dibromobicyclo[2.2.1] hepta-2,5-diene (109). $R_{f} 0.67$ (hexanes); ' $\mathrm{H} \mathrm{NMR}\left(\mathrm{CDCl}_{3}\right.$, $400 \mathrm{MHz}) \delta 6.88(\mathrm{~s}, 2 \mathrm{H}), 3.61(\mathrm{~m}, 2 \mathrm{H}), 2.45(\mathrm{dd}, 1 \mathrm{H}, J=6.3,1.1 \mathrm{~Hz}), 2.18(\mathrm{dt}, 1 \mathrm{H}, J=$ 6.3, 1.4 Hz); ${ }^{13} \mathrm{C} \mathrm{NMR}\left(\mathrm{CDCl}_{3}, 100 \mathrm{MHz}\right) \delta 141.2,133.0,72.0,58.6$. Spectral data were identical to those reported in the literature. ${ }^{64}$

Conversion of 109 to $110 \mathrm{~d}$. tert-Butyllithium $(24.0 \mathrm{~mL}, 1.7 \mathrm{M}, 40.8 \mathrm{mmol})$ was added to a flame-dried flask containing dibromide $109(5.10 \mathrm{~g}, 20.4 \mathrm{mmol})$ in THF (41 mL) at $78^{\circ} \mathrm{C}$. After the yellow mixture was stirred for $30 \mathrm{~m}, 2$-(4-iodo-butoxy)-tetrahydro-pyran $(4.43 \mathrm{~g}, 15.6 \mathrm{mmol})$ was added at $-78^{\circ} \mathrm{C}$. The reaction mixture was stirred at $-78^{\circ} \mathrm{C}$ for 1 $\mathrm{h}$ and at room temperature for $20 \mathrm{~h}$. After quenching the reaction with water $(80 \mathrm{~mL})$, the aqueous layer was extracted with diethyl ether $(3 \times 80 \mathrm{~mL})$, and the combined organic layers were washed sequentially with water $(100 \mathrm{~mL})$ and brine $(100 \mathrm{~mL})$ and dried over 
magnesium sulfate. The solvent was removed by rotary evaporation and the crude product was purified by column chromatography (EtOAc:hexanes $=1: 19)$ to give 110d $(6.01 \mathrm{~g}, 18.4 \mathrm{mmol}, 90 \%)$ as a colorless oil.

Compound 110d. A mixture of two diastereomers. $R_{f} 0.35$ (EtOAc:hexanes $=1: 19$ ); IR (neat, $\mathrm{NaCl}) 3067$ (w), 2939 (s), 2867 (s), 1633 (w), 1558 (m), 1440 (m), 1352 (m), 1323 (w), $1297(\mathrm{~m}), 1260(\mathrm{~m}), 1224(\mathrm{w}), 1201(\mathrm{~m}), 1137(\mathrm{~m}), 1120(\mathrm{~m}), 1077(\mathrm{~m}), 1033(\mathrm{~m})$ $\mathrm{cm}^{-1} ;{ }^{1} \mathrm{H} \mathrm{NMR}\left(\mathrm{CDCl}_{3}, 400 \mathrm{MHz}\right) \delta 6.84(\mathrm{dd}, 1 \mathrm{H}, J=4.9,2.9 \mathrm{~Hz}), 6.73(\mathrm{dd}, 1 \mathrm{H}, J=4.9$, $2.9 \mathrm{~Hz}), 4.55(\mathrm{~m}, 1 \mathrm{H}), 3.85(\mathrm{~m}, 1 \mathrm{H}), 3.71(\mathrm{~m}, 1 \mathrm{H}), 3.51-3.42(\mathrm{~m}, 3 \mathrm{H}), 3.37(\mathrm{~m}, 1 \mathrm{H})$, $2.27-2.10(\mathrm{~m}, 3 \mathrm{H}), 2.01(\mathrm{dm}, 1 \mathrm{H}, J=5.9 \mathrm{~Hz}), 1.80(\mathrm{~m}, 1 \mathrm{H}), 1.70(\mathrm{~m}, 1 \mathrm{H}), 1.59-1.42$ $(\mathrm{m}, 8 \mathrm{H}) ;{ }^{13} \mathrm{C} \mathrm{NMR}\left(\mathrm{CDCl}_{3}, 100 \mathrm{MHz}\right) \delta 150.9,141.8$ (2), 129.3, 98.8, 98.7, 71.5, 67.2, $62.24,62.22,57.9,53.3,30.7,29.1,28.9,25.4,23.13,23.11,19.61,19.59$. HRMS calcd. for $\mathrm{C}_{16} \mathrm{H}_{23} \mathrm{BrO}_{2}: \mathrm{m} / \mathrm{z} 326.0882$, found $\mathrm{m} / \mathrm{z} 326.0886$.

\section{Synthesis of Compound $110 f$.}

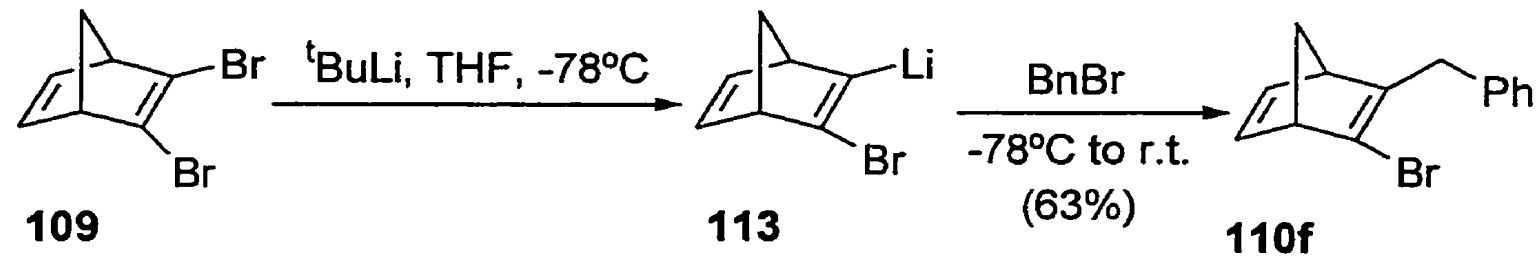

Preparation of 110f. tert-Butyllithium (19.0 mL, $1.7 \mathrm{M}, 32.3 \mathrm{mmol})$ was added to a flame-dried flask containing dibromide $109(4.0 \mathrm{~g}, 16 \mathrm{mmol})$ in THF $(48 \mathrm{~mL})$ at $-78^{\circ} \mathrm{C}$. After the yellow mixture was stirred for $1.2 \mathrm{~h}$, benzyl bromide $(2.85 \mathrm{~mL}, 24.0 \mathrm{mmol})$ was 
added at $-78^{\circ} \mathrm{C}$. The mixture was stirred at $-78^{\circ} \mathrm{C}$ for $2 \mathrm{~h}$ and at room temperature for 22 h. After quenching the reaction with water $(25 \mathrm{~mL})$, the aqueous layer was extracted with diethyl ether $(4 \times 25 \mathrm{~mL})$, and the combined organnic layers were washed sequentially with water $(25 \mathrm{~mL})$ and brine $(25 \mathrm{~mL})$ and dried over magnesium sulfate. The solvent was removed by rotary evaporation and the excess benzyl bromide was removed by bulbto-bulb distillation ( 5 torr at $120^{\circ} \mathrm{C}$ for $3 \mathrm{~h}$ ). The crude product was purified by column chromatography (hexanes) to give $110 \mathrm{f}(2.62 \mathrm{~g}, 10.0 \mathrm{rmmol}, 63 \%)$ as a yellow oil.

Compound 110f. $R_{f} 0.85$ (EtOAc:hexanes = 1:9); LR (neat, $\left.\mathrm{NaCl}\right) 3064$ (m), 3027 (s), $2976(\mathrm{~s}), 2938(\mathrm{~s}), 2867(\mathrm{~s}), 1630(\mathrm{~m}), 1601$ (m), 1557 (m), $1494(\mathrm{~s}), 1453$ (s), $1428(\mathrm{w})$, $1297(\mathrm{~s}), 1264(\mathrm{~m}), 1224(\mathrm{~m}), 1168(\mathrm{w}), 1087(\mathrm{w}), 1074(\mathrm{~m}), 1029(\mathrm{~s}), 1010(\mathrm{~m}) \mathrm{cm}^{-1} ;{ }^{1} \mathrm{H}$ $\operatorname{NMR}\left(\mathrm{CDCl}_{3}, 400 \mathrm{MHz}\right) \delta 7.31-7.20(\mathrm{~m}, 3 \mathrm{H}), 7.12(\mathrm{dm}, 2 \mathrm{H}, J=7.2 \mathrm{~Hz}), 6.81(\mathrm{dd}, 1 \mathrm{H}$, $J=4.9,3.0 \mathrm{~Hz}), 6.55(\mathrm{dd}, 1 \mathrm{H}, J=4.9,2.9 \mathrm{~Hz}), 3.57\left(\mathrm{~d}_{\mathrm{AB}}, 1 \mathrm{H}, J=14.9 \mathrm{~Hz}\right), 3.55$ (br. s, $1 \mathrm{H}), 3.48\left(\mathrm{~d}_{\mathrm{AB}}, 1 \mathrm{H}, J=14.9 \mathrm{~Hz}\right), 3.30(\mathrm{~m}, 1 \mathrm{H}), 2.21(\mathrm{dt}, 1 \mathrm{H}, J=6.0,1.5 \mathrm{~Hz}), 2.00(\mathrm{dt}$, $1 \mathrm{H}, J=6.0,1.6 \mathrm{~Hz}) ;{ }^{13} \mathrm{C} \mathrm{NMR}\left(\mathrm{CDCl}_{3}, 100 \mathrm{MHz}\right) \& 149.7,142.0,140.9,137.5,129.9$, 128.8, 128.3, 126.2, 71.4, 57.9, 53.4, 35.7. HRMS c:alcd. for $\mathrm{C}_{14} \mathrm{H}_{13} \mathrm{Br}: \mathrm{m} / \mathrm{z} 260.0201$, found $\mathrm{m} / \mathrm{z} 260.0189$. 


\section{Synthesis of 1101.}
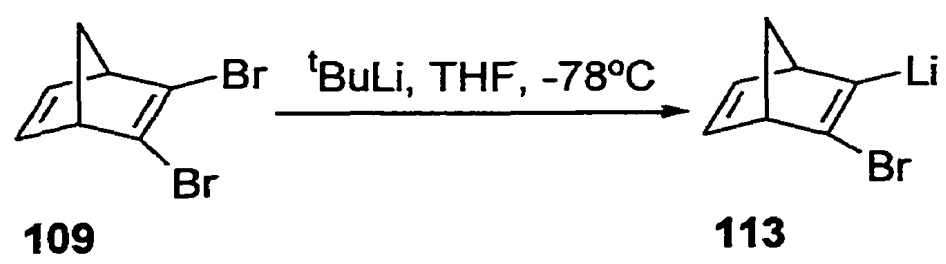

113

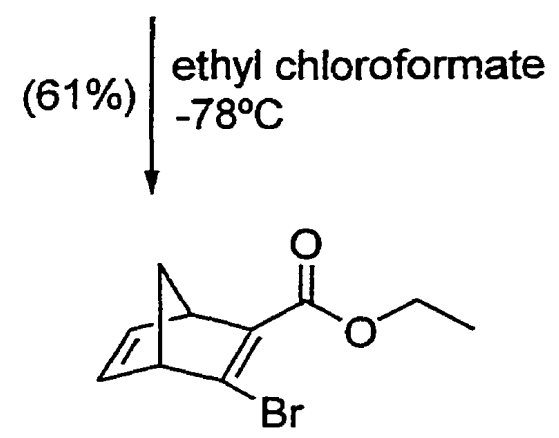

110I

Preparation of 1101 . tert-Butylithium $(1.20 \mathrm{~mL}, 1.7 \mathrm{M}, 2.04 \mathrm{mmol})$ was added to a flame-dried flask containing dibromide $109(219 \mathrm{mg}, 0.876 \mathrm{mmol})$ in THF $(2.4 \mathrm{~mL})$ at $-78^{\circ} \mathrm{C}$. After stirring the reaction mixture for $1 \mathrm{~h}$, the resulting yellow mixture was added to a flame-dried flask containing ethyl chloroformate $(0.40 \mathrm{~mL}, 4.18 \mathrm{mmol})$ in THF (2 $\mathrm{mL}$ ) at $-78^{\circ} \mathrm{C}$. The reaction mixture was stirred at $-78^{\circ} \mathrm{C}$ for $3 \mathrm{~h}$. After quenching the reaction with water $(15 \mathrm{~mL})$, the aqueous layer was extracted with diethyl ether $(4 \times 15$ $\mathrm{mL})$, and the combined organic layers were washed sequentially with water $(20 \mathrm{~mL})$ and brine $(20 \mathrm{~mL})$ and dried over magnesium sulfate. The solvent was removed by rotary evaporation and the crude product was purified by column chromatography (EtOAc:hexanes $=1: 19)$ to give $1101(130 \mathrm{mg}, 0.535 \mathrm{mmol}, 61 \%)$ as a colorless oil.

3-Bromobicyclo[2.2.1] hepta-2,5-diene-2-carboxylic acid ethyl ester (1101). $R_{f} 0.70$ (EtOAc:hexanes = 1:4); IR (neat, $\mathrm{NaCl}) 2980(\mathrm{~m}), 2943(\mathrm{~m}), 2872(\mathrm{w}), 1718$ (s), 1717 
(s), 1704 (s), 1699 (s), 1695 (s), 1559 (m), 1368 (m), 1310 (s), 1290 (s), 1277 (s), 1249

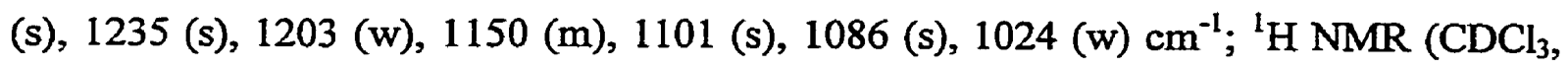
$400 \mathrm{MHz}) \delta 6.90$ (dd, $1 \mathrm{H}, J=4.9,3.0 \mathrm{~Hz}), 6.84(\mathrm{~m}, 1 \mathrm{H}), 4.21(\mathrm{~m}, 2 \mathrm{H}), 3.99(\mathrm{~m}, 1 \mathrm{H})$, $3.67(\mathrm{~m}, 1 \mathrm{H}), 2.30$ (dt, $1 \mathrm{H}, J=6.6,1.5 \mathrm{~Hz}), 2.11(\mathrm{dt}, 1 \mathrm{H}, J=6.7,1.6 \mathrm{~Hz}), 1.30(\mathrm{t}, 3 \mathrm{H}, J=$ $7.1 \mathrm{~Hz}) ;{ }^{13} \mathrm{C} \mathrm{NMR}\left(\mathrm{CDCl}_{3}, 100 \mathrm{MHz}\right) \delta 163.7,148.4,143.0,142.0,140.4,71.7,61.6$, 60.4, 52.0, 14.2. Anal. Calcd. for $\mathrm{C}_{10} \mathrm{H}_{11} \mathrm{BrO}_{2}: \mathrm{C}, 49.41 ; \mathrm{H}, 4.56$. Found $\mathrm{C}, 49.23 ; \mathrm{H}$, 4.58 .

\section{Synthesis of $110 \mathrm{~m}$.}

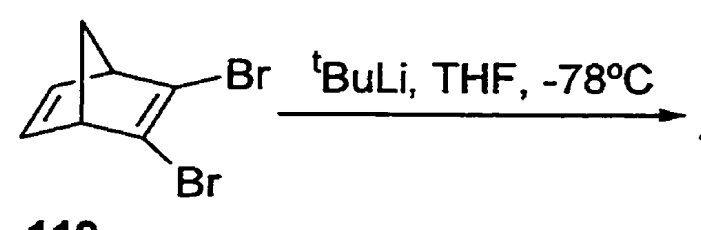

119

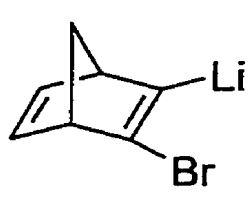

113

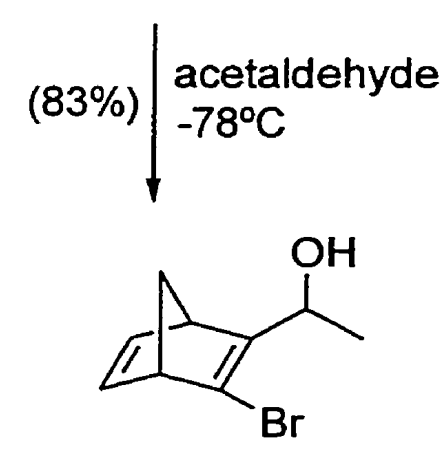

$110 m$

Preparation of $110 \mathrm{~m}$. tert-Butyllithium $(0.50 \mathrm{~mL}, 1.7 \mathrm{M}, 0.850 \mathrm{mmol})$ was added to a flame-dried flask containing dibromide 109 (106 mg, $0.424 \mathrm{mmol})$ in THF (2 mL) at $-78^{\circ} \mathrm{C}$. After the yellow reaction mixture was stirred for $45 \mathrm{~min}$., acetaldehyde $(0.10 \mathrm{~mL}$, 
$2.88 \mathrm{mmol}$ ) was added at $-78^{\circ} \mathrm{C}$. The reaction mixture was stirred at $-78^{\circ} \mathrm{C}$ for $1 \mathrm{~h}$. After quenching the reaction with water $(5 \mathrm{~mL})$, the aqueous layer was extracted with diethyl ether $(3 \times 10 \mathrm{~mL})$, and the combined organic layers were washed sequentially with water $(10 \mathrm{~mL})$ and brine $(10 \mathrm{~mL})$ and dried over magnesium sulfate. The solvent was removed by rotary evaporation and the crude product was purified by column chromatography (EtOAc:hexanes $=1: 4)$ to give $110 \mathrm{~m}(75.9 \mathrm{mg}, 0.353 \mathrm{mmol}, 83 \%, 1: 1$ inseparable mixture of diastereomers) as a colorless oil.

1-(3-Bromobicyclo[2.2.1]hepta-2,5-dien-2-yl)ethanol (110m). $R_{f} 0.33$ (EtOAc:hexanes = 1:4); IR (neat, $\mathrm{NaCl}) 3354$ (br. s), 3069 (w), 2973 (s), 2939 (s), 2869 (s), 1628 (m), $1558(\mathrm{~m}), 1449(\mathrm{~m}), 1368(\mathrm{~m}), 1327(\mathrm{~m}), 1296(\mathrm{~s}), 1268(\mathrm{~m}), 1224(\mathrm{~m}), 1209(\mathrm{~m}), 1091$ (s), $1062(\mathrm{~s}), 1030(\mathrm{~m}), 1009(\mathrm{~m}) \mathrm{cm}^{-1} ;{ }^{1} \mathrm{H}$ NMR $\left(\mathrm{CDCl}_{3}, 400 \mathrm{MHz}\right) \delta 6.86-6.76(\mathrm{~m}$, $2 \mathrm{H}), 4.70$ (q, $0.5 \mathrm{H}, J=6.2 \mathrm{~Hz}$ ), 4.69 (q, $0.5 \mathrm{H}, J=6.2 \mathrm{~Hz}$ ), 3.72 (br. s, $0.5 \mathrm{H}), 3.68$ (br. s, $0.5 \mathrm{H}), 3.50$ (br. s, $1 \mathrm{H}), 2.16(\mathrm{~m}, 1 \mathrm{H}), 2.04(\mathrm{~m}, 1 \mathrm{H}), 1.87$ (br. s, $1 \mathrm{H}), 1.62$ (br. s, $1 \mathrm{H}), 1.33$ $(\mathrm{d}, 1.5 \mathrm{H}, J=6.4 \mathrm{~Hz}), 1.11(\mathrm{~d}, 1.5 \mathrm{H}, J=6.5 \mathrm{~Hz}) ;{ }^{13} \mathrm{C} \mathrm{NMR}\left(\mathrm{CDCl}_{3}, 100 \mathrm{MHz}\right) \delta 152.6$, $152.4,142.9,142.5,141.4,141.2,130.4,130.2,71.8,71.3,64.6,64.5,58.2,58.1,50.0$, 49.5, 20.8, 18.9. Anal. Calcd. for $\mathrm{C}_{9} \mathrm{H}_{11} \mathrm{BrO}$ : C, 50.26; $\mathrm{H}, 5.15$. Found $\mathrm{C}, 50.09$; $\mathrm{H}$, 5.16 . 


\section{Synthesis of $110 n$.}

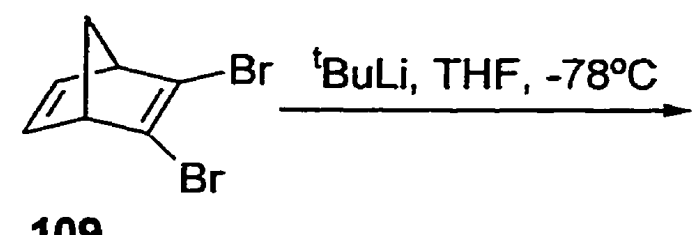

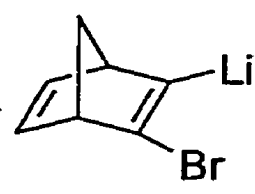

113

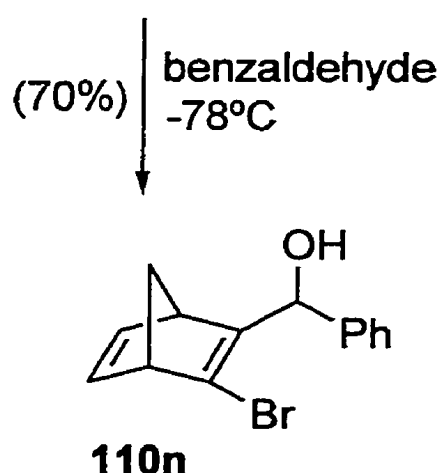

Preparation of $110 \mathrm{n}$. tert-Butyllithium $(1.10 \mathrm{~mL}, 1.7 \mathrm{M}, 1.87 \mathrm{mmol})$ was added to a flame-dried flask containing dibromide 109 (212 $\mathrm{mg}, 0.849 \mathrm{mmol})$ in THF (4.2 $\mathrm{mL})$ at $-78^{\circ} \mathrm{C}$. After the yellow reaction mixture was stirred for $1 \mathrm{~h}$, benzaldehyde $(0.10 \mathrm{~mL}$, $0.98 \mathrm{mmol}$ ) was added at $-78^{\circ} \mathrm{C}$. The reaction mixture was stirred at $-78^{\circ} \mathrm{C}$ for $2 \mathrm{~h}$. After quenching the reaction with water $(15 \mathrm{~mL})$, the aqueous layer was extracted with diethyl ether $(4 \times 15 \mathrm{~mL})$, and the combined organic layers were washed sequentially with water $(15 \mathrm{~mL})$ and brine $(15 \mathrm{~mL})$ and dried over magnesium sulfate. The solvent was removed by rotary evaporation and the crude product was purified by column chromatography (EtOAc:hexanes $=1: 9)$ to give $110 \mathrm{n}(164 \mathrm{mg}, 0.592 \mathrm{mmol}, 70 \%, 1: 1$ inseparable mixture of diastereomers) as a colorless oil.

Compound 110n. $R_{f} 0.55$ (EtOAc:hexanes = 1:4); IR (neat, $\left.\mathrm{NaCl}\right) 3395$ (s), 3064 (m), $3028(\mathrm{~m}), 2992(\mathrm{~s}), 2939$ (s), $2869(\mathrm{~m}), 1626(\mathrm{~m}), 1602(\mathrm{w}), 1557(\mathrm{w}), 1494(\mathrm{~m}), 1449$ 
(s), 1299 (s), 1266 (m), 1224 (m), 1127 (w), 1037 (s), 1021 (s), $1002(\mathrm{~s}) \mathrm{cm}^{-1} ;{ }^{1} \mathrm{H}$ NMR $\left(\mathrm{CDCl}_{3}, 400 \mathrm{MHz}\right) \delta 7.42-7.22(\mathrm{~m}, 5 \mathrm{H}), 6.88(\mathrm{dd}, 0.5 \mathrm{H}, J=5.0,3.0 \mathrm{~Hz}), 6.82(\mathrm{dd}$, $0.5 \mathrm{H}, J=5.0,3.0 \mathrm{~Hz}$ ), $6.58(\mathrm{dd}, 0.5 \mathrm{H}, J=4.9,3.0 \mathrm{~Hz}), 6.22(\mathrm{dd}, 0.5 \mathrm{H}, J=4.9,2.9 \mathrm{~Hz}$ ), 5.70 (br. s, $0.5 \mathrm{H}$ ), 5.68 (d, $0.5 \mathrm{H}, J=2.7 \mathrm{~Hz}$ ), 3.58 (br. s, $0.5 \mathrm{H}$ ), 3.55 (br. $\mathrm{s}, 1 \mathrm{H}$ ), 3.47 (br. $\mathrm{s}, 0.5 \mathrm{H}), 2.26(\mathrm{dm}, 0.5 \mathrm{H}, J=2.0 \mathrm{~Hz}), 2.19(\mathrm{dm}, 0.5 \mathrm{H}, J=6.2 \mathrm{~Hz}), 2.09(\mathrm{dm}, 0.5 \mathrm{H}, J=$ $6.2 \mathrm{~Hz}), 2.03(\mathrm{~d}, 0.5 \mathrm{H}, J=3.4 \mathrm{~Hz}), 1.98(\mathrm{dd}, 1 \mathrm{H}, J=6.2,1.3 \mathrm{~Hz}) ;{ }^{13} \mathrm{C} \mathrm{NMR}\left(\mathrm{CDCl}_{3}, 100\right.$ MHz) $\delta 151.3,151.1,142.7,142.5,141.5,141.1,139.2,139.0,132.0,130.9,128.4$, 128.2, 127.4, 127.3, 125.6, 125.5, 72.1, 70.4, 70.3, 70.0, 58.2, 58.1, 50.8, 49.6. Anal. Calcd. for $\mathrm{C}_{14} \mathrm{H}_{13} \mathrm{BrO}: \mathrm{C}, 60.67 ; \mathrm{H}, 4.73$. Found $\mathrm{C}, 60.83 ; \mathrm{H}, 4.71$. 


\section{Synthesis of 1100 .}

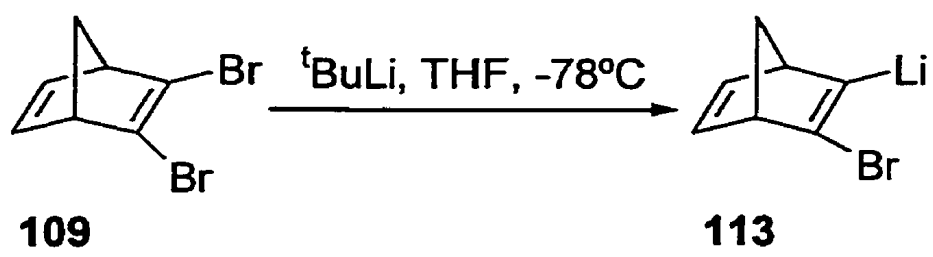

$(73 \%) \mid \begin{aligned} & \text { acetone } \\ & -78^{\circ} \mathrm{C}\end{aligned}$

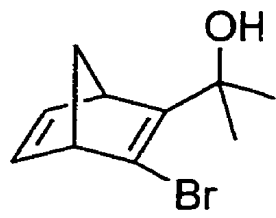

1100

Preparation of 110o. tert-Butyllithium (1.05 $\mathrm{mL}, 1.7 \mathrm{M}, 1.79 \mathrm{mmol}$ ) was added to a flame-dried flask containing dibromide 109 (199 $\mathrm{mg}, 0.797 \mathrm{mmol})$ in THF $(4.0 \mathrm{~mL})$ at $-78^{\circ} \mathrm{C}$. After the yellow reaction mixture was stirred for $1 \mathrm{~h}$, acetone $(0.40 \mathrm{~mL}, 5.4$ mmol) was added at $-78^{\circ} \mathrm{C}$. The reaction mixture was stirred at $-78^{\circ} \mathrm{C}$ for $2 \mathrm{~h}$. After quenching the reaction with water $(15 \mathrm{~mL})$, the aqueous layer was extracted with diethyl ether $(4 \times 15 \mathrm{~mL})$, and the combined organic layers were washed sequentially with water $(15 \mathrm{~mL})$ and brine $(15 \mathrm{~mL})$ and dried over magnesium sulfate. The solvent was removed by rotary evaporation and the crude product was purified by column chromatography (EtOAc:hexanes = 1:9) to give $\mathbf{1 1 0 0}(0.133 \mathrm{mg}, 0.580 \mathrm{mmol}, 73 \%)$ as a colorless oil.

2-(3-Bromobicyclo[2.2.1]hepta-2,5-dien-2-yl)propan-2-ol $\quad(1100) . \quad R_{f} \quad 0.45$ (EtOAc:hexanes = 1:4); IR (neat, NaCl) 3400 (s), 3122 (w), 3069 (w), 2975 (s), 2937 (s), $2869(\mathrm{~m}), 1614(\mathrm{~m}), 1557(\mathrm{~m}), 1463(\mathrm{~m}), 1363(\mathrm{~s}), 1296(\mathrm{~s}), 1269(\mathrm{~m}), 1249(\mathrm{~m}), 1232$ 
(m), $1170(\mathrm{~s}), 1141(\mathrm{~s}), 1058(\mathrm{~m}) \mathrm{cm}^{-1} ;{ }^{1} \mathrm{H} \mathrm{NMR}\left(\mathrm{CDCl}_{3}, 400 \mathrm{MHz}\right) \delta 6.87(\mathrm{dd}, 1 \mathrm{H}, J=$ $5,0,3.3 \mathrm{~Hz}), 6.80(\mathrm{dd}, 1 \mathrm{H}, J=5.0,2.9 \mathrm{~Hz}), 3.67(\mathrm{~m}, 1 \mathrm{H}), 3.47(\mathrm{~m}, 1 \mathrm{H}), 2.17$ (dt, $1 \mathrm{H}, J=$ 6.1, $1.5 \mathrm{~Hz}$ ), 2.13 (br. s, 1H), 1.94 (dt, $1 \mathrm{H}, J=6.1,1.7 \mathrm{~Hz}$ ), 1.38 (s, 3H), $1.37(\mathrm{~s}, 3 \mathrm{H}) ;{ }^{13} \mathrm{C}$ $\mathrm{NMR}\left(\mathrm{CDCl}_{3}, 100 \mathrm{MHz}\right) \delta 154.1,142.2,141.6,126.0,71.9,70.7,60.2,53.0,28.1,28.0$. Anal. Calcd. for $\mathrm{C}_{10} \mathrm{H}_{13} \mathrm{BrO}: \mathrm{C}, 52.42 ; \mathrm{H}, 5.72$. Found $\mathrm{C}, 52.61 ; \mathrm{H}, 5.70$.

\section{Synthesis of 110p.}

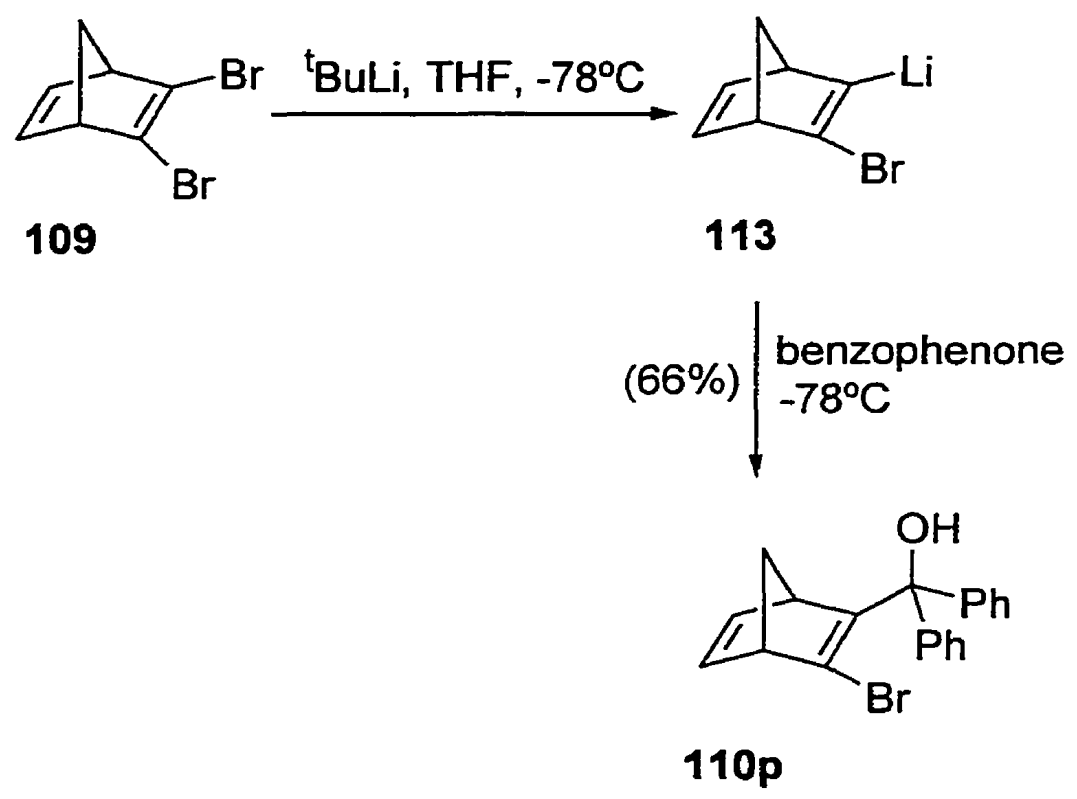

Preparation of 110p. tert-Butyllithium $(1.20 \mathrm{~mL}, 1.7 \mathrm{M}, 2.04 \mathrm{mmol})$ was added to a flame-dried flask containing dibromide $109(225 \mathrm{mg}, 0.902 \mathrm{mmol})$ in THF (4.5 mL) at $-78^{\circ} \mathrm{C}$. After the yellow reaction mixture was stirred for $1 \mathrm{~h}$, benzophenone $(204 \mathrm{mg}$, $1.12 \mathrm{mmol}$ ) was added at $-78^{\circ} \mathrm{C}$. The reaction mixture was stirred at $-78^{\circ} \mathrm{C}$ for $3 \mathrm{~h}$. After quenching the reaction with water $(15 \mathrm{~mL})$, the aqueous layer was extracted with 
diethyl ether $(4 \times 15 \mathrm{~mL})$, and the combined organic layers were washed sequentially with water $(20 \mathrm{~mL})$ and brine $(20 \mathrm{~mL})$ and dried over magnesium sulfate. The solvent was removed by rotary evaporation and the crude product was purified by column chromatography (EtOAc:hexanes $=1: 19)$ to give 110p $(210 \mathrm{mg}, 0.594 \mathrm{mmol}, 66 \%)$ as a colorless oil.

Compound (110p). $R_{f} 0.40$ (EtOAc:hexanes = 1:9); IR (neat, NaCl) 3560 (m), 3061 (m), 2938 (m), 2868 (m), 1557 (w), 1492 (s), 1448 (s), 1329 (m), 1295 (s), 1259 (w), 1210 (w), 1163 (m), 1032 (s), 1017 (s) $\mathrm{cm}^{-1}$; ${ }^{1} \mathrm{H} \mathrm{NMR}\left(\mathrm{CDCl}_{3}, 400 \mathrm{MHz}\right) \delta 7.34$ - 7.25 (m, $10 \mathrm{H}), 6.79(\mathrm{dd}, 1 \mathrm{H}, J=4.7,3.0 \mathrm{~Hz}), 6.48(\mathrm{dd}, 1 \mathrm{H}, J=4.8,2.9 \mathrm{~Hz}), 3.58(\mathrm{~m}, 1 \mathrm{H}), 3.41$ (m, 1H), $2.98(\mathrm{~s}, 1 \mathrm{H}), 2.36$ (dt, $1 \mathrm{H}, J=6.2,1.5 \mathrm{~Hz}), 1.95$ (dt, $1 \mathrm{H}, J=6.3,1.7 \mathrm{~Hz}$ ); ${ }^{13} \mathrm{C}$ $\mathrm{NMR}\left(\mathrm{CDCl}_{3}, 100 \mathrm{MHz}\right) \delta 153.0,143.81,143.77,142.5,140.2,129.7,128.1,128.0$, 127.6, 127.5, 80.7, 70.3, 60.7, 54.5. HRMS calcd. for $\mathrm{C}_{20} \mathrm{H}_{17} \mathrm{BrO}: \mathrm{m} / \mathrm{z} 352.0463$, found $\mathrm{m} / \mathrm{z} 352.0461$. 


\subsubsection{2,3-Disubstituted Norbornadienes from 2,3-Dibromonorbornadiene via Double}

\section{Lithium-Halide Exchange}

Synthesis of $111 f$.

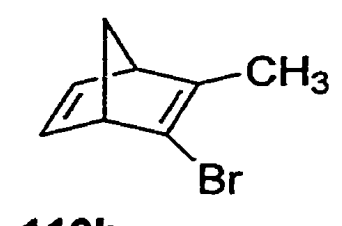

$110 b$

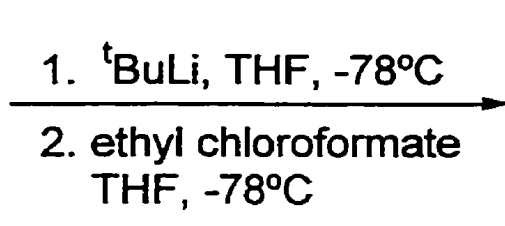

$(77 \%)$

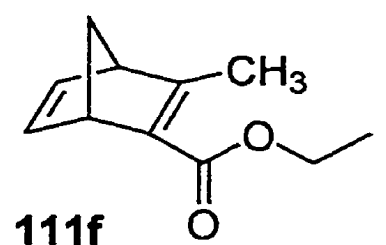

$111 f$

Preparation of 111f. tert-Butyllithium (1.10 mL, 1.7M, $1.87 \mathrm{mmol})$ was added to a flame-dried flask containing bromide $110 \mathrm{~b}(158 \mathrm{mg}, 0.852 \mathrm{mmol})$ in THF $(2.0 \mathrm{~mL})$ at $-78^{\circ} \mathrm{C}$. After stirring the reaction mixture for $1 \mathrm{~h}$, the resulting yellow mixture was added to a flame-dried flask containing ethyl chloroformate $(0.38 \mathrm{~mL}, 4.0 \mathrm{mmol})$ in THF (2.5 $\mathrm{mL}$ ) at $-78^{\circ} \mathrm{C}$. The mixture was stirred at $-78^{\circ} \mathrm{C}$ for $3 \mathrm{~h}$. After quenching the reaction with water $(15 \mathrm{~mL})$, the aqueous layer was extracted with diethyl ether $(4 \times 15 \mathrm{~mL})$, and the combined organic layers were washed sequentially with water $(20 \mathrm{~mL})$ and brine (20 $\mathrm{mL}$ ) and dried over magnesium sulfate. The solvent was removed by rotary evaporation and the crude product was purified by column chromatography (EtOAc:hexanes $=1: 9$ ) to give $111 \mathrm{f}$ ( $109 \mathrm{mg}, 0.655 \mathrm{mmol}, 77 \%$ ) as a colorless oil.

3-Methylbicyclo[2.2.1]hepta-2,5-diene-2-carboxylic acid ethyl ester (111f). $R_{f} 0.50$ (EtOAc:hexanes = 1:4); IR (neat, NaCl) 2978 (m), 2939 (m), 2870 (w), 1702 (s), 1632 (m), $1558(\mathrm{w}), 1370$ (m), 1331 (m), $1314(\mathrm{~m}), 1295$ (s), 1249 (m), 1237 (s), 1189 (m), $1146(\mathrm{~m}), 1101(\mathrm{~m}), 1066(\mathrm{~m}), 1047(\mathrm{~m}), 1019(\mathrm{w}) \mathrm{cm}^{-1} ;{ }^{\mathrm{l}} \mathrm{H} \mathrm{NMR}\left(\mathrm{CDCl}_{3}, 400 \mathrm{MHz}\right) \delta$ 
$6.86(\mathrm{dd}, 1 \mathrm{H}, J=5.0,3.0 \mathrm{~Hz}), 6.70(\mathrm{dd}, 1 \mathrm{H}, J=4.9,3.2 \mathrm{~Hz}), 4.14(\mathrm{~m}, 2 \mathrm{H}), 3.86(\mathrm{br} . \mathrm{s}$, $1 \mathrm{H}), 3.37$ (br. s, $1 \mathrm{H}), 2.19(\mathrm{~s}, 3 \mathrm{H}), 2.02(\mathrm{dm}, 1 \mathrm{H}, J=6.4 \mathrm{~Hz}), 1.92(\mathrm{dm}, 1 \mathrm{H}, J=6.4 \mathrm{~Hz}$ ), $1.26(\mathrm{t}, 3 \mathrm{H}, J=7.1 \mathrm{~Hz}) ;{ }^{13} \mathrm{C} \mathrm{NMR}\left(\mathrm{CDCl}_{3}, 100 \mathrm{MHz}\right) \delta 169.4,165.9,144.0,140.3$, 138.3, 70.8, 59.6, 58.0, 50.9, 17.1, 14.3. Anal. Calcd. for $\mathrm{C}_{11} \mathrm{H}_{14} \mathrm{O}_{2}: \mathrm{C}, 74.13 ; \mathrm{H}, 7.92$. Found C, 73.99; H, 7.95.

\section{Synthesis of 111g.}

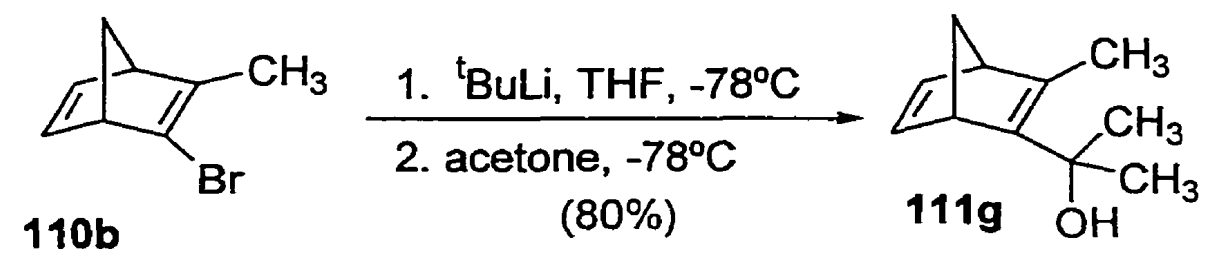

Preparation of $111 \mathrm{~g}$. tert-Butyllithium $(0.80 \mathrm{~mL}, 1.7 \mathrm{M}, 1.4 \mathrm{mmol})$ was added to a flame-dried flask containing bromide $110 \mathrm{~b}(116 \mathrm{mg}, 0.627 \mathrm{mmol})$ in THF $(3.0 \mathrm{~mL})$ at $-78^{\circ} \mathrm{C}$. After the yellow reaction mixture was stirred for $1 \mathrm{~h}$, acetone $(0.35 \mathrm{~mL}, 4.8$ mmol) was added at $-78^{\circ} \mathrm{C}$. The reaction mixture was stirred at $-78^{\circ} \mathrm{C}$ for $3 \mathrm{~h}$. After quenching the reaction with water $(15 \mathrm{~mL})$, the aqueous layer was extracted with diethyl ether $(4 \times 15 \mathrm{~mL})$, and the combined organic layers were washed sequentially with water $(20 \mathrm{~mL})$ and brine $(20 \mathrm{~mL})$ and dried over magnesium sulfate. The solvent was removed by rotary evaporation and the crude product was purified by column chromatography (EtOAc:hexanes = 1:4) to give $\mathbf{1 1 1 g}(82 \mathrm{mg}, 0.50 \mathrm{mmol}, 80 \%)$ as a colorless oil. 
(EtOAc:hexanes = 1:4); IR (neat, $\mathrm{NaCl}) 3384$ (s), 3063 (m), 2971 (s), 2932 (s), 2864 (s), 1557 (w), 1448 (m), 1372 (m), 1299 (s), 1250 (m), $1236(\mathrm{~m}), 1174(\mathrm{~m}), 1132(\mathrm{~m}), 1112$ (m), $1023(\mathrm{w}) \mathrm{cm}^{-1} ;{ }^{1} \mathrm{H} \mathrm{NMR}\left(\mathrm{CDCl}_{3}, 400 \mathrm{MHz}\right) \delta 6.76(\mathrm{~m}, 2 \mathrm{H}), 3.48(\mathrm{~m}, 1 \mathrm{H}), 3.16(\mathrm{~m}$, 1H), $1.92(\mathrm{~s}, 3 \mathrm{H}), 1.89(\mathrm{dm}, 1 \mathrm{H}, J=5.7 \mathrm{~Hz}), 1.75(\mathrm{dm}, 1 \mathrm{H}, J=5.7 \mathrm{~Hz}), 1.53$ (br. s, $1 \mathrm{H})$, $1.34(\mathrm{~s}, 3 \mathrm{H}), 1.32(\mathrm{~s}, 3 \mathrm{H}) ;{ }^{13} \mathrm{C} \mathrm{NMR}\left(\mathrm{CDCl}_{3}, 100 \mathrm{MHz}\right) \delta 150.3,143.0,142.9,141.9$, 72.4, 70.0, 57.6, 52.5, 29.2, 28.8, 15.9. HRMS calcd. for $\mathrm{C}_{11} \mathrm{H}_{16} \mathrm{O}: \mathrm{m} / \mathrm{z} 164.1201$, found $\mathrm{m} / \mathrm{z} 164.1206$.

Synthesis of 111i.

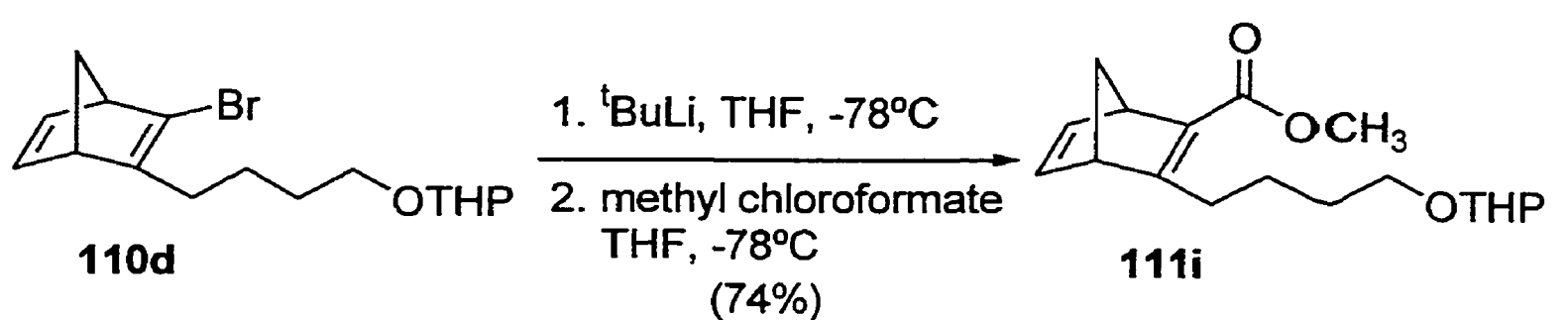

Preparation of 111i. tert-Butyllithium $(14.0 \mathrm{~mL}, 1.7 \mathrm{M}, 23.8 \mathrm{mmol})$ was added to a flame-dried flask containing bromide $110 d(3.00 \mathrm{~g}, 9.17 \mathrm{mmol})$ in THF $(17.0 \mathrm{~mL})$ at $-78^{\circ} \mathrm{C}$. After stirring the reaction mixture for $1 \mathrm{~h}$, the resulting yellow mixture was added via a cannula to a flame-dried flask containing methyl chloroformate $(3.0 \mathrm{~mL}, 39 \mathrm{mmol})$ in THF $(7.0 \mathrm{~mL})$ at $-78^{\circ} \mathrm{C}$. The reaction mixture was stirred at $-78^{\circ} \mathrm{C}$ for $3 \mathrm{~h}$. After quenching the reaction with water $(20 \mathrm{~mL})$, the aqueous layer was extracted with diethyl ether $(4 \times 20 \mathrm{~mL})$, and the combined organic layers were washed sequentially with water 
$(25 \mathrm{~mL})$ and brine $(25 \mathrm{~mL})$ and dried over magnesium sulfate. The solvent was removed by rotary evaporation and the crude product was purified by column chromatography (EtOAc:hexanes $=1: 9)$ to give $111 \mathrm{i}(2.07 \mathrm{~g}, 6.76 \mathrm{mmol}, 74 \%)$ as a colorless oil.

Compound 111i. A mixture of two diastereomers. $R_{f} 0.55$ (EtOAc:hexanes =1:4); IR (neat, $\mathrm{NaCl}) 2941(\mathrm{~s}), 2868(\mathrm{~m}), 1700(\mathrm{~s}), 1695(\mathrm{~s}), 1558(\mathrm{w}), 1435(\mathrm{~m}), 1342(\mathrm{~m}), 1295$ $(\mathrm{s}), 1238(\mathrm{~s}), 1200(\mathrm{~m}), 1163(\mathrm{~m}), 1138(\mathrm{~m}), 1119(\mathrm{~m}), 1103(\mathrm{~m}), 1074(\mathrm{~s}), 1034(\mathrm{~s}), 1022$ (m) $\mathrm{cm}^{-1} ;{ }^{1} \mathrm{H} \mathrm{NMR}\left(\mathrm{CDCl}_{3}, 400 \mathrm{MHz}\right) \delta 6.85$ (dd, $\left.1 \mathrm{H}, J=5.0,3.0 \mathrm{~Hz}\right), 6.67$ (dd, $1 \mathrm{H}, J=$ $4.7,3.3 \mathrm{~Hz}), 4.55(\mathrm{~m}, 1 \mathrm{H}), 3.86-3.84(\mathrm{~m}, 2 \mathrm{H}), 3.72(\mathrm{~m}, 1 \mathrm{H}), 3.69(\mathrm{~s}, 3 \mathrm{H}), 3.50-3.48$ $(\mathrm{m}, 2 \mathrm{H}), 3.37(\mathrm{~m}, 1 \mathrm{H}), 2.76-2.64(\mathrm{~m}, 2 \mathrm{H}), 2.01(\mathrm{dm}, 1 \mathrm{H}, J=6.4 \mathrm{~Hz}), 1.94(\mathrm{dm}, 1 \mathrm{H}, J=$ $6.4 \mathrm{~Hz}), 1.80(\mathrm{~m}, 1 \mathrm{H}), 1.69(\mathrm{~m}, 1 \mathrm{H}), 1.61-1.44(\mathrm{~m}, 8 \mathrm{H}) ;{ }^{13} \mathrm{C} \mathrm{NMR}\left(\mathrm{CDCl}_{3}, 100 \mathrm{MHz}\right) \delta$ $173.3,166.2,143.8,140.7,138.5,98.81,98.78,71.0,67.2,62.30,62.27,55.9,51.0,50.9$, 30.7, 29.9, 29.3, 25.4, 23.5, 19.64, 19.62. Anal. Calcd. for $\mathrm{C}_{18} \mathrm{H}_{26} \mathrm{O}_{4}: \mathrm{C}, 70.56 ; \mathrm{H}, 8.55$. Found C, 70.67; H, 8.52. 
5.4 Synthetic Procedures for Chapter 4: Intramolecular 1,3-Dipolar Cycloadditions of Norbornadiene-Tethered Nitrile Oxides with a C-3 Substituent

5.4.1 Norbornadiene-Tethered Nitrile Oxides Bearing a Halogen at the C-3 Position

5.4.1.1 Cycloadduct Bearing a Bromo Substituent

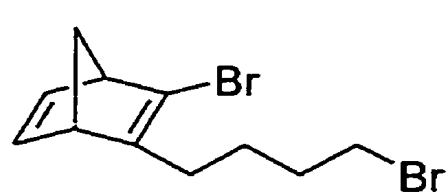

$110 e$

(1)

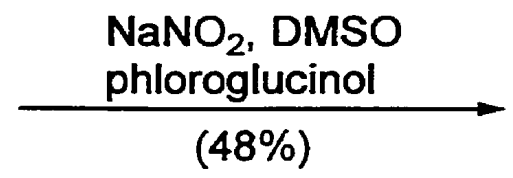

$(48 \%)$

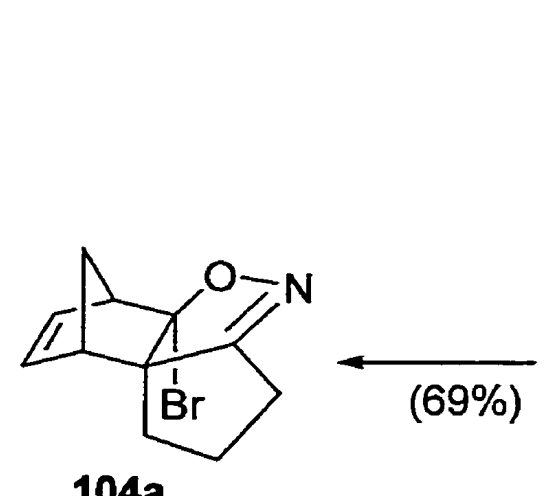

$104 a$
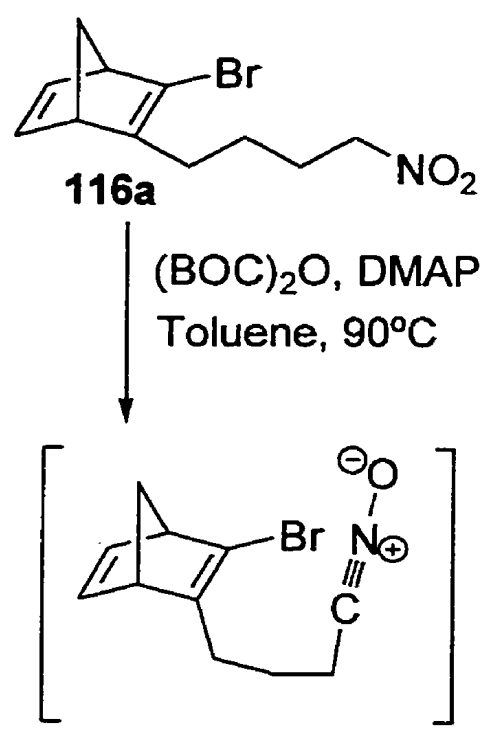

$101 a$

Conversion of Bromide 110e to Nitro Compound 116a. Bromide 110e (1.05 g, 3.42 $\mathrm{mmol})$ in DMSO $(10 \mathrm{~mL})$ was added via a cannula to a flask containing $\mathrm{NaNO}_{2}(896 \mathrm{mg}$, $13.0 \mathrm{mmol})$ and phloroglucinol (800 $\mathrm{mg}, 4.94 \mathrm{mmol})$ in DMSO $(15 \mathrm{~mL})$. The light brown reaction mixture was stirred at room temperature for $48 \mathrm{~h}$. After quenching the reaction with water $(50 \mathrm{~mL})$, the aqueous layer was extracted with diethyl ether $(4 \times 50$ $\mathrm{mL})$ and the combined organic layers were washed sequentially with water $(100 \mathrm{~mL})$ and 
brine $(100 \mathrm{~mL})$ and dried over magnesium sulfate. The solvent was removed by rotary evaporation and the crude product was purified by column chromatography (EtOAc:hexanes $=1: 9)$ to give 116a (448 $\mathrm{mg}, 1.65 \mathrm{mmol}, 48 \%$ ) as a colorless viscous oil.

2-Bromo-3-(4-nitrobutyl)bicyclo[2.2.1]hepta-2,5-diene $\quad$ (116a). $\quad \begin{array}{ll}R_{f} & 0.68\end{array}$ (EtOAc:hexanes = 1:9); IR (neat, NaCl) 3067 (w), 2975 (m), 2938 (m), 2867 (m), 1633 (w), 1553 (s), 1455 (w), 1434 (m), 1383 (m), 1297 (m), 1261 (w), 1225 (w) cm ${ }^{-1} ;{ }^{1} \mathrm{H}$ NMR $\left(\mathrm{CDCl}_{3}, 400 \mathrm{MHz}\right) \delta 6.84(\mathrm{dd}, 1 \mathrm{H}, J=5.1,3.3 \mathrm{~Hz}), 6.73(\mathrm{dd}, 1 \mathrm{H}, J=5.1,2.9 \mathrm{~Hz})$, $4.35(\mathrm{t}, 2 \mathrm{H}, J=2.0 \mathrm{~Hz}), 3.46(\mathrm{~m}, 1 \mathrm{H}), 3.40$ (br. s, $1 \mathrm{H}), 2.29-2.14(\mathrm{~m}, 3 \mathrm{H}), 2.02$ (dt, $1 \mathrm{H}$, $J=6.0,1.6 \mathrm{~Hz}), 1.89(\mathrm{~m}, 2 \mathrm{H}), 1.49(\mathrm{~m}, 2 \mathrm{H}) ;{ }^{13} \mathrm{C} \mathrm{NMR}\left(\mathrm{CDCl}_{3}, 100 \mathrm{MHz}\right) \delta$ 149.7, $141.9,141.6,130.4,75.2,71.6,57.9,53.2,28.1,26.4,22.9$. HRMS calcd. for $\mathrm{C}_{11} \mathrm{H}_{14} \mathrm{BrNO}_{2}: \mathrm{m} / \mathrm{z} 271.0208$, found $\mathrm{m} / \mathrm{z} 271.0207$.

In situ Generation of Nitrile Oxide from Nitro Compound 116a and Subsequent Cycloaddition.

Di-tert-butyl dicarbonate, $(\mathrm{BOC})_{2} \mathrm{O}(290 \mathrm{mg}, 1.33 \mathrm{mmol})$, in toluene $(2 \mathrm{~mL})$ was added via a cannula to a flame-dried flask containing the nitro compound 116a (104 mg, 0.382 mmol), 4-dimethylaminopyridine, DMAP (6.5 $\mathrm{mg}, 0.0530 \mathrm{mmol})$, in toluene $(2 \mathrm{~mL})$. The reaction mixture was stirred at $90^{\circ} \mathrm{C}$ for $48 \mathrm{~h}$. The solvent was removed by rotary evaporation and the crude product was purified by column chromatography (EtOAc:hexanes $=1: 9)$ to give cycloadduct $104 a(67.0 \mathrm{mg}, 0.264 \mathrm{mmol}, 69 \%)$ as white crystals. Recrystallization with $10 \%$ EtOAc/hexanes provided colorless needle-like crystals. 
Cycloadduct 104a. $R_{f} 0.28$ (EtOAc:hexanes = 1:9); IR $\left(\mathrm{CH}_{2} \mathrm{Cl}_{2}\right) 3074(\mathrm{w}), 3025(\mathrm{~m})$, 3011 (s), 2980 (s), 2879 (m), 1648 (w), 1463 (m), 1456 (m), 1452 (m), 1434 (m), 1252 (m), 1218 (w), $1180(\mathrm{~m}), 1130(\mathrm{~m}), 1103(\mathrm{w}), 1059(\mathrm{~m}) \mathrm{cm}^{-1} ;{ }^{1} \mathrm{H}$ NMR $\left(\mathrm{CDCl}_{3}, 400\right.$ MHz) $\delta 6.36(\mathrm{dd}, 1 \mathrm{H}, J=5.7,3.0 \mathrm{~Hz}), 6.21(\mathrm{dd}, 1 \mathrm{H}, J=5.6,3.1 \mathrm{~Hz}), 3.68(\mathrm{~m}, 1 \mathrm{H}), 3.03$ (m, $1 \mathrm{H}), 2.58-2.53(\mathrm{~m}, 2 \mathrm{H}), 2.28-2.12(\mathrm{~m}, 3 \mathrm{H}), 1.83(\mathrm{dm}, 1 \mathrm{H}, J=9.5 \mathrm{~Hz}), 1.75(\mathrm{dm}$, $1 \mathrm{H}, J=9.6 \mathrm{~Hz}), 1.37(\mathrm{~m}, 1 \mathrm{H}) ;{ }^{13} \mathrm{CNMR}\left(\mathrm{CDCl}_{3}, 100 \mathrm{MHz}\right) \delta 171.0,137.4,136.0,114.1$, 79.1, 58.5, 47.1, 44.0, 34.1, 25.9, 21.6. Anal. Calcd. for $\mathrm{C}_{11} \mathrm{H}_{12} \mathrm{BrNO}$ : C, 51.99; $\mathrm{H}, 4.76$; N, 5.51. Found C, 51.79; H, 4.79; N, 5.54. 


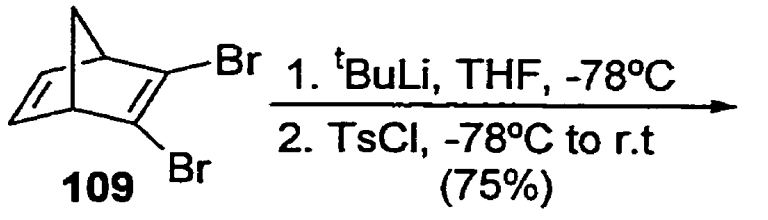

(91\%)<smiles>ClC1=C(Br)C2C=CC1C2</smiles>

1. 'BuLi, THF, $-78^{\circ} \mathrm{C}$

2. 1,4-dibromobutane $-78^{\circ} \mathrm{C}$ to r.t.<smiles>O=[N+]([O-])CCCCC1=C(Cl)C2C=CC1C2</smiles>
$116 b$ $(\mathrm{BOC})_{2} \mathrm{O}, \mathrm{DMAP}$ Toluene, $90^{\circ} \mathrm{C}$

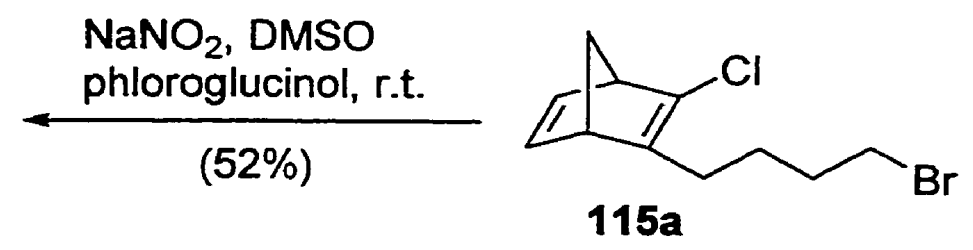<smiles>O=[N+]([O-])CCCC1=C(Cl)C2C=CC1C2</smiles><smiles>CO[Mg]</smiles>

Conversion of 109 to $110 \mathrm{i}$. tert-Butyllithium $(1.00 \mathrm{~mL}, 1.7 \mathrm{M}, 1.70 \mathrm{mmol})$ was added to a flame-dried flask containing dibromide 109 (213 mg, $0.852 \mathrm{mmol})$ in THF (4 mL) at $-78^{\circ} \mathrm{C}$. After the yellow mixture was stirred for $30 \mathrm{~min}$., $p$-toluenesulfonyl chloride $(345$ $\mathrm{mg}, 1.81 \mathrm{mmol}$ ) was added at $-78^{\circ} \mathrm{C}$. The reaction mixture was stirred at $-78^{\circ} \mathrm{C}$ for 45 min. and at room temperature for $1 \mathrm{~h}$. After quenching the reaction with water $(5 \mathrm{~mL})$, the aqueous layer was extracted with diethyl ether $(3 \times 10 \mathrm{~mL})$, and the combined organic 
layers were washed sequentially with water $(10 \mathrm{~mL})$ and brine $(10 \mathrm{~mL})$ and dried over magnesium sulfate. The solvent was removed by rotary evaporation and the crude product was purified by column chromatography (hexanes) to give $110 \mathrm{i}(130 \mathrm{mg}, 0.635$ $\mathrm{mmol}, 75 \%)$ as a colorless oil.

2-Bromo-3-chlorobicyclo[2.2.1]hepta-2,5-diene (110i). $\quad R_{f} 0.76$ (hexanes); ${ }^{1} \mathrm{H}$ NMR $\left(\mathrm{CDCl}_{3}, 400 \mathrm{MHz}\right) \delta 6.89(\mathrm{~m}, 2 \mathrm{H}), 3.60(\mathrm{~m}, 1 \mathrm{H}), 3.52(\mathrm{~m}, 1 \mathrm{H}), 2.43(\mathrm{dtd}, 1 \mathrm{H}, J=6.3$, $1.6,0.3 \mathrm{~Hz}), 2.19(\mathrm{dt}, 1 \mathrm{H}, J=6.3,1.9 \mathrm{~Hz}) ;{ }^{13} \mathrm{C} \mathrm{NMR}\left(\mathrm{CDCl}_{3}, 100 \mathrm{MHz}\right) \delta 144.0,141.6$, $141.1,128.3,71.5,57.8,56.8$. Spectral data were identical to those reported in the literature. $^{64}$

Conversion of 110i to $115 \mathrm{a}$. tert-Butyllithium $(12.5 \mathrm{~mL}, 1.7 \mathrm{M}, 21.3 \mathrm{mmol})$ was added to a flame-dried flask containing $110 \mathrm{i}(2.07 \mathrm{~g}, 10.1 \mathrm{mmol})$ in THF $(50 \mathrm{~mL})$ at $-78^{\circ} \mathrm{C}$. After stirring the reaction mixture for $1 \mathrm{~h}$, the resulting yellow mixture was added to a flame-dried flask containing 1,4-dibromobutane $(3.5 \mathrm{~mL}, 29.3 \mathrm{mmol})$ in THF (52 $\mathrm{mL})$ at $-78^{\circ} \mathrm{C}$. The reaction mixture was stirred at $-78^{\circ} \mathrm{C}$ for $1 \mathrm{~h}$ and at room temperature for 19 h. After quenching the reaction with water $(150 \mathrm{~mL})$, the aqueous layer was extracted with diethyl ether $(4 \times 150 \mathrm{~mL})$, and the combined organic layers were washed sequentially with water $(150 \mathrm{~mL})$ and brine $(150 \mathrm{~mL})$ and dried over magnesium sulfate. The solvent was removed by rotary evaporation and the crude product was purified by vacuum distillation to give two fractions. The first fraction $\left(2-5.5\right.$ torr at $\left.70^{\circ} \mathrm{C}-80^{\circ} \mathrm{C}\right)$ contained mainly the excess $1,4-$ dibromobutane. The second fraction $\left(0.5\right.$ torr at $70^{\circ} \mathrm{C}-$ $\left.80^{\circ} \mathrm{C}\right)$ contained $115 \mathrm{a}(2.40 \mathrm{~g}, 9.17 \mathrm{mmol}, 91 \%)$ as a colorless oil. 
2-(4-Bromobutyl)-3-chlorobicyclo[2.2.1]hepta-2,5-diene (115a). $R_{f} 0.63$ (hexanes); $\mathbb{R}$ (neat, $\mathrm{NaCl}) 2974$ (s), 2938 (s), 2867 (m), 1639 (w), 1558 (w), 1452 (m), 1297 (s), 1267 (m), 1249 (m), 1225 (m), 1093 (w) cm ${ }^{-1}$; ${ }^{\mathrm{H}} \mathrm{NMR}\left(\mathrm{CDCl}_{3}, 400 \mathrm{MHz}\right) \delta 6.86$ (dd, $1 \mathrm{H}, J=$ $5.0,3.0 \mathrm{~Hz}$ ), 6.78 (dd, $1 \mathrm{H}, J=5.0,3.0 \mathrm{~Hz}$ ), 3.45 (br. s, $1 \mathrm{H}$ ), 3.40 (t, $2 \mathrm{H}, J=6.7 \mathrm{~Hz}$ ), 3.38 (br. s, 1H), $2.28-2.14(\mathrm{~m}, 3 \mathrm{H}), 2.03(\mathrm{dm}, 1 \mathrm{H}, J=6.0 \mathrm{~Hz}), 1.76(\mathrm{~m}, 2 \mathrm{H}), 1.56(\mathrm{~m}, 2 \mathrm{H})$; ${ }^{13} \mathrm{C} \mathrm{NMR}\left(\mathrm{CDCl}_{3}, 100 \mathrm{MHz}\right) \delta 146.4,142.2,141.8,140.8,71.2,56.3,52.9,33.7,31.9$, 26.6, 25.0.

Conversion of 115a to Nitro Compound 116b. To a flame-dried flask containing 115a (501 $\mathrm{mg}, 1.92 \mathrm{mmol})$ in DMSO $(10 \mathrm{~mL}), \mathrm{NaNO}_{2}(729 \mathrm{mg}, 10.6 \mathrm{mmol})$ and phloroglucinol ( $583 \mathrm{mg}, 3.60 \mathrm{mmol}$ ) were added. The light brown reaction mixture was stirred at room temperature for $64 \mathrm{~h}$. After quenching the reaction with water $(25 \mathrm{~mL})$, the aqueous layer was extracted with diethyl ether $(4 \times 25 \mathrm{~mL})$ and the combined organic layers were washed sequentially with water $(25 \mathrm{~mL})$ and brine $(25 \mathrm{~mL})$ and dried over magnesium sulfate. The solvent was removed by rotary evaporation and the crude product was purified by column chromatography (EtOAc:hexanes $=1: 9$ ) to give 116b (227 mg, $0.995 \mathrm{mmol}, 52 \%$ ) as a colorless viscous oil.

2-Chloro-3-(4-nitrobutyl)bicyclo[2.2.1]hepta-2,5-diene $\quad(116 \mathrm{~b}) . \quad R_{f} \quad 0.63$ (EtOAc:hexanes = 1:4); IR (neat, $\mathrm{NaCl}) 2976$ (m), 2939 (m), 2869 (m), 1639 (w), 1553 (s), 1453 (m), 1434 (m), 1382 (m), 1297 (m), 1226 (w), 1097 (w), 1045 (m), 1015 (w) $\mathrm{cm}^{-1} ;{ }^{1} \mathrm{H} \mathrm{NMR}\left(\mathrm{CDCl}_{3}, 400 \mathrm{MHz}\right) \delta 6.86(\mathrm{dd}, 1 \mathrm{H}, J=5.0,2.7 \mathrm{~Hz}), 6.76(\mathrm{dd}, 1 \mathrm{H}, J=5.0$, $2.9 \mathrm{~Hz}$ ), 4.36 (t, 2H, $J=6.9 \mathrm{~Hz}$ ), 3.39 (br.s, $2 \mathrm{H}), 2.25$ (m, 2H), 2.17 (dm, $1 \mathrm{H}, J=6.0 \mathrm{~Hz}$ ), $2.03(\mathrm{dm}, 1 \mathrm{H}, J=6.0 \mathrm{~Hz}), 1.89$ (p, 2H, $J=7.3 \mathrm{~Hz}), 1.50(\mathrm{~m}, 2 \mathrm{H}) ;{ }^{13} \mathrm{C} \mathrm{NMR}\left(\mathrm{CDCl}_{3}, 100\right.$ 
$\mathrm{MHz}) \delta 145.8,142.1,141.9,141.4,75.3,71.3,56.4,52.9,26.7,26.5,23.2$. Anal. Calcd. for $\mathrm{C}_{11} \mathrm{H}_{14} \mathrm{ClNO}_{2}: \mathrm{C}, 58.03 ; \mathrm{H}, 6.20$. Found $\mathrm{C}, 58.01 ; \mathrm{H}, 6.21$.

\section{In situ Generation of Nitrile Oxide from Nitro Compound $116 b$ and Subsequent} Cycloaddition.

Di-tert-butyl dicarbonate, $(\mathrm{BOC})_{2} \mathrm{O}(493 \mathrm{mg}, 2.26 \mathrm{mmol})$, in toluene $(3 \mathrm{~mL})$ was added via a cannula to a flame-dried flask containing the nitro compound $116 \mathrm{~b}(138 \mathrm{mg}, 0.606$ mmol), 4-dimethylaminopyridine, DMAP (163 mg, $1.33 \mathrm{mmol})$, in toluene $(5.5 \mathrm{~mL})$. The reaction mixture was stirred at $90^{\circ} \mathrm{C}$ for $72 \mathrm{~h}$. The solvent was removed by rotary evaporation and the crude product was purified by column chromatography (EtOAc:hexanes $=1: 4)$ to give cycloadduct $104 \mathrm{~b}(114 \mathrm{mg}, 0.544 \mathrm{mmol}, 89 \%)$ as a colorless viscous oil.

Cycloadduct 104b. $R_{f} 0.47$ (EtOAc:hexanes = 1:4); $\mathrm{IR}\left(\mathrm{CH}_{2} \mathrm{Cl}_{2}\right) 3073(\mathrm{w}), 2979(\mathrm{~s})$, $2883(\mathrm{~m}), 1454(\mathrm{~m}), 1429(\mathrm{~m}), 1326(\mathrm{~s}), 1251(\mathrm{~m}), 1062(\mathrm{~m}), 1013(\mathrm{~s}) \mathrm{cm}^{-1} ;{ }^{\mathrm{l}} \mathrm{H}$ NMR $\left(\mathrm{CDCl}_{3}, 400 \mathrm{MHz}\right) \delta 6.35(\mathrm{dd}, 1 \mathrm{H}, J=5.7,3.0 \mathrm{~Hz}), 6.25(\mathrm{dd}, 1 \mathrm{H}, J=5.7,3.1 \mathrm{~Hz}), 3.54$ (dm, $1 \mathrm{H}, J=1.4 \mathrm{~Hz}$ ), 3.08 (br. s, $1 \mathrm{H}), 2.61-2.48(\mathrm{~m}, 2 \mathrm{H}), 2.33-2.17(\mathrm{~m}, 2 \mathrm{H}), 2.10-$ $2.02(\mathrm{~m}, 1 \mathrm{H}), 1.81(\mathrm{dm}, 1 \mathrm{H}, J=9.6 \mathrm{~Hz}), 1.73(\mathrm{dm}, 1 \mathrm{H}, J=9.6 \mathrm{~Hz}), 1.39(\mathrm{ddd}, 1 \mathrm{H}, J=$ $13.1,7.0,3.0 \mathrm{~Hz}) ;{ }^{13} \mathrm{C} \mathrm{NMR}\left(\mathrm{CDCl}_{3}, 100 \mathrm{MHz}\right) \delta 171.0,136.6,135.9,118.3,78.9,57.0$, 47.9, 44.3, 31.3, 26.0, 21.6. Anal. Calcd. for $\mathrm{C}_{11} \mathrm{H}_{12} \mathrm{CINO}$ : $\mathrm{C}, 63.01$; $\mathrm{H}, 5.77$; Found $\mathrm{C}$, $63.00 ; \mathrm{H}, 5.74$. 


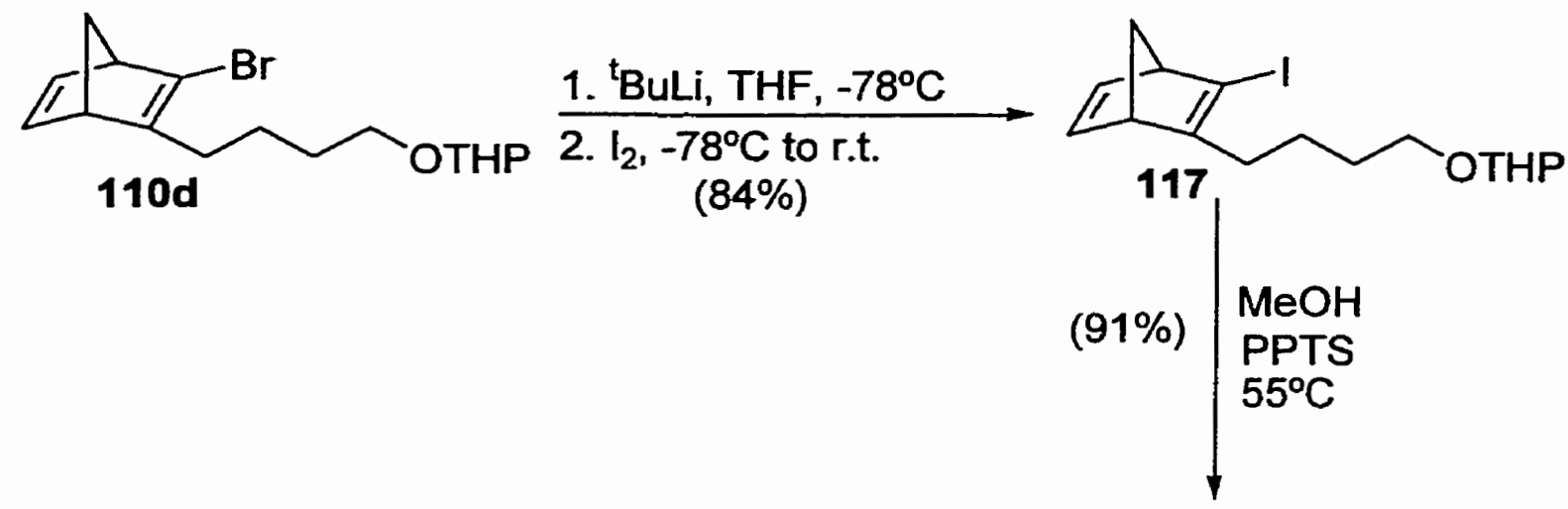

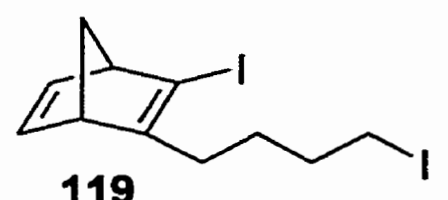

119

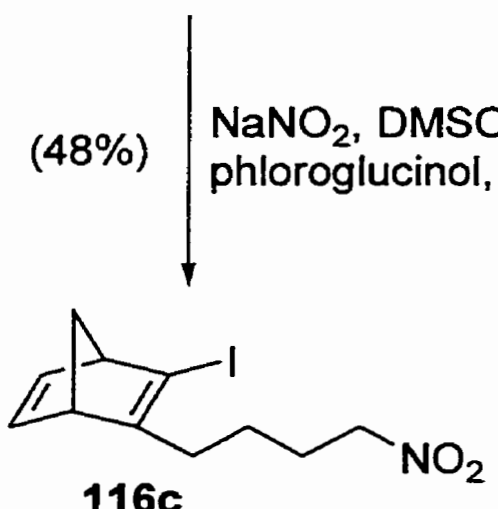

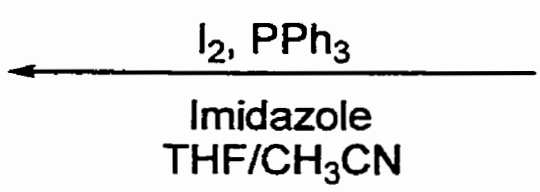

(77\%)

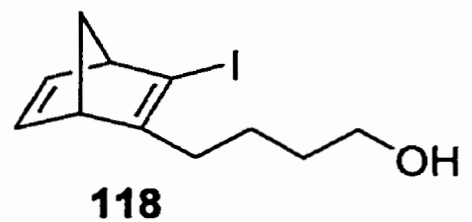

118 $\underset{\text { Toluene, } 90^{\circ} \mathrm{C}}{(\mathrm{BOC})_{2} \mathrm{O}, \mathrm{DMAP}}[\underbrace{-\mathrm{C}_{\mathrm{O}}^{\mathrm{O}}}_{101 \mathrm{c}}$

$(5 \%)$

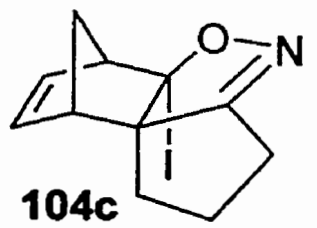


Conversion of 110d to 117. tert-Butyllithium (8.4 mL, 1.7M, 14.3 mmol) was added to a flame-dried flask containing bromide $110 \mathrm{~d}(2.12 \mathrm{~g}, 6.48 \mathrm{mmol})$ in $\mathrm{THF}(15 \mathrm{~mL})$ at $-78^{\circ} \mathrm{C}$. After stirring the reaction mixture for $30 \mathrm{~min}$., the resulting yellow mixture was added via a cannula to a flame-dried flask containing $I_{2}(1.73 \mathrm{~g}, 13.6 \mathrm{mmol})$ in THF (18 $\mathrm{mL}$ ) at $-78^{\circ} \mathrm{C}$. The reaction mixture was stirred at $-78^{\circ} \mathrm{C}$ for $3 \mathrm{~h}$ and at room temperature for $30 \mathrm{~min}$. After quenching the reaction with water $(50 \mathrm{~mL})$, the aqueous layer was extracted with diethyl ether $(4 \times 50 \mathrm{~mL})$, and the combined organic layers were washed sequentially with water $(50 \mathrm{~mL})$ and brine $(50 \mathrm{~mL})$ and dried over magnesium sulfate. The solvent was removed by rotary evaporation and the crude product was purified by column chromatography (EtOAc:hexanes = 1:19) to give $117(2.03 \mathrm{~g}, 5.42 \mathrm{mmol}, 84 \%)$ as a colorless oil.

Iodide 117. A mixture of two diastereomers. $R_{f} 0.70$ (EtOAc:hexanes $=1: 4$ ); $\mathbb{R}$ (neat, $\mathrm{NaCl}) 2938(\mathrm{~s}), 2866(\mathrm{~m}), 1557(\mathrm{w}), 1453(\mathrm{w}), 1440(\mathrm{w}), 1352(\mathrm{w}), 1323(\mathrm{w}), 1297(\mathrm{~m})$, $1259(\mathrm{w}), 1200(\mathrm{~m}), 1137(\mathrm{~m}), 1120(\mathrm{~m}), 1077(\mathrm{~m}), 1034(\mathrm{~s}), 1023(\mathrm{~s}) \mathrm{cm}^{-\mathrm{l}} ;{ }^{\mathrm{I}} \mathrm{H}$ NMR $\left(\mathrm{CDCl}_{3}, 400 \mathrm{MHz}\right) \delta 6.83(\mathrm{dd}, 1 \mathrm{H}, J=5.0,2.9 \mathrm{~Hz}), 6.70(\mathrm{dd}, 1 \mathrm{H}, J=5.0,2.9 \mathrm{~Hz}), 4.56$ $(\mathrm{m}, 1 \mathrm{H}), 3.85(\mathrm{~m}, 1 \mathrm{H}), 3.72(\mathrm{~m}, 1 \mathrm{H}), 3.57$ (br. s, $1 \mathrm{H}), 3.49(\mathrm{~m}, 1 \mathrm{H}), 3.42$ (br. s, $1 \mathrm{H}), 3.38$ $(\mathrm{m}, 1 \mathrm{H}), 2.25(\mathrm{~m}, 1 \mathrm{H}), 2.17-2.10(\mathrm{~m}, 2 \mathrm{H}), 1.99(\mathrm{dm}, 1 \mathrm{H}, J=6.0 \mathrm{~Hz}), 1.82(\mathrm{~m}, 1 \mathrm{H})$, $1.70(\mathrm{~m}, 1 \mathrm{H}), 1.60-1.44(\mathrm{~m}, 8 \mathrm{H}) ;{ }^{13} \mathrm{C} \mathrm{NMR}\left(\mathrm{CDCl}_{3}, 100 \mathrm{MHz}\right) \delta 158.5,142.0,141.4$, $101.0,98.8,98.7,72.1,67.3,67.2,62.2,60.95,60.88,53.4,31.8,30.7,29.1,25.4,23.2$, 19.6. HRMS Calcd. for $\mathrm{C}_{16} \mathrm{H}_{23} \mathrm{IO}_{2}: \mathrm{m} / \mathrm{z} 374.0743$, found $\mathrm{m} / \mathrm{z} 374.0740$.

Conversion of 117 to 118 . To a flame-dried flask containing 117 (1.93 g, $5.15 \mathrm{mmol}$ ) in MeOH (43 mL), pyridium p-toluenesulfonate, PPTS (332 mg, $1.28 \mathrm{mmol}$ ), was added at 
room temperature. The reaction mixture was stirred at $55^{\circ} \mathrm{C}$ for $1 \mathrm{~h}$. After quenching the reaction with water $(50 \mathrm{~mL})$, the aqueous layer was extracted with diethyl ether $(4 \times 50$ $\mathrm{mL})$, and the combined organic layers were washed sequentially with water $(50 \mathrm{~mL})$ and brine $(50 \mathrm{~mL})$ and dried over magnesium sulfate. The solvent was removed by rotary evaporation and the crude product was purified by column chromatography (EtOAc:hexanes = 1:4) to give $118(1.36 \mathrm{~g}, 4.69 \mathrm{mmol}, 91 \%)$ as a colorless oil.

4-(3-Iodobicyclo[2.2.1]hepta-2,5-dien-2-yl)butan-1-ol (118). $R_{f} 0.25$ (EtOAc:hexanes = 1:4); IR (neat, $\mathrm{NaCl}) 3334$ (s), 3066 (w), 2971 (s), 2935 (s), 2865 (s), 1653 (w), 1617 (w), $1557(\mathrm{~m}), 1456(\mathrm{~m}), 1296(\mathrm{~s}), 1259(\mathrm{w}), 1224(\mathrm{~m}), 1160(\mathrm{w}), 1052$ (s), $1023(\mathrm{~m})$, $1000(\mathrm{~m}) \mathrm{cm}^{-1} ;{ }^{1} \mathrm{H} \mathrm{NMR}\left(\mathrm{CDCl}_{3}, 400 \mathrm{MHz}\right) \delta 6.82(\mathrm{dd}, 1 \mathrm{H}, J=5.0,2.9 \mathrm{~Hz}), 6.70(\mathrm{dd}$, $1 \mathrm{H}, J=5.0,2.9 \mathrm{~Hz}), 3.63-3.57(\mathrm{~m}, 3 \mathrm{H}), 3.41(\mathrm{br} . \mathrm{s}, 1 \mathrm{H}), 2.25(\mathrm{~m}, 1 \mathrm{H}), 2.16-2.08(\mathrm{~m}$, $2 \mathrm{H}), 2.00(\mathrm{~m}, 1 \mathrm{H}), 1.53-1.40(\mathrm{~m}, 5 \mathrm{H}) ;{ }^{13} \mathrm{C} \mathrm{NMR}\left(\mathrm{CDCl}_{3}, 100 \mathrm{MHz}\right) \delta 158.4,142.0$, $141.4,101.2,72.1,62.5,60.9,53.4,32.0,31.8,22.6$. Anal. Calcd. for $\mathrm{C}_{11} \mathrm{H}_{15} \mathrm{IO}: \mathrm{C}$, 45.54; H, 5.21. Found C, 45.84; H, 5.05.

Conversion of Alcohol 118 to Iodide 119. To a flame-dried flask containing $\mathrm{PPh}_{3}(4.20$ $\mathrm{g}, 16.0 \mathrm{mmol})$, imidazole $(2.52 \mathrm{~g}, 37.0 \mathrm{mmol})$, acetonitrile $(12 \mathrm{~mL})$ and THF $(8.1 \mathrm{~mL}), \mathrm{I}_{2}$ $(4.30 \mathrm{~g}, 33.9 \mathrm{mmol})$ was added at $0^{\circ} \mathrm{C}$. The reddish-brown reaction mixture was stirred for $15 \mathrm{~min}$. at $0^{\circ} \mathrm{C}$. Alcohol $118(1.06 \mathrm{~g}, 3.65 \mathrm{mmol})$ in acetonitrile $(6 \mathrm{~mL})$ was added via a cannula at $0^{\circ} \mathrm{C}$. The reaction mixture was stirred at room temperature for $4 \mathrm{~h}$. After the reaction was quenched with water $(20 \mathrm{~mL})$, the aqueous layer was extracted with diethyl ether $(4 \times 20 \mathrm{~mL})$, and the combined organic layers were washed sequentially with water $(20 \mathrm{~mL})$, saturated sodium thiosulfate $(20 \mathrm{~mL})$ and brine $(20 \mathrm{~mL})$ and dried over 
magnesium sulfate. The solvent was removed by rotary evaporation and the crude product was purified by column chromatography (hexanes) to give iodide 119 (1.13 g, $2.82 \mathrm{mmol}, 77 \%$ ) as a colorless oil.

2-Iodo-3-(4-iodobutyl)bicyclo[2.2.1] hepta-2,5-diene (119). $R_{f} 0.80$ (EtOAc:hexanes $=$ 1:4); IR (neat, $\mathrm{NaCl}) 3065$ (w), 2971 (s), 2934 (s), 2864 (m), 1616 (w), 1557 (m), 1449 (m), $1426(\mathrm{~m}), 1295(\mathrm{~s}), 1260(\mathrm{~m}), 1216(\mathrm{~s}), 1181(\mathrm{~m}), 1163(\mathrm{~m}) \mathrm{cm}^{-1} ;{ }^{1} \mathrm{H}$ NMR $\left(\mathrm{CDCl}_{3}\right.$, $400 \mathrm{MHz}) \delta 6.85(\mathrm{dd}, 1 \mathrm{H}, J=5.1,2.9 \mathrm{~Hz}), 6.73(\mathrm{dd}, 1 \mathrm{H}, J=5.1,2.9 \mathrm{~Hz}$ ), 3.60 (br. s, $1 \mathrm{H}), 3.43$ (br. s, $1 \mathrm{H}), 3.20(\mathrm{t}, 2 \mathrm{H}, J=6.8 \mathrm{~Hz}), 2.27(\mathrm{~m}, 1 \mathrm{H}), 2.17(\mathrm{dm}, 1 \mathrm{H}, J=6.0 \mathrm{~Hz}$ ), $2.15(\mathrm{~m}, 1 \mathrm{H}), 2.02(\mathrm{dm}, 1 \mathrm{H}, J=6.0 \mathrm{~Hz}), 1.73(\mathrm{~m}, 2 \mathrm{H}), 1.53(\mathrm{~m}, 2 \mathrm{H}) ;{ }^{13} \mathrm{C} \mathrm{NMR}\left(\mathrm{CDCl}_{3}\right.$, $100 \mathrm{MHz}) \delta 158.0,142.0,141.4,101.6,72.2,61.0,53.4,32.5,30.9,27.2,7.1$. HRMS calcd. for $\mathrm{C}_{11} \mathrm{H}_{14} \mathrm{I}_{2}: \mathrm{m} / \mathrm{z} 399.9185$, found $\mathrm{m} / \mathrm{z} 399.9188$.

Conversion of Iodide 119 to Nitro Compound 116c. To a flame-dried flask containing iodide 119 (1.13 g, $2.82 \mathrm{mmol})$ in DMSO (9 mL), $\mathrm{NaNO}_{2}(822 \mathrm{mg}, 11.9 \mathrm{mmol})$ and phloroglucinol ( $688 \mathrm{mg}, 4.24 \mathrm{mmol}$ ) were added. The light brown reaction mixture was stirred at room temperature for $20 \mathrm{~h}$. After quenching the reaction with water $(20 \mathrm{~mL})$, the aqueous layer was extracted with diethyl ether $(4 \times 20 \mathrm{~mL})$ and the combined organic layers were washed sequentially with water $(50 \mathrm{~mL})$ and brine $(50 \mathrm{~mL})$ and dried over magnesium sulfate. The solvent was removed by rotary evaporation and the crude product was purified by column chromatography (EtOAc:hexanes $=1: 9$ ) to give 116c (431 mg, $1.35 \mathrm{mmol}, 48 \%$ ) as a colorless viscous oil.

2-Iodo-3-(4-nitrobutyl)bicyclo[2.2.1]hepta-2,5-diene (116c). $R_{f} 0.61$ (EtOAc:hexanes $=1: 4) ; \mathbb{R}$ (neat, $\mathrm{NaCl}$ ) $3066(\mathrm{w}), 2973(\mathrm{~m}), 2936(\mathrm{~m}), 2866(\mathrm{~m}), 1560(\mathrm{~s}), 1556(\mathrm{~s}), 1549$ 
(s), $1453(\mathrm{~m}), 1434(\mathrm{~m}), 1382(\mathrm{~m}), 1296(\mathrm{~m}), 1258(\mathrm{w}), 1225(\mathrm{w}), 1190(\mathrm{w}), 1163(\mathrm{w})$, 1131 (w), 1022 (w) cm ${ }^{-1} ;{ }^{1} \mathrm{H} \mathrm{NMR}\left(\mathrm{CDCl}_{3}, 400 \mathrm{MHz}\right) \delta 6.85$ (dd, $1 \mathrm{H}, J=5.0,2.9 \mathrm{~Hz}$ ), 6.71 (dd, 1H, $J=5.0,2.9 \mathrm{~Hz}$ ), 4.38 (t, 2H, $J=6.8 \mathrm{~Hz}$ ), 3.60 (br. s, $1 \mathrm{H}$ ), 3.41 (br. s, $1 \mathrm{H}$ ), $2.31(\mathrm{~m}, 1 \mathrm{H}), 2.18(\mathrm{~m}, 1 \mathrm{H}), 2.16(\mathrm{dm}, 1 \mathrm{H}, J=6.1 \mathrm{~Hz}), 2.03(\mathrm{dm}, 1 \mathrm{H}, J=6.1 \mathrm{~Hz}), 1.90$ (m, 2H), $1.52(\mathrm{~m}, 2 \mathrm{H}) ;{ }^{13} \mathrm{C}$ NMR $\left(\mathrm{CDCl}_{3}, 100 \mathrm{MHz}\right) \delta 157.4,142.2,141.2,102.3,75.4$, 72.3, 61.0, 53.4, 31.1, 26.5, 23.1. Anal. Calcd. for $\mathrm{C}_{11} \mathrm{H}_{14} \mathrm{INO}_{2}$ : C, 41.40; H, 4.42. Found $\mathrm{C}, 41.75 ; \mathrm{H}, 4.32$.

\section{In situ Generation of Nitrile Oxide from Nitro Compound 116c and Subsequent Cycloaddition.}

Di-tert-butyl dicarbonate, $(\mathrm{BOC})_{2} \mathrm{O}(518 \mathrm{mg}, 2.37 \mathrm{mmol})$, in toluene $(3 \mathrm{~mL})$ was added via a cannula to a flame-dried flask containing the nitro compound $116 \mathrm{c}(227 \mathrm{mg}, 0.712$ mmol), 4-dimethylaminopyridine, DMAP (195 mg, $1.56 \mathrm{mmol}$ ), in toluene (7 mL). The reaction mixture was stirred at $90^{\circ} \mathrm{C}$ for $137 \mathrm{~h}$. The solvent was removed by rotary evaporation and the crude product was purified by column chromatography (EtOAc:hexanes = 1:4) to give cycloadduct $104 \mathrm{c}(11.4 \mathrm{mg}, 0.0379 \mathrm{mmol}, 5 \%)$ as a colorless viscous oil.

Cycloadduct 104c. Unstable, gradually decomposed upon standing at room temperature (>80\% pure by NMR). $R_{f} 0.69$ (EtOAc:hexanes = 2:3); IR (neat, $\mathrm{NaCl}$ ) 2967(m), 2884 (w), 1747 (s), 1721 (s), 1716 (s), 1453 (w), 1405 (w), 1371 (w), 1320 (w), 1274 (m), 1252 (w), 1185 (w), 1148 (m), 1130 (w) cm ${ }^{-1} ;{ }^{1} \mathrm{H} \mathrm{NMR}\left(\mathrm{CDCl}_{3}, 400 \mathrm{MHz}\right) \delta 6.63$ (dd, $1 \mathrm{H}, J=5.5,2.8 \mathrm{~Hz}$ ), 6.24 (dd, $1 \mathrm{H}, J=5.4,3.4 \mathrm{~Hz}$ ), 3.11 (dd, $1 \mathrm{H}, J=3.1,1.5 \mathrm{~Hz}$ ), 3.03 (m, 1H), $2.93(\mathrm{dm}, 1 \mathrm{H}, J=9.7 \mathrm{~Hz}), 2.45-2.30(\mathrm{~m}, 2 \mathrm{H}), 2.17-2.04(\mathrm{~m}, 3 \mathrm{H}), 1.87(\mathrm{~m}$, 
$1 \mathrm{H}), 1.73-1.66(\mathrm{~m}, 1 \mathrm{H}) ;{ }^{13} \mathrm{C} \mathrm{NMR}\left(\mathrm{CDCl}_{3}, 100 \mathrm{MHz}\right) \delta 215.3,211.8,142.1,134.0$ $60.7,56.0,47.8,46.1,39.3,36.7,19.6$.

\subsubsection{Norbornadiene-Tethered Nitrile Oxides Bearing an Alkyl Substituent at the C-3 Position}

\subsubsection{Cycloadduct Bearing a Methyl Substituent}<smiles>CC1=C(CCCCBr)C2C=CC1C2</smiles>

111b

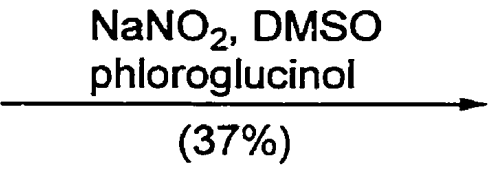

$(37 \%)$<smiles>CC1=C(CCCC[N+](=O)[O-])C2C=CC1C2</smiles>

116d

$(\mathrm{BOC})_{2} \mathrm{O}, \mathrm{DMAP}$ Toluene, $90^{\circ} \mathrm{C}$

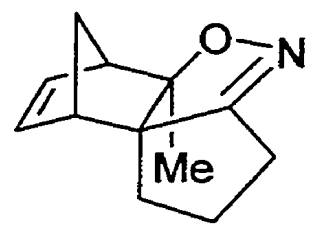

104d
$(82 \%)$

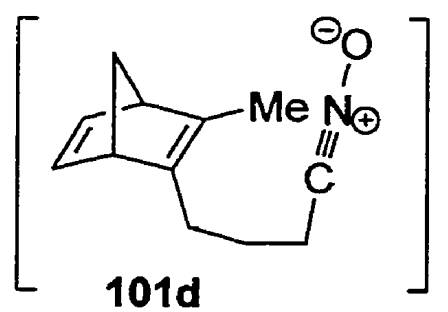

Conversion of Bromide 111b to Nitro Compound 116d. Bromide $111 \mathrm{~b}(1.98 \mathrm{~g}, 8.20$ $\mathrm{mmol})$ in DMSO $(9 \mathrm{~mL})$ was added via a cannula to a flask containing $\mathrm{NaNO}_{2}(1.49 \mathrm{~g}$, $22.0 \mathrm{mmol}$ ) and phloroglucinol (1.52 $\mathrm{g}, 9.40 \mathrm{mmol})$ in DMSO $(9 \mathrm{~mL})$. The light brown reaction mixture was stirred at room temperature for $48 \mathrm{~h}$. After quenching the reaction with water $(50 \mathrm{~mL})$, the aqueous layer was extracted with diethyl ether $(4 \times 50 \mathrm{~mL})$ and 
the combined organic layers were washed sequentially with water $(100 \mathrm{~mL})$ and brine (100 $\mathrm{mL})$ and dried over magnesium sulfate. The solvent was removed by rotary evaporation and the crude product was purified by column chromatography (EtOAc:hexanes $=1: 9)$ to give $116 \mathrm{~d}(630 \mathrm{mg}, 3.04 \mathrm{mmol}, 37 \%)$ as a colorless oil.

2-Methyl-3-(4-Nitrobutyl)bicyclo[2.2.1]hepta-2,5-diene $\quad(116 \mathrm{~d}) . \quad R_{f} \quad 0.40$ (EtOAc:hexanes = 1:9); IR (neat, NaCl) 3063 (w), 2964 (s), 2932 (s), 2863 (m), 1556 (s), $1436(\mathrm{~m}), 1382(\mathrm{~m}), 1302(\mathrm{~m}) \mathrm{cm}^{-1} ;{ }^{1} \mathrm{H} \mathrm{NMR}\left(\mathrm{CDCl}_{3}, 400 \mathrm{MHz}\right) \delta 6.73(\mathrm{~m}, 1 \mathrm{H}), 6.70$ (m, 1H), $4.33(\mathrm{t}, 2 \mathrm{H}, J=7.0 \mathrm{~Hz}), 3.26($ br. s, $1 \mathrm{H}), 3.21$ (br. s, $1 \mathrm{H}), 2.18(\mathrm{~m}, 1 \mathrm{H}), 2.10(\mathrm{~m}$, $1 \mathrm{H}), 1.90-1.81(\mathrm{~m}, 4 \mathrm{H}), 1.68(\mathrm{~s}, 3 \mathrm{H}), 1.45(\mathrm{~m}, 2 \mathrm{H}) ;{ }^{13} \mathrm{C} \mathrm{NMR}\left(\mathrm{CDCl}_{3}, 100 \mathrm{MHz}\right) \delta$ $144.6,144.2,142.5,142.1,75.5,70.9,55.2,52.9,27.0,26.7,23.9,14.1$. HRMS calcd. for $\mathrm{C}_{12} \mathrm{H}_{17} \mathrm{NO}_{2}: \mathrm{m} / \mathrm{z} 207.1259$, found $\mathrm{m} / \mathrm{z} 207.1255$.

\section{In situ Generation of Nitrile Oxide from Nitro Compound $116 \mathrm{~d}$ and Subsequent Cycloaddition.}

Di-tert-butyl dicarbonate, $(\mathrm{BOC})_{2} \mathrm{O}(247 \mathrm{mg}, 1.13 \mathrm{mmol})$, in toluene $(2.5 \mathrm{~mL})$ was added via a cannula to a flame-dried flask containing the nitro compound $116 \mathbf{d}(98.5 \mathrm{mg}, 0.475$ mmol), 4-dimethylaminopyridine, DMAP ( $8.6 \mathrm{mg}, 0.0704 \mathrm{mmol})$, in toluene $(3.5 \mathrm{~mL})$. The reaction mixture was stirred at $90^{\circ} \mathrm{C}$ for $48 \mathrm{~h}$. The solvent was removed by rotary evaporation and the crude product was purified by column chromatography (EtOAc:hexanes = 1:9) to give cycloadduct 104d (73.8 $\mathrm{mg}, 0.390 \mathrm{mmol}, 82 \%$ ) as white crystals. Recrystallization with 10\% EtOAc/hexanes provided colorless needle-like crystals. 


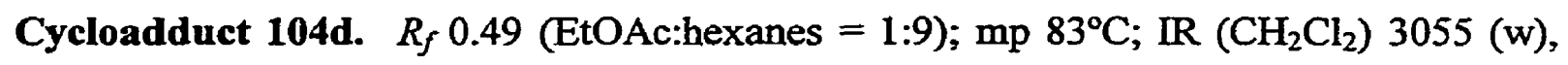
$2975(m), 2881(w), 2307(w), 1638(w), 1448(w), 1374(w), 1326(w), 1266(s), 1139$ (w), 1101 (w) $\mathrm{cm}^{-1}$; ${ }^{1} \mathrm{H} \mathrm{NMR}\left(\mathrm{CDCl}_{3}, 400 \mathrm{MHz}\right) \delta 6.17$ (m, 2H), 3.01 (br. s, 1H), 2.92 (br. s, $1 \mathrm{H}$ ), 2.43 (t, $2 \mathrm{H}, J=8.5 \mathrm{~Hz}$ ), $2.26-2.06(\mathrm{~m}, 2 \mathrm{H}$ ), 1.73 (d, $1 \mathrm{H}, J=9.0 \mathrm{~Hz}$ ), 1.58 $(\mathrm{m}, 1 \mathrm{H}), 1.49$ (d, 1H, $J=9.1 \mathrm{~Hz}), 1.09(\mathrm{~s}, 3 \mathrm{H}), 1.05$ (ddd, $1 \mathrm{H}, \mathrm{J}=13.0,7.8,2.4 \mathrm{~Hz}$ ); ${ }^{13} \mathrm{C}$ $\mathrm{NMR}\left(\mathrm{CDCl}_{3}, 100 \mathrm{MHz}\right) \delta 169.1,136.5,135.1,97.9,74.6,54.9,48.9,44.4,29.3,25.6$, 21.3, 21.0. Anal. Calcd. for $\mathrm{C}_{12} \mathrm{H}_{15} \mathrm{NO}: \mathrm{C}, 76.16 ; \mathrm{H}, 7.99 ; \mathrm{N} 7.40$; Found $\mathrm{C}, 76.29 ; \mathrm{H}$, $7.93 ; \mathrm{N}, 7.55$.

5.4.2.2 Cycloadduct Bearing a Hexyl Substituent

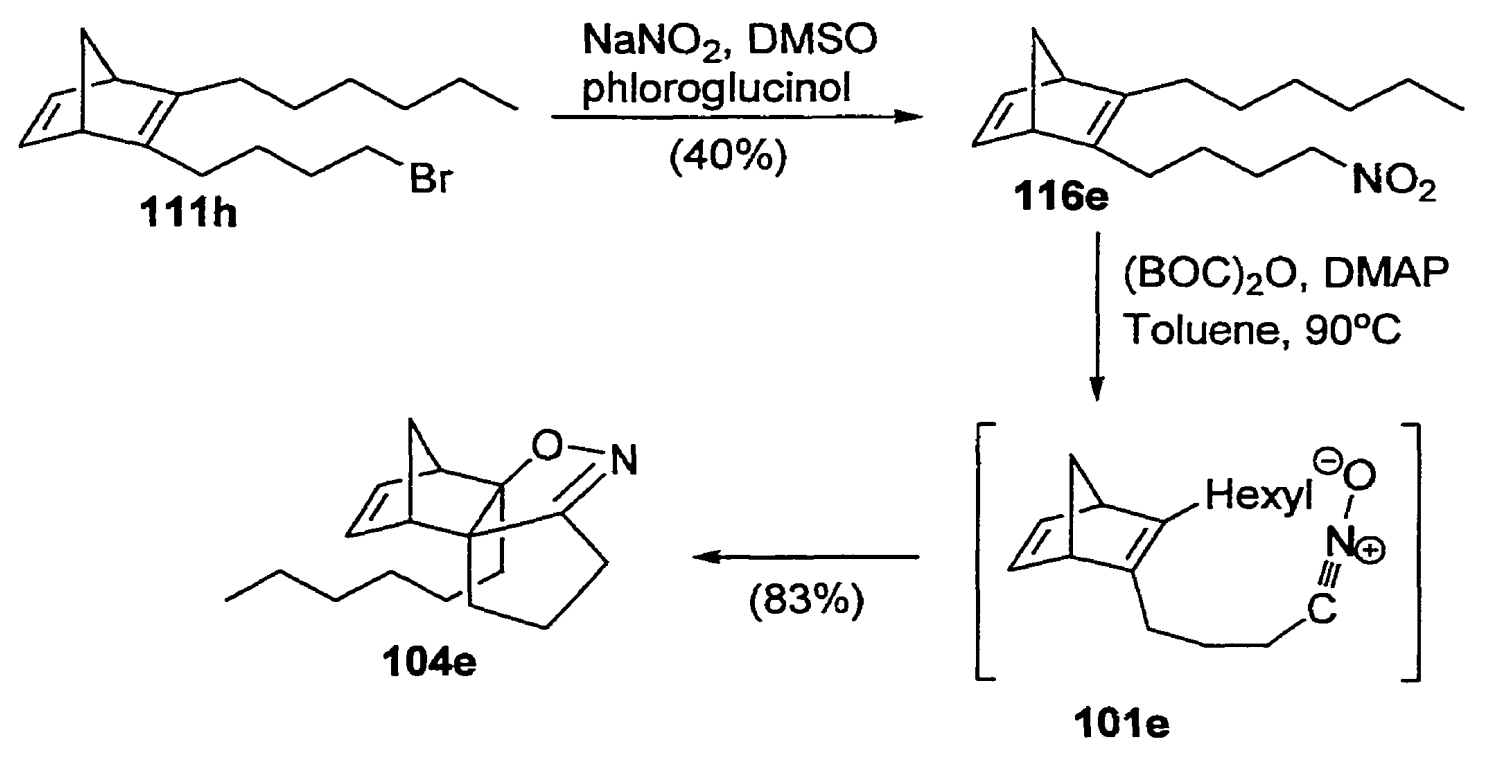


Conversion of Bromide $111 \mathrm{~h}$ to Nitro Compound 116e. Bromide $111 \mathrm{~h}$ (680 mg, 2.18 $\mathrm{mmol})$ in DMSO $(10 \mathrm{~mL})$ was added via a cannula to a flask containing $\mathrm{NaNO}_{2}(501 \mathrm{mg}$, $7.26 \mathrm{mmol})$ and phloroglucinol $(527 \mathrm{mg}, 3.25 \mathrm{mmol})$ in DMSO (10 mL). The light brown reaction mixture was stirred at room temperature for $48 \mathrm{~h}$. After quenching the reaction with water $(50 \mathrm{~mL})$, the aqueous layer was extracted with diethyl ether $(4 \times 50$ $\mathrm{mL})$ and the combined organic layers were washed sequentially with water $(100 \mathrm{~mL})$ and brine $(100 \mathrm{~mL})$ and dried over magnesium sulfate. The solvent was removed by rotary evaporation and the crude product was purified by column chromatography (EtOAc:hexanes $=1: 9)$ to give $116 \mathrm{e}(239 \mathrm{mg}, 0.862 \mathrm{mmol}, 40 \%)$ as a colorless viscous oil.

2-Hexyl-3-(4-nitrobutyl)bicyclo[2.2.1]hepta-2,5-diene (116e). $R_{f} 0.76$ (EtOAc:hexanes = 1:9); IR (neat, $\mathrm{NaCl}) 3063$ (w), 2960 (s), 2929 (s), 2859 (s), 1555 (s), 1465 (m), 1457 (m), 1435 (m), 1381 (m), 1303 (m), 1229 (w), 1200 (w) $\mathrm{cm}^{-1} ;{ }^{1} \mathrm{H} \mathrm{NMR}\left(\mathrm{CDCl}_{3}, 400\right.$ $\mathrm{MHz}) \delta 6.70(\mathrm{~m}, 2 \mathrm{H}), 4.35(\mathrm{t}, 2 \mathrm{H}, J=7.0 \mathrm{~Hz}), 3.32(\mathrm{~m}, 1 \mathrm{H}), 3.27(\mathrm{~m}, 1 \mathrm{H}), 2.23-1.97$ $(\mathrm{m}, 4 \mathrm{H}), 1.92-1.83(\mathrm{~m}, 4 \mathrm{H}), 1.50-1.33(\mathrm{~m}, 4 \mathrm{H}), 1.30-1.17(\mathrm{~m}, 6 \mathrm{H}), 0.87(\mathrm{t}, 3 \mathrm{H}, J=$ $6.8 \mathrm{~Hz}) ;{ }^{13} \mathrm{C} \mathrm{NMR}\left(\mathrm{CDCl}_{3}, 100 \mathrm{MHz}\right) \delta 148.3,145.0,142.6,142.2,75.6,71.1,53.2$, $52.9,31.7,29.0,28.2,27.5,27.2,26.8,24.1,22.6,14.1$. HRMS calcd. for $\mathrm{C}_{17} \mathrm{H}_{27} \mathrm{NO}_{2}$ : $\mathrm{m} / \mathrm{z} 277.2042$, found $\mathrm{m} / \mathrm{z} 277.2047$.

In situ Generation of Nitrile Oxide from Nitro Compound 116e and Subsequent Cycloaddition.

Di-tert-butyl dicarbonate, $(\mathrm{BOC})_{2} \mathrm{O}(205 \mathrm{mg}, 0.939 \mathrm{mmol})$, in toluene $(3 \mathrm{~mL})$ was added via a cannula to a flame-dried flask containing the nitro compound $116 \mathrm{e}(107 \mathrm{mg}, 0.385$ 
mmol), 4-dimethylaminopyridine, DMAP $(8.0 \mathrm{mg}, 0.0655 \mathrm{mmol})$, in toluene $(3 \mathrm{~mL})$. The reaction mixture was stirred at $90^{\circ} \mathrm{C}$ for $48 \mathrm{~h}$. The solvent was removed by rotary evaporation and the crude product was purified by column chromatography (EtOAc:hexanes $=1: 9)$ to give cycloadduct $104 \mathrm{e}(83.2 \mathrm{mg}, 0.320 \mathrm{mmol}, 83 \%$ ) as a colorless viscous oil.

Cycloadduct 104e. $R_{f} 0.33$ (EtOAc:hexanes $\left.=1: 9\right) ; \mathrm{IR}\left(\mathrm{CH}_{2} \mathrm{Cl}_{2}\right) 3135(\mathrm{w}), 3062(\mathrm{~m})$, 2956 (s), 2857 (s), 1638 (m), 1569 (w), 1455 (s), $1436(\mathrm{~m}), 1378$ (w), $1326(\mathrm{~s}), 1264$ (m), $1212(\mathrm{w}), 1145$ (w) cm ${ }^{-1}$; ${ }^{\mathrm{H}} \mathrm{NMR}\left(\mathrm{CDCl}_{3}, 400 \mathrm{MHz}\right) \delta 6.15$ (dd, $1 \mathrm{H}, J=5.7,2.9 \mathrm{~Hz}$ ), $6.11(\mathrm{dd}, 1 \mathrm{H}, J=5.5,3.1 \mathrm{~Hz}), 3.16(\mathrm{br} . \mathrm{s}, 1 \mathrm{H}), 2.91$ (br. $\mathrm{s}, 1 \mathrm{H}), 2.41(\mathrm{t}, 2 \mathrm{H}, J=6.9 \mathrm{~Hz})$, $2.19(\mathrm{~m}, \mathrm{IH}), 2.09(\mathrm{~m}, \mathrm{IH}), 1.70-1.31(\mathrm{~m}, 6 \mathrm{H}), 6.12-6.10(\mathrm{~m}, 6 \mathrm{H}), 1.01$ (ddd, $1 \mathrm{H}, J=$ $12.8,7.7,2.4 \mathrm{~Hz}), 0.90(\mathrm{dd}, 1 \mathrm{H}, J=12.9,4.0 \mathrm{~Hz}), 0.84(\mathrm{t}, 3 \mathrm{H}, J=6.0 \mathrm{~Hz}) ;{ }^{13} \mathrm{C} \mathrm{NMR}$ $\left(\mathrm{CDCl}_{3}, 100 \mathrm{MHz}\right) \delta 169.3,136.0,135.2,100.2,75.1,51.9,48.9,44.1,35.3,31.6,29.7$, 29.0, 25.6, 24.4, 22.5, 21.2, 14.0. HRMS calcd. for $\mathrm{C}_{17} \mathrm{H}_{25} \mathrm{NO}: \mathrm{m} / \mathrm{z} 259.1936$, found $\mathrm{m} / \mathrm{z}$ 259.1932 . 
5.4.3 Norbornadiene-Tethered Nitrile Oxides Bearing a Carbonyl-Containing Substituent at the C-3 Position

5.4.3.1 Cycloadduct Bearing a Carboxylic Acid Methyl Ester Substituent
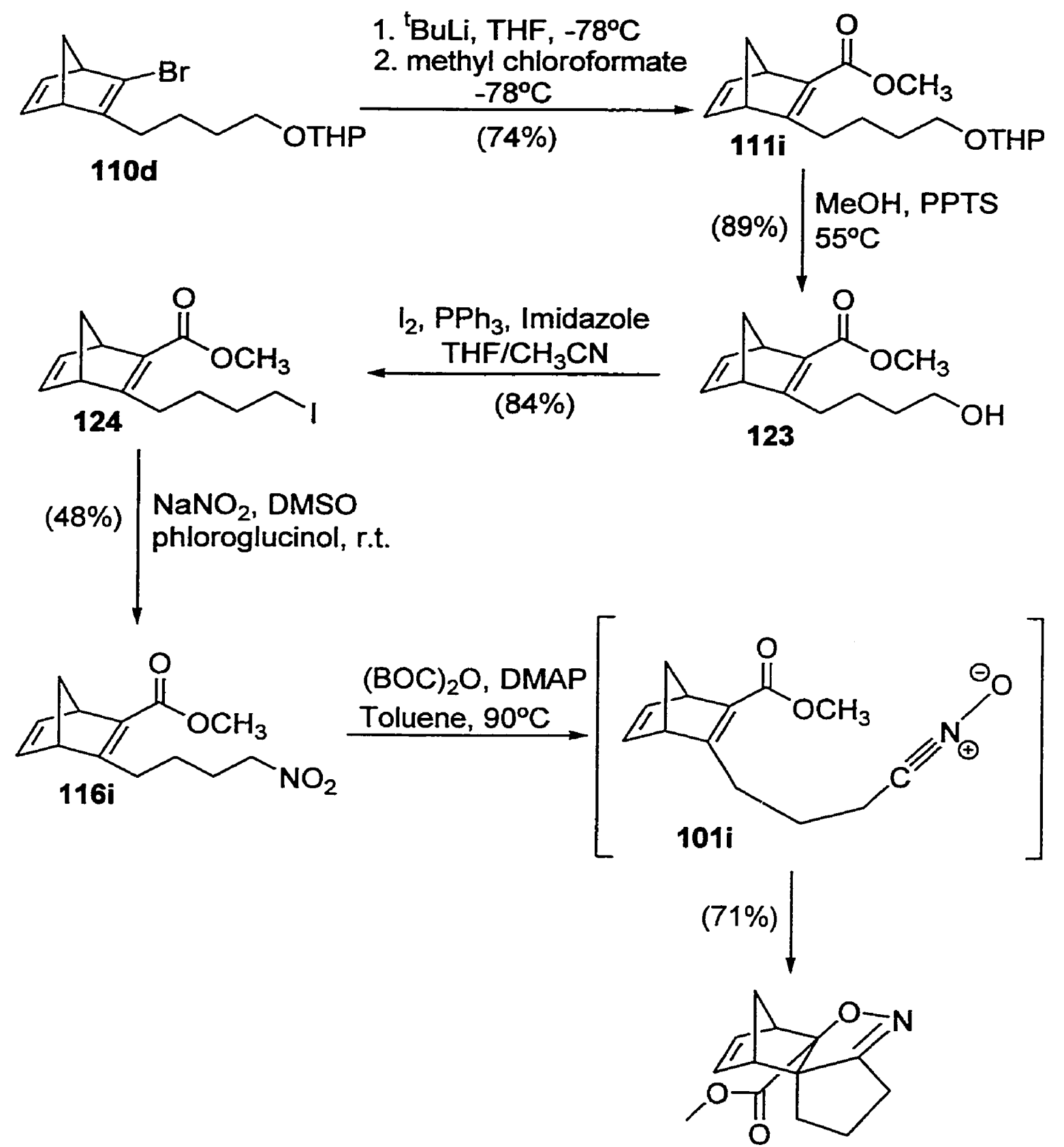

$104 i$ 
Conversion of $110 \mathrm{~d}$ to $111 \mathrm{i}$. tert-Butyllithium $(14.0 \mathrm{~mL}, 1.7 \mathrm{M}, 23.8 \mathrm{mmol})$ was added to a flame-dried flask containing bromide $110 \mathrm{~d}$ (page $142-143,3.00 \mathrm{~g}, 9.17 \mathrm{mmol}$ ) in THF $(17.0 \mathrm{~mL})$ at $-78^{\circ} \mathrm{C}$. After stirring the reaction mixture for $1 \mathrm{~h}$, the resulting yellow mixture was added via a cannula to a flame-dried flask containing methyl chloroformate $(3.0 \mathrm{~mL}, 39 \mathrm{mmol})$ in $\mathrm{THF}(7.0 \mathrm{~mL})$ at $-78^{\circ} \mathrm{C}$. The reaction mixture was stirred at $-78^{\circ} \mathrm{C}$ for $3 \mathrm{~h}$. After quenching the reaction with water $(20 \mathrm{~mL})$, the aqueous layer was extracted with diethyl ether $(4 \times 20 \mathrm{~mL})$, and the combined organic layers were washed sequentially with water $(25 \mathrm{~mL})$ and brine $(25 \mathrm{~mL})$ and dried over magnesium sulfate. The solvent was removed by rotary evaporation and the crude product was purified by column chromatography (EtOAc:hexanes = 1:9) to give $111 \mathrm{i}(2.07 \mathrm{~g}, 6.76 \mathrm{mmol}, 74 \%)$ as a colorless oil.

Compound 111i. A mixture of two diastereomers. $R_{f} 0.55$ (EtOAc:hexanes $\left.=1: 4\right)$; IR (neat, $\mathrm{NaCl}) 2941$ (s), $2868(\mathrm{~m}), 1700$ (s), $1695(\mathrm{~s}), 1558(\mathrm{w}), 1435(\mathrm{~m}), 1342(\mathrm{~m}), 1295$ (s), $1238(\mathrm{~s}), 1200(\mathrm{~m}), 1163(\mathrm{~m}), 1138(\mathrm{~m}), 1119(\mathrm{~m}), 1103(\mathrm{~m}), 1074(\mathrm{~s}), 1034(\mathrm{~s}), 1022$ (m) $\mathrm{cm}^{-1} ;{ }^{1} \mathrm{H} \mathrm{NMR}\left(\mathrm{CDCl}_{3}, 400 \mathrm{MHz}\right) \delta 6.85(\mathrm{dd}, 1 \mathrm{H}, J=5.0,3.0 \mathrm{~Hz}), 6.67(\mathrm{dd}, 1 \mathrm{H}, J=$ 4.7, $3.3 \mathrm{~Hz}), 4.55(\mathrm{~m}, 1 \mathrm{H}), 3.86-3.84(\mathrm{~m}, 2 \mathrm{H}), 3.72(\mathrm{~m}, 1 \mathrm{H}), 3.69(\mathrm{~s}, 3 \mathrm{H}), 3.50-3.48$ $(\mathrm{m}, 2 \mathrm{H}), 3.37(\mathrm{~m}, 1 \mathrm{H}), 2.76-2.64(\mathrm{~m}, 2 \mathrm{H}), 2.01(\mathrm{dm}, 1 \mathrm{H}, J=6.4 \mathrm{~Hz}), 1.94(\mathrm{dm}, 1 \mathrm{H}, J=$ $6.4 \mathrm{~Hz}), 1.80(\mathrm{~m}, 1 \mathrm{H}), 1.69(\mathrm{~m}, 1 \mathrm{H}), 1.61-1.44(\mathrm{~m}, 8 \mathrm{H}) ;{ }^{13} \mathrm{C} \mathrm{NMR}\left(\mathrm{CDCl}_{3}, 100 \mathrm{MHz}\right) \delta$ $173.3,166.2,143.8,140.7,138.5,98.81,98.78,71.0,67.2,62.30,62.27,55.9,51.0,50.9$, 30.7, 29.9, 29.3, 25.4, 23.5, 19.64, 19.62. Anal. Calcd. for $\mathrm{C}_{18} \mathrm{H}_{26} \mathrm{O}_{4}: \mathrm{C}, 70.56 ; \mathrm{H}, 8.55$. Found $\mathrm{C}, 70.67 ; \mathrm{H}, 8.52$. 
Conversion of 111i to 123 . To a flame-dried flask containing $111 \mathrm{i}$ ( $412 \mathrm{mg}, 1.34 \mathrm{mmol}$ ) in $\mathrm{MeOH}$ (11.2 mL), pyridium p-toluenesulfonate, PPTS (69.3 mg, $0.276 \mathrm{mmol}$ ), was added at room temperature. The reaction mixture was stirred at $55^{\circ} \mathrm{C}$ for $1 \mathrm{~h}$. After quenching the reaction with water $(10 \mathrm{~mL})$, the aqueous layer was extracted with diethyl ether $(4 \times 25 \mathrm{~mL})$, and the combined organic layers were washed sequentially with water $(25 \mathrm{~mL})$ and brine $(25 \mathrm{~mL})$ and dried over magnesium sulfate. The solvent was removed by rotary evaporation and the crude product was purified by column chromatography (EtOAc:hexanes $=2: 3$ ) to give $123(265 \mathrm{mg}, 1.19 \mathrm{mmol}, 89 \%$ ) as a colorless oil.

3-(4-Hydroxybutyl)bicyclo[2.2.1]hepta-2,5-diene-2-carboxylic acid methyl ester (123). $R_{f} 0.35$ (EtOAc:hexanes $=2: 3$ ); IR (neat, $\left.\mathrm{NaCl}\right) 3393(\mathrm{~m}), 2938(\mathrm{~s}), 2867(\mathrm{~m})$, $1700(\mathrm{~s}), 1695(\mathrm{~s}), 1683(\mathrm{~s}), 1653(\mathrm{~m}), 1628(\mathrm{~m}), 1558(\mathrm{w}), 1436(\mathrm{~m}), 1345(\mathrm{~m}), 1295(\mathrm{~s})$ 1239 (s), $1193(\mathrm{~m}), 1160$ (m), $1103(\mathrm{~m}), 1070(\mathrm{~m}) \mathrm{cm}^{-1} ;{ }^{\mathrm{l}} \mathrm{H} \mathrm{NMR}\left(\mathrm{CDCl}_{3}, 400 \mathrm{MHz}\right) \delta$ $6.85(\mathrm{dd}, 1 \mathrm{H}, J=5.0,3.0 \mathrm{~Hz}), 6.68(\mathrm{dd}, 1 \mathrm{H}, J=5.0,3.2 \mathrm{~Hz}$ ), 3.86 (br. s, $1 \mathrm{H}), 3.69$ (s, $3 \mathrm{H}), 3.63(\mathrm{t}, 2 \mathrm{H}, J=5.9 \mathrm{~Hz}), 3.50$ (br. s, $1 \mathrm{H}), 2.77-2.63(\mathrm{~m}, 2 \mathrm{H}), 2.01(\mathrm{dm}, 1 \mathrm{H}, J=6.4$ $\mathrm{Hz}), 1.95(\mathrm{dm}, 1 \mathrm{H}, J=6.4 \mathrm{~Hz}), 1.79$ (br. s, $1 \mathrm{H}), 1.61-1.24(\mathrm{~m}, 4 \mathrm{H}) ;{ }^{13} \mathrm{CNMR}\left(\mathrm{CDCl}_{3}\right.$, $100 \mathrm{MHz}) \delta 173.6,166.3,143.8,140.7,138.6,71.2,62.4,56.0,51.0,50.9,32.0,29.7$, 23.0. Anal. Calcd. for $\mathrm{C}_{13} \mathrm{H}_{18} \mathrm{O}_{3}$ : C, 70.24; $\mathrm{H}, 8.16$. Found $\mathrm{C}, 70.39 ; \mathrm{H}, 8.13$.

Conversion of Alcohol 123 to Iodide 124. To a flame-dried flask containing $\mathrm{PPh}_{3}(1.10$ g, $4.19 \mathrm{mmol})$, imidazole $(651 \mathrm{mg}, 9.56 \mathrm{mmol})$, acetonitrile $(2.9 \mathrm{~mL})$ and THF $(2 \mathrm{~mL}), \mathrm{I}_{2}$ $(1.18 \mathrm{~g}, 9.30 \mathrm{mmol})$ was added at $0^{\circ} \mathrm{C}$. The reddish-brown reaction mixture was stirred for $15 \mathrm{~min}$. at $0^{\circ} \mathrm{C}$. Alcohol $123(216 \mathrm{mg}, 0.970 \mathrm{mmol})$ in acetonitrile $(2 \mathrm{~mL})$ was added via a cannula at $0^{\circ} \mathrm{C}$. The reaction mixture was stirred at room temperature for $21 \mathrm{~h}$. The 
reaction mixture was diluted with $\mathrm{CH}_{2} \mathrm{Cl}_{2}(20 \mathrm{~mL})$ and quenched with water $(20 \mathrm{~mL})$. The aqueous layer was extracted with diethyl ether $(3 \times 40 \mathrm{~mL})$, and the combined organic layers were washed sequentially with water $(40 \mathrm{~mL})$, saturated sodium thiosulfate (40 $\mathrm{mL})$ and brine $(40 \mathrm{~mL})$ and dried over magnesium sulfate. The solvent was removed by rotary evaporation and the crude product was purified by column chromatography (EtOAc:hexanes = 1:9) to give iodide $124(272 \mathrm{mg}, 0.82 \mathrm{mmol}, 84 \%)$ as a colorless oil.

3-(4-Iodobutyl)bicyclo[2.2.1]hepta-2,5-diene-2-carboxylic acid methyl ester (124). $R_{f}$ 0.68 (EtOAc:hexanes = 1:4); IR (neat, $\mathrm{NaCl}$ ) 3067 (w), 2970 (s), 2937 (s), 2867 (m), $1694(\mathrm{~s}), 1682$ (m), 1626 (s), 1558 (m), 1433 (s), 1340 (s), 1294 (s), 1249 (s), 1239 (s), 1191 (s), 1155 (s), 1102 (s), 1068 (m), 1038 (w), 1019 (w) $\mathrm{cm}^{-1} ;{ }^{1} \mathrm{H}$ NMR (CDCl, 400 $\mathrm{MHz}) \delta 6.87(\mathrm{dd}, 1 \mathrm{H}, J=5.0,3.0 \mathrm{~Hz}), 6.71(\mathrm{dd}, 1 \mathrm{H}, J=5.0,3.2 \mathrm{~Hz}), 3.88$ (br. s, $1 \mathrm{H})$, $3.71(\mathrm{~s}, 3 \mathrm{H}), 3.51$ (br. s, $1 \mathrm{H}), 3.19(\mathrm{t}, 2 \mathrm{H}, J=6.8 \mathrm{~Hz}), 2.71(\mathrm{~m}, 2 \mathrm{H}), 2.03(\mathrm{dm}, 1 \mathrm{H}, J=6.4$ $\mathrm{Hz}), 1.97(\mathrm{dm}, 1 \mathrm{H}, J=6.4 \mathrm{~Hz}), 1.75(\mathrm{p}, 2 \mathrm{H}, J=7.1 \mathrm{~Hz}), 1.67-1.50(\mathrm{~m}, 2 \mathrm{H}) ;{ }^{13} \mathrm{C}$ NMR $\left(\mathrm{CDCl}_{3}, 100 \mathrm{MHz}\right) \delta 172.6,166.1,143.8,140.7,139.0,71.2,55.9,51.1,51.0,32.6,28.9$ 27.5, 6.8. Anal. Calcd. for $\mathrm{C}_{13} \mathrm{H}_{17} \mathrm{IO}_{2}$ : C, 47.01; $\mathrm{H}, 5.16$. Found $\mathrm{C}, 46.87 ; \mathrm{H}, 5.18$.

Conversion of Iodide 124 to Nitro Compound 116i. Iodide 124 (209 mg, $0.628 \mathrm{mmol}$ ) in DMSO ( $1 \mathrm{~mL}$ ) was added via a cannula to a flask containing $\mathrm{NaNO}_{2}(184 \mathrm{mg}, 2.66$ $\mathrm{mmol}$ ) and phloroglucinol (155 $\mathrm{mg}, 0.955 \mathrm{mmol})$ in DMSO (1 mL). The light brown reaction mixture was stirred at room temperature for $36 \mathrm{~h}$. After quenching the reaction with water $(10 \mathrm{~mL})$, the aqueous layer was extracted with diethyl ether $(4 \times 20 \mathrm{~mL})$ and the combined organic layers were washed sequentially with water $(20 \mathrm{~mL})$ and brine (20 $\mathrm{mL}$ ) and dried over magnesium sulfate. The solvent was removed by rotary evaporation 
and the crude product was purified by column chromatography (EtOAc:hexanes $=2: 3$ ) to give $116 \mathrm{i}(75.7 \mathrm{mg}, 0.301 \mathrm{mmol}, 48 \%)$ as a colorless viscous oil.

3-(4-Nitrobutyl)bicyclo[2.2.1]hepta-2,5-diene-2-carboxylic acid methyl ester (116i). $R_{f} 0.75$ (EtOAc:hexanes = 2:3); IR (neat, $\mathrm{NaCl}$ ) 3068 (w), 2972 (s), 2949 (s), 2869 (m), 1704 (s), 1699 (s), 1683 (s), 1626 (s), 1563 (s), 1557 (s), 1549 (s), 1455 (m), 1435 (s), $1384(\mathrm{~s}), 1295$ (s), 1239 (s), 1193 (m), 1162 (s), 1135 (w), 1103 (s), 1072 (s), 1019 (w), $1004(\mathrm{w}) \mathrm{cm}^{-1} ;{ }^{\mathrm{l}} \mathrm{H} \mathrm{NMR}\left(\mathrm{CDCl}_{3}, 400 \mathrm{MHz}\right) \delta 6.87(\mathrm{dd}, 1 \mathrm{H}, J=4.9,3.1 \mathrm{~Hz}), 6.69(\mathrm{dd}$, $1 \mathrm{H}, J=4.9,3.3 \mathrm{~Hz}), 4.39(\mathrm{t}, 2 \mathrm{H}, J=6.9 \mathrm{~Hz}), 3.89$ (br. s, $1 \mathrm{H}), 3.71$ (s, 3H), 3.48 (br. s, $1 \mathrm{H}), 2.75(\mathrm{~m}, 2 \mathrm{H}), 2.03(\mathrm{dm}, 1 \mathrm{H}, J=6.5 \mathrm{~Hz}), 1.98(\mathrm{dm}, 1 \mathrm{H}, J=6.5 \mathrm{~Hz}), 1.93(\mathrm{p}, 2 \mathrm{H}, J=$ $7.2 \mathrm{~Hz}), 1.65-1.50(\mathrm{~m}, 2 \mathrm{H}) ;{ }^{13} \mathrm{C} \mathrm{NMR}\left(\mathrm{CDCl}_{3}, 100 \mathrm{MHz}\right) \delta 171.9,166.0,143.9,140.6$, 139.7, 75.2, 71.4, 55.8, 51.1, 51.0, 28.9, 26.5, 23.3. Anal. Calcd. for $\mathrm{C}_{13} \mathrm{H}_{17} \mathrm{NO}_{4}$ : C, 62.14; H, 6.82. Found C, 63.56; H, 6.74.

In situ Generation of Nitrile Oxide from Nitro Compound 116i and Subsequent Cycloaddition.

Di-tert-butyl dicarbonate, $(\mathrm{BOC})_{2} \mathrm{O}(146 \mathrm{mg}, 0.668 \mathrm{mmol})$, in toluene $(1 \mathrm{~mL})$ was added via a cannula to a flame-dried flask containing the nitro compound $116 \mathbf{i}(48.7 \mathrm{mg}, 0.194$ mmol), 4-dimethylaminopyridine, DMAP (48.1 mg, $0.394 \mathrm{mmol}$ ), in toluene (1.5 mL). The reaction mixture was stirred at $90^{\circ} \mathrm{C}$ for $24 \mathrm{~h}$. The solvent was removed by rotary evaporation and the crude product was purified by column chromatography (EtOAc:hexanes $=1: 4)$ to give cycloadduct $104 \mathrm{i}(32.3 \mathrm{mg}, 0.138 \mathrm{mmol}, 71 \%)$ as a colorless viscous oil. 
Cycloadduct 104i. $R_{f} 0.25$ (EtOAc:hexanes = 1:4); IR (neat, $\mathrm{NaCl}$ ) 3070 (w), 2979 (s), 2956 (s), 2882 (m), 2847 (w), 1732 (s), $1571(w), 1456(\mathrm{~m}), 1435$ (s), 1325 (s), $1286(\mathrm{~s})$, $1256(\mathrm{~s}), 1193(\mathrm{~m}), 1168$ (w), $1129(\mathrm{~m}), 1104(\mathrm{~m}), 1081(\mathrm{~s}), 1054(\mathrm{w}), 1008(\mathrm{w}) \mathrm{cm}^{-1} ;{ }^{1} \mathrm{H}$ $\operatorname{NMR}\left(\mathrm{CDCl}_{3}, 400 \mathrm{MHz}\right) \delta 6.32(\mathrm{dd}, 1 \mathrm{H}, J=5.6,3.2 \mathrm{~Hz}), 6.25(\mathrm{dd}, 1 \mathrm{H}, J=5.6,3.1 \mathrm{~Hz})$, $3.72(\mathrm{~s}, 3 \mathrm{H}), 3.37(\mathrm{~m}, 1 \mathrm{H}), 2.98($ br. $\mathrm{s}, 1 \mathrm{H}), 2.54-2.41(\mathrm{~m}, 2 \mathrm{H}), 2.29-2.10(\mathrm{~m}, 2 \mathrm{H})$, $1.83(\mathrm{dm}, 1 \mathrm{H}, J=9.4), 1.82(\mathrm{~m}, 1 \mathrm{H}), 1.61(\mathrm{dm}, 1 \mathrm{H}, J=9.4 \mathrm{~Hz}), 1.22$ (ddd, $1 \mathrm{H}, J=12.9$, 7.5, 2.6 Hz); ${ }^{13} \mathrm{C} \mathrm{NMR}\left(\mathrm{CDCl}_{3}, 100 \mathrm{MHz}\right) \delta 170.2,168.9,137.4,134.5,99.4,81.4,52.7$, 52.2, 48.9, 44.5, 30.4, 25.8, 20.7. Anal. Calcd. for $\mathrm{C}_{13} \mathrm{H}_{15} \mathrm{NO}_{3}: \mathrm{C}, 66.94 ; \mathrm{H}, 6.84$. Found C, $66.71 ; \mathrm{H}, 6.49$.

\subsubsection{Cycloadduct Precursors Bearing a Carbaldehyde Substituent}

Synthesis of 125 .

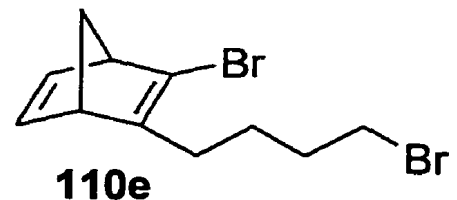

110 e

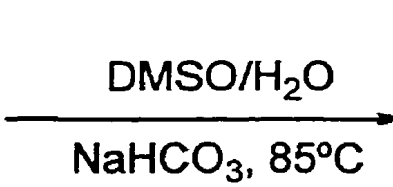

$(80 \%)$

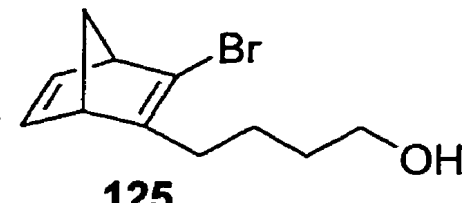

125

Conversion of $110 \mathrm{I}$ to 125 . To a flame-dried flask containing 1101 (4.10 g, $13.4 \mathrm{mmol})$, $\mathrm{NaHCO}_{3}(3.12 \mathrm{~g}, 37.2 \mathrm{mmol})$, DMSO $(56 \mathrm{~mL})$ and $\mathrm{H}_{2} \mathrm{O}(14 \mathrm{~mL})$ were added at room temperature. The reaction mixture was stirred at $85^{\circ} \mathrm{C}$ for $24 \mathrm{~h}$. After quenching the reaction with water $(100 \mathrm{~mL})$, the aqueous layer was extracted with diethyl ether $(4 \times 100$ 
$\mathrm{mL})$, and the combined organic layers were washed sequentially with water $(100 \mathrm{~mL})$ and brine $(100 \mathrm{~mL})$ and dried over magnesium sulfate. The solvent was removed by rotary evaporation and the crude product was purified by column chromatography (EtOAc:hexanes = 1:4) to give $125(2.60 \mathrm{~g}, 10.7 \mathrm{mmol}, 80 \%)$ as a colorless oil.

4-(3-Bromobicyclo[2.2.1] hepta-2,5-dien-2-yl)butan-1-ol $\quad(125) . \quad R_{f} \quad 0.23$ (EtOAc:hexanes = 1:4); IR (neat, NaCl) 3334 (s), 3067 (w), 2973 (s), 2937 (s), 2866 (s), $1633(\mathrm{w}), 1557(\mathrm{~m}), 1455(\mathrm{~m}), 1435(\mathrm{~m}), 1297(\mathrm{~s}), 1262(\mathrm{~m}), 1224(\mathrm{~m}), 1204(\mathrm{w}) .1163$ (w), 1054 (s), 1030 (s), $1011(\mathrm{~m}) \mathrm{cm}^{-1} ;{ }^{1} \mathrm{H} \mathrm{NMR}\left(\mathrm{CDCl}_{3}, 400 \mathrm{MHz}\right) \delta 6.84$ (ddm, 1H, $J=$ $5.1,2.9 \mathrm{~Hz}), 6.74(\mathrm{ddm}, 1 \mathrm{H}, J=5.1,2.9 \mathrm{~Hz}), 3.62(\mathrm{t}, 2 \mathrm{H}, J=6.2 \mathrm{~Hz}), 3.46(\mathrm{dm}, 2 \mathrm{H}, J=$ $13.1 \mathrm{~Hz}), 2.27-2.11(\mathrm{~m}, 3 \mathrm{H}), 2.02(\mathrm{dt}, 1 \mathrm{H}, J=6.0,1.7 \mathrm{~Hz}), 1.61$ (br. $\mathrm{s}, 1 \mathrm{H}), 1.52-1.40$ $(\mathrm{m}, 4 \mathrm{H}) ;{ }^{13} \mathrm{C} \mathrm{NMR}\left(\mathrm{CDCl}_{3}, 100 \mathrm{MHz}\right) \delta 150.8,141.9,141.8,129.5,71.6,62.6,57.9$, 53.4, 32.0, 28.8, 22.6. Anal. Calcd. for $\mathrm{C}_{11} \mathrm{H}_{15} \mathrm{BrO}$ : C, 54.34; $\mathrm{H}, 6.22$. Found $\mathrm{C}$, 53.96; $H, 6.53$.

Synthesis of 127.

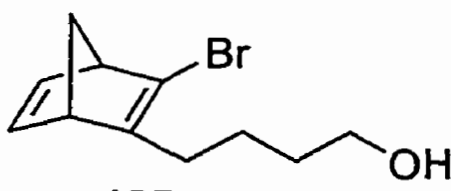

125

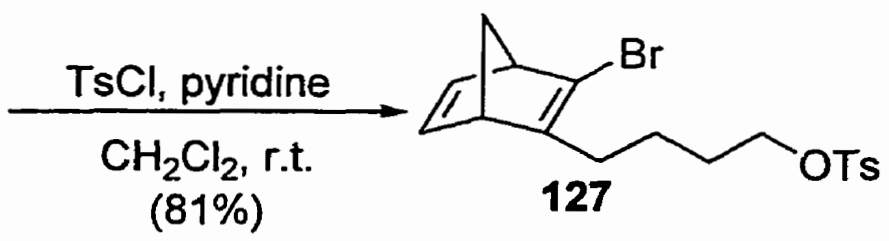

$(81 \%)$
127

Conversion of 125 to 127 . To a flame-dried flask containing 125 (50.3 $\mathrm{mg}, 0.207 \mathrm{mmol}$ ) in $\mathrm{CH}_{2} \mathrm{Cl}_{2}(0.8 \mathrm{~mL})$, pyridine $(0.05 \mathrm{~mL})$ and $\mathrm{TsCl}(104 \mathrm{mg}, 547 \mathrm{mmol})$ were added. The 
reaction mixture was stirred at room temperature for $23.5 \mathrm{~h}$. After quenching the reaction with water $(3 \mathrm{~mL})$, the aqueous layer was extracted with $\mathrm{CH}_{2} \mathrm{Cl}_{2}(4 \times 10 \mathrm{~mL})$, and the combined organic layers were washed sequentially with water $(15 \mathrm{~mL})$, saturated $\mathrm{CuSO}_{4}$ $(15 \mathrm{~mL})$ and brine $(15 \mathrm{~mL})$ and dried over magnesium sulfate. The solvent was removed by rotary evaporation and the crude product was purified by column chromatography (EtOAc:hexanes = 1:9) to give $127(66.2 \mathrm{mg}, 0.167 \mathrm{mmol}, 81 \%$ ) as a colorless oil.

Compound 127. $R_{f} 0.50$ (EtOAc:hexanes = 1:4); $\mathbb{R}$ (neat, $\mathrm{NaCl}$ ) $3066(\mathrm{w}), 2974(\mathrm{~s}$ ), 2940 (s), 2867 (m), 1633 (w), 1598 (m), 1557 (w), 1495 (w), 1360 (s), 1297 (s), 1260 (w), 1224 (w), 1189 (s), 1178 (s), 1120 (w), 1098 (s), 1010 (m) cm ${ }^{-1} ;{ }^{1} \mathrm{H} \mathrm{NMR}$ (CDCl ${ }_{3}$, $400 \mathrm{MHz}) \delta 7.79-7.77(\mathrm{~m}, 2 \mathrm{H}), 7.35-7.33(\mathrm{~m}, 2 \mathrm{H}), 6.82(\mathrm{dd}, 1 \mathrm{H}, J=5.0,2.9 \mathrm{~Hz})$, $6.70(\mathrm{dd}, 1 \mathrm{H}, J=4.9,2.9 \mathrm{~Hz}), 4.00(\mathrm{tm}, 2 \mathrm{H}, J=6.3 \mathrm{~Hz}), 3.45(\mathrm{~m}, 1 \mathrm{H}), 3.37(\mathrm{~m}, 1 \mathrm{H})$, 2.44 (br. s, 3H), $2.18-2.05(\mathrm{~m}, 3 \mathrm{H}), 2.01(\mathrm{dt}, 1 \mathrm{H}, J=6.0,1.6 \mathrm{~Hz}), 1.60-1.35(\mathrm{~m}, 4 \mathrm{H})$; ${ }^{13} \mathrm{C} \mathrm{NMR}\left(\mathrm{CDCl}_{3}, 100 \mathrm{MHz}\right) \delta 150.2,144.7,141.9,141.7,133.0,130.0,129.8,127.8$, $71.6,70.3,57.9,53.3,28.3,28.0,22.2,21.6$. 


\section{Synthesis of 130 .}

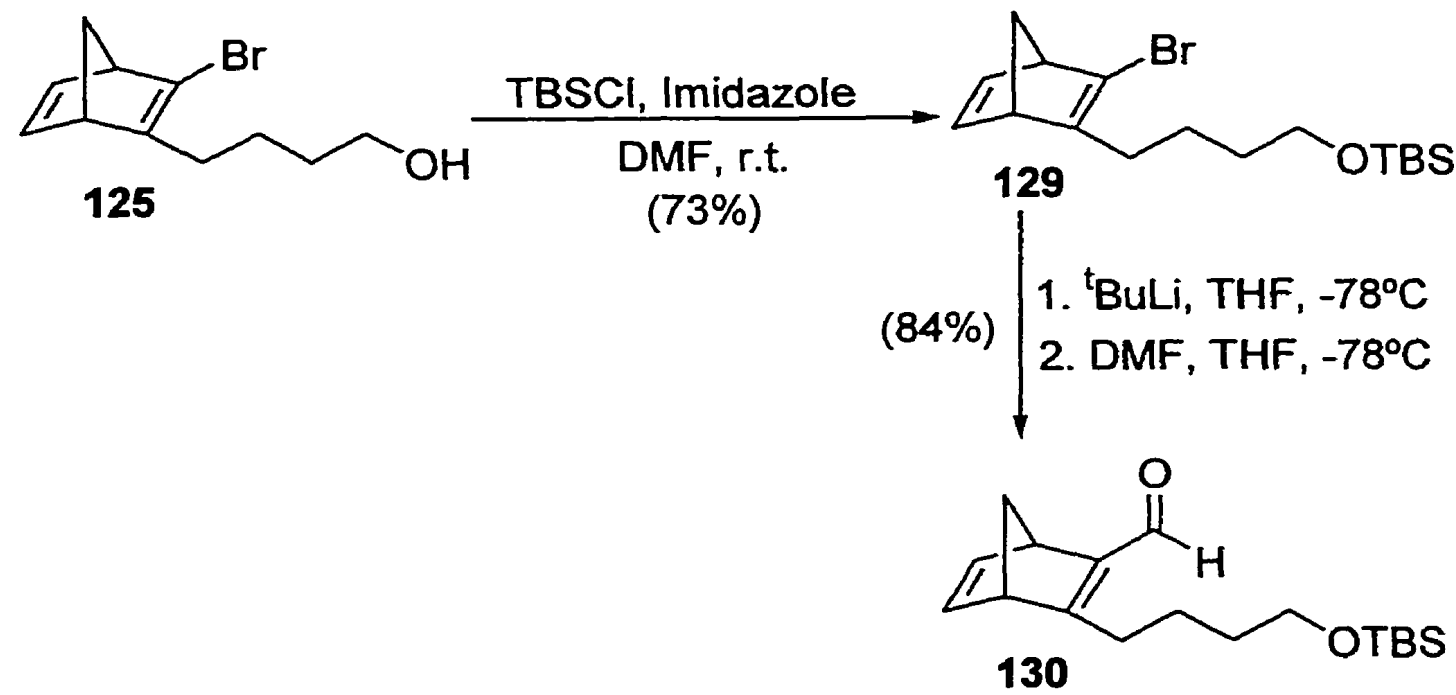

Conversion of 125 to 129. To a flame-dried flask containing 125 (168 $\mathrm{mg}, 0.691 \mathrm{mmol}$ ) in DMF (3 mL), imidazole (117 mg, $1.72 \mathrm{mmol})$ and TBSCl (209 mg, $1.39 \mathrm{mmol})$ were added. The reaction mixture was stirred at room temperature for $3 \mathrm{~h}$. After quenching the reaction with water $(15 \mathrm{~mL})$, the aqueous layer was extracted with 1:9 $\mathrm{CH}_{2} \mathrm{Cl}_{2} /$ hexanes $(4 \times 15 \mathrm{~mL})$, and the combined organic layers were washed sequentially with water $(15 \mathrm{~mL})$ and brine $(15 \mathrm{~mL})$ and dried over magnesium sulfate. The solvent was removed by rotary evaporation and the crude product was purified by column chromatography (EtOAc:hexanes $=1: 19)$ to give $129(180 \mathrm{mg}, 0.504 \mathrm{mmol}, 73 \%)$ as a colorless oil.

Compound 129. $R_{f} 0.80$ (EtOAc:hexanes =1:19); $\mathbb{R}$ (neat, $\mathrm{NaCl}$ ) $3069(\mathrm{w}), 2936(\mathrm{~s})$, $2858(\mathrm{~s}), 1633(\mathrm{w}), 1558(\mathrm{w}), 1472(\mathrm{~m}), 1463(\mathrm{~m}), 1388(\mathrm{~m} 0,1361(\mathrm{~m}), 1297(\mathrm{~m}), 1256$

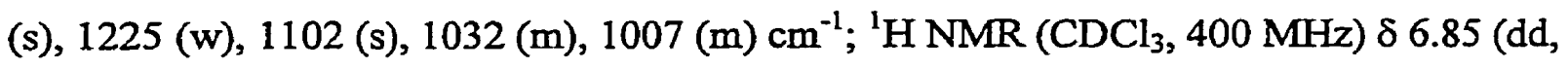
$1 \mathrm{H}, J=5.0,2.9 \mathrm{~Hz}), 6.74(\mathrm{dd}, 1 \mathrm{H}, J=5.0,2.9 \mathrm{~Hz}), 3.61-3.58(\mathrm{~m}, 2 \mathrm{H}), 3.47-3.43$ (m, 
$2 \mathrm{H}), 2.26-2.09(\mathrm{~m}, 3 \mathrm{H}), 2.02(\mathrm{~m}, 1 \mathrm{H}), 1.5 \mathrm{I}-1.38(\mathrm{~m}, 4 \mathrm{H}), 0.89(\mathrm{~s}, 9 \mathrm{H}), 0.05(\mathrm{~s}, 6 \mathrm{H})$

${ }^{13} \mathrm{C} \mathrm{NMR}\left(\mathrm{CDCl}_{3}, 100 \mathrm{MHz}\right) \delta 151.1,141.92,141.90,129.3,71.5,62.8,57.9,53.4,32.2$, $28.9,26.0,22.7,18.4,-5.3$.

Conversion of 129 to 130 . tert-Butyllithium $(0.56 \mathrm{~mL}, 1.7 \mathrm{M}, 0.952 \mathrm{mmol})$ was added to a flame-dried flask containing bromide $129(170 \mathrm{mg}, 0.475 \mathrm{mmol})$ in THF $(2.4 \mathrm{~mL})$ at $-78^{\circ} \mathrm{C}$. After stirring the reaction mixture for $40 \mathrm{~min}$., DMF $(0.11 \mathrm{~mL}, 1.42 \mathrm{mmol})$ was added. The reaction mixture was stirred at $-78^{\circ} \mathrm{C}$ for $3 \mathrm{~h}$. After quenching the reaction with water $(5 \mathrm{~mL})$, the aqueous layer was extracted with diethyl ether $(4 \times 10 \mathrm{~mL})$, and the combined organic layers were washed sequentially with water $(10 \mathrm{~mL})$ and brine $(10 \mathrm{~mL})$ and dried over magnesium sulfate. The solvent was removed by rotary evaporation and the crude product was purified by column chromatography (EtOAc:hexanes $=1: 9$ ) to give 130 (122 $\mathrm{mg}, 0.398 \mathrm{mmol}, 84 \%$ ) as a colorless oil.

Compound 130. $R_{f} 0.33$ (EtOAc:hexanes = 1:9); $\mathbb{R}$ (neat, $\mathrm{NaCl}$ ) $3070(\mathrm{w}), 2952(\mathrm{~s})$, 2935 (s), 2858 (s), 2737 (w), 1661 (s), 1613 (m), 1558 (w), 1472 (m), 1463 (m), 1387 (m), $1361(w), 1336(w), 1292(m), 1256(m), 1231(w), 1217(m), 1102(s), 1022(w)$, $1006(\mathrm{w}) \mathrm{cm}^{-1}$; ${ }^{1} \mathrm{H} \mathrm{NMR}\left(\mathrm{CDCl}_{3}, 400 \mathrm{MHz}\right) \delta 9.83(\mathrm{~s}, 1 \mathrm{H}), 6.82(\mathrm{~m}, 1 \mathrm{H}), 6.67(\mathrm{~m}, 1 \mathrm{H})$, 4.00 (br. s, 1H), $3.62-3.57$ (m, 3H), $2.70-2.67$ (m, 2H), 2.03 (dm, 1H, $J=6.6 \mathrm{~Hz}$ ), $1.98(\mathrm{dm}, 1 \mathrm{H}, J=6.4 \mathrm{~Hz}), 1.66(\mathrm{~m}, 1 \mathrm{H}), 1.58-1.42(\mathrm{~m}, 3 \mathrm{H}), 0.88(\mathrm{~s}, 9 \mathrm{H}), 0.04(\mathrm{~s}, 6 \mathrm{H})$; ${ }^{13} \mathrm{C} \mathrm{NMR}\left(\mathrm{CDCl}_{3}, 100 \mathrm{MHz}\right) \delta 184.8,180.9,148.8,143.8,140.6,70.4,62.5,55.8,47.4$, $32.2,28.9,25.9,23.4,18.3,-5.3$. 


\subsubsection{Norbornadiene-Tethered Nitrile Oxide Bearing a Methoxy-Containing}

Substituent at the C-3 Position

5.4.4.1 Cycloadduct Bearing a Methoxymethyl Substituent<smiles>COC(=O)C1=C(CCCC[OH+])C2C=CC1C2</smiles><smiles>OCC1=C(CCCC[OH+])C2C=CC1C2</smiles>

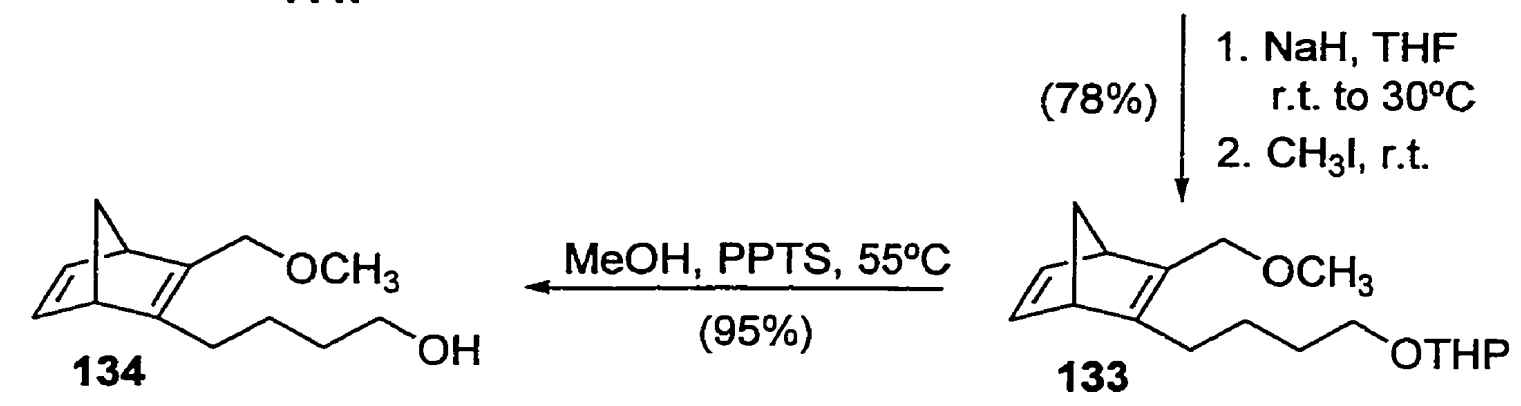<smiles>COCC1=C(CCCCI)[C@H]([C@H](C)OC)[C@H]2C=C[C@H]1C2</smiles>

$\mathrm{NaNO}_{2}$, DMSO phloroglucinol, r.t. (48\%)<smiles>COCC1=C(CCCC[N+](=O)[O-])C2C=CC1C2</smiles>

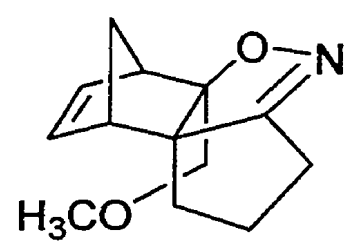

$104 k$
(66\%)

$104 k$

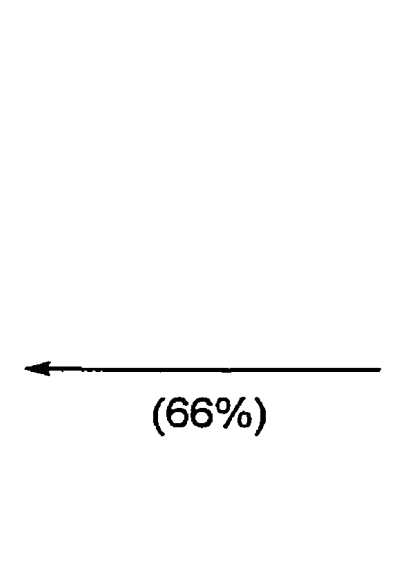


Conversion of 111 to 132 . To a flame-dried flask containing 111 (page 155 - 156, 1.84 $\mathrm{g}, 6.00 \mathrm{mmol})$ in $\mathrm{CH}_{2} \mathrm{Cl}_{2}(10 \mathrm{~mL}), \operatorname{DIBAL}(16.0 \mathrm{~mL}, 1.0 \mathrm{M}, 16.0 \mathrm{mmol})$, was added at $-78^{\circ} \mathrm{C}$. The reaction mixture was stirred at $-78^{\circ} \mathrm{C}$ for $50 \mathrm{~min}$. After quenching the reaction with water $(10 \mathrm{~mL})$, the aqueous layer was extracted with $\mathrm{CH}_{2} \mathrm{Cl}_{2}(4 \times 25 \mathrm{~mL})$, and the combined organic layers were washed sequentially with water $(30 \mathrm{~mL})$ and brine $(30 \mathrm{~mL})$ and dried over magnesium sulfate. The solvent was removed by rotary evaporation and the crude product was purified by column chromatography (EtOAc:hexanes $=1: 4)$ to give $132(1.17 \mathrm{~g}, 4.20 \mathrm{mmol}, 70 \%)$ as a colorless oil.

Compound 132. A mixture of two diastereomers. $R_{f} 0.16$ (EtOAc:hexanes $\left.=1: 4\right) ; \mathrm{R}$ (neat, $\mathrm{NaCl}) 3423$ (m), 3062 (w), 2939 (s), 2865 (s), 1658 (w), 1556 (w), 1453 (m), 1441 (m), $1353(\mathrm{~m}), 1323(\mathrm{w}), 1201(\mathrm{~m}), 1137(\mathrm{~m}), 1120(\mathrm{~m}), 1076(\mathrm{~m}), 1023(\mathrm{~s}) \mathrm{cm}^{-1} ;{ }^{1} \mathrm{H}$ $\operatorname{NMR}\left(\mathrm{CDCl}_{3}, 400 \mathrm{MHz}\right) \delta 6.78(\mathrm{dd}, 1 \mathrm{H}, J=5.0,2.9 \mathrm{~Hz}), 6.71(\mathrm{dd}, 1 \mathrm{H}, J=4.9,2.9 \mathrm{~Hz})$, $4.54(\mathrm{~m}, 1 \mathrm{H}), 4.23\left(\mathrm{~d}_{\mathrm{AB}}, 1 \mathrm{H}, J=12.2 \mathrm{~Hz}\right), 4.11\left(\mathrm{~d}_{\mathrm{AB}} \mathrm{d}, 1 \mathrm{H}, J=12.2,2.0 \mathrm{~Hz}\right), 3.85(\mathrm{~m}$, $1 \mathrm{H}), 3.71(\mathrm{~m}, 1 \mathrm{H}), 3.53(\mathrm{~m}, \mathrm{lH}), 3.49(\mathrm{~m}, 1 \mathrm{H}), 3.39-3.33(\mathrm{~m}, 2 \mathrm{H}), 2.25(\mathrm{~m}, 1 \mathrm{H}), 2.15$ $(\mathrm{m}, 1 \mathrm{H}), 1.93(\mathrm{dm}, 1 \mathrm{H}, J=5.8 \mathrm{~Hz}), 1.88(\mathrm{dm}, 1 \mathrm{H}, J=5.8 \mathrm{~Hz}), 1.80(\mathrm{~m}, 1 \mathrm{H}), 1.67(\mathrm{~m}$, $1 \mathrm{H}), 1.56-1.38(\mathrm{~m}, 9 \mathrm{H}) ;{ }^{13} \mathrm{C} \mathrm{NMR}\left(\mathrm{CDCl}_{3}, 100 \mathrm{MHz}\right) \delta 152.1,145.7,143.0,142.13$, $142.11,98.79,98.76,71.4,67.3,62.34,62.31,58.8,53.5,51.87,51.85,30.7,28.94$, 28.92, 27.8, 25.4, 23.9, 19.62, 19.60. Anal. Calcd. for $\mathrm{C}_{17} \mathrm{H}_{26} \mathrm{O}_{3}:$ C, 73.55; $\mathrm{H}, 9.41$. Found $\mathrm{C}, 73.74 ; \mathrm{H}, 9.18$.

Conversion of 132 to 133 . Alcohol $132(1.01 \mathrm{~g}, 3.63 \mathrm{mmol})$ in THF ( $1.3 \mathrm{~mL})$ was added via a cannula to a flame-dried flask containing $\mathrm{NaH}$ (212 mg, $8.83 \mathrm{mmol})$ in THF (4 mL). The reaction mixture was stirred at room temperature for $30 \mathrm{~min}$. and at $30^{\circ} \mathrm{C}$ for $1.5 \mathrm{~h}$. 
Iodomethane $(1.20 \mathrm{~mL}, 19.3 \mathrm{mmol})$ was then added, and the reaction mixture was allowed to stir at room temperature for $3 \mathrm{~h}$. After quenching the reaction with water (20 $\mathrm{mL})$, the aqueous layer was extracted with diethyl ether $(4 \times 20 \mathrm{~mL})$, and the combined organic layers were washed sequentially with water $(20 \mathrm{~mL})$ and brine $(20 \mathrm{~mL})$ and dried over magnesium sulfate. The solvent was removed by rotary evaporation and the crude product was purified by column chromatography (EtOAc:hexanes $=1: 9)$ to give $133(831$ $\mathrm{mg}, 2.84 \mathrm{mmol}, 78 \%$ ) as a coloriess oil.

Compound 133. $R_{f} 0.55$ (EtOAc:hexanes = 1:4); IR (neat, $\mathrm{NaCl}$ ) 3064 (w), 2936 (s), $2865(\mathrm{~s}), 2815(\mathrm{~m}), 1658(\mathrm{w}), 1557(\mathrm{w}), 1453(\mathrm{~m}), 1441(\mathrm{~m}), 1376(\mathrm{~m}), 1353(\mathrm{~m}), 1323$ $(w), 1305(w), 1260(w), 1229(w), 1200(\mathrm{~m}), 1191(\mathrm{~m}), 1160(\mathrm{~m}), 1139(\mathrm{~s}), 1120(\mathrm{~s})$, 1077 (s), 1035 (s), 1023 (s) $\mathrm{cm}^{-1}$; ${ }^{1} \mathrm{H} \operatorname{NMR}\left(\mathrm{CDCl}_{3}, 400 \mathrm{MHz}\right) \delta 6.73$ (dd, $1 \mathrm{H}, J=5.0,3.0$ $\mathrm{Hz}), 6.65(\mathrm{dd}, 1 \mathrm{H}, J=5.0,3.1 \mathrm{~Hz}), 4.50(\mathrm{~m}, 1 \mathrm{H}), 3.99\left(\mathrm{~d}_{\mathrm{AB}}, 1 \mathrm{H}, J=11.8 \mathrm{~Hz}\right), 3.83\left(\mathrm{~d}_{\mathrm{AB}}\right.$, $1 \mathrm{H}, J=11.8 \mathrm{~Hz}), 3.79(\mathrm{~m}, 1 \mathrm{H}), 3.67(\mathrm{~m}, 1 \mathrm{H}), 3.47-3.41(\mathrm{~m}, 2 \mathrm{H}), 3.32-3.30(\mathrm{~m}, 2 \mathrm{H})$, $3.16(\mathrm{~s}, 3 \mathrm{H}), 2.21(\mathrm{~m}, 1 \mathrm{H}), 2.11(\mathrm{~m}, 1 \mathrm{H}), 1.89(\mathrm{dm}, 1 \mathrm{H}, J=5.8 \mathrm{~Hz}), 1.83(\mathrm{dm}, 1 \mathrm{H}, J=$ $5.8 \mathrm{~Hz}), 1.77(\mathrm{~m}, 1 \mathrm{H}), 1.66(\mathrm{~m}, 1 \mathrm{H}), 1.55-1.35(\mathrm{~m}, 8 \mathrm{H}) ;{ }^{13} \mathrm{C} \mathrm{NMR}\left(\mathrm{CDCl}_{3}, 100 \mathrm{MHz}\right) \delta$ $153.1,143.4,142.8,141.8,98.62,98.60,71.1,67.9,67.1,62.1,57.3,53.5,51.9,30.6$, 29.1, 27.9, 25.3, 23.9, 19.5. Anal. Calcd. for $\mathrm{C}_{18} \mathrm{H}_{28} \mathrm{O}_{3}$ : C, 73.93; $\mathrm{H}, 9.65$. Found $\mathrm{C}$, $73.96 ; \mathrm{H}, 9.64$

Conversion of 133 to 134 . To a flame-dried flask containing 133 (690 mg, $2.36 \mathrm{mmol}$ ) in $\mathrm{MeOH}(20 \mathrm{~mL}$ ), pyridium p-toluenesulfonate, PPTS (149 $\mathrm{mg}, 0.593 \mathrm{mmol}$ ), was added at room temperature. The reaction mixture was stirred at $55^{\circ} \mathrm{C}$ for $1 \mathrm{~h}$. After quenching the reaction with water $(20 \mathrm{~mL})$, the aqueous layer was extracted with diethyl ether $(4 \times 40$ 
$\mathrm{mL})$, and the combined organic layers were washed sequentially with water $(40 \mathrm{~mL})$ and brine $(40 \mathrm{~mL})$ and dried over magnesium sulfate. The solvent was removed by rotary evaporation and the crude product was purified by column chromatography (EtOAc:hexanes = 1:4) to give $134(466 \mathrm{mg}, 2.24 \mathrm{mmol}, 95 \%)$ as a colorless oil.

4-(3-Methoxymethylbicyclo[2.2.1] hepta-2,5-dien-2-yl)butan-1-ol $\quad(134) . \quad R_{f} \quad 0.30$ (EtOAc:hexanes =2:3); IR (neat, NaCl) 3394 (m), 3064 (w), 2975 (s), 2934 (s), 2864 (s), 2819 (m), 1556 (w), 1451 (m), 1376 (m), 1355 (m), 1307 (m), 1190 (m), 1141 (m), 1073

(s), $1025(\mathrm{~m}) \mathrm{cm}^{-1} ;{ }^{1} \mathrm{H}$ NMR $\left(\mathrm{CDCl}_{3}, 400 \mathrm{MHz}\right) \delta 6.75$ (dd, $\left.1 \mathrm{H}, J=4.8,3.0 \mathrm{~Hz}\right), 6.67$ (dd, $1 \mathrm{H}, J=4.8,3.0 \mathrm{~Hz}), 4.01\left(\mathrm{~d}_{\mathrm{AB}}, 1 \mathrm{H}, J=11.8 \mathrm{~Hz}\right), 3.85\left(\mathrm{~d}_{\mathrm{AB}}, 1 \mathrm{H}, J=11.8 \mathrm{~Hz}\right), 3.56$ (t, $2 \mathrm{H}, J=6.2 \mathrm{~Hz}$ ), 3.46 (br. s, 1H), 3.34 (br. s, 1H), 3.18 (s, 3H), 2.28 (br. s, 1H), $2.19-$ $2.26(\mathrm{~m}, 2 \mathrm{H}), 1.91(\mathrm{dm}, 1 \mathrm{H}, J=5.8 \mathrm{~Hz}), 1.85(\mathrm{dm}, 1 \mathrm{H}, J=5.8 \mathrm{~Hz}), 1.34-1.55(\mathrm{~m}, 4 \mathrm{H})$; ${ }^{13} \mathrm{C} \mathrm{NMR}\left(\mathrm{CDCl}_{3}, 100 \mathrm{MHz}\right) \delta 153.3,143.3,142.9,141.8,71.2,68.0,62.4,57.3,53.5$, $51.9,32.1,27.9,23.5$.

Conversion of Alcohol 134 to Iodide 135. To a flame-dried flask containing $\mathrm{PPh}_{3}(2.56$ g, $9.86 \mathrm{mmol})$, imidazole $(1.54 \mathrm{~g}, 22.6 \mathrm{mmol})$, acetonitrile $(8 \mathrm{~mL})$ and THF $(5 \mathrm{~mL}), \mathrm{I}_{2}$ $(2.76 \mathrm{~g}, 21.7 \mathrm{mmol})$ was added at $0^{\circ} \mathrm{C}$. The reddish-brown reaction mixture was stirred for $15 \mathrm{~min}$. at $0^{\circ} \mathrm{C}$. Alcohol $134(466 \mathrm{mg}, 2.24 \mathrm{mmol})$ in acetonitrile $(3 \mathrm{~mL})$ was added via a cannula at $0^{\circ} \mathrm{C}$. The reaction mixture was stirred at room temperature for $3 \mathrm{~h}$. After the reaction was quenched with water $(20 \mathrm{~mL})$, the aqueous layer was extracted with diethyl ether $(4 \times 20 \mathrm{~mL})$, and the combined organic layers were washed sequentially with water $(40 \mathrm{~mL})$, saturated sodium thiosulfate $(40 \mathrm{~mL})$ and brine $(40 \mathrm{~mL})$ and dried over magnesium sulfate. The solvent was removed by rotary evaporation and the crude 
product was purified by column chromatography (EtOAc:hexanes =1:9) to give iodide 135 (584 mg, $1.84 \mathrm{mmol}, 82 \%$ ) as a colorless oil.

2-(4-Iodobutyl)-3-methoxymethylbicyclo[2.2.1]hepta-2,5-diene $\quad$ (135). $\quad R_{f} \quad 0.44$ (EtOAc:hexanes = 1:9); IR (neat, $\mathrm{NaCl}$ ) 3062 (w), 2968 (s), 2931 (s), 2863 (s), 2814 (m), $1556(w), 1449(\mathrm{~m}), 1376(\mathrm{w}), 1354(\mathrm{w}), 1307(\mathrm{~m}), 1288(\mathrm{~m}), 1216(\mathrm{~m}), 1189(\mathrm{~m}), 1170$ (m), 1141 (m), 1098 (s) $\mathrm{cm}^{-1} ;{ }^{1} \mathrm{H} \mathrm{NMR}\left(\mathrm{CDCl}_{3}, 400 \mathrm{MHz}\right) \delta 6.79$ (dd, $1 \mathrm{H}, J=5.0,3.0$ $\mathrm{H}), 6.73(\mathrm{dd}, 1 \mathrm{H}, J=5.0,3.0 \mathrm{~Hz}), 4.02\left(\mathrm{~d}_{\mathrm{AB}}, 1 \mathrm{H}, J=11.8 \mathrm{~Hz}\right), 3.88\left(\mathrm{~d}_{\mathrm{AB}}, 1 \mathrm{H}, J=11.8\right.$ $\mathrm{Hz}), 3.50$ (br. s, $1 \mathrm{H}), 3.38$ (br. s, $1 \mathrm{H}), 3.23(\mathrm{~s}, 3 \mathrm{H}), 3.17(\mathrm{t}, 2 \mathrm{H}, J=6.8 \mathrm{~Hz}), 2.26(\mathrm{~m}, 1 \mathrm{H})$, $2.15(\mathrm{~m}, 1 \mathrm{H}), 1.95(\mathrm{dm}, 1 \mathrm{H}, J=5.8 \mathrm{~Hz}), 1.89(\mathrm{dm}, 1 \mathrm{H}, J=5.8 \mathrm{~Hz}), 1.77-1.68(\mathrm{~m}, 2 \mathrm{H})$, $1.59-1.40(\mathrm{~m}, 2 \mathrm{H}) ;{ }^{13} \mathrm{C} \mathrm{NMR}\left(\mathrm{CDCl}_{3}, 100 \mathrm{MHz}\right) \delta 152.6,144.0,143.0,141.9,71.4$, $68.1,57.6,53.6,52.1,32.8,28.1,27.1,6.9$.

Conversion of Iodide 135 to Nitro Compound 116k. To a flame-dried flask containing iodide $135(523 \mathrm{mg}, 1.64 \mathrm{mmol})$ in DMSO $(7.5 \mathrm{~mL}), \mathrm{NaNO}_{2}(528 \mathrm{mg}, 7.65 \mathrm{mmol})$ and phloroglucinol (428 mg, $2.64 \mathrm{mmol}$ ) were added. The light brown reaction mixture was stirred at room temperature for $20 \mathrm{~h}$. After quenching the reaction with water $(25 \mathrm{~mL})$, the aqueous layer was extracted with diethyl ether $(4 \times 25 \mathrm{~mL})$ and the combined organic layers were washed sequentially with water $(30 \mathrm{~mL})$ and brine $(30 \mathrm{~mL})$ and dried over magnesium sulfate. The solvent was removed by rotary evaporation and the crude product was purified by column chromatography (EtOAc:hexanes $=1: 9$ ) to give 116k (187 $\mathrm{mg}, 0.788 \mathrm{mmol}, 48 \%$ ) as a colorless viscous oil.

2-Methoxymethyl-3-(4-nitrobutyl)bicyclo[2.2.1]hepta-2,5-diene $\quad(116 \mathrm{k}) . \quad R_{f} \quad 0.73$ (EtOAc:hexanes = 2:3); IR (neat, $\mathrm{NaCl}$ ) 3064 (w), 2969 (s), 2932 (s), 2865 (s), 2818 (m), 
$1660(\mathrm{w}), 1552$ (s), 1452 (m), 1435 (m), $1382(\mathrm{~s}), 1355$ (m) 1306 (m), $1288(\mathrm{w}), 1247$

(w), $1230(\mathrm{w}), 1190$ (m), $1141(\mathrm{~m}), 1095(\mathrm{~s}) \mathrm{cm}^{-1} ;{ }^{1} \mathrm{H}$ NMR $\left(\mathrm{CDCl}_{3}, 400 \mathrm{MHz}\right) \delta 6.79$ (dd, $1 \mathrm{H}, J=5.1,3.0 \mathrm{~Hz}$ ), 6.70 (dd, $1 \mathrm{H}, J=5.1,3.0 \mathrm{~Hz}$ ), $4.35(\mathrm{t}, 2 \mathrm{H}, J=6.9 \mathrm{~Hz}$ ), 4.02 $\left(\mathrm{d}_{\mathrm{AB}}, 1 \mathrm{H}, J=11.8 \mathrm{~Hz}\right), 3.88\left(\mathrm{~d}_{\mathrm{AB}}, 1 \mathrm{H}, J=11.8 \mathrm{~Hz}\right.$ ), 3.50 (br. s, $\left.1 \mathrm{H}\right), 3.34$ (br. s, $\left.1 \mathrm{H}\right), 3.23$ (s, 3H), $2.29(\mathrm{~m}, 1 \mathrm{H}), 2.19(\mathrm{~m}, 1 \mathrm{H}), 1.94(\mathrm{dm}, 1 \mathrm{H}, J=5.9 \mathrm{~Hz}), 1.89(\mathrm{dm}, 1 \mathrm{H}, J=5.9$ $\mathrm{Hz}), 1.87(\mathrm{~m}, 2 \mathrm{H}), 1.45(\mathrm{~m}, 2 \mathrm{H}) ;{ }^{13} \mathrm{C} \mathrm{NMR}\left(\mathrm{CDCl}_{3}, 100 \mathrm{MHz}\right) \delta 151.8,144.7,143.1$, $141.8,75.4,71.5,68.1,57.7,53.5,52.2,27.3,26.7,23.9$.

\section{In situ Generation of Nitrile Oxide from Nitro Compound 116k and Subsequent Cycloaddition.}

Di-tert-butyl dicarbonate, $(\mathrm{BOC})_{2} \mathrm{O}(281 \mathrm{mg}, 1.29 \mathrm{mmol})$, in toluene $(2 \mathrm{~mL})$ was added via a cannula to a flame-dried flask containing the nitro compound $116 \mathrm{k}(83.0 \mathrm{mg}, 0.350$ mmol), 4-dimethylaminopyridine, DMAP (95.6 $\mathrm{mg}, 0.783 \mathrm{mmol})$, in toluene $(3 \mathrm{~mL})$. The reaction mixture was stirred at $90^{\circ} \mathrm{C}$ for $66 \mathrm{~h}$. The solvent was removed by rotary evaporation and the crude product was purified by column chromatography (EtOAc:hexanes $=2: 3)$ to give cycloadduct $104 \mathrm{k}(50.9 \mathrm{mg}, 0.232 \mathrm{mmol}, 66 \%)$ as a colorless viscous oil.

Cycloadduct 104k. $R_{f} 0.50$ (EtOAc:hexanes = 2:3); IR (neat, NaCl) $3072(\mathrm{w}), 2998(\mathrm{~m}$ ), 2973 (s), 2950 (s), 2876 (m), 2816 (w), 2752 (w), 1637 (w), 1475 (w), 1450 (m), 1391 (w), 1329 (m), 1299 (w), 1271 (w), 1254 (w), 1247 (m), 1202 (m), 1148 (w), 1129 (m), 1111 (s), 1098 (s) cm ${ }^{-1} ;{ }^{1} \mathrm{H}$ NMR $\left(\mathrm{CDCl}_{3}, 400 \mathrm{MHz}\right) \delta 6.21$ (dd, $1 \mathrm{H}, J=5.7,3.0 \mathrm{~Hz}$ ), 6.17 (dd, $1 \mathrm{H}, J=5.6,3.1 \mathrm{~Hz}), 3.36(\mathrm{~s}, 3 \mathrm{H}), 3.27$ (d, $1 \mathrm{H}, J=10.5 \mathrm{~Hz}), 3.21$ (br. s, $1 \mathrm{H}$ ), 3.16 (d, 1H, $J=10.5 \mathrm{~Hz}$ ), 2.94 (br. s, 1H), $2.46-2.42$ (m, 2H), 2.22 (m, 1H), 2.11 (m, 
$1 \mathrm{H}), 1.76(\mathrm{dm}, 1 \mathrm{H}, J=9.2 \mathrm{~Hz}), 1.71(\mathrm{~m}, 1 \mathrm{H}), 1.54(\mathrm{dm}, 1 \mathrm{H}, J=9.2 \mathrm{~Hz}), 0.96$ (ddd, $1 \mathrm{H}, J$ $=12.7,7.7,2.5 \mathrm{~Hz}) ;{ }^{13} \mathrm{C} \mathrm{NMR}\left(\mathrm{CDCl}_{3}, 100 \mathrm{MHz}\right) \delta 169.5,136.3,135.3,99.5,75.5,74.9$, 59.6, 51.6, 49.1, 44.4, 28.5, 25.7, 21.1. Anal. Calcd. for $\mathrm{C}_{13} \mathrm{H}_{17} \mathrm{NO}_{2}$ : C, $71.21 ; \mathrm{H}, 7.81$. Found C, 70.87; H, 7.84 . 


\section{Epilogue}


The intramolecular 1,3-dipolar cycloaddition of norbornadiene-tethered nitrile oxides has been demonstrated to be a convenient and simple method for the preparation of isoxazolines. These cycloadditions were found to be highly regio- and stereoselective, giving the exo cycloadducts in good yields. The significance of these reactions, however, lies in the access it provides to functionalized carbon skeletons by cleavage of the isoxazoline ring. The sequence of reactions-cycloaddition, ring cleavage of the isoxazoline and manipulation of functional groups-can provide a valuable regio- and stereocontrolled route to a variety of useful spirocyclic systems (Scheme 78).

Natural products containing spirocyclic ring systems are widespread. $^{76-81}$ Knowledge of spirocyclic compounds possessing interesting biological activity is continually expanding. Representative examples are shown in Fig. 5. Powell et al. have reported antileukemic activity associated with sesbanine (136), a spirocyclic compound based on the 2,7-naphthyridine nucleus and an extract from seeds of Sesbania drummondii. $^{82-85}$ The spirocycle lubimin $(137)$ has been isolated as a stress metabolite from infected potato tubers. ${ }^{86,87}$ It has been demonstrated that 137 possesses antifungal properties which may be involved in the defense mechanism of the potato against various pathogens. Many spirocyclic compounds, well-known for their olfactory properties, have prompted the fragrance industries to develop convenient methods to prepare suitable and useful spirocycles. An example of a compound with such properties is hinesol (138). ${ }^{\mathbf{8 8}}$ Although numerous spirocyclic compounds with a spiro[4.5]decane framework have led to successful synthesis of one or more natural products, the development of other spirocyclic systems including the spiro[4.4]nonane group should be pursued. 
Scheme 78. Angular-fused Tricyclic and Spirocyclic Compounds Derived from 104

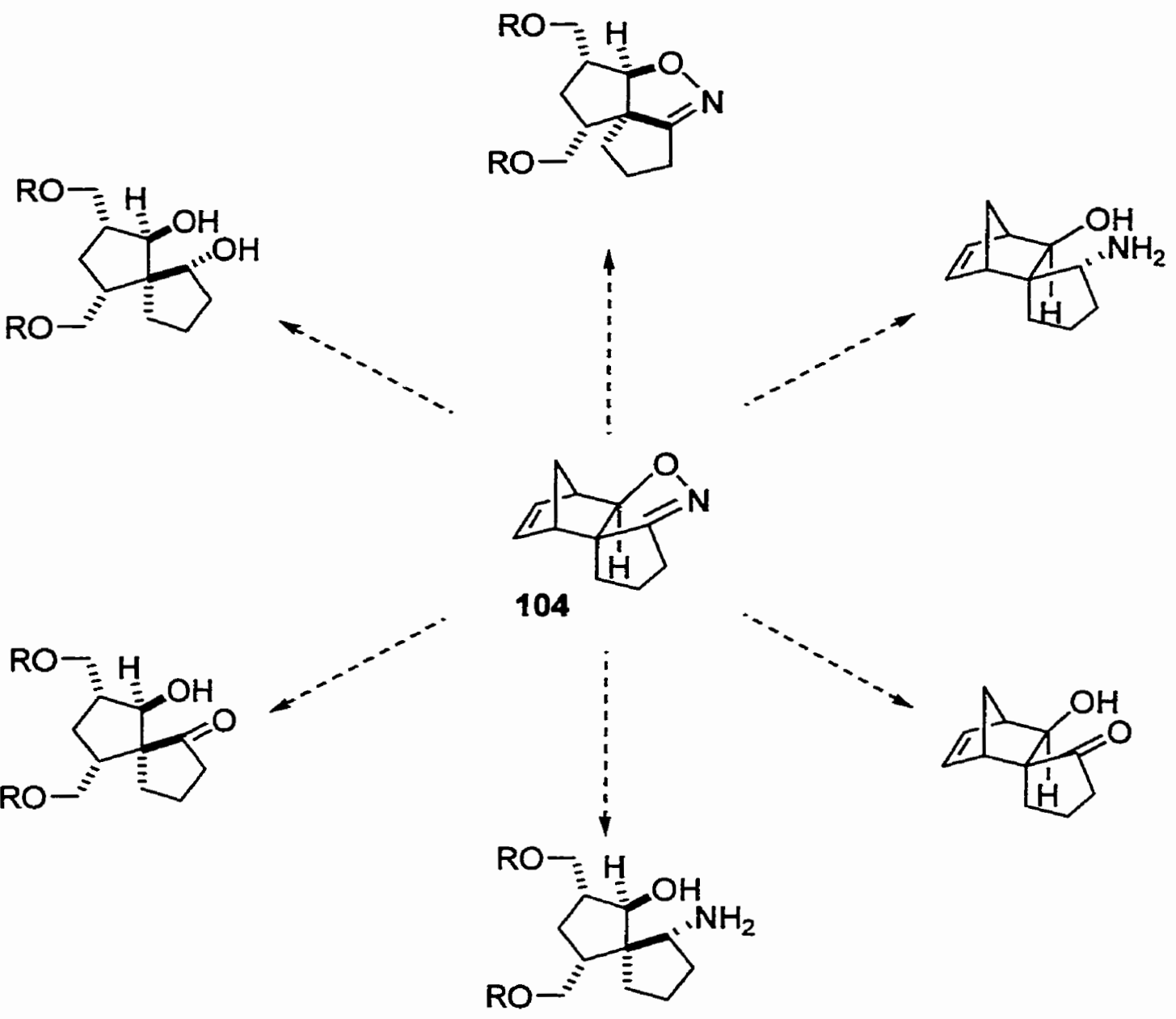

Fig. 5<smiles>O=C1NC(=O)[C@]2(CCC(O)C2)c2ccncc21</smiles>

136<smiles>C=C(C)[C@@H]1CC[C@]2(C1)[C@@H](C)C[C@@H](O)C[C@H]2C</smiles>

137<smiles>CC1=CCC[C@H](C)[C@]12CC[C@@H](C(C)(C)O)C2</smiles>

138 
There are several difficulties in the construction of spirocycles. In addition to the problem of constructing the quaternary centre, one needs unambiguous stereochemical control between substituents in the two carbocyclic rings. The major stereochemical problem is establishing the correct sense of chirality of the spirocarbon relative to the centres present in one or both rings. Since the cycloadduct 104 is a rigid skeleton, mild reduction of the labile $\mathrm{N}-\mathrm{O}$ bond will yield the spirocyclic compound with complete stereochemical control (Scheme 78). Thus, the ease of preparation of the cycloadduct and facility of stereocontrolled fragmentation will make them ideal building blocks in the synthesis of structurally complex spirocycles. ${ }^{89,90}$ In addition, the various functionalities that will be generated through the cleavage of the isoxazoline ring will allow these spirocycles to serve as useful intermediates for the construction of other systems. The $\gamma$ amino alcohol unit is present in several natural product classes, e.g. amino polyols, amino sugars, and amino acids. Many of these exhibit notable physiological properties. ${ }^{91}$ Another important functionalized unit is the $\beta$-hydroxy carbonyl, which is found in a large number of important natural products. ${ }^{92}$ From the standpoint of synthetic strategy, the vast majority of $\beta$-hydroxy ketones are constructed by a carbonyl addition as the key carbon-carbon bond-forming reaction. Clearly the development of other fundamentally different strategies that might complement the aldol type reaction would be desirable. Hence, the synthesis of the $\beta$-hydroxy carbonyl unit of the spirocycles that involves cycloaddition, rather than carbonyl addition as the key carbon-carbon bond-forming reaction might then have tremendous potential for applications in complex natural product synthesis. 
With increasing demand for optically active compounds, the investigation of new approaches to chiral spirocycles is important. An extension of this work might allow the generation of chiral spirocycles from chiral norbornadiene-tethered nitrile oxides. Nitrile oxide cycloaddition chemistry can serve as a powerful tool for crafting the diverse molecules of Nature. 
References 
1. Lautens, M.; Klute, W.; Tam, W. Chem. Rev. 1996, 96, 49.

2. Gilchrist, T.L. Heterocyclic Chemistry; Third Edition, Addison Wesley Longman: Essex, 1997.

3. Carey, F.; Sundberg, R. Advanced Organic Chemistry, Part B: Reactions and Synthesis; Third Edition, Plenum Press: New York, 1993.

4. Lautens, M.; Tam, W. Advances in Metal-Organic Chemistry; JAI Press Inc.: New York, 1998; Vol. 6, p. 49.

5. Cristina, D.; De Amici, M.; De Micheli, C. Tetrahedron 1991, 37, 1349.

6. Lautens, M.; Tam, W.; Lautens, J.C.; Edwards, L.G.; Crudden, C.M.; Smith, A.C. J. Am. Chem. Soc. 1995, 117, 6863.

7. Taniguchi, H.; Ikeda, T.; Yoshida, Y.; Imoto, E. Bull. Chem. Soc. Jpn. 1977, 50, 2694.

8. Krespan, C.G.; McKusick, B.C.; Cairns, T.L. J. Am. Chem. Soc. 1961, 83, 3428.

9. Torssell, K.B.G. Nitrile Oxides, Nitrones, and Nitronates in Organic Synthesis; VCH: Weinheim, 1988.

10. Gothelf, K.V.; Jorgensen, K. A. Chem. Rev. 1998, 98, 863.

11. Curran, D.P. Advances in Dipolar Cycloaddition Chemistry; Curran, D.P., Ed; JAI Press: Greenwich, 1988; Vol. 1, p. 129.

12. Padwa, A. 1,3-Dipolar Cycloaddition Chemistry; Padwa, A., Ed; John Wiley \& Sons: New York, 1984; Vol. 2, p. 277.

13. Huisgen, R. in 1,3-Dipolar Cycloaddition; Padwa, A., Ed.; John Wiley \& Sons: New York, 1984; Vol. 1, p. 1. 
14. Woodward, R.B.; Hoffmann, R. Angew. Chem., Int. Ed. Engl. 1969, 8, 781.

15. Sustmann, R.; Trill, H. Angew. Chem., Int. Ed. Engl. 1972, 11, 838.

16. Cinquini, M.; Cozzi, F. in Organic Synthesis; Houben-Weyl; 1995; Vol. E21, p. 2953-2987.

17. Chung, W.; Tsai, T.; Ho, C.; Chiang, M.Y.N.; Le Noble,W.J. J. Org. Chem. 1997, 62,4672 .

18. Lacoste, J.; Soucy, C.; Rochon, F.D.; Breau, L. Tetrahedron 1998, 39, 9121.

19. Basel, Y.; Hassner, A. Synthesis 1997, 309.

20. De Micheli, C.; Gandolfi, R.; Oberti, R. J. Org. Chem. 1980, 45, 1209.

21. Hassner, A.; Friedman, O.; Dehaen, W. Liebigs Ann./Recueil 1997, 587.

22. Hassner, A.; Amarasekara, A.S.; Padwa, A.; Bullock, W.H. Tetrahedron Lett. $1988,29,715$.

23. Caramella, P. in 1,3-Dipolar Cycloaddition Chemistry; John Wiley \& Sons: New York, 1984; Vol. 1, p. 291.

24. Garanti, L.; Sala, A.; Zecchi, G. Synthesis 1975, 666.

25. Wollenberg, R.H.; Goldstein, J.E. Synthesis 1980, 757.

26. Jaeger, V., Gunther, H.J. Angew. Chem., Int. Ed. Engl. 1977, 16, 246.

27. Kozikowski, A.P.; Ishida, H. J. Am. Chem. Soc. 1980, 102, 4265.

28. Confalone, P.N.; Pizzolato, G.; Confalone, D.L.; Uskokovic, M.R. J. Am. Chem. Soc. 1980, 102, 1954.

29. Zhang, R.; Chen, J. Synthesis 1990, 817.

30. Kamimura, A.; Hori, K. Tetrahedron Lett. 1994, 50, 7969.

31. Hassner, A.; Maurya, R.; Mesko, E. Tetrahedron Lett. 1988, 41, 5313. 
32. Ukaji, Y.; Sada, K.; Inomata, K. Chem. Lett. 1993, 1847.

33. Tranmer, G.K.; Yip, C.; Handerson, S.; Jordan, R.W.; Tam, W. Can. J. Chem. $2000,78,527$.

34. Corey E.J.; Shibasaki, M.; Nicolaou, K.C.; Malmsten, C.L.; Samuelesson, B. Tetrahedron Lett. 1976, 737.

35. Lee, M.; Ikeda, I.; Kawabe, T.; Mori, S.; Kanematsu, K. J. Org. Chem. 1996, 61, 3406.

36. Sato, K.; Miyamoto, O.; Inoue, S.; Honda, K. Chem. Lett. 1981, 1183.

37. Monti, H.; Corriol, C.; Bertrand, M. Tetrahedron Lett. 1982, 23, 5539.

38. Trost, B.M.; Fleming, I.; Paquette, L.A. Comprehensive Organic Synthesis; Trost, B.M.; Fleming, I., Eds; Pergamon: Oxford, 1991; Vol. 5, Chapter 1.

39. Kanemasa, S.; Tsuge, O. Heterocycles 1990, 30, 719.

40. Brandsma, L.; Verkruijsse, H.D. Recl. Trav. Chim. Pays-Bas 1986, I05, 66.

41. Lautens, M.; Tam, W.; Edwards, L.G. J. Org. Chem. 1992, 57, 8.

42. Sandler, S.R.; Karo, W. Organic Functional Group Preparation; Academic Press: New York, 1968; Vol. 1, p. 425.

43. Mukaiyama, T.; Hoshino, T. J. Am. Chem. Soc. 1960, 82, 5339.

44. Shimizu, T.; Hayashi, T.; Shibafuchi, H.; Teramura, K. Bull. Chem. Soc. Jpn. $1986,59,2827$.

45. Flautt, T.J.; Erman, W.F. J. Am. Chem. Soc. 1963, 85, 3212.

46. Mazzocchi, P.H.; Stahly, B.; Dodd, J.; Rondan, N.G.; Domelsmith, L.N.; Rozeboom, M.D.; Caramella, P.; Houk, K.N. J. Am. Chem. Soc. 1980, I02, 6482. 
47. The exo and endo cycloadducts 33 and 100 were modeled for energy minimization at PM3 level (CS Chem 3D Pro Version 3.5.1) using MOPAC for the assessment of the dihedral angles between $\mathrm{H}^{\mathrm{a}}$ and $\mathrm{H}^{\mathrm{b}}$. These dihedral angles were then compared to the Karplus curve for the determination of the theoretical coupling constants.

48. Yip, C.; Handerson, S.; Jordan, R.; Tam, W. Org. Lett. 1999, 1, 791.

49. Holmes, H.L.; Org. React. 1948, 4, 60.

50. Trost, B.M.; Fleming, I.; Paquette, L.A. Comprehensive Organic Synthesis; Trost, B.M.; Fleming, I. Eds; Pergamon: Oxford, 1991; Vol. 5, Chapter 4.1.

51. Ishihara, K. Kondo, S.; Kurihara, H.; Yamamoto, H. J. Org. Chem. 1997, 62, 3026.

52. Corey, E.J.; Lee, T.W.; Tetrahedron Lett. 1997, 38, 5755.

53. Nishikubo, T. Kameyama, A.; Kishi, K.; Mochizuki, Y. J. Polym. Sci. Part A: Polym. Chem. 1994, 32, 2765.

54. Raj, C.P.; Dhas, N.A.; Cherkinski, M.; Gedanken, A.; Braverman, S. Tetrahedron Lett. 1998, 39, 5413.

55. Dauben, W.G.; Cargill, R.L. Tetrahedron 1961, 15, 197.

56. Hammond, G.S. Turro, N.J.; Fisher, A. J. Am. Chem. Soc. 1961, 83, 4674.

57. Turro, N.J.; Cherry, W.R.; Manfred, M.F.; Mairbach, M.J. J. Am. Chem. Soc. $1977,99,7390$.

58. Tomioka, H.; Hamano, Y.; Izawa, Y. Bull Chem. Soc. Jpn. 1987, 60, 821.

59. Rohde, U.; Ruthe, F.; Jones, P.G.; Streubel, R. Angew. Chem. Int. Ed. 1999, 38, 215. 
60. Bonfantini, E.E.; Officer, D.L. J. Chem. Soc. Chem. Commun. 1994, 1445.

61. Maafi, M.; Lion, C.; Aaron, J.J. New J. Chem. 1996, 20, 559.

62. Chernoivanov, V.A.; Dubonosov, A.D.; Bren, V.A.; Minkin, V.I.; Suslov, A.N.; Borodkin, G.S. Mol. Cryst. Liq. Cryst. 1997, 297, 239.

63. Stäble, M.; Lehmann, R.; Kramaø, J.; Schlosser, M. Chimia 1995, 39, 229.

64. Kenndoff, J.; Polborn, K.; Szeimies, G. J. Am. Chem. Soc. 1990, I12, 6117.

65. Gassman, P.G.; Gennick, I. J. Am. Chem. Soc. 1980, I02, 6117.

66. Scott, W.J.; Stille, J.K. J. Am. Chem. Soc. 1986, 108, 3033.

67. Farina, V.; Krishnamurthy, V.; Scott, W.J. Org. React. 1997, 50, 1.

68. Miyaura, N.; Suzuki, A. Chem. Rev. 1995, 95, 2457.

69. Heck, R.F. in Comprehensive Organic Synthesis; Trost, B.M.; Fleming, I., Eds; Pergamon Press: New York, 1991; Vol. 4, p. 883.

70. Sonogashira, K. in Comprehensive Organic Synthesis; Trost, B.M.; Fleming, I., Eds; Pergamon Press: New York, 1991; Vol. 3, p. 521.

71. Tam, W.; Handerson, S.; Ferguson, G. Acta Cryst., 2000, C56, e71.

72. Still, W.C.; Kahn, M.; Mitra, A. J. Org. Chem. 1978, 43, 2923.

73. Lautens, M.; Edwards. L.G.; Tam, W.; Lough, A.J. J. Am. Chem. Soc. 1995, 117, 10276.

74. Rosini, G.; Ballini, R.; Sorrenti, P. Synthesis 1983, 1014.

75. Heinze, I.; Knoll, K.; Moller, R.; Eberbach, W. Chem. Ber. 1989, 122, 2147.

76. Heathcock, C.H. The Total Synthesis of Natural Products; ApSimon, J., Ed.; Wiley: New York, 1973; Vol. 2, p. 466 
77. Marshall, J.A.; Brady, S.F.; Andersen, N.H. Fortschr. Chem. Org. Naturst. 1974, $31,283$.

78. Krapcho, P.A. Synthesis 1978, 77.

79. Vandewalle, M.; De Clercq, P. Tetrahedron 1985, 41, 1767.

80. Ibuka, T.; Hayashi, K.; Minakata, H.; Inubushi, Y. Tetrahedron Lett. 1979, 2, 159.

81. Buchi, G.; Berthet, D.; Decorzant, R.; Grieder, A.; Hauser, A. J. Org. Chem. 1976, $41,3208$.

82. Powell, R.G; Smith, C.R.; Madrigal, R.V. Planta Med. 1976, 30, 1

83. Tomioka, K.; Koga, K. Tetrahedron Lett. 1980, 21, 2321.

84. Kende, A.S.; Demuth, T.P. Tetrahedron Lett. 1980, $21,715$.

85. Hassner, A.; Murthy, K.S.K. Tetrahedron Lett. 1986, 27, 1407.

86. Dauben, W.G.; Hart, D.J. J. Am. Chem. Soc. 1977, 99, 7307.

87. Ibuka, T.; Hayashi, K.; Minakata, H.; Ito, Y.; Inubushi, Y. Can. J. Chem. 1979, $57,1579$.

88. Marshall, J.A.; Brady, S.F. J. Org. Chem. 1970, 35, 4068.

89. Kozikowki, A.P.; Acc. Chem. Res. 1984, 17, 410.

90. Jager, V.; Schwab, W. Tetrahedron Lett. 1978, 34, 3129.

91. Jager, V.; Schohe, R. Tetrahedron 1984, 40, 2199.

92. Curran, D.P.J. Am. Chem. Soc. 1983, 105, 5826. 